\author{
Universidade de São Paulo \\ Escola de Engenharia de São Carlos \\ Departamento de Engenharia Elétrica e de Computação
}

DANIEL PETEAN

\title{
Metodologia para Avaliação da Influência de Geradores Distribuídos nos Níveis de Curto-Circuito em Sistemas de Distribuição de Energia
}

Tese apresentada à Escola de Engenharia de São Carlos, da Universidade de São Paulo, como parte dos requisitos para obtenção do Título de Doutor em Ciências, Programa de Engenharia Elétrica.

Área de Concentração: Sistemas Elétricos de Potência Orientador: Prof. Dr. José Carlos de Melo Vieira Júnior

São Carlos

2014

Trata-se da versão corrigida da tese. A versão original se encontra disponível na EESC/USP que aloja o Programa de Pós-Graduação de Engenharia Elétrica 


\section{AUTORIZO A REPRODUČ̃O TOTAL OU PARCIAL DESTE TRABALHO POR QUALQUER MEIO CONVENCIONAL OU ELETRÔNICO, PARA FINS' DE ESTUDO E PESQUISA, DESDE QUE CITADA A FONTE.}

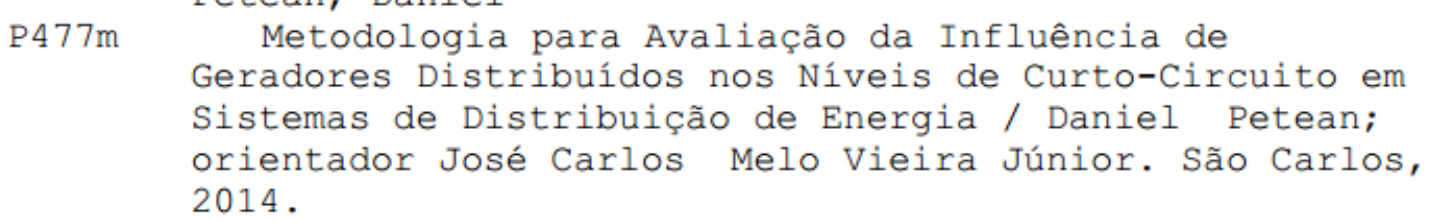

Tese (Doutorado) - Programa de Pós-Graduação em Engenharia Elétrica e Área de Concentração em Sistemas Elétricos de Potência -- Escola de Engenharia de São Carlos da Universidade de São Paulo, 2014.

1. Geração distribuída. 2. Curto-circuito. 3. Distribuição de energia elétrica. 4. Inversor de frequência. I. Título. 


\section{FOLHA DE JULGAMENTO}

Candidato: Tecnólogo DANIEL PETEAN.

Título da tese: "Metodologia para avaliação da influência de geradores distribuídos nos níveis de curto-circuito em sistemas de distribuição de energia".

Data da defesa: 27/02/2015

Comissão Julgadora:

Resultado:

Prof. Dr. José Carlos de Melo Vieira júnior (Orientador) APROVADO (Escola de Engenharia de São Carlos/EESC)

Prof. Dr. Fernando Lessa Tofoli

APROVADO

(Universidade Federal de São João Del-Rei/UFSJ)

Prof. Dr. Igor Kopcak

(Universidade Federal de Goiás/UFG)

Prof. Dr. Mário Oleskovicz

(Escola de Engenharia de São Carlos/EESC)

Prof. Associado Rodrigo Andrade Ramos

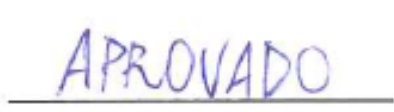

(Escola de Engenharia de São Carlos/EESC)

Coordenador do Programa de Pós-Graduação em Engenharia Elétrica: Prof. Associado Luis Fernando Costa Alberto

Presidente da Comissão de Pós-Graduação:

Prof. Associado Paulo César Lima Segantine 
Dedico este trabalho à minha esposa Paula e meu filho Gabriel 



\section{Agradecimentos}

Em primeiro lugar a Deus pelo direcionamento dos meus caminhos.

Aos meus pais Leonídio e Cleonice pelo amor, carinho e apoio.

Às minhas irmãs Denise e Deise e a todos os meus familiares que estão sempre na torcida por mim.

À minha esposa Paula por sua presença ao meu lado me dando forças para superar todos os obstáculos.

Ao meu filho Gabriel por me fornecer a motivação necessária ao desempenho de minhas atividades.

Ao professor Dr. José Carlos Melo Vieira Júnior pela orientação, oportunidade e ajuda no decorrer deste trabalho.

Aos amigos do Laboratório de Sistemas de Energia Elétrica - LSEE da USP de São Carlos.

Ao meu amigo Fábio Lima de Albuquerque por ter me direcionado para a carreira de professor.

Ao Instituto Federal de São Paulo Campus Sertãozinho pela concessão do afastamento para qualificação.

A todos que de alguma forma contribuíram para que este trabalho fosse realizado. 



\section{Resumo}

PETEAN, D. Metodologia para Avaliação da Influência de Geradores Distribuídos nos Níveis de Curto-Circuito em Sistemas de Distribuição de Energia. Tese de Doutorado Escola de Engenharia de São Carlos, Universidade de São Paulo, São Carlos, 2014.

A instalação de geração distribuída nas redes de distribuição e de subtransmissão de energia elétrica tem apresentado significativo crescimento em âmbito mundial, impulsionada pelos benefícios que pode proporcionar aos sistemas elétricos, pela necessidade de diversificação da matriz energética dos países, pela desregulamentação do setor de energia elétrica em diversos países e pela necessidade de gerar energia elétrica de forma sustentável. No entanto, para que os geradores distribuídos possam de fato beneficiar a operação das redes elétricas, seus impactos técnicos devem ser cuidadosamente estudados, sobretudo em redes de distribuição, as quais foram inicialmente planejadas para operar com fluxo de potência unidirecional. Dentre esses impactos, destaca-se a elevação do nível de curto-circuito da rede, pois correntes de curto-circuito com valores elevados podem causar violação das capacidades dos equipamentos em suportar os esforços térmicos e dinâmicos e também provocar a perda da coordenação entre os dispositivos de proteção contra sobrecorrente. Neste contexto, este trabalho analisa a influência de geradores distribuídos baseados em inversores na corrente de curto-circuito trifásica em um sistema de distribuição de energia, e sobretudo, comprova que sua contribuição no valor da corrente de falta não supera o dobro de sua corrente nominal. Além disso, com base nesta comprovação, apresenta duas estratégias para inserção desse tipo de gerador nos cálculos de curto-circuito de um sistema de distribuição de energia elétrica. As duas estratégias apresentam resultados satisfatórios, utilizam conceitos básicos de circuitos elétricos, independem de dados minuciosos dos inversores e são validadas através de aplicações numéricas com resultados confrontados aos obtidos das simulações.

Palavras chave: geração distribuída; curto-circuito; distribuição de energia elétrica; inversor de frequência. 


\section{Abstract}

PETEAN, D. Methodology for Assessment of Distributed Generators Influence on Short Circuit Levels of Power Distribution Systems. Doctorate Thesis -São Carlos Engineering School, University of São Paulo, São Carlos, 2014.

The installation of distributed generation in distribution and subtransmission systems has shown significant growth worldwide, driven by the benefits it can provide to electrical systems, the need to diversify the energy sources, deregulation of the electricity industry in several countries and the need to generate electricity in a sustainable manner. However, in order to evaluate if distributed generators benefit the operation of power networks, their technical impacts should be carefully studied, especially in distribution networks, which were originally designed to operate with unidirectional power flow. Among the aforementioned impacts, there is the increase of the short circuit level in the distribution network, since high short-circuit currents may exceed the capabilities of equipment to support the dynamic and thermal stresses and also cause loss of coordination between the overcurrent protection devices. Within this context, this thesis analyzes the influence of inverter based distributed generators on three-phase short circuit currents in a power distribution systems. Especially it confirms that the contribution to the fault current does not exceed twice its rated value. Furthermore, based on this issue, this work presents two strategies for the inclusion of this type of generator in short circuit calculations. Both strategies presented satisfactory results, use basic concepts of electrical circuits, they do not depend on detailed data from the inverters and the results are validated by using simulation results.

Keywords: distributed generation; short circuit; power distribution; frequency inverter. 



\section{Lista de Abreviaturas}

AESO - Alberta Electric System Operator

ANEEL - Agência Nacional de Energia Elétrica

CA - Corrente Alternada

$\mathrm{CC}-$ Corrente Contínua

CEMIG - Companhia Energética de Minas Gerais

CIRED - International Conference on Electricity Distribution

CPFL - Companhia Paulista de Força e Luz

FRT - Fault Ride Through

GD - Gerador Distribuído

GE - Gerador Equivalente da Concessionária

IEC - International Electrotechnical Commission

IEEE - Institute of Electrical and Electronics Engineers

IGBT - Insulated Gate Bipolar Transistor

LD - Linha de Distribuição de Energia Elétrica

LVRT - Low Voltage Ride Through

MATLAB - Matrix Laboratory

NREL - National Renewable Energy

PCH - Pequena Central Hidrelétrica

PI - Proporcional e Integral

PLL - Phase Locked Loop

PR - Proporcional Ressonante

PSCAD - Power System Computer Aided Design

PWM - Pulse Width Modulation

SD - Sistema de Distribuição de Energia Elétrica 
SE - Subestação de Energia

SG - Sem Gerador Distribuído

SimPowerSystems - Electrical Power Systems Simulation

$\mathrm{UL}$ - Underwriter Laboratory

VSI - Voltage Source Inverter 


\section{Lista de Símbolos}

$3 \mathrm{~F}+\mathrm{N}-$ Três Fases mais Neutro

$3 \emptyset$ - Trifásico

abc - Coordenadas Naturais

$\mathrm{C}_{\mathrm{F}}-$ Capacitor do Filtro de Saída do Inversor

$\mathrm{CH}$ - Chave Seccionadora

$d q 0$ - Coordenadas Síncronas Girantes

$E_{a b c}-$ Tensões de Referência das Fases A, B e C em Coordenadas Naturais

FP - Fator de Potência

$F_{S}-$ Fator de Segurança

I - Corrente Constante

$\mathrm{I}_{\mathrm{a}}, \mathrm{I}_{\mathrm{b}}$ e $\mathrm{I}_{\mathrm{c}}-$ Correntes de Fase do Sistema Elétrico

I $_{\text {CGD }}$ - Corrente de Curto-Circuito do Gerador GD

$\mathrm{I}_{\mathrm{d}}-$ Componente de Corrente do Eixo Direto

$\mathrm{I}_{\text {dref }}-$ Valor de Referência de Corrente do Eixo Direto

$\mathrm{I}_{\mathrm{F}}$ - Valor Total da Corrente de Falta

$\mathrm{I}_{\mathrm{FGD}}$ - Valor da Corrente de Saída do Gerador GD Representado como Fonte de Corrente

IGD - Contribuição do Gerador GD para Corrente de Falta

IGE - Contribuição do Gerador GE para Corrente de Falta

$\mathrm{I}_{\mathrm{q}}$ - Componente de Corrente do Eixo em Quadratura

$\mathrm{I}_{\text {qref }}$ - Valor de Referência de Corrente do Eixo em Quadratura

$k_{i i}$ - Ganho Integral do Controle de Corrente

$k_{i p}$ - Ganho Integral do Controle de Potência

$k_{i P L L}-$ Ganho Integral do Controle do PLL

$k_{i v}$ - Ganho Integral do Controle de Tensão 
$k_{p i}$ - Ganho Proporcional do Controle de Corrente

$k_{p p}$ - Ganho Proporcional do Controle de Potência

$k_{P P L L}$ - Ganho Proporcional do Controle do PLL

$k_{p v}-$ Ganho Proporcional do Controle de Tensão

$\mathrm{L}_{\mathrm{F}}$ - Indutor do Filtro de Saída do Inversor

๑ - Frequência Angular

$\varpi_{f f}-$ Frequência Angular de Ajuste e Referência do PLL

ФPLL - Frequência Angular Fornecida pelo PLL

$\mathrm{P}$ - Potência Ativa

$P_{a t}$ ref - Valor de Referência da Potência Ativa

$P_{\text {ativ inst }}-$ Valor Instantâneo de Potência Ativa

PQ - Potências Ativa e Reativa Constantes

PV - Potência Ativa e Tensão Terminal Constantes

Q - Potência Reativa

Qreat inst - Valor Instantâneo de Potência Reativa

Qreat ref - Valor de Referência de Potência Reativa

$\mathrm{R}$ - Resistência

RL - Religador

$\mathrm{R}_{\mathrm{T}}(\%)$ - Regulação Percentual de Tensão

$s$ - Operador de Laplace

$\mathrm{S}_{\mathrm{b} 1}-$ Valor de Potência na Base Anterior

$\mathrm{S}_{\mathrm{b} 2}-$ Valor de Potência na Base Nova

T1 - Transformador da Saída do Gerador GE

TGD - Transformador da Saída do Gerador GD

$\mathrm{U}_{\mathrm{d}}-$ Tensão de Eixo Direto Resultante do Bloco de Controle

$\mathrm{U}_{\mathrm{q}}$ - Tensão de Eixo em Quadratura Resultante do Bloco de Controle 
V - Valor de Pico da Tensão de Fase

$\mathrm{V}_{\mathrm{a}}, \mathrm{V}_{\mathrm{b}}$ e $\mathrm{V}_{\mathrm{c}}-$ Tensões de Fase do Sistema Elétrico

$\mathrm{V}_{\mathrm{b} 1}$ - Valor da Tensão na Base Anterior

$\mathrm{V}_{\mathrm{b} 2}$ - Valor da Tensão na Base Nova

$\mathrm{V}_{\mathrm{CC}}-$ Fonte Regulada de Tensão Contínua

$\mathrm{V}_{\mathrm{d}}-$ Componente de Tensão do Eixo Direto

$\mathrm{V}_{\text {dref }}-$ Valor de Referência de Tensão do Eixo Direto

$\mathrm{V}_{\text {eq }}-$ Tensão Equivalente no Local Identificado

V

V ${ }_{I 1}(\%)$ - Índice Percentual de Variação de Tensão Devido a Saída Repentina do Gerador

$\mathrm{V}_{\text {inst }}-$ Valor Instantâneo de Tensão

$\mathrm{V}_{\mathrm{q}}$ - Componente de Tensão do Eixo em Quadratura

$\mathrm{V}_{\text {qref }}$ - Valor de Referência de Tensão do Eixo em Quadratura

$\mathrm{V}_{\text {ref }}-$ Valor de Referência de Tensão

X - Reatância

$\mathrm{X}_{\mathrm{GD}}$ - Impedância Interna do Gerador GD

$\mathrm{X}_{\mathrm{GDT}}$ - Impedância Total do Ramo do Gerador GD

$\mathrm{X}_{\mathrm{GE}}$ - Impedância Interna do Gerador GE

$\mathrm{X}_{\mathrm{GET}}$ - Impedância Total do Ramo do Gerador GE

$\mathrm{X}_{\mathrm{T} 1}$ - Impedância do Transformador T1

$\mathrm{X}_{\mathrm{TGD}}$ - Impedância do Transformador TGD

$\mathrm{Z}_{\mathrm{b} 1}$ - Valor de Impedância na Base Anterior

$\mathrm{Z}_{\mathrm{b} 2}$ - Valor de Impedância na Base Nova

$Z_{\text {bus }}$ - Matriz de impedâncias da rede de distribuição de energia

$\mathrm{Z}_{\mathrm{eq}}$ - Impedância Equivalente Total do Circuito

$\mathrm{Z}_{\mathrm{LD}}$ - Impedância da Linha LD 
$Z_{\text {LDeq1 }}$ - Impedância Equivalente da Linha LD desde o GE até a Falta

$\mathrm{Z}_{\text {LDeq2 }}$ - Impedância Equivalente da Linha LD desde o Final das Linhas até a Falta

$\delta_{0}-$ Ângulo de Fase Inicial da Tensão

$\theta$ - Ângulo da Tensão de Fase Obtido pelo PLL

$\theta_{\mathrm{PLL}}-$ Ângulo Fornecido pelo PLL 


\section{Índice}

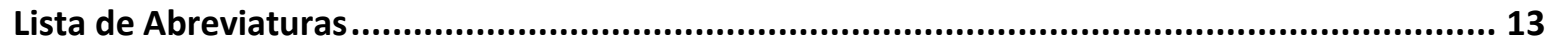

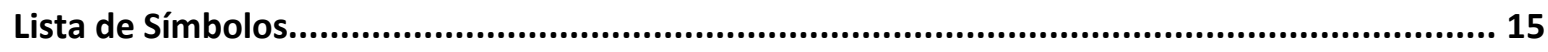

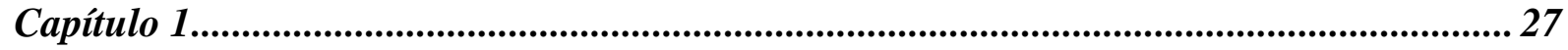

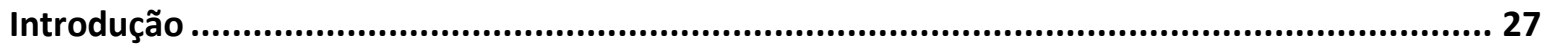

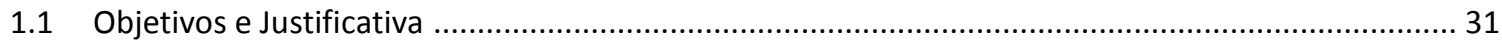

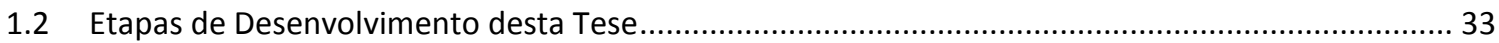

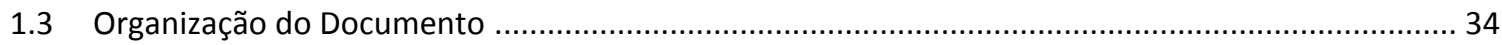

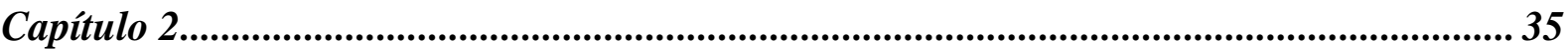

Impactos dos Geradores Distribuídos no Nível de Curto-Circuito de Sistemas de Distribuição de

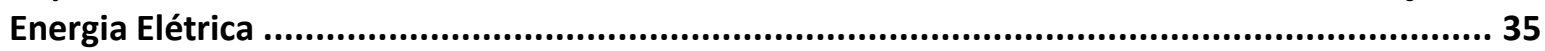

2.1 Contribuição de Geradores Distribuídos Baseados em Inversores nos Valores das Correntes de

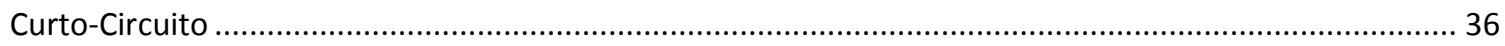

2.2 Contribuição de Geradores Distribuídos Tipo Síncrono no Valor da Corrente de Curto-Circuito...... 40

2.3 Contribuição de Geradores Tipo Assíncronos no Valor da Corrente de Curto-Circuito.................... 41

2.4 Permanência dos Geradores Distribuídos Durante o Período de Falta no Sistema "Fault Ride

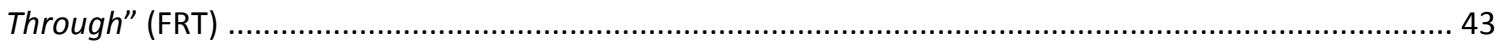

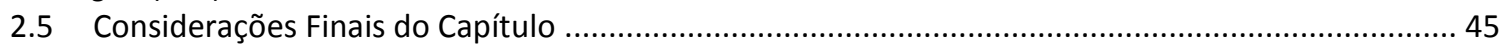

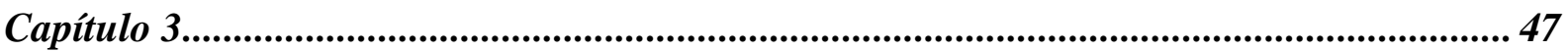

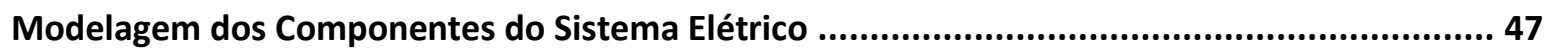

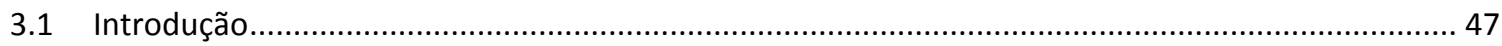

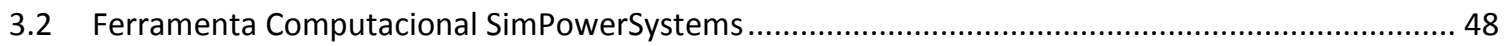

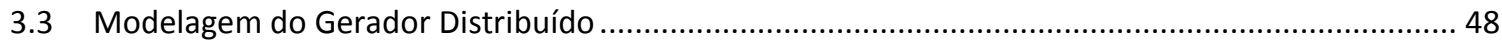

3.4 Descrição dos Principais Blocos dos Circuitos ............................................................................ 50

3.4.1 Tensões de Fase e Sistema de Energia da Concessionária .................................................... 50

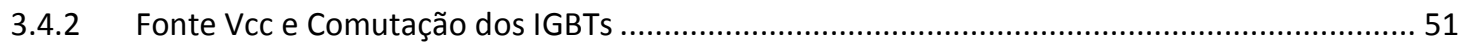

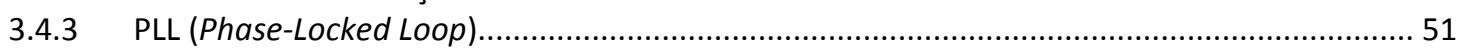

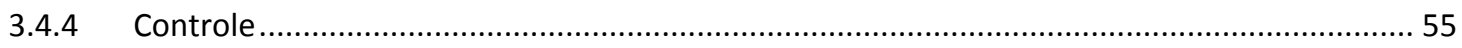

3.4.4.1 Controle por Corrente Constante (I) ………............................................................ 55

3.4.4.2 Controle de Potências Ativa e Reativa (PQ) ................................................................ 57

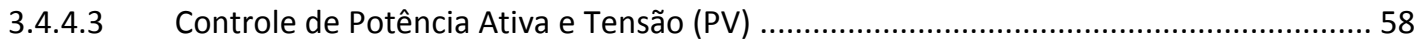

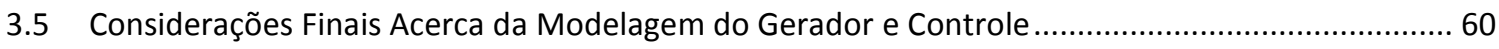

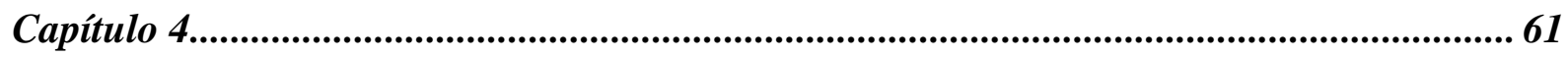

Impactos da Instalação de Geradores Distribuídos Baseados em Inversores e sua Contribuição

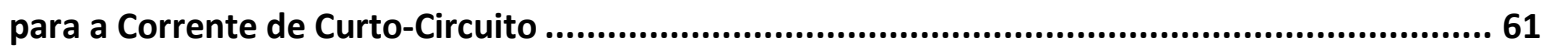

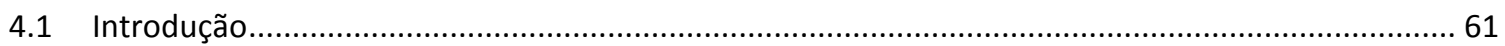

4.2 Impactos da Instalação de Geradores Baseados em Inversores no Sistema de Distribuição de

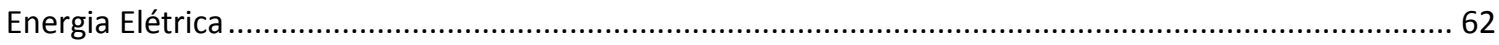
4.2.1 Objetivo

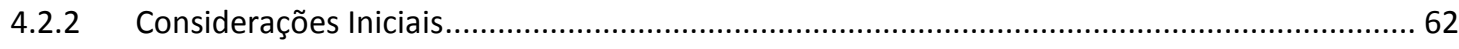

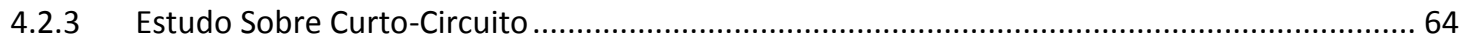

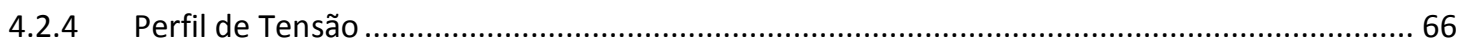

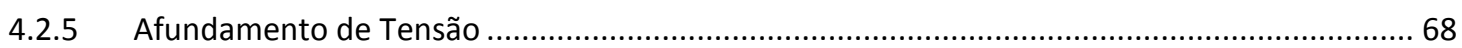
4.2.6 Variação da Tensão Devido à Saída Repentina do Grupo Gerador ....................................... 70 


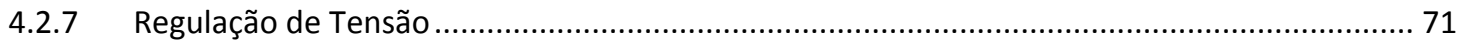

4.2.8 Perdas de Potência Ativa ........................................................................................... 72

4.3 Análise Detalhada da Contribuição de Corrente de Curto-Circuito de Geradores Baseados em

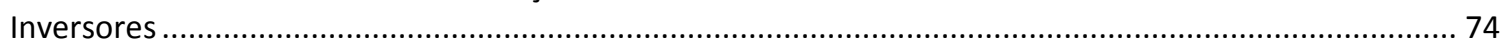

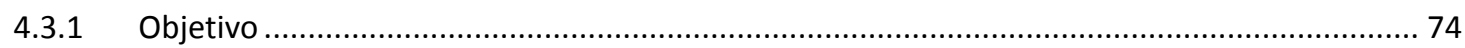

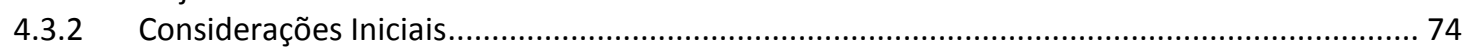

4.3.3 Análise Sobre a Influência do Ângulo de Aplicação de Falta .................................................. 76

4.3.4 Análise Sobre a Influência da Variação dos Parâmetros de Controle do Inversor .................. 79

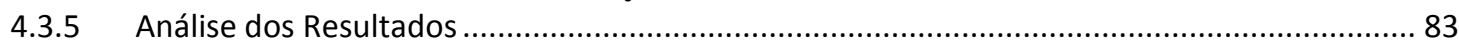

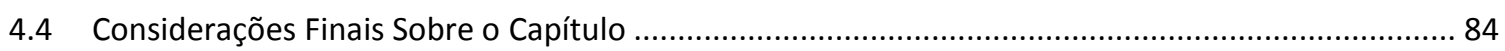

Capítulo 5............................................................................................................................. 87

Metodologias para a Inserção dos Geradores Baseados em Inversores nos Cálculos de Curto-

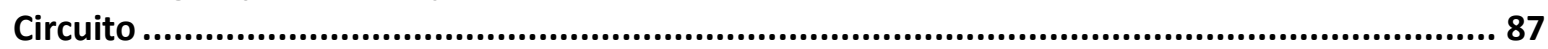

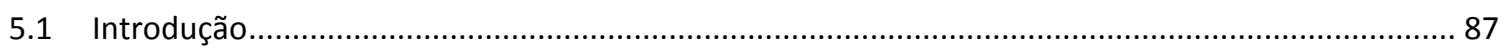

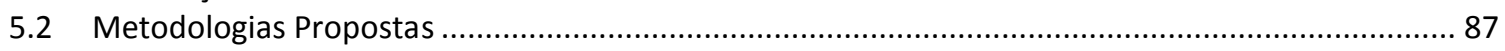

5.2.1 Metodologia 1 para a Inserção do Gerador Baseado em Inversor GD nos Cálculos de Corrente

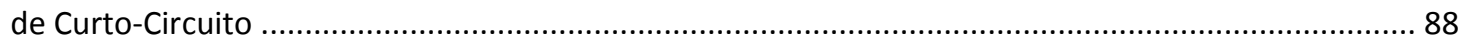

5.2.2 Metodologia 2 para Inserção do Gerador Baseado em Inversor nos Cálculos de Corrente de

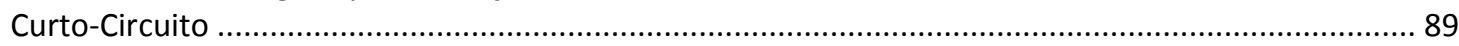

5.3 Aplicações e Análises das Metodologias de Cálculos de Curto-Circuito ...........................................92

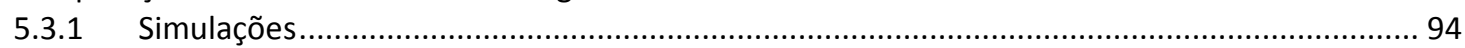

5.3.2 Cálculo da Corrente de Curto-Circuito do Sistema de Distribuição de Energia Sem a Inclusão do Gerador Distribuído GD .............................................................................................. 101

5.3.3 Aplicação da Metodologia 1 para a Inserção do Gerador Baseado em Inversor GD nos Cálculos de Corrente de Curto-Circuito ................................................................................................. 104

5.3.3.1 Aplicação da Metodologia 1 - Cálculo da Corrente de Curto-Circuito com Gerador GD no Início da Linha do Sistema de Distribuição .......................................................................... 105

5.3.3.2 Aplicação da Metodologia 1 - Cálculo da Corrente de Curto-Circuito com Gerador GD no Final da Linha do Sistema de Distribuição .......................................................................... 107

5.3.3.3 Aplicação da Metodologia 1 - Cálculo da Corrente de Curto-Circuito Com Dois

Geradores Distribuídos .................................................................................................. 109

5.3.3.4 Análise dos Resultados da Metodologia 1 para Inserção dos Geradores Baseados em Inversores nos Cálculos de Curto-Circuito ............................................................................ 111

5.3.4 Aplicação da Metodologia 2 para Inserção do Gerador Baseado em Inversor nos Cálculos de

Corrente de Curto-Circuito ...................................................................................................... 114

5.3.4.1 Aplicação da Metodologia 2 - Cálculo da Corrente de Curto-Circuito com Gerador GD no Início da Linha do Sistema de Distribuição ......................................................................... 116

5.3.4.2 Aplicação da Metodologia 2 - Cálculo da Corrente de Curto-Circuito com Gerador GD no Final da Linha do Sistema de Distribuição ......................................................................... 120

5.3.4.3 Aplicação da Metodologia 2 - Cálculo da Corrente de Curto-Circuito com Dois Geradores Distribuídos .................................................................................................... 123

5.3.4.4 Análise dos Resultados da Metodologia 2 para Inserção dos Geradores Baseados em Inversores de Frequência nos Cálculos de Curto-Circuito ...................................................... 127

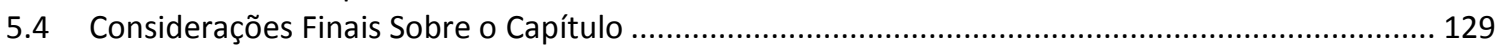

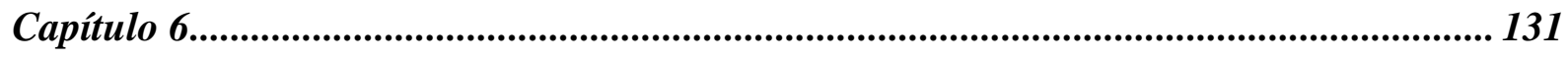

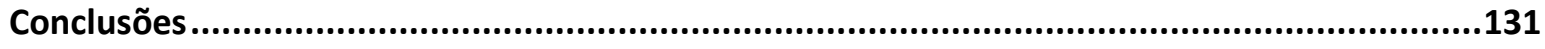

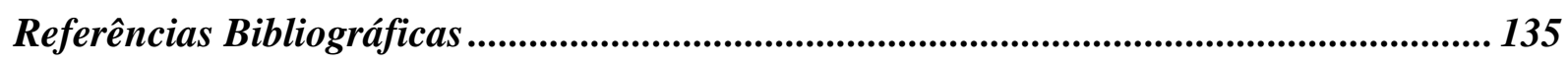

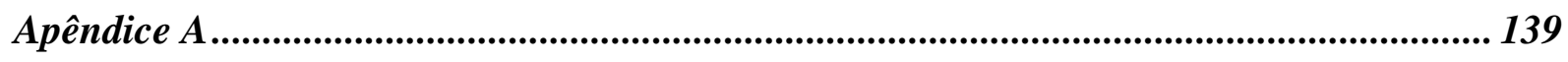

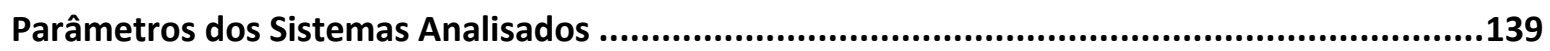




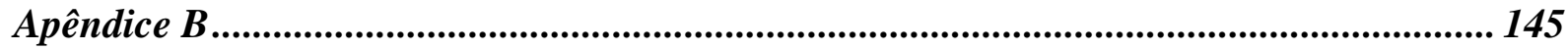

Divulgação do Trabalho em Eventos Científicos .....................................................................145

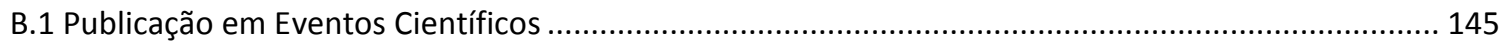




\section{Índice de Figuras}

Figura 1.1 Exemplo de um sistema de geração distribuída (adaptado de ANEEL 2014). ..............................28

Figura 1.2 Fluxograma das etapas de desenvolvimento da tese.........................................................33

Figura 2.1 - Esquema utilizado para o estudo de caso em Massoud et al. (2010)...........................................37

Figura 2.2 - Perfil de duração de tensão estabelecido por AESO-Alberta Canadá para geradores eólicos com potência inferior a 5 MW (lov et al., 2007). .........................................................................................44

Figura 3.1 - Esquema generalizado dos geradores trifásicos baseados em inversores de frequência............. 49

Figura 3.2 - Esquema do bloco PLL trifásico e suas ações no circuito do inversor. ........................................ 52

Figura 3.3 - Relação de $\vartheta \mathrm{com}$ as coordenadas nas formas abc e dq0...................................................5 53

Figura 3.4 - Diagrama de blocos do controle de corrente constante (I)..................................................55

Figura 3.5 - Diagrama de blocos do controle de potência ativa e reativa (PQ). ...........................................55

Figura 3.6 - Diagrama de blocos do controle de potência ativa e tensão (PV). .........................................58

Figura 4.1- Sistema modelado: acessante com central de geração $3 \mathrm{MVA}-13,8 \mathrm{kV}$.....................................63

Figura 4.2 - Comportamento da corrente na saída do gerador GD em função do tipo de controle.................64

Figura 4.3 - Comportamento da corrente na saída do gerador GD em função do tipo de controle.................65

Figura 4.4 - Perfil de tensão nos barramentos em função do tipo de controle do gerador distribuído, potência

de geração e carga do sistema................................................................................................67

Figura 4.5 - Afundamento de tensão nos barramentos - Curto-Circuito trifásico na Linha 6.........................69

Figura 4.6 - Perdas de potência ativa nas linhas em função do carregamento, geração e tipo de controle.... 73

Figura 4.7 - Sistema modelado: acessante com minigeração 300kVA - 380V. .............................................74

Figura 4.8 - Controle I - Influência do ângulo de incidência da falta na corrente de curto-circuito. ............... 76

Figura 4.9 - Controle PQ - Influência do ângulo de incidência da falta na corrente de curto-circuito............. 77

Figura 4.10 - Controle PV - Influência do ângulo de incidência da falta na corrente de curto-circuito........... 78

Figura 4.11 - Controle I - Influência da variação dos parâmetros de operação do inversor na corrente de curtocircuito.

Figura 4.12 - Controle PQ - Influência da variação dos parâmetros de operação do inversor na corrente de curto-circuito...

Figura 4.13 - Controle PV - Influência da variação dos parâmetros de operação do inversor na corrente de curto-circuito..

Figura 5.1 - Gerador GD como fonte de tensão operando em condições nominais de fornecimento de energia

para carga.

Figura 5.2 - Transformação da fonte de corrente sob condição de falta em fonte de tensão, considerando os

valores de base do Gerador GD. .......................................................................................................90

Figura 5.3 - Sistema de distribuição de energia elétrica em estudo. .......................................................92

Figura 5.4 - Resultados das simulações com aplicação da Falta 1...................................................... 95

Figura 5.5 - Resultados das simulações com aplicação da Falta 2. .............................................................96

Figura 5.6- Resultados das simulações com aplicação da Falta 3..........................................................97

Figura 5.7 - Resultados das simulações com aplicação da Falta 4.........................................................98

Figura 5.8 - Resultados das simulações com aplicação da Falta 5.........................................................99

Figura 5.9 - Metodologia Convencional - Circuito resultante para Falta 3 sem gerador GD. ....................... 102

Figura 5.10 - Metodologia Convencional - Simplificação do circuito de impedâncias para Falta 3 .............. 102

Figura 5.11 - Metodologia Convencional - Circuito resultante total e cálculo de corrente de curto-circuito

para Falta 3 - Sistema de distribuição de energia sem Gerador GD. ................................................... 103

Figura 5.12 - Metodologia 1 - Circuito resultante para Falta 3 com a inserção do GD no início das linhas. .. 105

Figura 5.13 - Metodologia 1 - Diagrama de impedâncias para a Falta 3 e GD no início das linhas.............. 106

Figura 5.14 - Metodologia 1- Simplificação do diagrama de impedâncias para a Falta 3 e GD no início das

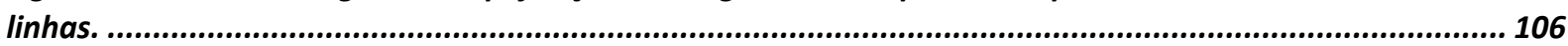

Figura 5.15 - Metodologia 1- Circuito resultante total e cálculo de corrente de curto-circuito para Falta 3 com GD no início das linhas. ............................................................................................................ 107

Figura 5.16 - Metodologia 1 - Circuito resultante para Falta 3 com a inserção do GD no final das linhas. ... 107

Figura 5.17 - Diagrama de impedâncias para a Falta 3 e GD no final das linhas. ......................................... 108

Figura 5.18 - Simplificação do diagrama de impedâncias para Falta 3 e GD no final das linhas................... 108 
Figura 5.19 - Metodologia 1 - Circuito resultante total e cálculo de corrente de curto-circuito para Falta 3 com

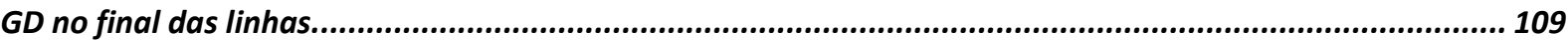
Figura 5.20 - Metodologia 1 - Circuito de resultante para a Falta 3 e dois GDs instalados......................... 109 Figura 5.21 - Metodologia 1 - Diagrama de impedâncias para a Falta 3 e dois GDs instalados. .................. 110 Figura 5.22 - Metodologia 1 - Simplificação do diagrama de impedâncias para Falta 3 com dois GDs instalados.

Figura 5.23 - Metodologia 1 - Circuito resultante total e cálculo de corrente de curto-circuito para Falta 3 com dois GDs instalados.

Figura 5.24 - Transformação da fonte de corrente em fonte de tensão sob condição de falta, conforme valores das bases consideradas no estudo - Unidade do GD de 0,3 MVA.

Figura 5.25 - Transformação da fonte de corrente em fonte de tensão sob condição de falta, conforme valores das bases consideradas no estudo - Unidade do GD de 0,15 MVA.

Figura 5.26 - Metodologia 2 GD no início das linhas - Circuito resultante para Falta 3.

Figura 5.27 - Metodologia 2 GD no início das linhas - Simplificação do circuito considerando a contribuição do gerador GE.

Figura 5.28 - Metodologia 2 GD no início das linhas - Circuito equivalente total e cálculo da contribuição do gerador GE para a corrente de Falta 3.

Figura 5.29 - Metodologia 2 GD no início das linhas - Simplificação do circuito considerando a contribuição do gerador GD.

Figura 5.30 - Metodologia 2 GD no início das linhas - Circuito equivalente total e cálculo da contribuição do gerador GD para a corrente de Falta 3.

Figura 5.31 - Metodologia 2 GD no início das linhas - Cálculo do valor total da corrente da Falta 3 (IF3).... 119

Figura 5.32 - Metodologia 2 GD no final das linhas - circuito resultante para Falta 3. ............................... 120

Figura 5.33 - Metodologia 2 - Simplificação do circuito considerando a contribuição do gerador GE.......... 120

Figura 5.34 - Metodologia 2 GD no final das linhas - Circuito equivalente total e cálculo da contribuição do gerador GE para a corrente de Falta 3.

Figura 5.35 - Metodologia 2 GD no final das linhas - Simplificação do circuito considerando a contribuição do gerador GD.

Figura 5.36 - Metodologia 2 GD no final das linhas - Circuito equivalente total e cálculo da contribuição do gerador GD para a corrente de Falta 3.

Figura 5.37 - Metodologia 2 GD no final das linhas - Cálculo do valor total da corrente da Falta 3 (IF3). ..... 122 Figura 5.38 - Metodologia 2 com dois GDs instalados - Circuito de resultante para a Falta 3..................... 123 Figura 5.39 - Metodologia 2 com dois GDs instalados - Simplificação do circuito considerando a contribuição do gerador GE.

Figura 5.40 - Metodologia 2 com dois GDs instalados - Circuito equivalente total e cálculo da contribuição do

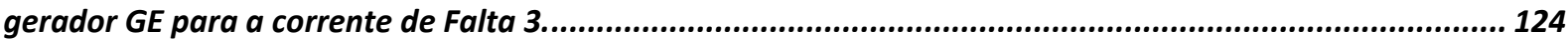
Figura 5.41 - Metodologia 2 com dois GDs instalados - Simplificação do circuito considerando a contribuição do gerador GD1 124 Figura 5.42 - Metodologia 2 com dois GDs instalados - Circuito equivalente total e cálculo da contribuição de corrente do gerador GD1 para a Falta 3. 125 Figura 5.43 - Metodologia 2 com dois GDs instalados - Simplificação do circuito considerando a contribuição do gerador GD2. 125 Figura 5.44 - Metodologia 2 com dois GDs instalados - Circuito equivalente total e cálculo da contribuição de corrente do gerador GD2 para a Falta 3. 


\section{Índice de Tabelas}

Tabela 4.1 - Variação de tensão de regime permanente durante a desconexão repentina do gerador. ......... 70

Tabela 4.2 - Análise da regulação de tensão em função dos tipos de controle do gerador distribuído. .......... 71 Tabela 4.3 - Valores máximos de corrente de curto-circuito em função do tipo de controle e condições de aplicação da falta trifásica.

Tabela 5.1 - Nomenclatura utilizada nas aplicações numéricas das metodologias propostas neste capítulo.. 94

Tabela 5.2 - Resultados dos valores das correntes de curto-circuito obtidos das simulações. 100

Tabela 5.3 - Valores das correntes de curto-circuito obtidos dos cálculos e simulações realizadas no Sistema de Distribuição de Energia sem o Gerador GD.

103

Tabela 5.4 - Valores das correntes de curtos-circuitos obtidos das simulações e cálculos realizados através da aplicação da metodologia 1 com a inserção do gerador GD no início das linhas. 112 Tabela 5.5 - Valores das correntes de curtos-circuitos obtidos das simulações e cálculos realizados através da aplicação da metodologia 1 com a inserção do gerador GD no final das linhas. 112 Tabela 5.6 - Valores das correntes de curtos-circuitos obtidos dos cálculos e simulações realizadas no Sistema de Distribuição de Energia com aplicação da metodologia 1 para inserção de dois grupos geradores de 1,5 MVA. 113

Tabela 5.7 - Valores das correntes de curtos-circuitos obtidos das simulações e cálculos realizados através da aplicação da metodologia 2 com a inserção do gerador GD no início das linhas. 127 Tabela 5.8 - Valores das correntes de curtos-circuitos obtidos das simulações e cálculos realizados através da aplicação da metodologia 2 com a inserção do gerador GD no final das linhas. 127 Tabela 5.9 - Valores das correntes de curtos-circuitos obtidos dos cálculos e simulações realizadas no Sistema de Distribuição de Energia (SD) com aplicação da metodologia 2 para inserção de dois grupos geradores de 1,5 MVA. 128

Tabela 5.10 - Valores de correntes de curtos-circuitos obtidos através das simulações e metodologias 1 e 2.

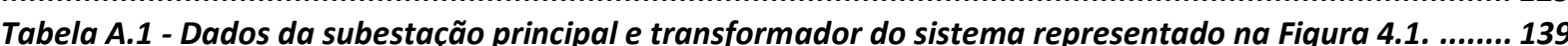
Tabela A.2 - Dados das linhas do sistema representado na Figura 4.1....................................................... 140 Tabela A.3 - Dados e parâmetros de uma unidade dos inversores do sistema representado na Figura 4.1. 140 Tabela A.4 - Dados do transformador elevador (saída do gerador GD) do sistema da Figura 4.1. .............. 141 Tabela A.5 - Dados da subestação principal do sistema de energia apresentado na Figura 4.7. .................. 141 Tabela A.6 - Dados da linha de distribuição do sistema de energia apresentado na Figura 4.7. .................. 141 Tabela A.7 - Dados do transformador T1 do sistema de energia apresentado na Figura 4.7. ...................... 141 Tabela A.8 - Dados do transformador T2 do sistema de energia apresentado na Figura 4.7. ...................... 142 Tabela A.9 - Dados do transformador T3 do sistema de energia apresentado na Figura 4.7. ...................... 142 Tabela A.10 - Dados do gerador distribuído do sistema de energia apresentado na Figura 4.7. ................. 142 Tabela A.11 - Dados da subestação principal e transformador do sistema representado na Figura 5.3. ...... 143 Tabela A.12 - Dados das linhas do sistema representado na Figura 5.3. .................................................. 143 Tabela A.13 - Dados e parâmetros de uma unidade dos inversores do sistema representado na Figura 5.3.144 Tabela A.14 - Dados do transformador elevador (saída do gerador GD) do sistema representado na Figura 5.3. 


\section{Capítulo 1}

\section{Introdução}

Nos últimos anos, fatores como a reestruturação do setor de energia elétrica em diversos países, a necessidade de aproveitamento de diferentes fontes primárias de energia como forma de diversificação da matriz energética, avanços tecnológicos na eletrônica de potência e maior conscientização sobre conservação ambiental têm provocado o aumento considerável do interesse por geração distribuída (Tu; Chaitusaney, 2012), (Jenkins et al., 2000) e (CIRED Working Group 4, 1999). Observa-se na literatura técnica, relevante a esse tema, que ainda não existe uma definição sobre geração distribuída de forma consistente e com aceitação generalizada. Apesar das grandes semelhanças, a maioria dos autores ainda define a geração distribuída conforme as particularidades de seu projeto ou estudo. Em Severino, Camargo e Oliveira (2008), faz-se a proposta da seguinte definição generalizada: “Geração distribuída é a denominação genérica de um tipo de geração de energia elétrica que se diferencia da realizada pela geração centralizada por ocorrer em locais em que não seria instalada uma usina geradora convencional, contribuindo para aumentar a distribuição geográfica da geração de energia elétrica em determinada região". Neste trabalho, entende-se que a geração distribuída seja toda forma de produção de energia elétrica com origem não convencional da concessionária, podendo ser realizada pelos próprios consumidores e injetada no sistema de energia em pontos distribuídos ao longo dos alimentadores de distribuição. Como exemplo, a Figura 1.1 apresenta a configuração de um sistema de geração distribuída conectado a uma rede de distribuição de energia elétrica. Neste exemplo, observa-se que o consumidor pode receber energia elétrica tanto da concessionária como da fonte alternativa ou de ambas ao mesmo tempo. Além disso, no caso de sobra de produção por parte da fonte alternativa, a concessionária se torna um potencial consumidor. 


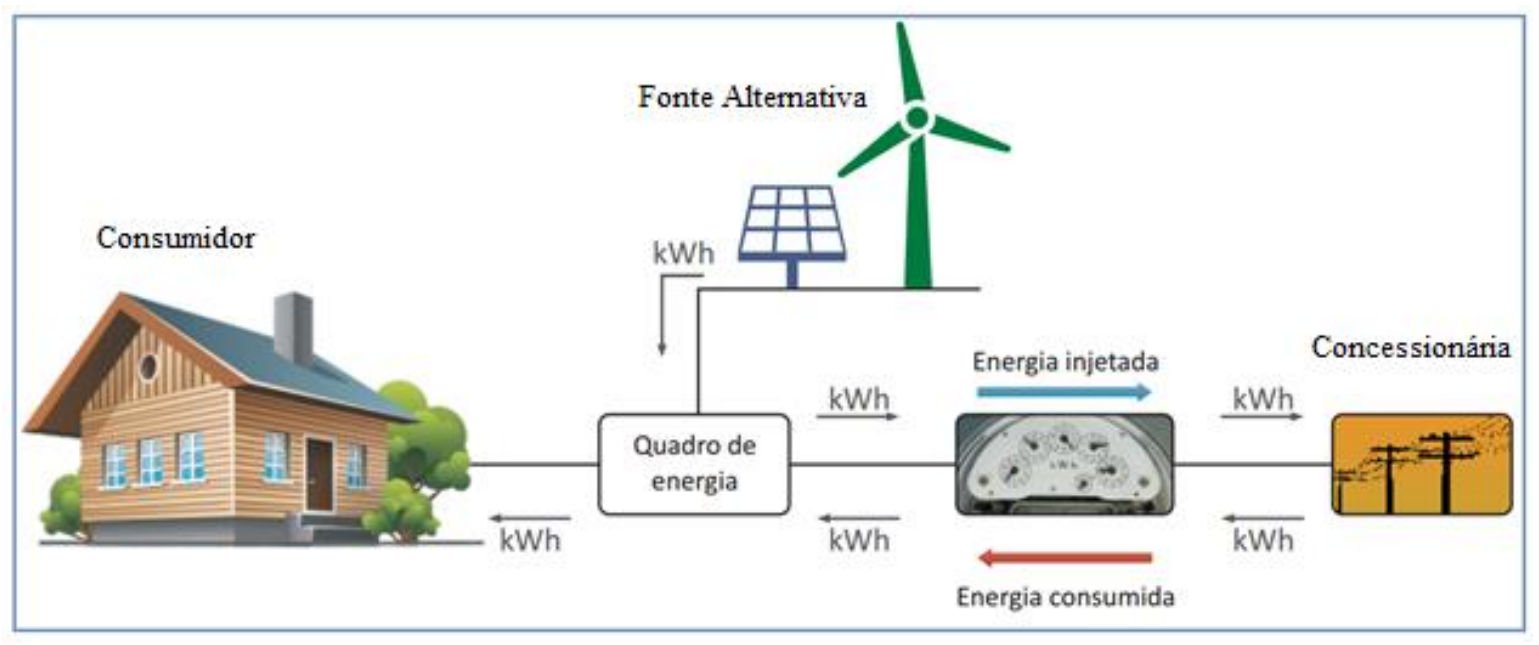

Figura 1.1 Exemplo de um sistema de geração distribuída (adaptado de ANEEL 2014).

Uma característica marcante relacionada à geração distribuída é a diversidade de tecnologias disponíveis que fazem uso de fontes alternativas de energia, sendo essas fontes, renováveis ou não-renováveis. Entre as principais tecnologias existentes, destacam-se em Lora e Haddad (2006), Jenkins et al. (2000) e Borbely e Kreider (2001): turbinas a gás natural, turbinas a vapor (combustíveis fósseis ou biomassa), máquinas de combustão interna (diesel ou gás natural), pequenas centrais hidrelétricas (PCHs), aerogeradores e também os geradores conectados na rede via inversores e que fazem uso de células a combustível, painéis fotovoltaicos, microturbinas e algumas configurações de aerogeradores. Neste trabalho, estes geradores serão referenciados como geradores baseados em inversores.

A instalação de geradores distribuídos exige modificações nas metodologias de planejamento e adaptações na operação das redes de distribuição de energia, visto que essas foram inicialmente projetadas como redes passivas com fluxo de potência unidirecional, ou seja, da subestação da concessionária para as cargas. Sendo assim, a instalação de geradores distribuídos nessas redes deve ser necessariamente acompanhada de um conjunto de estudos para avaliar os possíveis impactos que possam ocorrer no sistema elétrico. Os principais aspectos que podem ser afetados são: perfil de tensão de regime permanente, estabilidade de tensão, estabilidade de ângulo, filosofia do sistema de proteção, transitórios de tensão, correntes de curto-circuito (ou correntes de falta), distorção harmônica, ferro-ressonância e confiabilidade. A determinação dos fatores que realmente serão mais afetados depende da quantidade de geração a ser instalada, do tipo de gerador a ser empregado e das características da rede elétrica. 
A geração distribuída se insere como potencial agente capaz de elevar as correntes de curto-circuito no sistema elétrico no qual está instalada. Essa elevação pode não ser significativa diante da instalação de um único gerador distribuído. No entanto, a presença de vários geradores distribuídos de pequeno porte ou poucos geradores de médio e grande porte pode causar um aumento acentuado do nível de curto-circuito no sistema elétrico a ponto de violar os limites dos equipamentos e/ou provocar a perda de coordenação dos dispositivos de proteção contra sobrecorrente (Barker; DeMello, 2000). Sendo assim, a instalação de geradores distribuídos pode se tornar inviável sob o ponto de vista técnico e econômico, caso o nível de curto-circuito se eleve demasiadamente.

O cálculo das correntes de curto-circuito em qualquer sistema elétrico é importante para determinação da capacidade de interrupção de disjuntores, dimensionamento e ajuste dos dispositivos de proteção e também para a especificação técnica e determinação da capacidade dos demais equipamentos da rede (transformadores, cabos, transformadores de instrumentos, chaves seccionadoras etc.) para suportar os esforços térmicos e dinâmicos causados pelos elevados valores dessas correntes. Além disso, o cálculo da corrente de curto-circuito também é necessário para determinar o afundamento de tensão ao longo da rede durante faltas equilibradas e desequilibradas, o que representa um importante parâmetro na qualidade da energia elétrica entregue ao consumidor (Jenkins et al., 2000). Como exemplo, em Freitas et al. (2005a) mostra-se que a instalação de geradores distribuídos pode agravar ou melhorar o afundamento de tensão em função da variação do nível de curto-circuito ao longo da rede.

Em se tratando de geradores distribuídos compostos de máquinas rotativas e conectados diretamente nas redes de distribuição de energia elétrica, como é o caso da maioria das instalações com gerador síncrono e de indução com rotor em gaiola de esquilo, seu impacto no nível de curto-circuito pode ser analisado através de programa especializado para cálculo de curtos-circuitos. Neste caso, a rede é representada por modelos estáticos trifásicos e tipicamente a teoria de componentes simétricos é utilizada para facilitar a solução das equações de rede (Monticelli; Garcia, 2003), (Jenkins et al., 2000), (Elgerd, 1971).

Nos casos em que se necessita determinar a resposta da corrente no tempo, utiliza-se um programa de análise de transitórios eletromagnéticos. Adicionalmente, a resposta no tempo da corrente de curto-circuito difere consideravelmente entre geradores síncronos e de indução (Freitas et al., 2005b).

Para os geradores síncronos, dependendo da forma como o sistema de excitação é controlado, as respostas das correntes de curto-circuito são diferentes (Freitas et al., 2005b). 
Observa-se, portanto, que a análise de curto-circuito envolvendo geradores síncronos e de indução é um assunto já amplamente abordado na literatura técnica. Além das referências já mencionadas, tem-se, por exemplo, Fitzgerald et al. (1992) e Kundur (1994) que também tratam do tema.

Ao contrário do que ocorre com os geradores rotativos, há poucas referências bibliográficas que abordam, de forma abrangente, o cálculo das correntes de curto-circuito de geradores conectados na rede elétrica por meio de inversores. Além disso, devido às suas inerentes limitações de sobrecorrente, geralmente as contribuições dos geradores baseados em inversores para corrente de falta são negligenciadas, quando comparadas aos geradores síncronos (Darwish et al., 2013).

Outro aspecto importante sobre o cálculo das correntes de curto-circuito em sistemas elétricos com geradores baseados em inversores é o método de cálculo empregado. Em programas convencionais de curto-circuito, utiliza-se a matriz de impedâncias $Z_{\text {bus }}$ do sistema elétrico, onde as impedâncias de sequência positiva, negativa e zero dos elementos do sistema são consideradas. Em Zanetta (2006) e Elgerd (1971), empregam-se hipóteses conservadoras para que os resultados obtidos estejam sempre a favor da segurança, o que é uma característica importante no processo de especificação de equipamentos. Logo, essa metodologia se aplica facilmente aos geradores síncronos e de indução diretamente conectados na rede elétrica.

Para os geradores baseados em inversores, a construção da matriz $Z_{\text {bus }}$ pode se tornar um processo complexo devido à dificuldade em estimar as impedâncias dos inversores (Nimpitiwan et al., 2007). Portanto, opta-se por utilizar simulação dinâmica para cálculo das correntes de curto-circuito, como os autores apresentam em Borghetti et al. (2003). Nesse caso, as simulações podem ser demoradas devido à complexidade da rede, do gerador e do tipo do curto-circuito (simétrico ou assimétrico). Além disso, os resultados podem não ser conservadores, como o são em programas convencionais de cálculo de curto-circuito. Nessa linha de pesquisa, em Baran e El-Markaby (2005) foi proposto um método analítico-iterativo para determinar as correntes de curto-circuito de regime subtransitório e transitório de geradores baseados em inversores. Os valores máximos das correntes de curto-circuito, obtidos mediante a aplicação da metodologia proposta, foram comparados com os obtidos via simulação dinâmica em vários instantes de tempo, após a ocorrência do curto-circuito. $\mathrm{Na}$ maioria desses instantes, os valores máximos obtidos pela metodologia proposta foram 
inferiores aos obtidos pela simulação, caracterizando uma desvantagem do método, visto que a geração de resultados conservadores não ocorreu neste caso.

Diante do que foi exposto, entende-se que existe a necessidade de mais estudos referentes aos geradores baseados em inversores, sobretudo, no que se refere à sua capacidade de fornecimento de corrente de curto-circuito e também aos impactos que a instalação desse tipo de gerador pode ocasionar no sistema de energia elétrica.

\subsection{Objetivos e Justificativa}

O objetivo principal deste trabalho é o desenvolvimento de metodologias para incorporar os geradores distribuídos baseados em inversores nos cálculos de curto-circuito, considerando as diferentes estratégias de controle e a obtenção de resultados conservadores. Para atingir este objetivo principal, são conduzidos vários estudos sobre a modelagem e os impactos desse tipo de geração distribuída. Assim, como objetivos secundários são investigados os possíveis impactos na qualidade de energia em um sistema de distribuição de energia elétrica, devido à instalação do gerador baseado em inversor e também é avaliada a contribuição de corrente de curto-circuito que esse tipo de gerador pode fornecer ao sistema onde está instalado.

Os estudos são realizados por meio de simulações dinâmicas não lineares do tipo de transitórios eletromagnéticos e envolverão o emprego de diferentes tecnologias e estratégias de controle dos inversores desses geradores: controle PV (potência ativa e tensão terminal constantes), controle PQ (potência ativa e reativa constantes) e controle I (corrente constante). Os resultados dessas simulações também são utilizados para comparação e validação das metodologias de inserção desse tipo de gerador nos cálculos da corrente de curto-circuito.

A realização deste trabalho proporciona subsídios para o desenvolvimento de metodologias para avaliar impactos da instalação de geradores baseados em inversores e orientar as concessionárias distribuidoras e proprietários de geradores distribuídos na definição das características de manuseio mais adequadas para a operação desses equipamentos.

A justificativa para este trabalho é o aumento do número de geradores baseados em inversores nos sistema de distribuição de energia em praticamente todo mundo. Essa expansão tende a crescer e vem sendo impulsionada por inovações tecnológicas e no desenvolvimento de materiais semicondutores e microprocessadores, que culminam em conversores com respostas rápidas aos transitórios; pela possibilidade de redução ou limitação das correntes de curto-circuito; pelo fato de que esses geradores podem ser mais flexíveis do que geradores 
síncronos em proporcionar suporte de potência reativa e regulação de tensão; pela modularidade e padronização de seus componentes, que podem levar a grandes volumes de produção culminando com a redução dos preços dos equipamentos (Kroposki et al., 2006).

No Brasil, o emprego de geradores baseados em inversores ainda é pequeno, mas está em expansão. Algumas companhias de distribuição de energia elétrica como a CEMIG e a Eletropaulo têm investido na pesquisa de células a combustível e microturbinas e os recentes empreendimentos de geração eólica no país são constituídos por turbinas de velocidade variável acopladas a geradores síncronos conectados na rede elétrica via inversores de frequência (ANEEL, 2010). Com essa expansão, torna-se essencial que aspectos técnicos relativos às correntes de curto-circuito desses geradores, entre outros fatores técnicos, sejam mais investigados, visto que não existe, até o momento, nenhum documento técnico que apresente uma análise abrangente envolvendo as diversas estratégias de controle dos inversores. Além disso, também não foi abordada pela literatura técnica a inclusão de geradores distribuídos baseados em inversores em programas de cálculo de curto-circuito que forneçam resultados conservadores e coerentes com o comportamento dos inversores frente às faltas. 


\subsection{Etapas de Desenvolvimento desta Tese}

O desenvolvimento desta tese segue as etapas que se articulam no fluxograma apresentado na Figura 1.2.

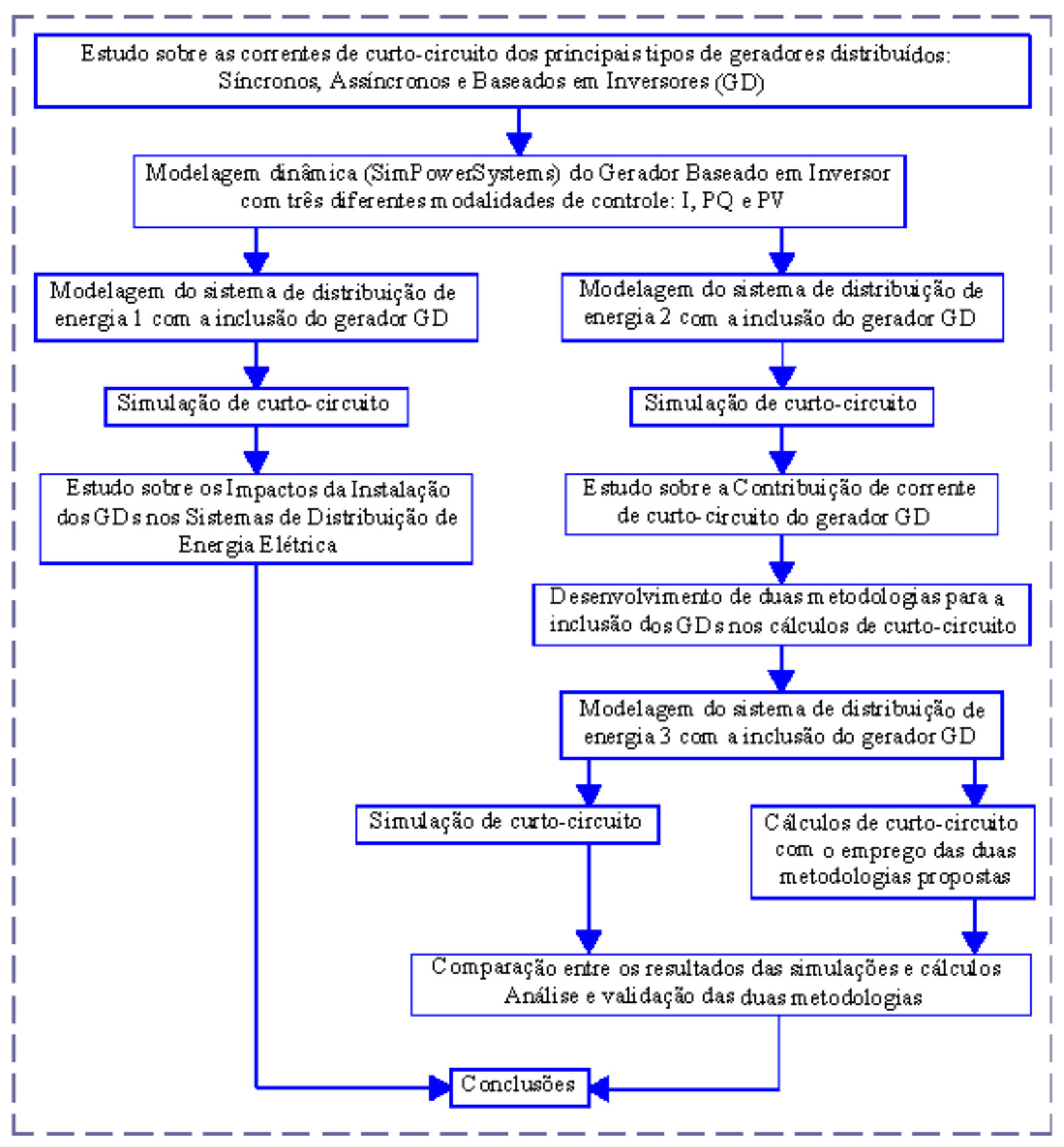

Figura 1.2 Fluxograma das etapas de desenvolvimento da tese. 


\subsection{Organização do Documento}

Este documento está organizado da seguinte maneira:

Capítulo 2: Tem-se uma descrição do problema a ser analisado e uma revisão bibliográfica sobre a influência dos geradores distribuídos nos níveis de curto-circuito dos sistemas de energia elétrica e também uma abordagem sobre o tema "Fault Ride Through";

Capítulo 3: Descreve os modelos computacionais dos geradores distribuídos utilizados neste trabalho, mostrando os diagramas dos sistemas analisados e os esquemas de controles utilizados;

Capítulo 4: São apresentados os resultados da avaliação sobre os impactos da instalação do gerador baseado em inversor em um sistema de distribuição de energia elétrica e também da avaliação sobre a contribuição de corrente de curto-circuito desse tipo de gerador;

Capítulo 5: São apresentadas duas metodologias para a inserção dos geradores baseados em inversores nos cálculos de curto-circuito;

Capítulo 6: São apresentadas as conclusões deste trabalho.

Apêndice A: São apresentadas as tabelas com dados e parâmetros dos sistemas simulados e analisados;

Apêndice B: Apresentam-se as referências dos trabalhos divulgados em eventos científicos. 


\section{Capítulo 2}

\section{Impactos dos Geradores Distribuídos no Nível de Curto-Circuito de Sistemas de Distribuição de Energia Elétrica}

Os estudos sobre o nível de curto-circuito e a obtenção dos valores das correntes de falta são essenciais para o planejamento e operação de um sistema de distribuição de energia. Os valores obtidos representam dados importantes para as especificações técnicas dos componentes do sistema no que se refere à capacidade de condução da corrente de curtocircuito, suportabilidade aos efeitos térmicos e às solicitações mecânicas, definição da capacidade de interrupção de dispositivos de seccionamento e na coordenação e seletividade dos dispositivos de proteção contra sobrecorrente. Nesse contexto, a instalação de geradores distribuídos em sistemas de distribuição pode alterar o nível de curto-circuito de forma a provocar efeitos indesejados, tais como: perda de coordenação dos dispositivos de proteção contra sobrecorrente, violação da capacidade de interrupção de disjuntores, superação dos limites térmicos e mecânicos de equipamentos e outros efeitos. Dessa forma, avaliar os impactos da instalação de geradores distribuídos nos sistemas elétricos é de suma importância para previsão de eventuais efeitos nocivos e o estabelecimento de metodologias para mitigar ou eliminar os efeitos negativos.

Dentro desse cenário, este capítulo aborda os principais impactos de diferentes tecnologias de geradores distribuídos no nível de curto-circuito de sistemas de distribuição. 


\subsection{Contribuição de Geradores Distribuídos Baseados em Inversores nos Valores das Correntes de Curto-Circuito}

Atualmente, a aplicação de inversores representa um papel importante na combinação de unidades de geradores distribuídos (GD) com as necessidades e exigências de um sistema de energia, sobretudo no suprimento à crescente demanda por energia elétrica. Embora ainda não exista uma grande quantidade de referências relacionadas ao estudo sobre o comportamento de geradores baseados em inversores sob condição de falta, alguns estudos promovem discussões e apresentações de testes e resultados referentes ao tema.

Os geradores baseados em máquinas rotativas apresentam comportamento dinâmico e características eletromagnéticas que provocam transitórios elétricos (tensão e corrente) e também necessitam de um tempo maior para adequar o seu fornecimento de energia (tempo de resposta) diante das ocorrências ou alterações (entrada ou saída de cargas) no sistema elétrico no qual estão acoplados. Devido ao emprego da eletrônica de potência, os geradores distribuídos baseados em inversores não estão submetidos às consequências das características indutivas que envolvem o funcionamento das máquinas rotativas, possuem respostas mais rápidas diante das possíveis ocorrências de faltas e contam com a possibilidade de programação e controle que os tornam mais versáteis e com maior capacidade de adaptação e atendimento às necessidades e exigências de um sistema de energia.

Nos estudos de curto-circuito envolvendo geradores baseados em inversores, o cálculo do valor inicial (valores eficaz e de pico) das correntes de curto-circuito é baseado nas hipóteses previstas pela norma IEC60909 para motores de indução acionados via inversores (Jenkins et al., 2000). Segundo essa norma, a corrente de curto-circuito de motores acionados por inversores é limitada a três vezes o valor de sua corrente nominal. No entanto, para o caso de geradores não rotativos baseados em inversores, essa hipótese pode ser conservadora.

Em Borghetti et al. (2003), estabeleceu-se uma hipótese menos conservadora em que a corrente de curto-circuito esperada de um gerador baseado em inversor é, no máximo, igual à sua corrente nominal. Porém, este valor depende do comportamento do inversor, o qual por sua vez, depende das características dos dispositivos empregados e da estratégia de controle adotada. Ainda em Borghetti et al. (2003), os impactos no nível de curto-circuito em uma rede de distribuição devido à instalação de um gerador síncrono e de um gerador baseado em inversor foram comparados. Nesse trabalho, o sistema de controle do inversor foi configurado para manter constantes as potências ativa e reativa fornecidas pelo gerador. Os resultados 
mostraram que a contribuição do gerador baseado em inversor é cerca de sete vezes menor do que a contribuição de um gerador síncrono, ambos de mesmo porte.

Outro estudo que também promove a comparação entre geradores síncronos e baseados em inversores quanto à contribuição para uma falta foi desenvolvido por Nimpitiwan et al. (2007). Nesse trabalho, a corrente de curto-circuito de um gerador baseado em inversor mostrou-se ligeiramente inferior à corrente de curto-circuito de um gerador síncrono, sendo que o inversor foi configurado para manter constantes a potência ativa e a tensão terminal.

Observa-se, portanto, que Borghetti et al. (2003) e Nimpitiwan et al. (2007) realizaram estudos semelhantes. No entanto, obtiveram resultados diferentes, visto que, as condições de controle do inversor foram distintas. Existe ainda a possibilidade de o inversor ser controlado para manter a corrente constante, apresentando, portanto, a vantagem de limitação da amplitude da corrente de curto-circuito (Borghetti et al., 2003).

Em Massoud et al. (2010), estudou-se o comportamento de um sistema de energia elétrica diante da ocorrência de curto-circuito trifásico e os efeitos causados pela instalação de um gerador baseado em inversor e com capacidade de fornecimento de $10 \mathrm{~kW}$, conforme ilustra a Figura 2.1. Nesse caso, verificou-se que a contribuição total do gerador distribuído para o curto-circuito trifásico atingiu cerca de $10 \%$ da contribuição do "Sistema Principal". Desse modo, a inclusão do gerador distribuído não causou o comprometimento do sistema de proteção e nem impactos negativos ao funcionamento normal do sistema elétrico. Os fatores responsáveis por esse comportamento foram a baixa potência da geração distribuída e a restrição imposta ao fornecimento de corrente dos mesmos: o gerador foi limitado a fornecer no máximo uma corrente $50 \%$ superior ao valor de sua corrente nominal durante o período de aplicação do curto-circuito. Destaca-se, portanto, a possibilidade de limitar a corrente fornecida por esse tipo de gerador, atuando no próprio sistema de controle.

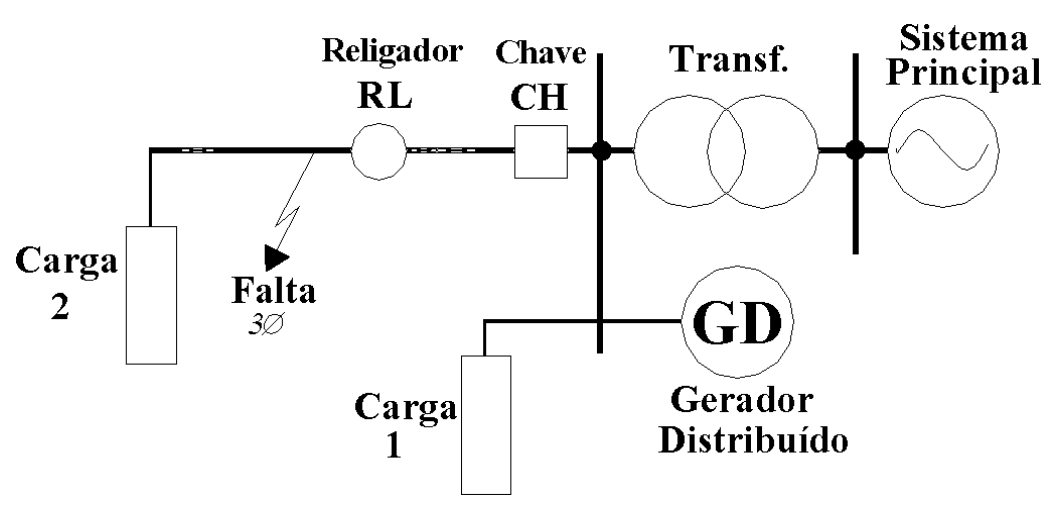

Figura 2.1 - Esquema utilizado para o estudo de caso em Massoud et al. (2010). 
Em Turcotte e Katiraei (2010), apresenta-se um estudo sobre a contribuição de geradores distribuídos baseados em inversores instalados em um sistema de distribuição de energia elétrica típico do Canadá. O sistema foi modelado e simulado por meio do aplicativo PSCAD e é constituído por uma subestação principal com dois transformadores de 47 MVA, uma linha de distribuição com extensão de $25 \mathrm{~km}$, tensão $27,6 \mathrm{kV}$ e uma carga total de aproximadamente $15 \mathrm{MW}$ distribuída ao longo da linha. Os alimentadores adjacentes foram aglomerados formando uma única carga de aproximadamente $60 \mathrm{MW}$. O modelo foi construído para dois possíveis cenários de ocorrência de faltas do tipo trifásica, sendo que o primeiro considera a falta na saída dos transformadores da subestação principal e o outro no final da linha. O gerador distribuído de 7,5 MW com fator de potência unitário foi instalado no final da linha e, para a obtenção dos dados necessários ao estudo, três medidores foram instalados em pontos estratégicos, sendo um no início do alimentador, outro para obter dados da corrente de falta e o último para obter dados da corrente do gerador distribuído. As simulações foram realizadas sem a presença do gerador no sistema e, posteriormente, com a inclusão do gerador (GD) equipado com o dispositivo de proteção contra sobrecorrente instantânea. Para ambas as situações, foram considerados os cenários de ocorrência de falta na saída da subestação principal e o outro com a ocorrência da falta no final da linha.

Após as simulações, observou-se que a atuação do dispositivo de proteção existente no gerador ocorreu em menos de $50 \mathrm{~ms}$, o que tornou suas contribuições em valores de corrente de curto-circuito insignificantes em ambos cenários (início e final de linha) de ocorrência de falta. No intuito de avaliar a máxima contribuição do gerador, o dispositivo de proteção instantânea foi desabilitado e o resultado obtido mostrou que a contribuição da corrente de falta do gerador foi de aproximadamente $40 \%$ superior ao valor da sua corrente nominal. Apesar da detecção de uma parcela de contribuição da corrente de falta do gerador, nada foi mencionado sobre alguma possibilidade de comprometimento do sistema no qual o gerador foi instalado.

Em Keller e Kroposki (2010), apresenta-se um trabalho com intuito de determinar as contribuições de corrente de falta de geradores baseados em inversores. O principal objetivo do trabalho foi avaliar o que a indústria adota como padrão de contribuição de corrente de falta para os inversores que, chamado de "via de regra", é aproximadamente duas vezes a corrente nominal do inversor. Os ensaios foram conduzidos pelo National Renewable Energy Laboratory (NREL) e por fabricantes de inversores. Os testes e procedimentos adotados foram baseados nas diretrizes estabelecidas pelo Underwriter Laboratory (UL 1741, S. 47.3). 
Os ensaios conduzidos pelo NREL consideraram um gerador monofásico de $1 \mathrm{~kW}$ interligado a um pequeno sistema elétrico por meio de um inversor controlado por corrente. Esse sistema elétrico foi constituído de uma fonte de tensão alternada de $120 \mathrm{~V}, 60 \mathrm{~Hz}$ com potência de 15 $\mathrm{kW}$, a qual representava o sistema de energia elétrica. Foram aplicados curtos-circuitos nesse sistema e os resultados mostraram que o valor de pico de corrente variou entre quatro e cinco vezes a corrente nominal do inversor, durante um intervalo de 1,6 ms (aproximadamente 0,1 ciclo). Esses resultados representam praticamente o dobro dos valores praticados na literatura técnica, que, segundo os autores desse trabalho, é de duas vezes a corrente nominal.

Os ensaios conduzidos pelos fabricantes de inversores tiveram procedimentos de testes semelhantes aos que foram relatados para o NREL. No entanto, utilizaram um circuito trifásico com capacidade de $500 \mathrm{kVA}$ e as medições foram realizadas para ocorrência de faltas bifásicas. Os registros apontaram que os períodos de duração das faltas estão em torno de 1,1 a 4,25 ms e os valores de pico da corrente de falta atingiram valores em torno de duas a três vezes a corrente nominal do inversor.

Outras abordagens importantes sobre o tema são feitas por Baran e El-Markaby (2005). Nesse trabalho, observa-se, durante a ocorrência de curto-circuito, a diferença no tempo de resposta do inversor em função da modalidade de controle adotada, que no caso, sob controle de tensão, tanto o pico inicial de corrente de falta quanto o restabelecimento das condições normais foram mais rápidas em ralação ao controle por corrente. Ainda nesse trabalho, considerando-se que a contribuição de corrente de falta do inversor não supera o dobro do valor de sua corrente nominal, apresenta-se uma metodologia que representa uma extensão do cálculo tradicional de corrente de curto-circuito, no qual, também se inclui o gerador baseado em inversor de frequência. Entretanto, necessita-se da estimativa de dados minuciosos tais como impedância de saída do gerador e do transformador de acoplamento.

Em Tu e Chaitusaney (2012), avaliam-se os impactos na corrente de um sistema de distribuição com gerador baseado em inversor, devido à ocorrência de curtos-circuitos. Nesse trabalho, constata-se que as variações na corrente do sistema dependem do nível de penetração de geradores distribuídos e também do tipo de controle desses geradores. Além disso, é proposto um algoritmo para inserção dos geradores baseados em inversores de frequência nos cálculos de corrente de curto-circuito. Entretanto, os testes foram realizados em um sistema de pequeno porte, com baixo nível de penetração de geradores distribuídos e a metodologia proposta necessita de dados referentes ao tipo de controle utilizado no inversor. 
No intuito de amenizar o impacto no sistema de proteção devido à contribuição de corrente de curto-circuito do gerador baseado em inversor, Darwish et al. (2013) propõem a utilização de um limitador de corrente que faz uso do controle Proporcional Ressonante (PR). Nesse trabalho, os autores efetuam testes utilizando controle com um único circuito PR e outro com duplo ciclo de controle PR. Dos testes realizados, os autores verificam que a utilização do controle com duplo ciclo PR produz respostas mais rápidas que diminuem os picos de correntes nos períodos transitórios de ocorrência da falta e também são mais estáveis. Apesar de amenizar a contribuição do gerador para os picos iniciais de corrente de falta, a proposta não se apresenta como solução definitiva para coordenação do sistema de proteção nos casos de permanência de funcionamento do gerador durante a ocorrência da falta.

\subsection{Contribuição de Geradores Distribuídos Tipo Síncrono no Valor da Corrente de Curto-Circuito}

Nos geradores síncronos, a corrente do enrolamento de campo é fornecida por uma fonte externa. Portanto, diante da situação de curto-circuito do sistema no qual o gerador está conectado, essa fonte (independente) continua a fornecer a tensão no enrolamento de campo do gerador e, como consequência, o mesmo continua a fornecer elevada corrente de curtocircuito durante alguns ciclos após a ocorrência da falta.

Segundo Pizzali (2006), a contribuição dos geradores síncronos para corrente de falta depende da tensão pré-falta, das características da excitatriz e das reatâncias transitória e subtransitória da máquina e, de acordo com Barker e Mello (2000), os valores iniciais para a corrente de falta podem atingir valores em torno de cinco a dez vezes sua corrente nominal.

Em Boljevic e Conlon (2008), apresenta-se um estudo sobre a contribuição de geradores síncronos instalados em um sistema de distribuição de energia elétrica. Esse estudo estabelece a determinação e análise dos valores das correntes de curto-circuito trifásico nos barramentos de média tensão $(11 \mathrm{kV})$ e de baixa tensão $(0,415 \mathrm{kV})$ de um sistema de distribuição, onde se consideram as situações de inclusão e exclusão de geradores distribuídos tipo síncrono de 0,5 MVA. Segundo os autores, os cálculos foram efetuados conforme as diretrizes estabelecidas pela norma IEC 60909.

Os resultados mostraram um pequeno impacto na elevação do nível de curto-circuito do barramento de média tensão e um grande impacto no valor da corrente de curto-circuito do barramento de baixa tensão. Entretanto, esse estudo não informa dados sobre as condições e 
capacidades dos dispositivos de chaveamentos e componentes instalados no local. Portanto, não há informações se houve ou não a superação dos esforços máximos suportados pelos componentes elétricos do sistema.

Considerando a instalação direta de geradores síncronos distribuídos em um sistema de distribuição de energia elétrica, Silva, Trindade e Freitas (2012) investigaram o impacto no valor de corrente de curto-circuito em diversos pontos do sistema de distribuição de energia elétrica. Dentre os resultados, o valor de corrente de curto-circuito trifásico no barramento mais distante do local de instalação do GD passou de 562 A (sem GD) para 696,5 A com a instalação do gerador distribuído, o que representa uma elevação de aproximadamente $24 \%$. Para o alimentador mais próximo do GD, o valor passou de 263,5 A para 412 A, o que equivale a um aumento de 56\%. Apesar de quantificar os valores de corrente de curto-circuito nos barramentos, os autores não apresentam a parcela de contribuição de corrente de falta específica de cada gerador. Ainda nesse trabalho, observou-se que estes aumentos nos valores de correntes de curtos-circuitos provocaram a perda de coordenação entre os sistemas de proteção.

\subsection{Contribuição de Geradores Tipo Assíncronos no Valor da Corrente de Curto-Circuito}

O gerador de indução pode ser uma opção viável para geração de energia elétrica com aplicação em aerogeradores e microhidrelétricas, principalmente devido à sua robustez que pode reduzir seu custo em até $40 \%$ em relação ao síncrono (Medeiros, 2005). No entanto, como a frequência elétrica é uma variável adicional a ser controlada e as relações torque versus velocidade e torque versus fluxo no entreferro não são lineares, seu controle pode ser mais complexo.

Diante da ocorrência de uma falta nos terminais desse tipo de gerador, o valor de corrente poderá atingir valores iniciais em torno de seis vezes a corrente nominal. No entanto, esse elevado valor persiste durante apenas alguns ciclos, pois, ao contrário dos geradores síncronos, os geradores de indução usualmente não contam com uma fonte externa para fornecer corrente e tensão no enrolamento de campo. Esse tipo de gerador também pode se apresentar com diferentes tipos e configurações que influenciam em suas contribuições no que se refere às correntes de falta. Pela teoria do fluxo constante no entreferro, essas máquinas reagem mediante a ocorrência de qualquer distúrbio (curto-circuito) que possa causar 
alterações nesse fluxo. Tais reações correspondem às mudanças na magnitude e forma de onda das correntes que envolvem seus circuitos. Portanto, em função da variedade das características, tecnologias de excitação e controle aplicados aos geradores de indução, os efeitos e comportamento relacionados à magnitude e forma de onda de corrente de curtocircuito se apresentam de forma diferente (Morcos; Gomez, 2008).

Em Gomez, Nesci e Barbero (2010), estuda-se o comportamento de geradores de indução com cinco diferentes tipos de excitação: campo magnético remanescente, excitação por capacitor, corrente contínua no rotor, dupla alimentação e tripla alimentação. Os testes foram realizados utilizando um osciloscópio digital empregado em máquinas com potências que variam entre 5 a $10 \mathrm{~kW}$, submetidas às condições de curto-circuito.

Para o primeiro caso analisado, o trabalho mostra que a magnitude da corrente de curtocircuito do gerador excitado exclusivamente pelo alimentador da rede, tanto para gerador com rotor tipo gaiola de esquilo quanto rotor bobinado, pode atingir valores semelhantes aos da corrente de partida (seis a oito vezes a corrente nominal). O segundo ensaio avalia a corrente de curto-circuito de um gerador com rotor tipo gaiola de esquilo com excitação através de capacitor. Para este caso, a corrente de curto-circuito se apresenta com pequena magnitude e com longa duração. No terceiro caso, avalia-se o gerador com rotor bobinado excitado através de corrente contínua no rotor. O comportamento da corrente de curto-circuito, neste caso, apresentou-se de forma semelhante ao de um gerador síncrono, mas com menor magnitude e fenômenos transitórios de curta duração. No quarto caso, avalia-se um gerador com dupla alimentação, rotor bobinado e excitação feita através de corrente alternada no rotor. De forma semelhante, o comportamento da corrente de curto-circuito é análogo ao caso de um gerador síncrono. No quinto caso, efetua-se a análise de um gerador com tripla alimentação, ou seja, em relação à configuração do caso anterior, acrescentou-se um capacitor de forma paralela ao estator operando como fonte extra de excitação. A corrente de curto-circuito, para este caso, apresenta-se inicialmente com um elevado valor de pico devido à corrente de descarga do capacitor, e apresenta também um componente em corrente contínua. Conclui-se, portanto, que a contribuição de corrente de curto-circuito proporcionada por geradores de indução pode variar em função do tipo do rotor e do tipo de excitação. 


\subsection{Permanência dos Geradores Distribuídos Durante o Período de Falta no Sistema "Fault Ride Through" (FRT)}

As normas atuais que orientam a conexão de geradores distribuídos nos sistemas de distribuição de energia elétrica estabelecem a rápida desconexão do gerador em caso de ocorrência de curtos-circuitos. Essa medida visa proteger os equipamentos da rede elétrica e os geradores distribuídos contra os excessivos afundamentos de tensão, elevados valores de corrente de curto-circuito e garantir a coordenação dos dispositivos de proteções (IEEE1547.2, 2009) e (Leite; Barros; Miranda, 2009). Por outro lado, a desconexão dos geradores pode cessar os possíveis benefícios que os mesmos proporcionam à operação dos sistemas elétricos, dentre os quais, pode-se citar o suporte de potência reativa e a redução do afundamento de tensão da rede.

Com incentivos à expansão da geração distribuída em diversos países, a operação de alguns sistemas de energia elétrica se tornou muito dependente desses geradores (Katiraei; Aguero, 2011). Logo, a desconexão massiva de geradores distribuídos pode provocar afundamentos de tensão severos, comprometimento da qualidade da energia elétrica nesses sistemas e causar desligamentos indesejados que, eventualmente, culminem em apagões e em colapso de tensão (Probert; Nutt, 2009). Diante dessa realidade, pesquisadores e demais profissionais envolvidos no setor elétrico de diversos países estudam e estabelecem diretrizes para o comportamento e permanência do funcionamento dos geradores distribuídos frente à ocorrência de curtos-circuitos e de afundamentos de tensão. Associando a esse contexto o aumento da utilização de geradores baseados em inversores, entende-se que também ocorre o aumento no interesse em quantificar os valores da parcela de contribuição de corrente de falta desse tipo de gerador que, por conseguinte, cresce também a necessidade de sua introdução nos cálculos de curto-circuito.

A capacidade dos geradores distribuídos permanecerem conectados e atuantes durante e após a eliminação da falta no sistema elétrico é chamado pela literatura de "Fault Ride Through" (FRT) e pela relação com a suportabilidade ao consequente afundamento de tensão, "Low Voltage Ride Through" (LVRT). A Figura 2.2 apresenta um exemplo de requisitos estabelecidos pela Alberta Electric System Operator (AESO) no Canadá (Iov et al., 2007), referentes à permanência de funcionamento de geradores distribuídos, classificados como aerogeradores e com capacidade inferior a $5 \mathrm{MW}$, diante da ocorrência de um afundamento de tensão (LVRT) que possivelmente pode ser causado por um curto-circuito no sistema elétrico. 


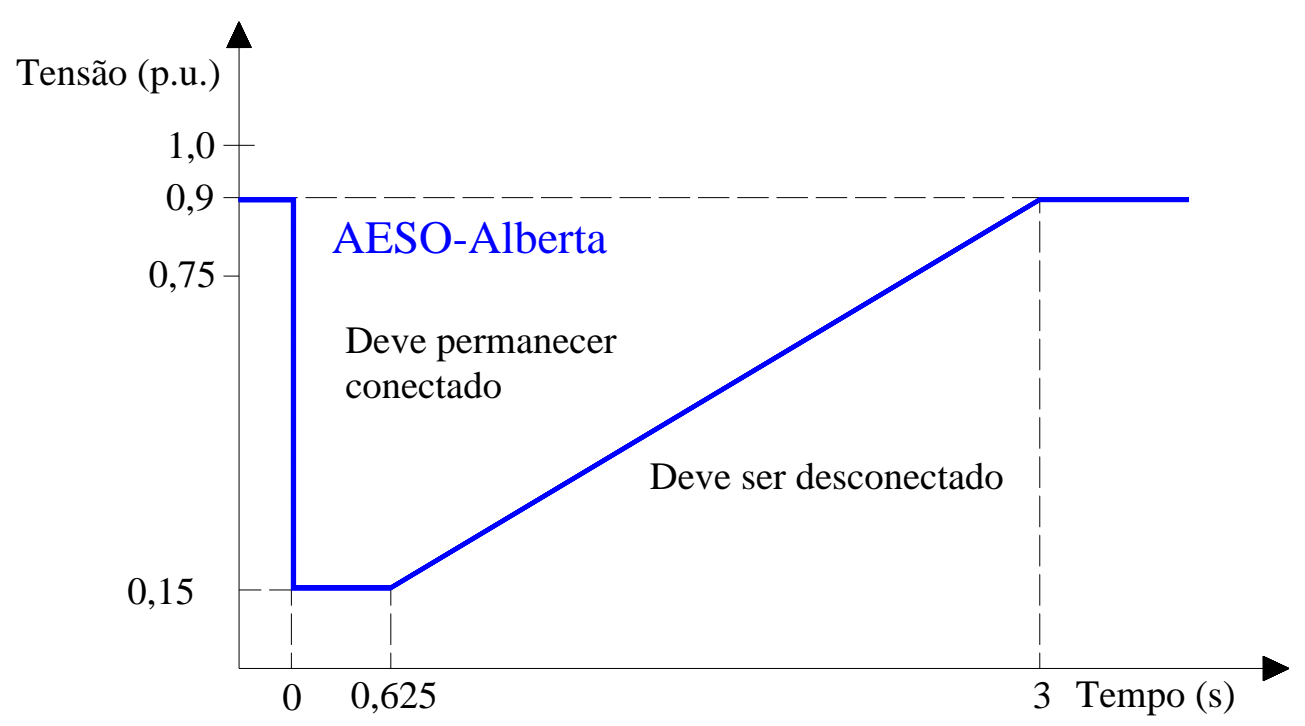

Figura 2.2 - Perfil de duração de tensão estabelecido por AESO-Alberta Canadá para geradores eólicos com potência inferior a 5 MW (Iov et al., 2007).

De acordo com a curva, os geradores distribuídos devem ser desconectados do sistema elétrico se a relação entre a intensidade e duração do afundamento de tensão estiver abaixo da linha destacada em azul. Como exemplo do caso apresentado na Figura 2.2, se a magnitude do afundamento de tensão for igual a 0,15 pu, o gerador poderá ser desligado.

Os geradores baseados em inversores apresentam maior flexibilidade de controle em relação aos demais tipos tradicionais (síncronos e assíncronos), não estão submetidos aos fatores mecânicos que envolvem as máquinas rotativas e podem efetuar controle independente por fase em termos de magnitude de corrente, tensão, conteúdo harmônico e potência. Esses fatores despertam interesse em desenvolvimentos de projetos que utilizam esses tipos de geradores em sistemas que dependem e necessitam da permanência do funcionamento dos geradores distribuídos diante da ocorrência de uma falta, para que não entrem em colapso (Keller; Kroposki, 2010). Esse tipo de gerador pode ser ajustado para continuar fornecendo corrente mesmo diante de um sistema em situação de falta e em queda de tensão. No entanto, devido às limitações térmicas dos componentes eletrônicos (semicondutores de potência IGBTs), a capacidade de fornecimento de corrente é inferior aos das máquinas rotativas em situação de falta. 


\subsection{Considerações Finais do Capítulo}

Nas seções anteriores, foram citados alguns trabalhos que envolvem a análise e comportamento das correntes de falta dos tipos mais comuns de geradores distribuídos. Notase que a contribuição dos geradores distribuídos no nível de curto-circuito depende do tipo da tecnologia empregada. No caso de máquinas rotativas conectadas diretamente ou através de transformadores ao sistema de energia, os estudos sobre o comportamento e metodologias de cálculos estão bastante difundidos. Dependendo do caso, esses tipos de geradores necessitam de dispositivos limitadores de corrente de falta para que possam ser introduzidos no sistema de energia.

Com base nos valores das impedâncias internas das máquinas rotativas, diversos autores, tais como: Kindermann (1997) e Almeida e Freitas (1995), apresentam de forma contundente as metodologias convencionais de cálculos de curtos-circuitos que incluem os geradores rotativos. Entretanto, essa ainda não é uma realidade para os geradores baseados em inversores.

Os geradores baseados em inversores apresentam menor contribuição de corrente de curtocircuito em relação às máquinas rotativas. $\mathrm{O}$ fato pode ser atribuído aos dispositivos de proteção dos próprios inversores que detectam a falta através de dispositivos sensíveis a subtensão ou sobrecorrente e que também limitam os valores de corrente em torno de 1,1 a 1,5 vezes a corrente nominal para que não haja danos ao próprio equipamento (Turcotte; Katiraei, 2009).

As limitações de corrente e tempo de resposta do inversor frente à ocorrência de curtocircuito estão, na maioria das vezes, atrelados aos dispositivos de controle. Entretanto, a diversidade nos modos de controle e a resposta dinâmica dos inversores frente a curtoscircuitos dificultam a obtenção de uma conclusão generalizada sobre o comportamento desse tipo de gerador, considerando eventos desta natureza.

O estudo referente ao comportamento do gerador baseado em inversor quando inserido no sistema elétrico e submetido ao curto-circuito ainda é relativamente recente e os trabalhos analisados ainda estão muito limitados à inserção de geradores de baixa potência que representam uma pequena parcela em relação à capacidade total do sistema principal de energia envolvido. Além disso, devido as suas inerentes limitações de sobrecorrente, geralmente as contribuições dos geradores baseados em inversores para corrente de falta são negligenciadas, quando comparadas aos geradores síncronos. 
Os fatos supracitados contribuem para torná-los, na grande parte das situações, inofensivos ao sistema elétrico. Contudo, a tendência de crescimento e dependência de fontes geradoras com representatividade maior de contribuição de potência e distribuídas ao longo dos alimentadores pode ampliar, na mesma proporção, os malefícios decorrentes de suas contribuições para as correntes de curto-circuito. Isso aumenta a necessidade de investigações sobre o comportamento e consequências de geradores distribuídos em sistemas sob condição de falta. Acrescenta-se a isso um cenário futuro em que, devido ao elevado nível de penetração e dependência do sistema elétrico por geradores baseados em inversores de frequência, será desejável que os mesmos permaneçam em operação durante e após a ocorrência de faltas no sistema elétrico. Essa situação demanda alterações na proteção do inversor fazendo-os permanecer conectados e fornecendo, mesmo que seja de baixo valor, a corrente de curto-circuito por um período mais longo, diante da ocorrência de falta. Isso também aumenta o interesse em quantificar os valores da parcela de contribuição de corrente de falta de cada gerador distribuído instalado no sistema de energia elétrica.

Juntamente com o interesse em quantificar a contribuição de corrente de falta, surge a necessidade de inclusão dos geradores baseados em inversores nos cálculos de corrente de curto-circuito dos sistemas elétricos. Nesse contexto, esses aspectos serão abordados nos capítulos seguintes deste trabalho. 


\section{Capítulo 3}

\section{Modelagem dos Componentes do Sistema Elétrico}

\subsection{Introdução}

Nesta seção, são mostradas as metodologias, ferramentas e modelagens utilizadas para a análise da influência dos geradores distribuídos GD nos níveis de corrente de curto-circuito em sistemas de distribuição de energia.

Apresentam-se, nos sub-tópicos posteriores, os modelos computacionais dos geradores baseados em inversores que são implementados e utilizados no desenvolvimento deste trabalho. Destaca-se que as estruturas desses modelos foram baseadas em coletâneas de informações obtidas em bibliografias e trabalhos científicos referentes aos assuntos de modelagem e inversores. Apesar da diversidade de trabalhos e propostas acadêmicas que envolvem o desenvolvimento e aprimoramento dos modelos de inversores, para este trabalho, optou-se pela implantação de modelos convencionais já difundidos no meio acadêmico.

As parametrizações, especificações dos valores das variáveis e componentes serão apresentados em função das necessidades dos estudos de casos, exibidos no próximo capítulo ou no apêndice A.

$\mathrm{Na}$ sequência, apresentam-se a ferramenta computacional, os diagramas, simbologias e figuras que envolvem os principais componentes, controle dos geradores baseados em inversores e sistema elétrico de distribuição. Não faz parte do escopo deste trabalho estudos que envolvam aprimoramentos dos modelos de inversores. 


\subsection{Ferramenta Computacional SimPowerSystems}

Como forma de obtenção de dados e resultados necessários ao desenvolvimento do tema proposto, utiliza-se neste trabalho a ferramenta computacional SimPowerSystems para a construção, modelagem e simulação de circuitos elétricos. Todas as simulações realizadas são do tipo transitório eletromagnético.

O SimPowerSystems é um aplicativo que opera através da utilização da plataforma Matlab/Simulink e provê um ambiente interativo com base em diagramas de blocos voltados para criação, simulação e análise de sistemas dinâmicos contínuos, discretos ou híbridos. Disponibiliza, em sua biblioteca, uma grande quantidade e variedade de blocos que permitem a montagem e simulação de circuitos com características típicas de sistemas elétricos de potência. Sua validação é baseada em testes e experiências realizadas em laboratórios reconhecidos internacionalmente. Os componentes utilizados no SimPowerSystems podem ser parametrizados, compartilhados e interagidos com os do Simulink ou mesmo serem desenvolvidos pelo usuário por meio de linguagens apropriadas de programação (Matsumoto, 2008; TransÉnergie, 2010).

\subsection{Modelagem do Gerador Distribuído}

Os geradores baseados em inversores de frequência, de uma maneira geral, são compostos por três estágios. O primeiro deles compreende uma fonte primária conectada a um conversor CC/CC ou CA/CC (dependendo se a fonte primária fornece tensão contínua ou alternada), um elo de corrente contínua e um inversor CC/CA conectado à rede elétrica. Esses inversores são controlados via modulação PWM (Pulse Width Modulation) e são responsáveis pela interligação e entrega da potência gerada pelo gerador GD ao sistema de energia (concessionária). A Figura 3.1 apresenta a estrutura generalizada do gerador modelado e sua interligação com o sistema de energia da concessionária. 


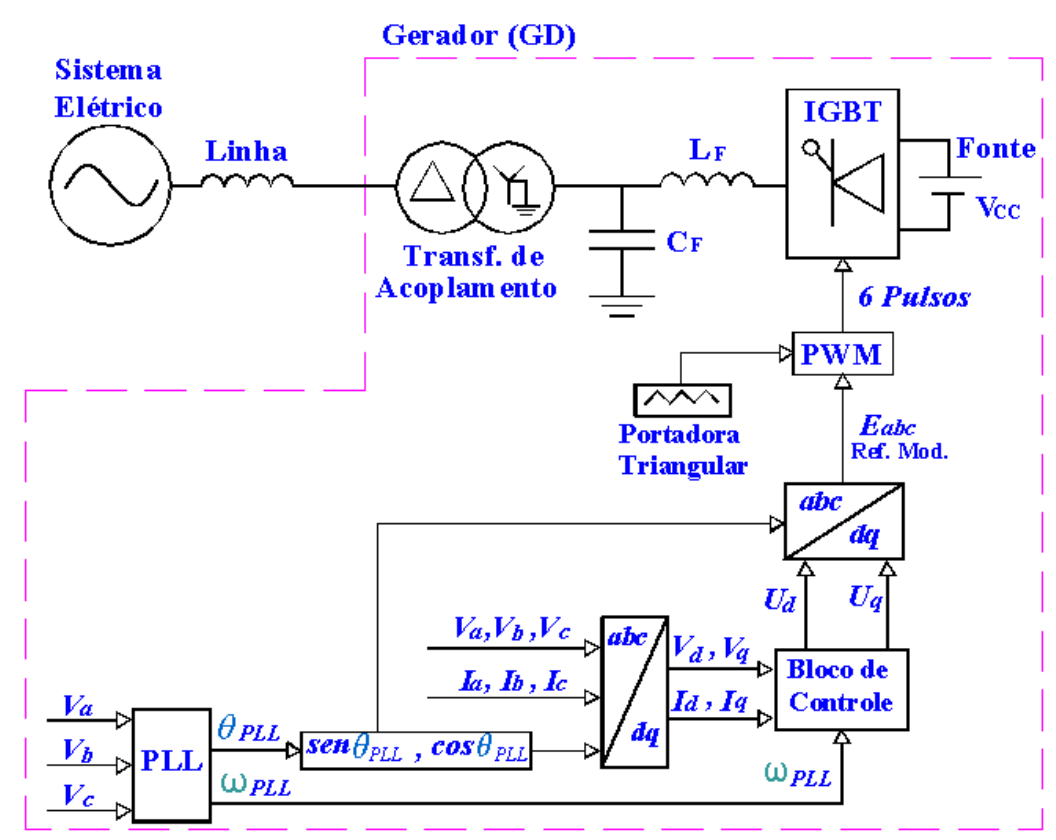

Figura 3.1 - Esquema generalizado dos geradores trifásicos baseados em inversores de frequência.

Sendo:

$V_{a}, V_{b}$ e $V_{c} \rightarrow$ Tensões de fase do sistema elétrico no terminal do inversor;

$I_{a}, I_{b}$ e $I_{c} \rightarrow$ Correntes de fase do sistema elétrico no terminal do inversor;

$V_{d} \rightarrow$ Componente da tensão do eixo direto (eixo $d$ );

$V_{q} \rightarrow$ Componente da tensão do eixo em quadratura (eixo $q$ )

$U_{d} \rightarrow$ Tensão de eixo direto resultante do bloco de controle;

$U_{q} \rightarrow$ Tensão de eixo em quadratura resultante do bloco de controle;

$\omega_{P L L} \rightarrow$ Frequência angular fornecida pelo PLL (Phase-Locked Loop);

$\theta_{P L L} \rightarrow$ Ângulo fornecido pelo PLL;

$\mathrm{PWM} \rightarrow$ Bloco geração de pulsos de comando dos IGBTs;

$E_{a b c} \rightarrow$ Tensões de referência em coordenadas naturais - referências moduladoras para o módulo PWM;

$\mathrm{V}_{\mathrm{cc}} \rightarrow$ Fonte regulada de tensão contínua;

IGBT $\rightarrow$ Bloco dos semicondutores de potência (IGBT - Insulated Gate Bipolar Transistor);

$\mathrm{L}_{\mathrm{F}} \rightarrow$ Indutor do filtro de saída do inversor;

$\mathrm{C}_{\mathrm{F}} \rightarrow$ Capacitor do filtro de saída do inversor. 


\subsection{Descrição dos Principais Blocos dos Circuitos}

Com intuito de engrandecer a abordagem sobre o gerador GD e ainda com referência à Figura 3.1, apresenta-se nesta seção a descrição e funcionamento sequencial dos principais blocos que compõem o GD e sua interligação com o sistema de energia da concessionária.

\subsubsection{Tensões de Fase e Sistema de Energia da Concessionária}

Na Figura 3.1, observa-se que o gerador GD está conectado a um barramento "infinito" que é representado pelo sistema elétrico da concessionária e linha. As tensões de fase $\left(V_{a}, V_{b} e\right.$ $V_{c}$ ) do barramento do sistema trifásico são representadas pelas equações em (3.1).

$$
\begin{gathered}
V_{a}=V \operatorname{sen}\left(\omega t+\delta_{0}\right) \\
V_{b}=V \operatorname{sen}\left(\omega t-\frac{2}{3} \pi+\delta_{0}\right) \\
V_{c}=V \operatorname{sen}\left(\omega t+\frac{2}{3} \pi+\delta_{0}\right)
\end{gathered}
$$

Sendo:

$V \rightarrow$ Valor de pico da tensão de fase no terminal do inversor;

$\omega \rightarrow$ Frequência angular da tensão no terminal do inversor;

$\delta_{0} \rightarrow$ Ângulo de fase inicial da tensão no terminal do inversor.

Para conexão do inversor ao sistema trifásico, este trabalho, por opção, se referencia nas instruções normativas da concessionária local CPFL (2012) e adota um transformador acoplador com enrolamentos delta (concessionária) / estrela (acessante). O objetivo dessa configuração é evitar a injeção e circulação de componentes de corrente de sequência zero na rede da concessionária, que são proporcionadas pelo desbalanço entre fases e faltas assimétricas. Essa configuração também evita a injeção de componentes de correntes harmônicas múltiplas de terceira ordem ao sistema de energia. 


\subsubsection{Fonte Vcc e Comutação dos IGBTs}

Para este trabalho, considera-se que a fonte primária de alimentação seja contínua (Vcc). Sendo assim, o primeiro estágio dos geradores baseados em inversores de frequência é composto por conversores CC/CC e juntamente com este estágio e o elo de corrente contínua, há capacitores adequadamente dimensionados para desempenhar a função de armazenar energia e entregá-la rapidamente à carga quando for solicitada. Para isto, considera-se que esses capacitores têm elevada capacidade de armazenamento e, segundo Jenkins et al. (2000) e Buso e Mattavelli (2006), devido a essa característica, o conversor CC/CC e os capacitores podem ser representados por uma fonte de tensão contínua ideal.

Para o propósito de análise de curto-circuito, pode-se admitir que a tensão de saída dessa fonte de tensão contínua (Vcc) seja regulada e essencialmente constante no intervalo de 0 a 1 segundo, após a ocorrência do curto-circuito (Nimpitiwan et al., 2007). Como neste trabalho os curtos-circuitos simulados terão duração inferior a esse tempo (1 segundo), a hipótese anterior garante a validade dos resultados obtidos.

Para os geradores em estudo, empregam-se inversores tipo VSI (Voltage Source Inverter) com transístores bipolares de portas isoladas (IGBT) que, acionados através da tecnologia de modulação por largura de pulso (PWM) e filtros $\mathrm{L}_{\mathrm{F}}$ e $\mathrm{C}_{\mathrm{F}}$, sintetizam formas de ondas de tensão e corrente em conformidade com a qualidade desejada.

\subsubsection{PLL (Phase-Locked Loop)}

O PLL é o principal dispositivo utilizado em equipamentos que fazem uso da eletrônica de potência para interliga-los ao sistema de energia. Ele é responsável por promover o sincronismo entre sinais no que se refere à magnitude, ângulo de fase e frequência. Sua estrutura e algoritmo se apresentam de forma variada na literatura, entretanto, para este trabalho, o PLL segue algoritmo de operação em coordenadas síncronas $d q 0$, que pode eliminar erros de controle em regime permanente e proporcionar bom desempenho diante das variações de tensão que, comumente, ocorrem nos sistemas de energia (Rafal et al., 2011). A Figura 3.2 apresenta, em destaque, o diagrama de bloco do PLL trifásico juntamente com as indicações de suas atuações em outros blocos dos circuitos do inversor. 


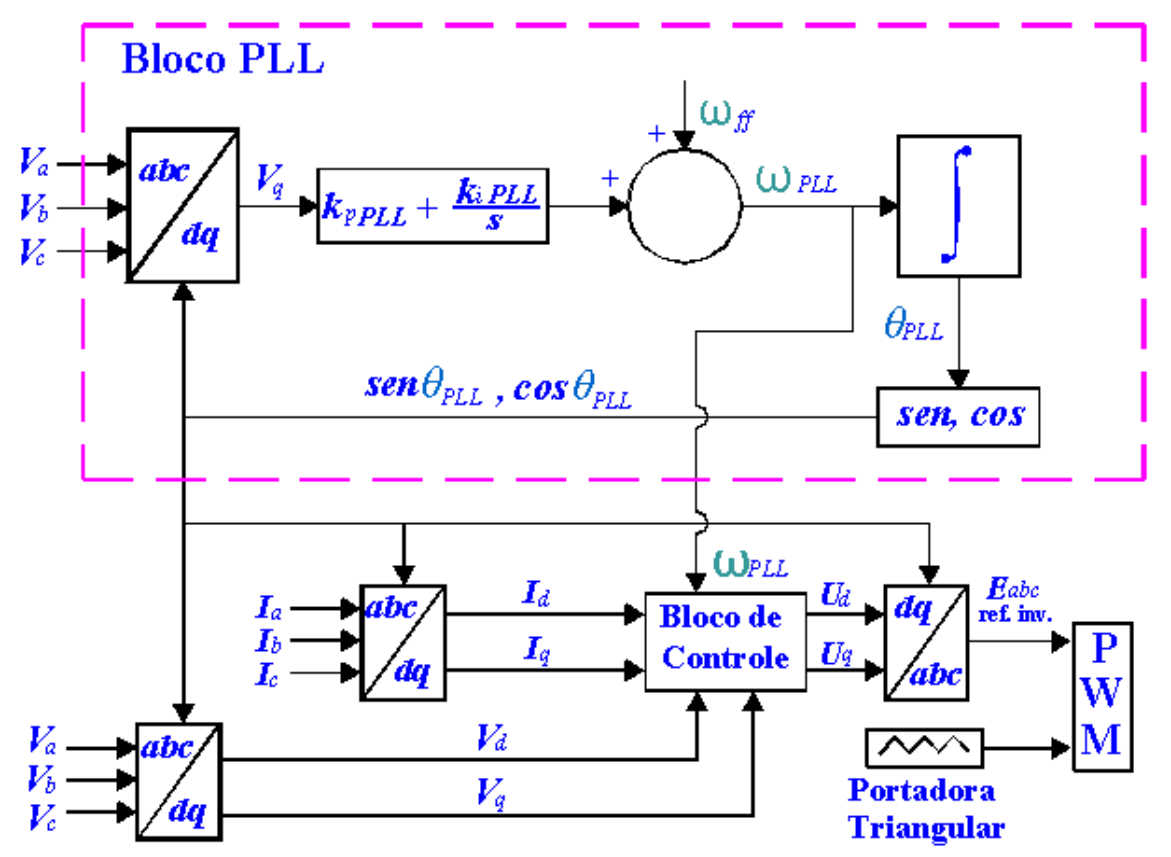

Figura 3.2 - Esquema do bloco PLL trifásico e suas ações no circuito do inversor.

Sendo no bloco PLL:

$V_{a}, V_{b}$ e $V_{c} \rightarrow$ Tensão de fase no terminal do inversor trifásico;

$V_{d} \rightarrow$ Componente da tensão do eixo direto (eixo $d$ );

$V_{q} \rightarrow$ Componente da tensão do eixo em quadratura (eixo $q$ );

$k_{p P L L} \rightarrow$ Ganho proporcional do controle do PLL;

$k_{i P L L} \rightarrow$ Ganho integral do controle do PLL;

$s \rightarrow$ Operador de Laplace;

$\omega_{f f} \rightarrow$ Frequência angular de ajuste e referência do PLL;

$\omega_{P L L} \rightarrow$ Frequência angular fornecida pelo PLL;

$\theta_{P L L} \rightarrow$ Ângulo fornecido pelo PLL.

O PLL recebe os valores das tensões de fase $V_{a}, V_{b}$ e $V_{c}$ e frequência do sistema no qual o inversor está conectado e, como operação inicial, efetua-se, por meio da equação (3.2), a transformação das componentes de fases $a b c$ para girante síncrona $d q 0$.

$$
\left[\begin{array}{l}
V_{d} \\
V_{q} \\
V_{0}
\end{array}\right]=\frac{2}{3}\left[\begin{array}{ccc}
\operatorname{sen} \theta & \operatorname{sen}(\theta-2 \pi / 3) & \operatorname{sen}(\theta+2 \pi / 3) \\
\cos \theta & \cos (\theta-2 \pi / 3) & \cos (\theta+2 \pi / 3) \\
1 / 2 & 1 / 2 & 1 / 2
\end{array}\right] \cdot\left[\begin{array}{c}
V_{a} \\
V_{b} \\
V_{c}
\end{array}\right]
$$


O ângulo $\theta$, inicialmente utilizado nas transformações de coordenadas, corresponde ao ângulo da tensão de fase obtido pelo PLL no terminal do inversor e é composto pela equação (3.3).

$$
\theta=\omega t+\delta_{0}
$$

Sendo:

$\omega \rightarrow$ Frequência angular da tensão obtida pelo PLL;

$\delta_{0} \rightarrow$ Ângulo de fase inicial da tensão obtida pelo PLL.

Observa-se pela equação (3.3) que qualquer alteração na frequência angular de fase $\omega$ da tensão proporciona mudança do ângulo de fase $\theta$ da tensão.

A Figura 3.3 ilustra a relação de $\theta$ com as coordenadas nas formas $a b c$ e $d q 0$.

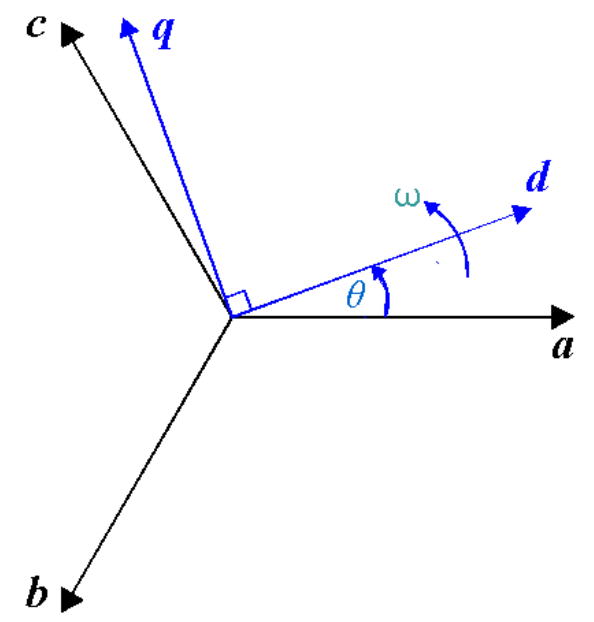

Figura 3.3 - Relação de $\theta$ com as coordenadas nas formas $a b c$ e $d q 0$.

Observa-se na figura anterior que $\theta$ é o ângulo formado entre o eixo $a$ das coordenadas naturais $a b c$ e o eixo $d$ das coordenadas síncronas $d q 0$.

O ângulo da tensão $\theta_{P L L}$ fornecido pelo PLL tende a acompanhar (se alinhar) o ângulo $\theta$ obtido da tensão no terminal do inversor, ou seja, no período de regime permanente e estável da tensão, $\theta_{P L L}$ tende a se igualar a $\theta$ e no momento transitório com variação de tensão, são diferentes entre si (Kaura; Blasko, 1997). A tensão $V_{q}$ representa a diferença (erro) entre os ângulos $\theta_{P L L}$ e $\theta$, conforme equação (3.4).

$$
V_{q}=V \operatorname{sen}\left(\theta_{P L L}-\theta\right)
$$


Na sequência, adota-se o bloco de controle tipo PI (proporcional + integral) para processar o sinal de $V_{q}$ (resultado da diferença entre $\theta_{P L L}$ e $\theta$ ) enquanto $V_{d}$ acompanha em fase o vetor de tensão do sistema. Soma-se ao sinal de saída do controle PI a frequência $\omega_{f f}$ (feed-forward) que é detectada e memorizada em torno de seu valor de referência nominal (Timbus et al., 2006), o que também a torna uma referência para o PLL. O resultado dessa soma produz a frequência de controle $\omega_{P L L}$ do PLL, conforme equação (3.5).

$$
\omega_{P L L}=\left(k_{p_{P L L}}+\frac{k_{i_{P L L}}}{s}\right) V_{q}+\omega_{f f}
$$

A frequência $\omega_{P L L}$ é utilizada na composição das três filosofias de controle (Corrente I, PQ e PV) dos inversores, que são utilizadas alternadamente nesse trabalho. Sua integração proporciona $\theta_{P L L}$, cujos valores de seno e cosseno são utilizados para as conversões entre as componentes de fases $a b c$ e síncronas $d q 0$ das tensões e correntes, conforme equações (3.6) à (3.8). Os blocos de conversões de coordenadas também estão dispostos no esquema da Figura 3.2 .

$$
\begin{aligned}
& {\left[\begin{array}{l}
V_{d} \\
V_{q} \\
V_{0}
\end{array}\right]=\frac{2}{3}\left[\begin{array}{ccc}
\operatorname{sen} \theta_{P L L} & \operatorname{sen}\left(\theta_{P L L}-2 \pi / 3\right) & \operatorname{sen}\left(\theta_{P L L}+2 \pi / 3\right) \\
\cos \theta_{P L L} & \cos \left(\theta_{P L L}-2 \pi / 3\right) & \cos \left(\theta_{P L L}+2 \pi / 3\right) \\
1 / 2 & 1 / 2 & 1 / 2
\end{array}\right] \cdot\left[\begin{array}{c}
V_{a} \\
V_{b} \\
V_{c}
\end{array}\right]} \\
& {\left[\begin{array}{c}
I_{d} \\
I_{q} \\
I_{0}
\end{array}\right]=\frac{2}{3}\left[\begin{array}{ccc}
\operatorname{sen} \theta_{P L L} & \operatorname{sen}\left(\theta_{P L L}-2 \pi / 3\right) & \operatorname{sen}\left(\theta_{P L L}+2 \pi / 3\right) \\
\cos \theta_{P L L} & \cos \left(\theta_{P L L}-2 \pi / 3\right) & \cos \left(\theta_{P L L}+2 \pi / 3\right) \\
1 / 2 & 1 / 2 & 1 / 2
\end{array}\right] \cdot\left[\begin{array}{c}
I_{a} \\
I_{b} \\
I_{c}
\end{array}\right]} \\
& {\left[\begin{array}{l}
V_{a} \\
V_{b} \\
V_{c}
\end{array}\right]=\left[\begin{array}{ccc}
\operatorname{sen} \theta_{P L L} & \cos \left(\theta_{P L L}\right) & 1 \\
\operatorname{sen}\left(\theta_{P L L}-2 \pi / 3\right) & \cos \left(\theta_{P L L}-2 \pi / 3\right) & 1 \\
\operatorname{sen}\left(\theta_{P L L}+2 \pi / 3\right) & \cos \left(\theta_{P L L}+2 \pi / 3\right) & 1
\end{array}\right] \cdot\left[\begin{array}{c}
V_{d} \\
V_{q} \\
V_{0}
\end{array}\right]}
\end{aligned}
$$




\subsubsection{Controle}

Para este bloco, também apresentado na Figura 3.1 e Figura 3.2, adota-se uma das três modalidades de controle que fazem parte desta pesquisa, sendo elas: controle de corrente I (corrente constante), controle PQ (potência ativa e reativa constantes) e controle PV (potência ativa e tensão terminal constante). Seguem nas próximas subseções as sínteses operacionais das modalidades de controle adotadas neste trabalho.

\subsubsection{Controle por Corrente Constante (I)}

Esse tipo de controle se propõe a controlar o inversor com base nas referências de valores de correntes pré-determinados. Neste trabalho, essa estratégia é referenciada como controle I e é baseada nos esquemas apresentados em Wang (2008). Dentre as três modalidades de controle (I, PQ e PV) adotadas neste trabalho, esta possui o circuito mais simplificado e com menor quantidade de operações e cálculos. A Figura 3.4 apresenta o diagrama geral de funcionamento do bloco de controle de corrente.

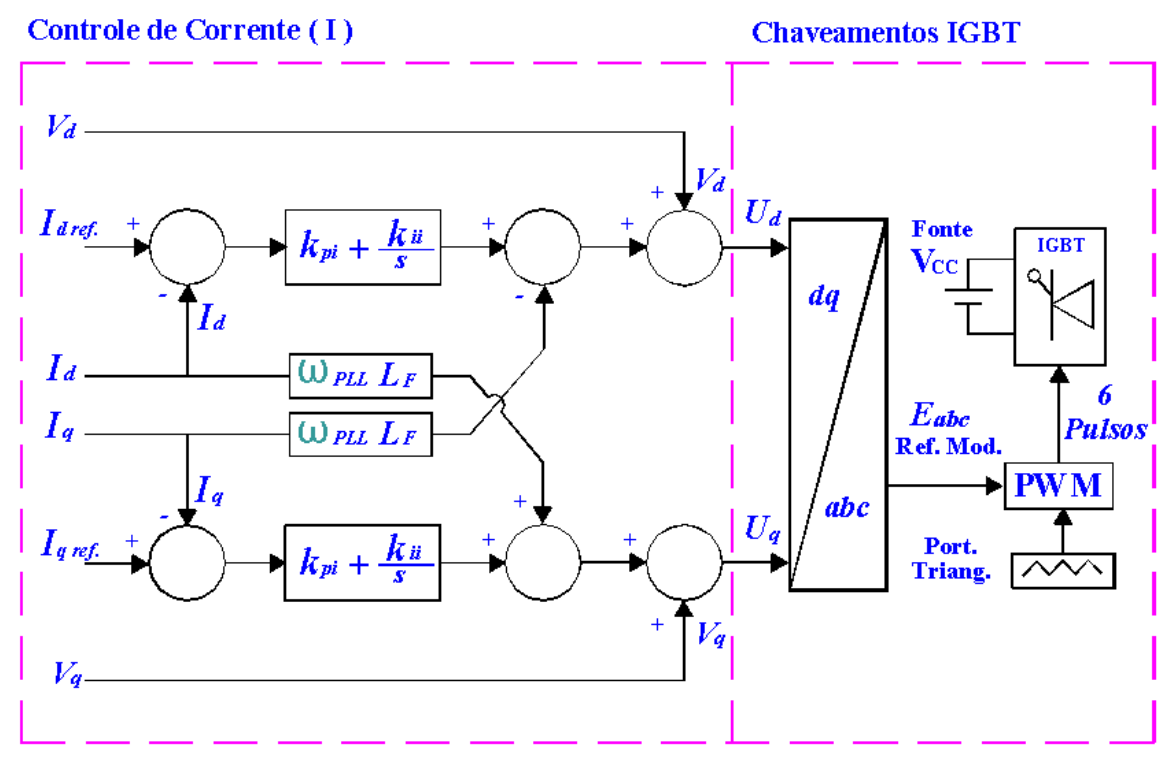

Figura 3.4 - Diagrama de blocos do controle de corrente constante (I).

Sendo:

$I_{d r e f} \rightarrow$ Valor de referência de corrente de eixo direto (eixo $d$ );

$I_{q r e f} \rightarrow$ Valor de referência de corrente de eixo em quadratura (eixo $q$ );

$k_{p i} \rightarrow$ Ganho proporcional do controle de corrente;

$k_{i i} \rightarrow$ Ganho integral do controle de corrente. 
Inicialmente, o inversor obtém os valores de tensões e correntes dispostos em componentes de fase $a b c$ nos seus terminais de interligação com o sistema elétrico. Na sequência, através de $\theta_{P L L}$ fornecido pelo PLL e das equações de (3.6) à (3.8), efetua a transformação dessas coordenadas para síncrona girante $d q 0$, como mostram os blocos conversores de coordenadas dispostos na Figura 3.2. Como próxima etapa, os valores de tensões $V_{d}$ e $V_{q}$, de correntes $I_{d}$ e $I_{q}$ e frequência $\omega_{P L L}$ são fornecidos ao bloco de controle adotado. As etapas seguidas até agora são comuns às três modalidades de controle (I, PQ e PV). A partir de então, iniciam-se as particularidades de atuação de cada modalidade de controle.

Para o controle de corrente, utiliza-se a leitura dos valores de $I_{d}$ e $I_{q}$ como forma de obtenção de dados instantâneos dos valores de correntes que o inversor fornece ao sistema. Efetua-se a comparação desses valores aos de referência $I_{d r e f}$ e $I_{q r e f}$, que são fornecidos pelo programador ou operador do inversor. A diferença (erro) entre os valores instantâneos de correntes obtidos da saída do inversor $\left(I_{d}\right.$ e $\left.I_{q}\right)$ com os de referência $\left(I_{d r e f}\right.$ e $\left.I_{q r e f}\right)$ é processada pelo controle PI, cujo sinal de saída, interage com a frequência $\omega_{P L L}$ e indutor do filtro $L_{F}$, que somados respectivamente aos valores de $V_{d}$ e $V_{q}$, obtém-se como resultado, os valores de $U_{d}$ e $U_{q}$, que são resultantes, respectivamente, das tensões de referência em eixo direto e em quadratura. A partir dessa etapa (obtenção de $U_{d}$ e $U_{q}$ ), os procedimentos seguintes são comuns às três modalidades de controle (I, PQ e PV) estudadas no trabalho.

Os valores de tensões $U_{d}$ e $U_{q}$ são transformados para componentes de fases $a b c$, através da equação (3.8). Após essa transformação, obtêm-se os valores das tensões $E_{a}, E_{b}$ e $E_{c}\left(E_{a b c}\right)$, que representam as tensões moduladoras de referência que, associadas aos sinais das portadoras triangulares, exercem a modulação PWM, promovendo os chaveamentos dos transístores bipolares (IGBT) que, a partir da fonte Vcc, produz as tensões de saída adequadas em magnitude e frequência para a interligação do inversor com o sistema elétrico de potência. 


\subsubsection{Controle de Potências Ativa e Reativa (PQ)}

Essa estratégia de controle têm como base de referência os valores de potências ativa e reativa, previamente ajustados pelo programador do inversor. Nesse trabalho, essa estratégia é chamada de controle PQ e é baseada nos esquemas apresentados em Wang (2008). A Figura 3.5 apresenta o diagrama geral e funcionamento do bloco de controle PQ.

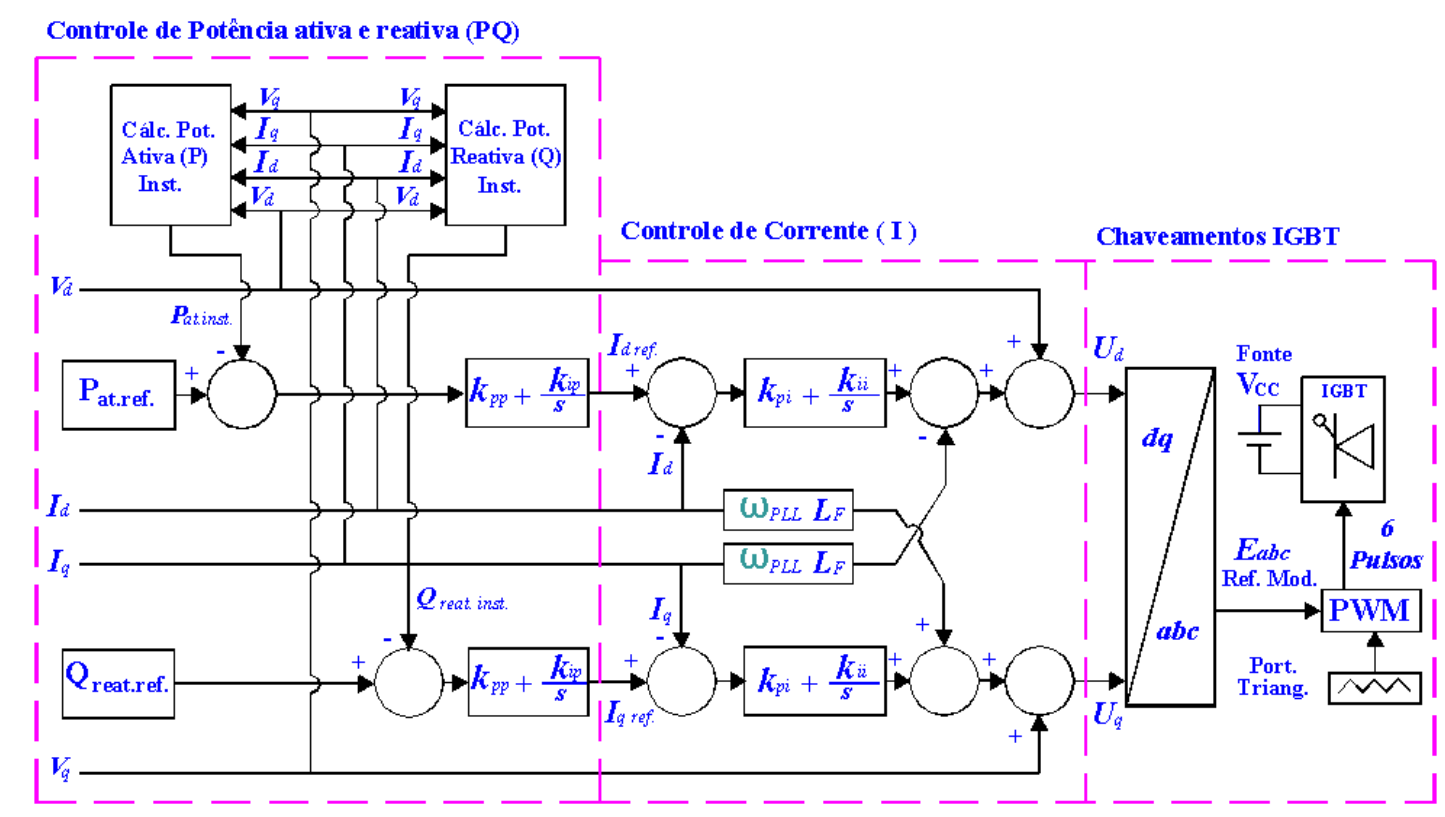

Figura 3.5 - Diagrama de blocos do controle de potência ativa e reativa (PQ).

Sendo:

$P_{\text {at.ref }} \rightarrow$ Valor de referência para potência ativa;

$Q_{\text {reat.ref }} \rightarrow$ Valor de referência para potência reativa;

$k_{p p} \rightarrow$ Ganho proporcional do controle de potência;

$k_{i p} \rightarrow$ Ganho integral do controle de potência.

Assim como abordado nas seções anteriores, inicialmente o inversor efetua as transformações de componentes de fases $a b c$ para síncrona girante $d q 0$, obtendo-se assim, os valores de tensões $V_{d}$ e $V_{q}$, de correntes $I_{d}$ e $I_{q}$ e a frequência $\omega_{P L L}$. De posse desses dados e, considerando que neste trabalho não há tensões e correntes de sequência zero, efetuam-se os cálculos de potências instantâneas ativa e reativa fornecidas pelo inversor, conforme equações (3.9) e (3.10).

$$
\begin{aligned}
& P_{\text {ativ.inst }}=\left(V_{d} \times I_{d}\right)+\left(V_{q} \times I_{q}\right) \\
& Q_{\text {reat.inst }}=\left(V_{d} \times I_{q}\right)-\left(V_{q} \times I_{d}\right)
\end{aligned}
$$


Obedecendo a conformidade de operações em eixo direto e em quadratura, os valores instantâneos calculados de potência ativa $\left(P_{\text {ativinst. }}\right)$ e potência reativa $\left(Q_{\text {reat.inst. }}\right)$ são respectivamente comparados às referências $P_{\text {ativ.ref. }}$ e $Q_{\text {reat.ref., }}$ que são previamente fornecidas pelo programador ao inversor. A diferença (erro) entre os valores de potências instantâneas ( $\left.P_{\text {ativ.inst. e }} Q_{\text {reat.inst. }}\right)$ com os de referência ( $P_{\text {ativ.ref. }}$ e $\left.Q_{\text {reat.ref. }}\right)$ é processada pelo controle PI, sendo que $k_{p p}$ e $k_{i p}$, respectivamente, representam o ganho proporcional e o ganho integral das malhas de controle de potências. A saída do controle PI apresenta, como resultado, os valores de correntes $I_{\text {dref. }}$ e $I_{\text {qref. }}$, que atuam como referência para comparação com os valores de correntes $I_{d}$ e $I_{q}$. Seguem-se a partir dessa etapa, as mesmas diretrizes operacionais do controle de corrente I, cujo diagrama também é apresentado na Figura 3.5.

\subsubsection{Controle de Potência Ativa e Tensão (PV)}

Essa estratégia de controle tem como base de referência os valores de potências ativa e tensão que são ajustados pelo programador do inversor. Neste trabalho, essa estratégia é referenciada como controle PV e é baseada nos esquemas apresentados em Zeineldin, ElSaadany e Salama (2006) e Jiang e Yu (2009). A Figura 3.6 apresenta o diagrama de blocos modelado.

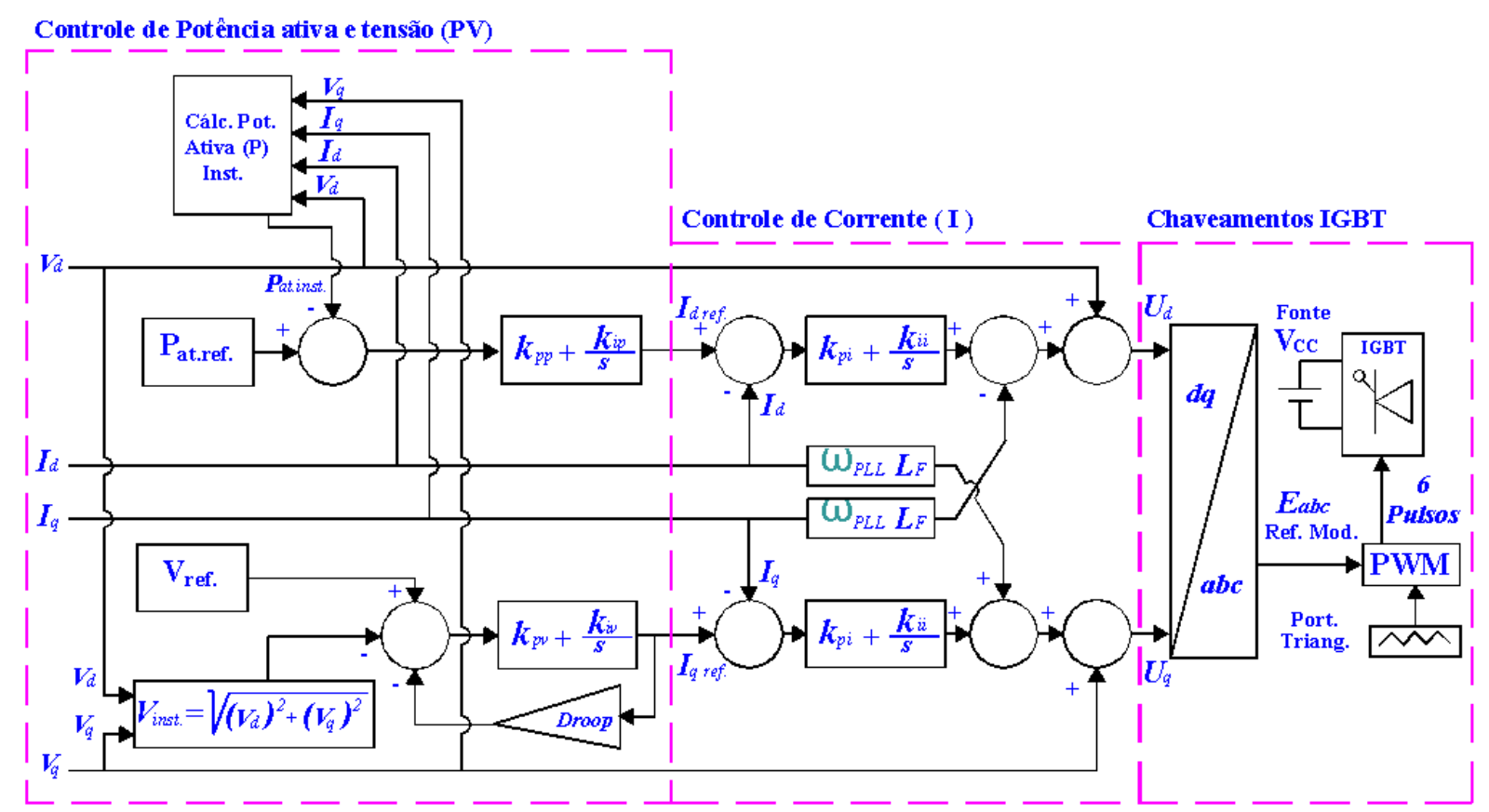

Figura 3.6 - Diagrama de blocos do controle de potência ativa e tensão (PV). 
Sendo:

$V_{r e f} \rightarrow$ Valor de referência para tensão;

$V_{\text {inst }} \rightarrow$ Valor de tensão instantânea - obtida através dos valores de $V_{d}$ e $V_{q}$;

Droop $\rightarrow$ Bloco de ganho "Droop" - evita oscilações no controle;

$Q_{\text {reat.ref }} \rightarrow$ Valor de referência para potência reativa;

$k_{p v} \rightarrow$ Ganho proporcional do controle de tensão;

$k_{i v} \rightarrow$ Ganho integral do controle de tensão.

Observa-se na Figura 3.6 que a partir da obtenção dos valores das tensões $V_{d}$ e $V_{q}$ e de correntes $I_{d}$ e $I_{q}$, calcula-se por meio da equação (3.9) o valor instantâneo de potência ativa $P_{\text {ativ.inst }}$ fornecida pelo inversor e, na sequência, faz-se a comparação desse valor com o de

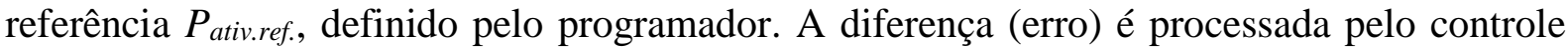
PI, sendo que $k_{p p}$ e $k_{i p}$, respectivamente, representam o ganho proporcional e o ganho integral da malha de controle de potência. O resultado do sinal de saída corresponde ao valor de referência de corrente de eixo direto $I_{d r e f}$.

Ainda na Figura 3.6, observa-se no controle de tensão que, de posse dos valores de $V_{d}$ e $V_{q}$, calcula-se o valor instantâneo de tensão na saída do inversor $V_{\text {inst.inv. }}$, conforme equação (3.11).

$$
V_{\text {inst.inv. }}=\sqrt{\left(V_{d}\right)^{2}+\left(V_{q}\right)^{2}}
$$

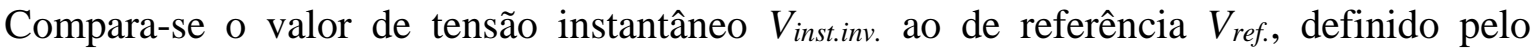
programador e, considerando-se que essa malha de controle de tensão tem uma característica em declive com a corrente de eixo em quadratura, associa-se ao bloco comparador o bloco de ganho "droop", que atua no sentido de permitir que haja pequenas variações na tensão terminal e evita o comportamento oscilatório do controlador. Na sequência, o sinal de saída é processado pelo controle PI, sendo que $k_{p v}$ e $k_{i v}$, respectivamente, representam o ganho proporcional e o ganho integral da malha de controle de tensão. O resultado do sinal de saída do controle PI corresponde ao valor de referência de corrente de eixo em quadratura $I_{q r e f}$.

De posse dos valores de $I_{d r e f}$. e $I_{\text {qref. }}$, seguem-se a partir dessa etapa, as mesmas diretrizes operacionais do controle de corrente I, cujo diagrama também é representado na Figura 3.6. 


\subsection{Considerações Finais Acerca da Modelagem do Gerador e Controle}

As modalidades de controle adotadas para o inversor de frequência foram: controle de corrente (I), controle de potências ativa e reativa (PQ) e controle de potência ativa e tensão (PV).

Através dos esquemas de controle apresentados neste capítulo, observou-se que o controle de corrente é o mais simplificado e seu esquema também se encontra inserido dentro dos esquemas das outras duas modalidades estudadas (PQ e PV). Observa-se no controle I, que o programador ajusta diretamente os valores de corrente de referência $I_{d r e f}$ e $I_{\text {qref }}$, enquanto que para as outras duas modalidades (PQ e PV) esses valores são obtidos de forma indireta, ou seja, para o controle PQ o programador fornece, como referência, os valores de $P_{r e f}$ e $Q_{r e f}$ e para o controle PV os valores de $P_{\text {ref }}$ e $V_{\text {ref. }}$. Entretanto, em ambos, esses valores de referência são processados para fornecerem, como resultado, os valores de $I_{d r e f}$ e $I_{q r e f}$ que, a partir de então, segue as diretrizes do controle de corrente I.

Através das ferramentas e recursos computacionais apresentados nos tópicos anteriores, realizam-se os testes e os estudos que são apresentados no próximo capítulo. Esses, por sua vez, são responsáveis pelo fornecimento dos resultados conclusivos para esse trabalho. 


\section{Capítulo 4}

\section{Impactos da Instalação de Geradores Distribuídos Baseados em Inversores e sua Contribuição para a Corrente de Curto-Circuito}

\subsection{Introdução}

A dependência e o crescimento da inserção de geradores distribuídos nos sistemas de distribuição de energia elétrica fazem parte da realidade atual. Embora os geradores síncronos e de indução diretamente ligados à rede sejam amplamente utilizados em aplicações de geração distribuída, existe um crescente interesse em geradores baseados em inversores. Isso ocorre principalmente devido à sua flexibilidade de controle, bem como ao aumento da utilização de energias renováveis.

Este capítulo apresenta dois estudos relacionados ao comportamento do gerador baseado em inversores, sendo que o primeiro analisa os impactos em um sistema de distribuição de energia elétrica devido à introdução desse tipo de gerador e o segundo estudo avalia a capacidade de contribuição para a corrente de curto-circuito dessa modalidade de gerador. 


\subsection{Impactos da Instalação de Geradores Baseados em Inversores no Sistema de Distribuição de Energia Elétrica}

\subsubsection{Objetivo}

O objetivo desse estudo é promover a modelagem computacional, efetuar simulações que consideram as operações funcionais de um sistema de distribuição de energia elétrica e analisar o comportamento desse sistema diante da instalação de uma central de geradores distribuídos e os impactos relacionados ao curto-circuito e alguns aspectos da qualidade de energia.

Verifica-se o comportamento do sistema através de comparações entre operações do sistema sem gerador distribuído (SG) e com a inserção do grupo gerador, sendo este submetido aos tipos de controle descritos no Capítulo 3: controle de corrente (I), potência ativa e reativa (PQ) e potência ativa e tensão (PV). Os estudos realizados nesta seção são:

- Curto-circuito trifásico em um dos barramentos do sistema;

- Perfil de tensão nos barramento;

- Afundamento de tensão;

- Variação de tensão devido à saída repentina do grupo gerador;

- Regulação de tensão;

- Perdas técnicas de potência ativa nas linhas.

\subsubsection{Considerações Iniciais}

Para este estudo, considera-se um sistema elétrico com uma central de geração distribuída, sendo que os parâmetros de modelagem e controle estão dispostos nas Tabelas de A.1 a A.4 do apêndice A. A disposição dos elementos e sistema modelado configuram um acessante com uma central de geração com dez unidades de geradores trifásicos baseados em inversores, sendo que cada unidade de geração possui capacidade de produzir $300 \mathrm{kVA}$ de potência em tensão de $380 \mathrm{~V}$. Os geradores são instalados de forma paralela e cada unidade é conectada ao barramento comum através de um transformador acoplador $380 \mathrm{~V} / 13,8 \mathrm{kV}$, compondo assim, uma central de geração com capacidade total de 3 MVA de potência e tensão 13,8 kV instalada em um sistema de distribuição. A Figura 4.1 apresenta o esquema do sistema adotado neste estudo. 


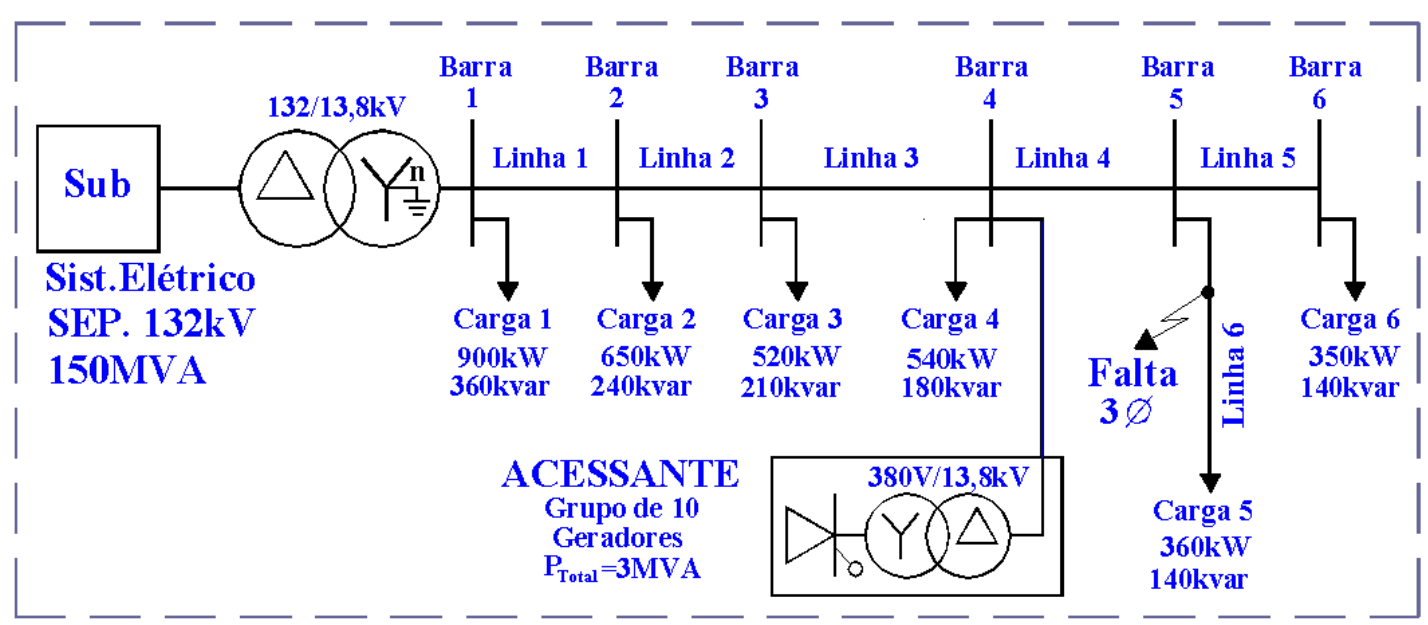

Figura 4.1- Sistema modelado: acessante com central de geração $3 \mathrm{MVA}-13,8 \mathrm{kV}$.

Em função das instruções normativas referentes à interligação de acessantes ao sistema de energia elétrica ANEEL (2012), o transformador $380 \mathrm{~V} / 13,8 \mathrm{kV}$ utilizado na saída de cada gerador, exerce também a função de acoplamento do acessante à concessionária e, com base nas diretrizes da concessionária local CPFL (2012), utiliza-se, para este transformador, a configuração delta para o lado da concessionária e estrela para o lado do acessante.

Como forma referenciar os estudos consideram-se os seguintes itens para as simulações:

- Falta trifásica com ocorrência na linha 6;

- A aplicação da falta foi realizada a partir da estabilização do sistema e do índice de modulação, sendo: 0,2485 segundo para ângulo de incidência da falta de $0^{\circ}$;

- Tempo de eliminação da falta de cinco ciclos;

- Potência de cada gerador igual a 300 kVA, sendo o total da central de geração correspondente a 3 MVA;

- Em relação à potência reativa injetada/absorvida pela central de geração, optou-se por empregar valores típicos nas variáveis de referência, a depender do tipo de controle, conforme a seguir:

- Operação do gerador com fator de potência unitário no caso de controle PQ (potência reativa de referência igual a zero) e no caso de controle I (referência da corrente $\mathrm{I}_{\mathrm{q}}$ igual a zero);

○ Tensão de referência igual à nominal $(1$ pu $)$ no caso de controle PV.

- Mínima geração igual a 10\% (0,1 pu) da capacidade total da central de geração;

- Mínima carga igual a 20\% (0,2 pu) da carga total instalada no sistema. 


\subsubsection{Estudo Sobre Curto-Circuito}

A instalação de geradores distribuídos pode aumentar significativamente o nível de curtocircuito da rede de distribuição. Portanto, a suportabilidade dos equipamentos e do sistema de proteção contra sobrecorrentes deve ser analisada antes da instalação dos geradores. Nesse contexto, estuda-se o impacto no nível de curto-circuito que a instalação da central de geradores baseados em inversores pode proporcionar ao sistema de distribuição. Considera-se que todos os dez geradores contidos no grupo estejam em operação e que o curto-circuito do tipo trifásico ocorra na linha 6 , sendo a programação de início da falta no tempo igual a 0,2485 segundo com ângulo $0^{\circ}$ e sua duração de cinco ciclos.

Considerando-se a medição na saída do transformador acoplador $(13,8 \mathrm{kV})$ da central dos geradores, analisa-se o comportamento e os valores das correntes fornecidas pelos geradores ao sistema de distribuição, durante a aplicação da falta. As simulações foram realizadas considerando os três tipos de controle (I, PQ e PV). A Figura 4.2 apresenta os resultados obtidos.

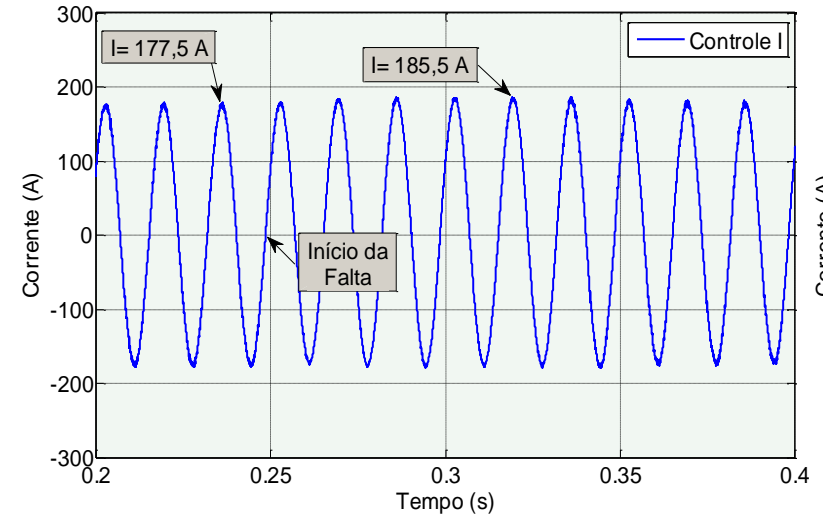

(a) Controle (I)

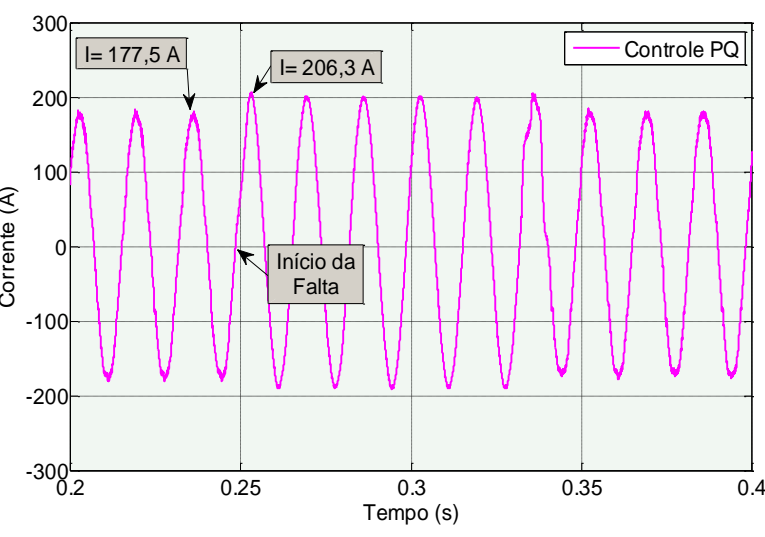

(b) Controle (PQ)

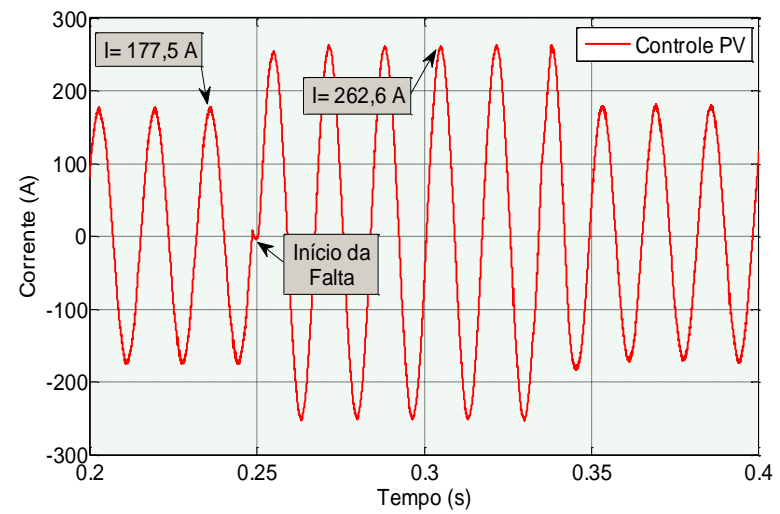

(c) Controle (PV)

Figura 4.2 - Comportamento da corrente na saída do gerador GD em função do tipo de controle. 
Considerando-se que o valor nominal da corrente de pico fornecida pelo grupo gerador de 3 MVA/ 13800 V é de 177,5 A, verifica-se na Figura 4.2 que, durante a aplicação da falta, o valor de corrente do grupo gerador submetido ao controle (I) atinge 185,5 A, o que representa um acréscimo de 4,5\%, em relação ao nominal. Para o grupo com controle (PQ), esse valor se eleva de 16\%, chegando a 206,3 A, durante a aplicação da falta. Para o controle (PV), o valor de pico da corrente de falta chega a 262,6 A, representando assim, o acréscimo de 47,9\% em relação ao valor nominal. Verifica-se também que, neste caso, a utilização dos controles (PQ) e (PV) exige maiores cuidados para o estudo e dimensionamentos dos componentes do sistema de proteção e da rede de distribuição.

Seguindo a ordem e sequência do mesmo estudo (curto-circuito), efetuam-se as medições de corrente na linha 6 , junto ao local de ocorrência do curto-circuito. Os valores obtidos neste ponto estão submetidos às limitações impostas pelas impedâncias do sistema e representam a soma total das contribuições do gerador equivalente da concessionária e do grupo de geradores distribuídos. A Figura 4.3 apresenta os resultados obtidos.

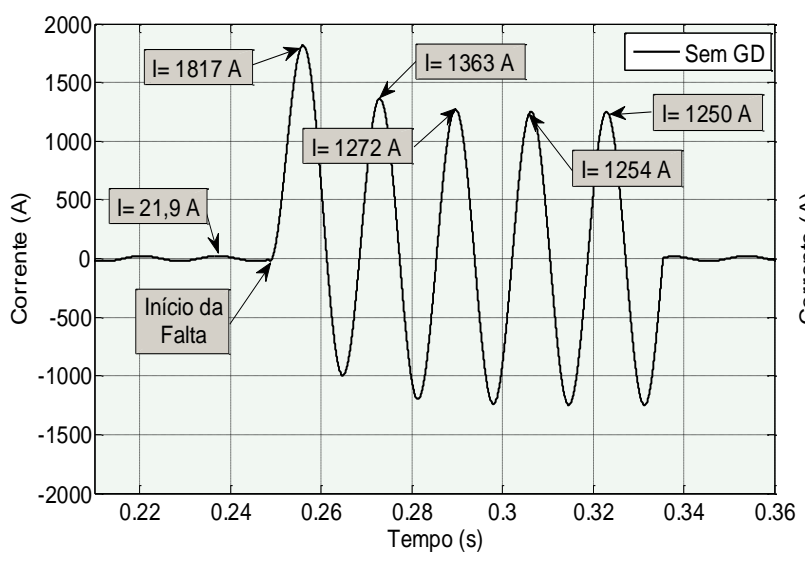

(a) Sem gerador

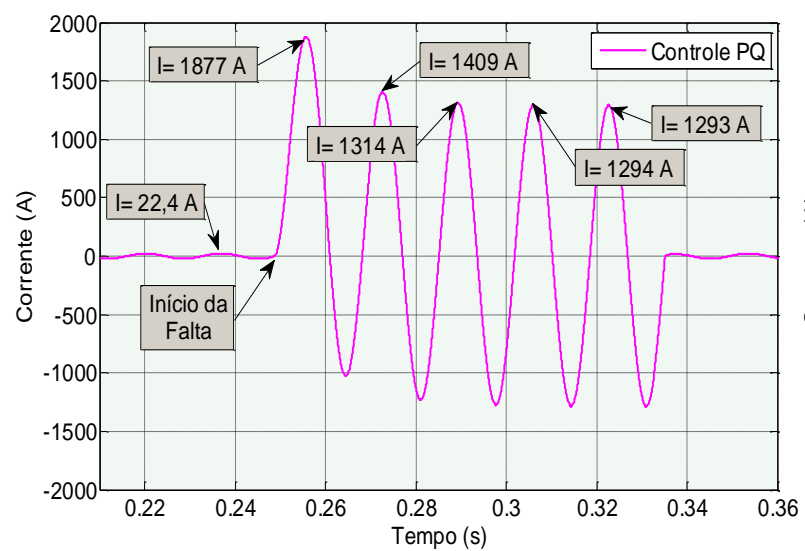

(c) Gerador com controle (PQ)

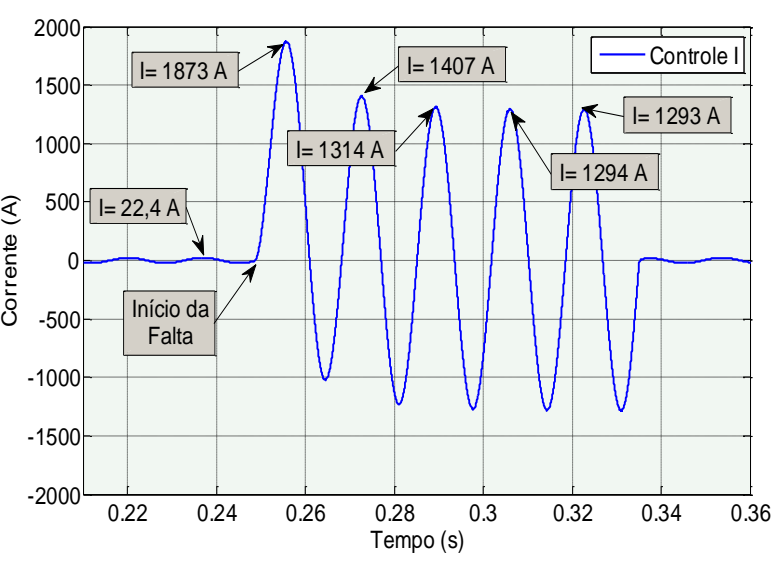

(b) Gerador com controle (I)

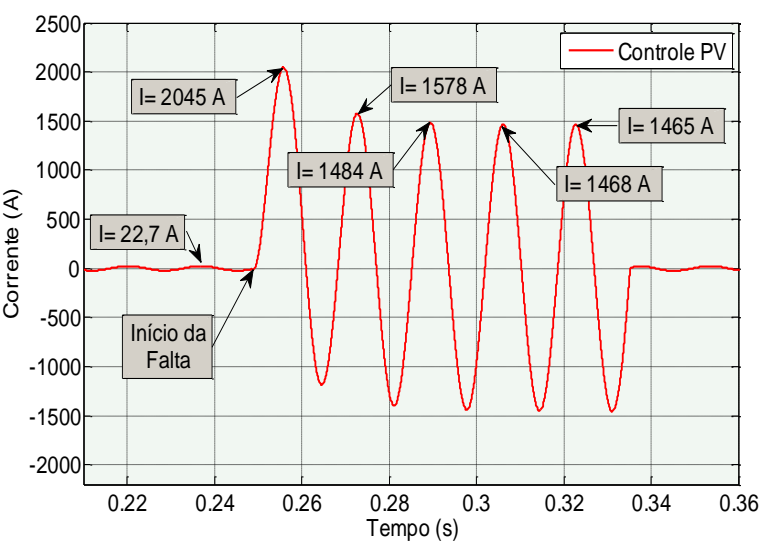

(d) Gerador com controle (PV)

Figura 4.3 - Comportamento da corrente na saída do gerador GD em função do tipo de controle. 
Considerando como referência o valor de 1817 A (figura 4.3(a)), que é o maior valor de pico da corrente de falta na linha 6 sem a inserção do grupo gerador, nota-se que a inserção da central de geração distribuída (GD) proporciona a elevação do valor da corrente de falta nesta barra. O valor de corrente com a inserção do grupo gerador submetido ao controle (I) foi de 1873 A, o que representa uma elevação de $3 \%$ em relação à referência. Para o grupo com controle (PQ), esse valor se eleva de 3,3\%, chegando a 1877 A. Para o controle (PV), o valor chegou a $2045 \mathrm{~A}$, representando assim, o acréscimo de 12,5\% em relação à referência.

\subsubsection{Perfil de Tensão}

A violação do perfil de tensão devido à presença de geradores distribuídos pode ser um fator limitante para a quantidade de geradores a serem instalados na rede (Jenkins et al., 2000). Antes de efetuar a instalação de geradores, devem-se analisar os cenários de funcionamento para que os perfis de tensões não sejam afetados. Os cenários considerados nesse estudo apresentam as seguintes características:

- Máxima geração e mínima demanda de carga;

- Máxima geração e máxima demanda de carga;

- Mínima geração e mínima demanda de carga;

- Mínima geração e máxima demanda de carga.

Considera-se como mínima geração $10 \%$ da capacidade total de geração do gerador distribuído e mínima demanda como $20 \%$ do total da carga do sistema. A Figura 4.4 apresenta os valores, em pu, das tensões nas barras do sistema de distribuição de energia elétrica representado pela Figura 4.1, em função das condições de geração, demanda de carga e tipo de controle utilizado no gerador. 


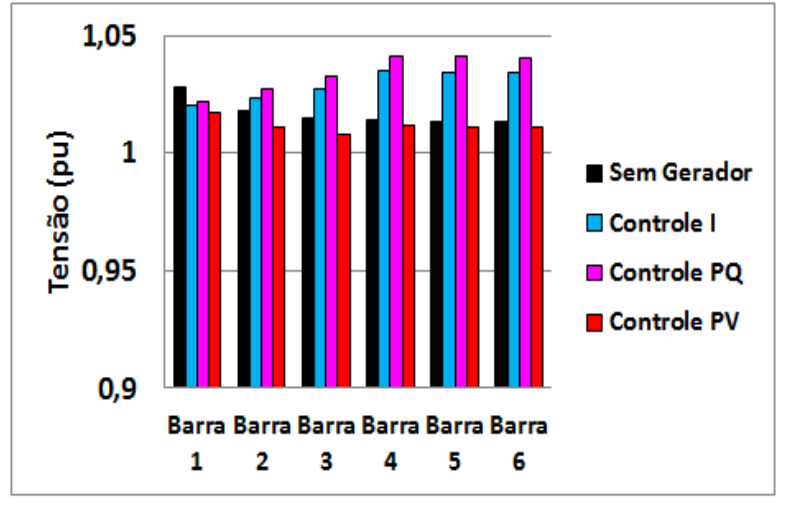

(a) Máxima geração e mínima carga

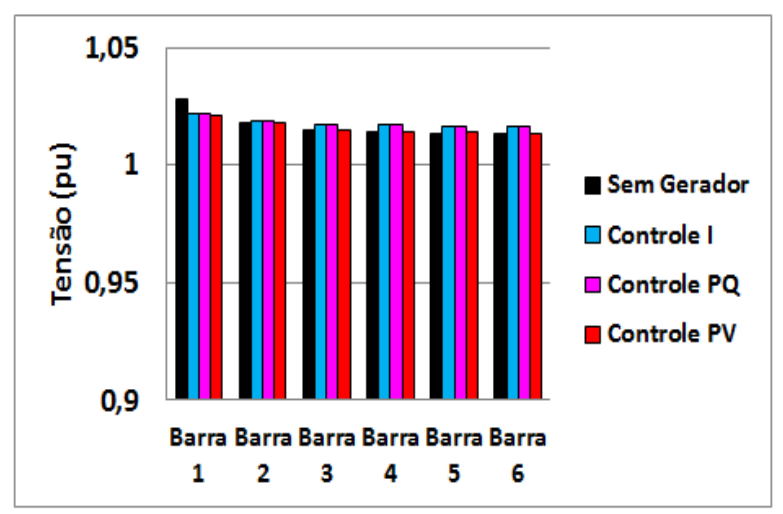

(c) Mínima geração e mínima carga

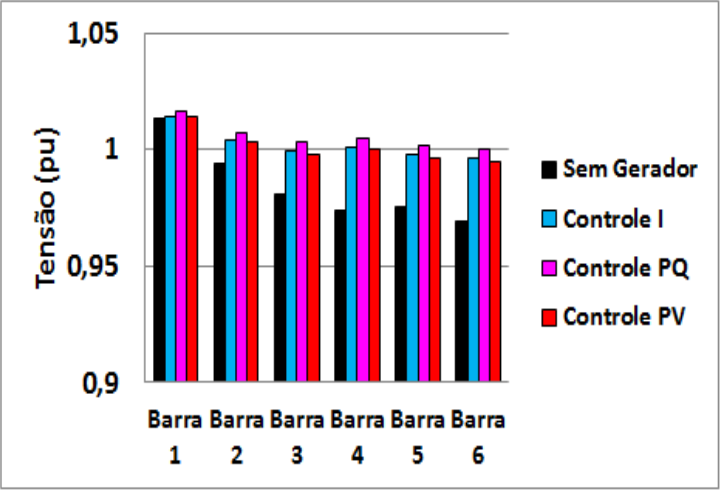

(b) Máxima geração e máxima carga

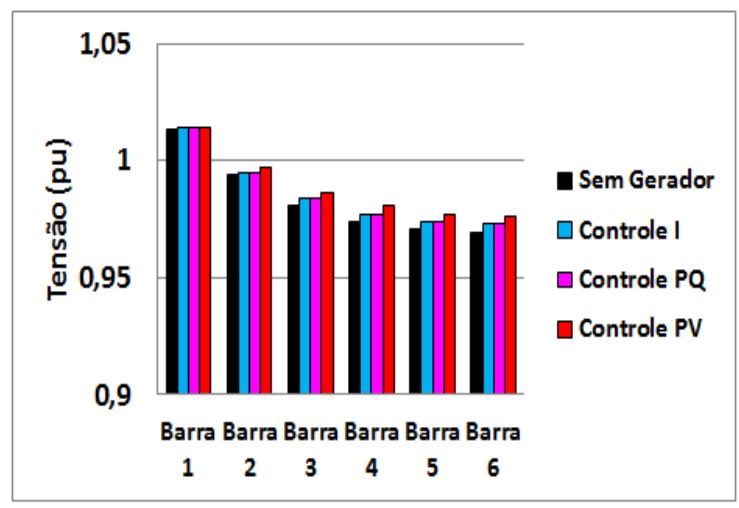

(d) Mínima geração e máxima carga

Figura 4.4 - Perfil de tensão nos barramentos em função do tipo de controle do gerador distribuído, potência de geração e carga do sistema.

Observa-se nos resultados apresentados na Figura 4.4, que o sistema analisado não depende do gerador, pois, para todos cenários, o funcionamento do sistema sem o gerador distribuído (GD) manteve todas as barras com o perfil de tensão dentro dos limites adequados, que, segundo ANEEL - PRODIST (2012), para 13,8 kV estão entre 0,93 e 1,05 pu.

Analisando-se o perfil de tensão em função do tipo de controle adotado no gerador, verifica-se na Figura 4.4 (a) que o controle de corrente (I) e controle de potências ativa e reativa (PQ) oferecem risco de violação de perfil de tensão, pois proporcionam uma tendência à elevação das tensões nodais dos barramentos mais próximos do grupo gerador, podendo esperar até a superação dos limites de tensão dos barramentos, caso sejam adicionados mais geradores.

Para todos cenários, o controle (PV) se mostra mais adequado, pois tende a manter o perfil de tensão de todas as barras em torno do valor nominal de $1 \mathrm{pu}$. 


\subsubsection{Afundamento de Tensão}

A ocorrência de curtos-circuitos pode causar afundamento de tensão nos barramentos do sistema e a presença de gerador distribuído pode influenciar na magnitude e duração do afundamento (Freitas et al, 2006). Em função dessas possíveis consequências, apresenta-se nesta seção a análise sobre o afundamento de tensão devido à ocorrência de falta. Assim como no caso anterior de estudo de curto-circuito, considera-se que o curto-circuito trifásico com duração de cinco ciclos ocorra na linha 6, e também considera-se uma demanda total da carga. Tendo como referência o sistema sem gerador distribuído (Sem GD), estabelece-se a comparação da influência do grupo gerador no afundamento de tensão em função de sua modalidade de controle.

Observa-se na Figura 4.5 que a influência do grupo gerador no afundamento de tensão é inversamente proporcional à distância entre o grupo gerador e a linha em análise, ou seja, quanto maior a distância entre o grupo gerador e a linha, menor é a influência do gerador. Observa-se na barra 1 (mais distante do GD) que praticamente não houve amenização do afundamento de tensão por parte do grupo gerador. No entanto, observa-se nas barras 2, 3 e 4 que a influência do gerador se mostra na tentativa discreta de amenizar o afundamento, durante a aplicação da falta.

Nas barras 5 e 6, em função da proximidade do local de curto-circuito, nada se observa de atuação do grupo gerador em relação à magnitude do afundamento de tensão. 


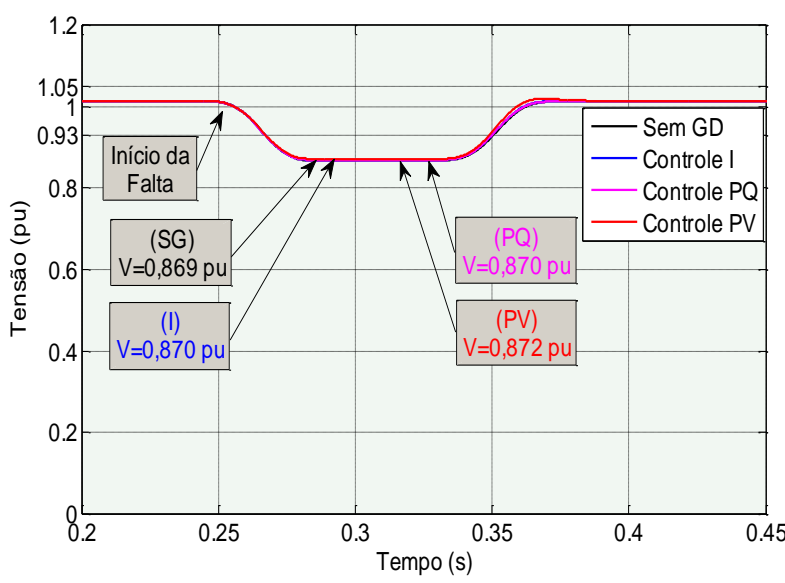

(a) Afundamento de tensão na barra 1

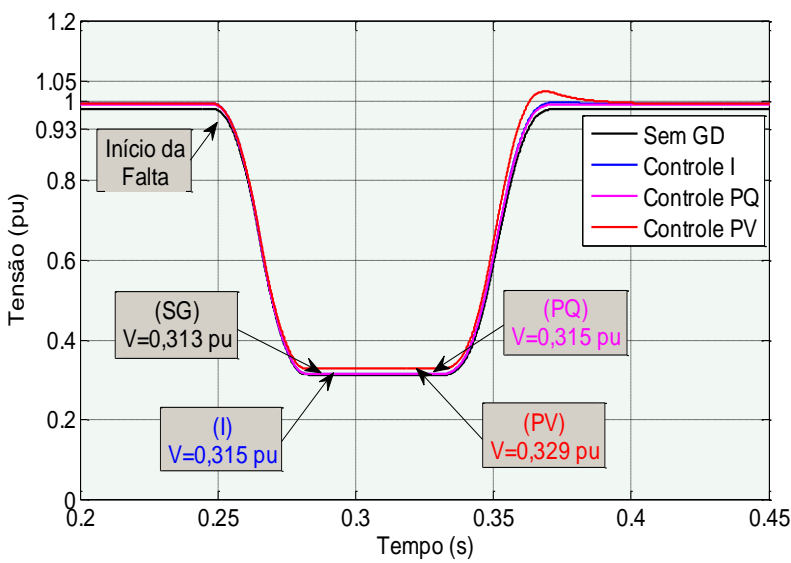

(c) Afundamento de tensão na barra 3

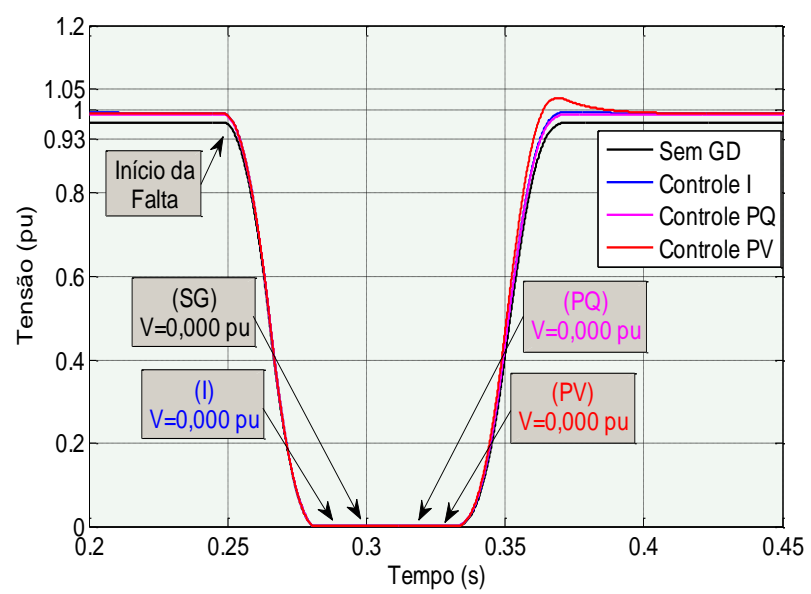

(e) Afundamento de tensão na barra 5

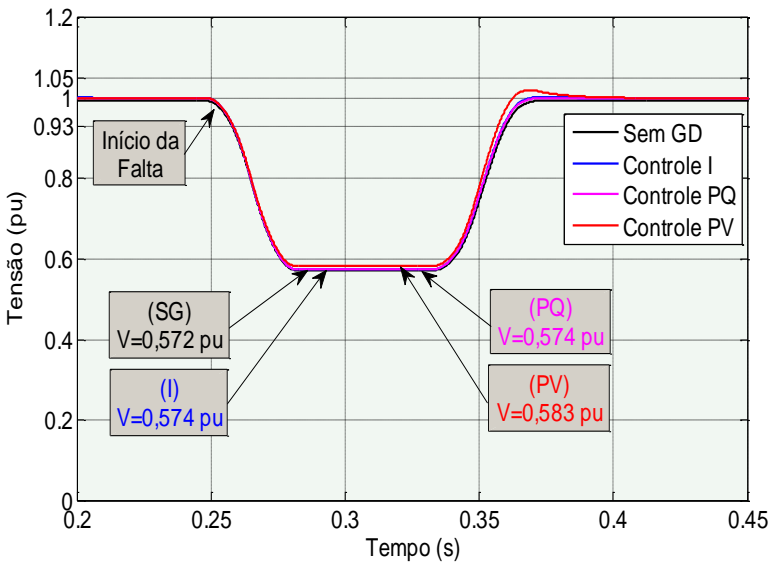

(b) Afundamento de tensão na barra 2

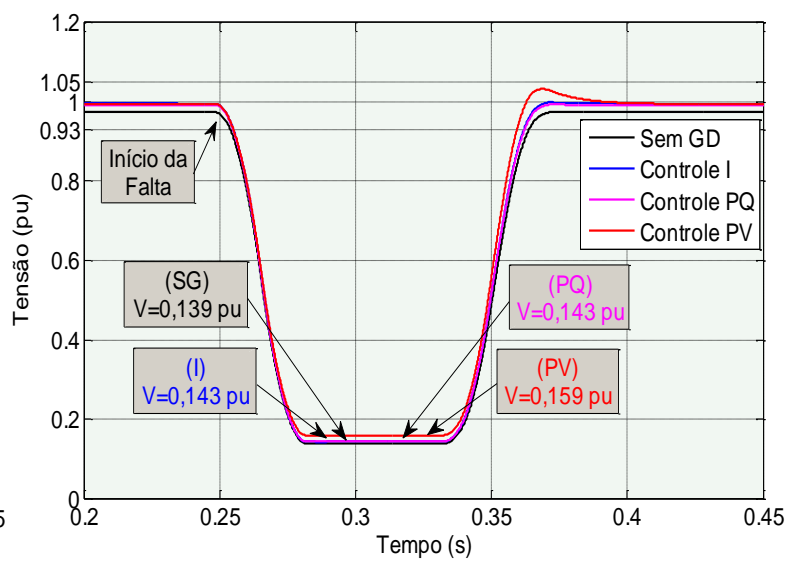

(d) Afundamento de tensão na barra 4

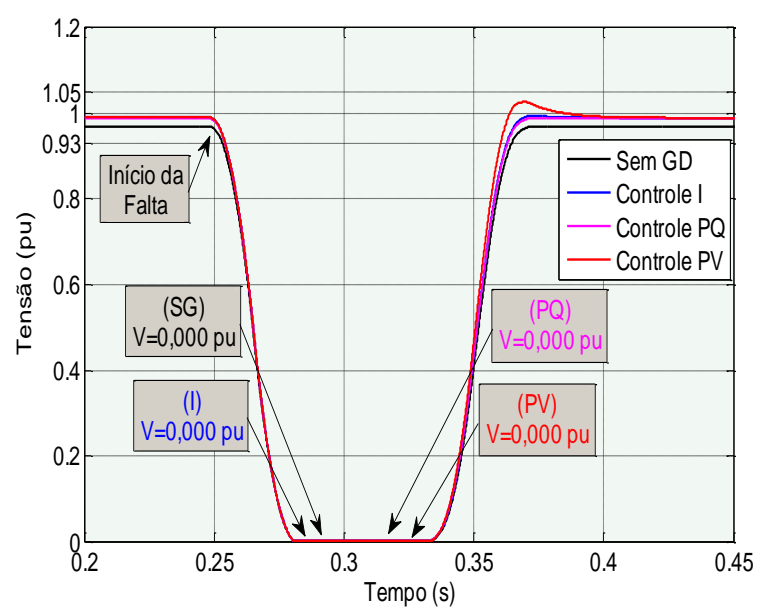

(f) Afundamento de tensão na barra 6

Figura 4.5 - Afundamento de tensão nos barramentos - Curto-Circuito trifásico na Linha 6.

Na observação geral dos resultados apresentados na Figura 4.5, nota-se que a diferença entre os valores de tensão é muito pequena. Entretanto, observa-se a tendência de vantagem para o controle PV em amenizar o afundamento de tensão. Isso ocorre porque o gerador com controle PV, na tentativa de manter a tensão ajustada, injeta potência reativa no sistema. 


\subsubsection{Variação da Tensão Devido à Saída Repentina do Grupo Gerador}

Uma importante questão relacionada à interligação de geradores distribuídos em sistemas de distribuição é a possibilidade de ocorrência de variações de tensão devido à saída repentina de operação do grupo gerador. Nesta condição, deseja-se que a variação de tensão seja a menor possível e que permaneça dentro dos limites toleráveis à preservação da qualidade de energia. Para que seja feita a estimativa, (Freitas et al., 2006) propõem o cálculo do índice $V_{I 1}(\%)$ através da equação (4.1).

$$
V_{I 1}(\%)=\frac{1}{n b} \frac{\sum_{i=1}^{n b}\left|V_{i}^{g}-V_{i}^{n}\right|}{\sum_{i=1}^{n b} V_{i}^{n}} \times 100
$$

Sendo $n b$ o número total de barramentos, $V_{i}^{g}$ a magnitude da tensão nodal do barramento $i$ em presença do gerador distribuído e $V_{i}^{n}$ a magnitude da tensão nodal do barramento $i$ sem o gerador distribuído.

Os resultados dos cálculos são apresentados na Tabela 4.1, considerando a desconexão do gerador durante a operação do sistema sob mínima e também sob máxima carga.

Tabela 4.1 - Variação de tensão de regime permanente durante a desconexão repentina do gerador.

\begin{tabular}{|c|c|c|}
\hline \multirow{2}{*}{ Tipo de controle } & \multicolumn{2}{|c|}{$V_{I I}(\%)$} \\
\cline { 2 - 3 } & Mínimo carregamento 0,2 pu & Máximo carregamento 1,0 pu \\
\hline Controle I & 0,197 & 0,311 \\
\hline Controle PQ & 0,281 & 0,37 \\
\hline Controle PV & 0,085 & 0,294 \\
\hline
\end{tabular}

Observa-se na Tabela 4.1, que os valores obtidos para o índice de variação de tensão $V_{I 1}(\%)$ são pequenos para todas as estratégias de controle e carregamento. Conforme constatado e relatado anteriormente no estudo do perfil de tensão, entende-se que o sistema analisado pode ser considerado forte e independente do grupo gerador, portanto, valores pequenos para o índice $V_{I 1}(\%)$ já eram esperados. Apesar de pequenos, nota-se que os valores encontrados para o sistema com carregamento total são superiores aos encontrados para carregamento mínimo. Esse fato reforça a constatação de que, quanto maior o carregamento do sistema, maior a parcela de contribuição e dependência do grupo gerador, portanto, quanto mais carregado o sistema, maior será o impacto na tensão diante da saída repentina do grupo gerador. 
Quanto às estratégias de controle, em sistemas fortes e independentes do grupo gerador, a tensão tende a se manter com valores próximos ao nominal, independentemente da presença do grupo gerador. Portanto, para sistemas fortes e com geradores com controle PV, esperamse pequenos valores de $V_{I 1}(\%)$ pois, esse tipo de controle tende a manter os valores de tensão próximos ao nominal, que, naturalmente já ocorre em sistemas fortes.

\subsubsection{Regulação de Tensão}

A regulação de tensão é mais um dos importantes aspectos que deve ser analisado diante da instalação de geradores distribuídos, pois mostra o quanto a tensão nodal varia em função das condições de mínima e máxima carga. No intuito de avaliar esse aspecto, emprega-se o cálculo da regulação percentual da tensão através da equação (4.2). (Stevenson Jr., 1986).

$$
R_{T}(\%)=\frac{\left|V_{\text {mín }}^{\text {carga }}-V_{\text {máx }}^{\text {carga }}\right|}{V_{\text {máx }}^{\text {carga }}} \times 100
$$

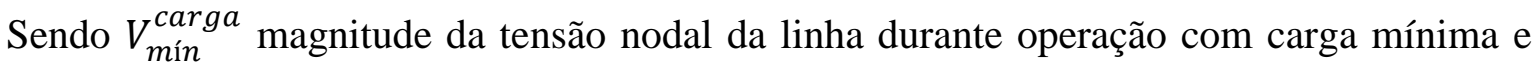
$V_{m a ́ x}^{\text {carga }}$ a magnitude da tensão nodal da linha durante operação com carga máxima.

Os resultados da avaliação são apresentados na Tabela 4.2.

Tabela 4.2 - Análise da regulação de tensão em função dos tipos de controle do gerador distribuído.

\begin{tabular}{|c|c|c|c|c|}
\hline \multirow{2}{*}{ Barras } & \multicolumn{4}{|c|}{ Regulação de Tensão (\%) } \\
\cline { 2 - 5 } & $\begin{array}{c}\text { Sem } \\
\text { Gerador } \\
\text { (SG) }\end{array}$ & $\begin{array}{c}\text { Controle } \\
\text { (I) }\end{array}$ & $\begin{array}{c}\text { Controle } \\
\text { (PQ) }\end{array}$ & $\begin{array}{c}\text { Controle } \\
\text { (PV) }\end{array}$ \\
\hline Barra 1 & 1,48 & 0,60 & 0,60 & 0,30 \\
\hline Barra 2 & 2,41 & 1,89 & 1,98 & 0,80 \\
\hline Barra 3 & 3,47 & 2,80 & 3,00 & 1,00 \\
\hline Barra 4 & 4,11 & 3,40 & 3,58 & 1,2 \\
\hline Barra 5 & 4,33 & 3,61 & 3,90 & 1,51 \\
\hline Barra 6 & 4,54 & 3,82 & 4,00 & 1,61 \\
\hline
\end{tabular}

Os valores apresentados na Tabela 4.2 demonstram a grande influência do gerador distribuído no controle e adequação da regulação de tensão. Nota-se que, para qualquer uma das três estratégias de controle utilizadas, os índices percentuais de regulação de tensão do sistema com gerador distribuído são inferiores, quando comparados ao sistema sem gerador distribuído. O destaque fica para o controle PV que apresentou os menores índices e, portanto, a melhor condição em relação à regulação de tensão. Esse fato pode ser atribuído à capacidade dessa estratégia de controle em fazer o grupo gerador injetar ou absorver potência 
reativa no sistema. Isso não ocorre para as outras estratégias de controle, no entanto, elas (I e PQ) ainda apresentaram resultados melhores do que sem a conexão do grupo gerador.

Do que foi constatado e relatado, entende-se que além dos capacitores e transformadores em geral, o gerador distribuído também pode estar incluso na lista dos principais recursos a serem utilizados para auxiliar na regulação de tensão de um sistema de energia.

\subsubsection{Perdas de Potência Ativa}

Embora as perdas ativas nos barramentos e linhas não representem um fator impeditivo para instalação de geradores distribuídos na rede, o aspecto econômico é considerado fator importante na otimização de investimentos. Nesta seção, estuda-se o impacto das perdas técnicas de potência ativa em função do tipo de controle empregado no grupo gerador. A Figura 4.6 apresenta os resultados das perdas nas linhas em função do carregamento do sistema, geração distribuída e tipo de controle.

Observa-se na Figura 4.6 (a) que na condição de carga máxima, a inclusão dos geradores distribuídos proporciona redução da somatória total das perdas técnicas nas linhas, para os três tipos de controle analisados, sendo que os maiores valores de perdas totais foram proporcionados pelos controles I e PV e a menor perda total foi proporcionada pela utilização do controle PQ.

Para o sistema em condição de carga mínima, observa-se na Figura 4.6 (b) que a presença dos geradores distribuídos aumenta a somatória total de perdas nas linhas, sendo que o maior valor de perda total corresponde ao controle I, o intermediário ao controle PV e o menor valor de perda total foi proporcionado pelo controle PQ. Esse comportamento é devido às correntes provenientes dos geradores que estão fluindo pelas linhas 1,2 e 3, onde se observam as maiores perdas. Entende-se, neste caso, que para o sistema operando sob condição de carga mínima, as perdas poderiam se tornar uma limitação para otimização da quantidade de energia a ser fornecida pelo grupo gerador. 


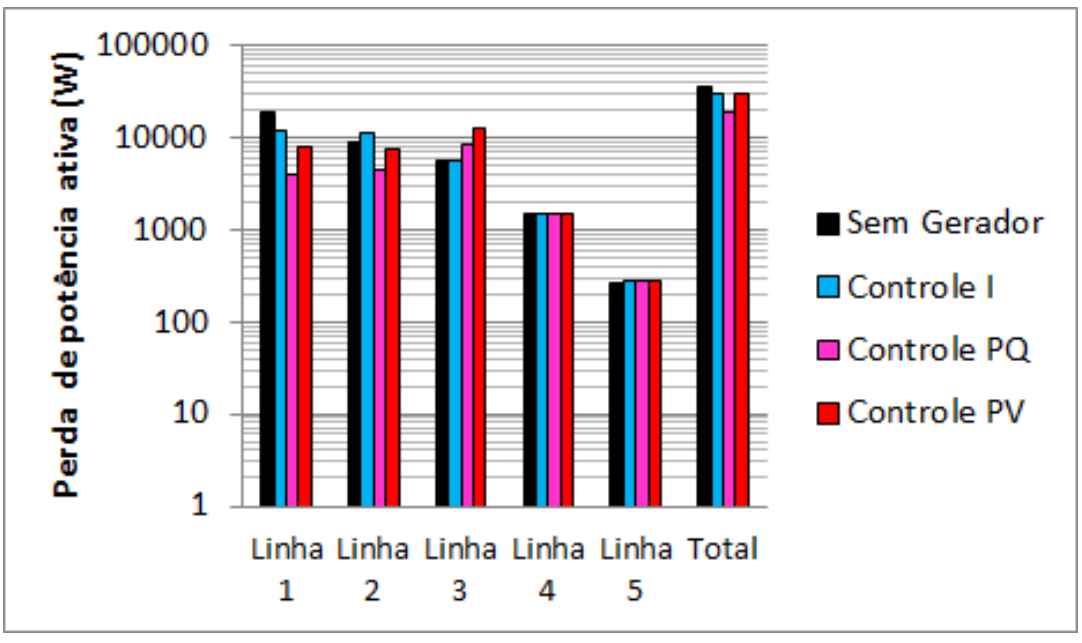

(a) Carga máxima (1,0 pu)

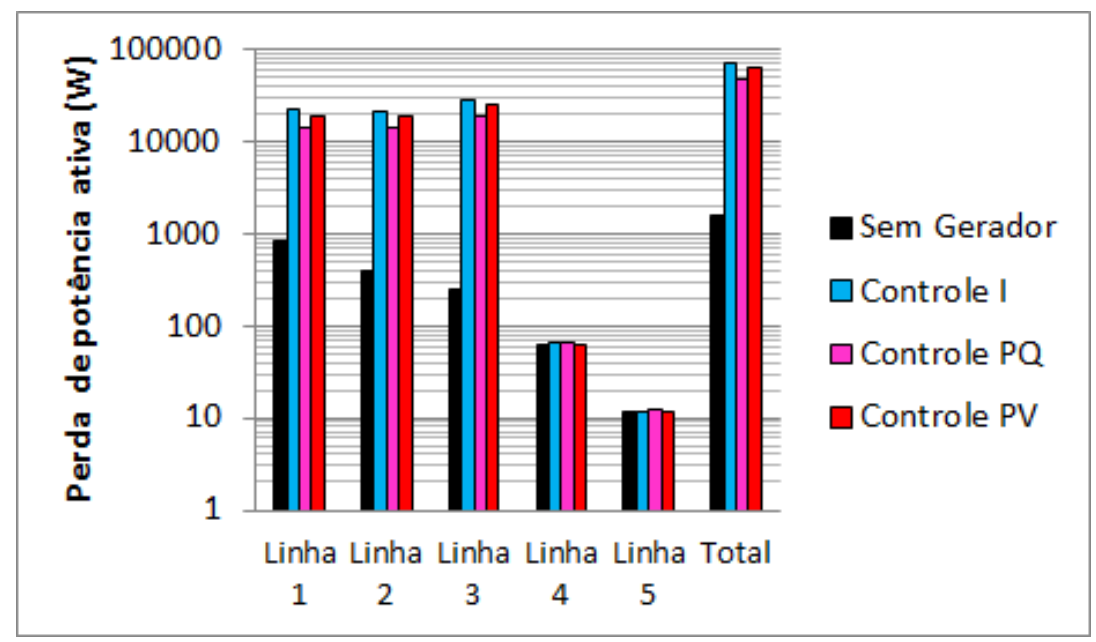

(b) Carga mínima (0,2 pu)

Figura 4.6 - Perdas de potência ativa nas linhas em função do carregamento, geração e tipo de controle.

Entende-se também que os resultados aqui apresentados são referentes a um sistema sob condições específicas do estudo. Portanto, as observações aqui relatadas não representam uma regra para todos os sistemas. Em (Salman, 1996), observa-se que o nível de perdas elétricas pode diminuir ou aumentar, dependendo da localização do gerador, da quantidade de potência gerada e da topologia do sistema analisado. 


\subsection{Análise Detalhada da Contribuição de Corrente de Curto-Circuito de Geradores Baseados em Inversores}

\subsubsection{Objetivo}

O objetivo deste estudo é investigar a contribuição de corrente de curto-circuito do gerador baseado em inversor de frequência quando este está inserido em um sistema de distribuição de energia elétrica. Verifica-se também o comportamento do inversor quando submetido às variações nas formas de controle, sendo: controle de corrente (I), potência ativa e reativa (PQ) e potência ativa e tensão (PV).

Os resultados obtidos neste estudo servirão de base e subsídio para o desenvolvimento de estratégias para inserção desse tipo de gerador nos cálculos de correntes de curtos-circuitos, conforme será abordado no Capítulo 5.

\subsubsection{Considerações Iniciais}

Em função de que o foco deste estudo está na corrente de saída do gerador, utilizou-se um sistema de distribuição de energia mais simplificado, o qual está representado pela Figura 4.7 cujos parâmetros de modelagem e controle estão dispostos nas tabelas A.5 a A.10 do apêndice A. A disposição dos elementos e sistema modelado configuram um acessante com minigeração que, segundo (ANEEL, 2012), classifica-se como uma unidade consumidora participante do sistema de compensação de energia elétrica.

O gerador utilizado é baseado em inversor de frequência e possui a capacidade de gerar $300 \mathrm{kVA}$ de potência em tensão de $380 \mathrm{~V}$.

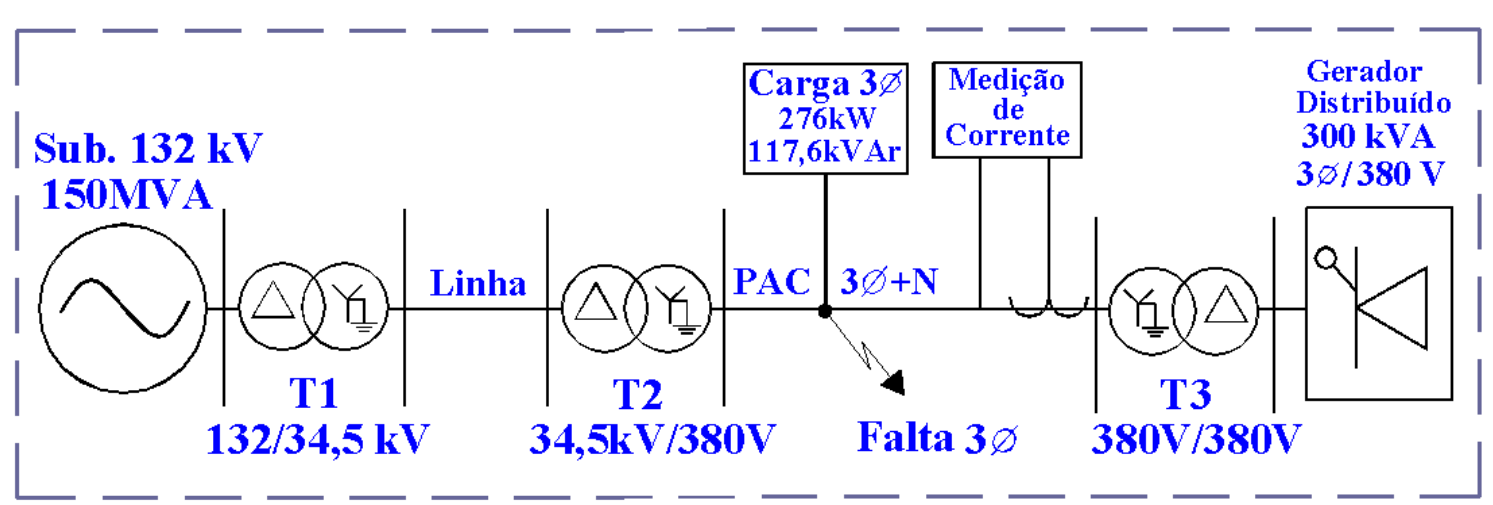

Figura 4.7 - Sistema modelado: acessante com minigeração 300kVA - 380V.

Observa-se na Figura 4.7 que, além das três fases, a rede de baixa tensão (380V) possui o neutro. Essa configuração $(3 \mathrm{~F}+\mathrm{N})$ de rede possibilita o funcionamento ocasional de forma ilhada das cargas do acessante (proprietário do gerador GD), que, apesar de ainda não ser 
admitido por nenhuma concessionária nacional, o ilhamento tende a ser uma das formas de garantir o abastecimento de um grupo de cargas e aumentar a confiabilidade do sistema elétrico. Seguindo essa tendência e incluindo a busca pela melhoria na qualidade do fornecimento, utiliza-se um transformador acoplador na saída do gerador, sendo a configuração estrela aterrada do lado da carga para manter a referência de neutro aterrado e delta do lado do gerador para conter as harmônicas múltiplas de terceira ordem.

Em função das instruções normativas referentes aos consumidores classificados como acessante de minigeração (ANEEL, 2012), utiliza-se também um transformador para acoplar o acessante à concessionária e, com base nas diretrizes da concessionária local (CPFL, 2012), utiliza-se, para este transformador, a configuração delta para o lado da concessionária e estrela aterrada para o lado do acessante. De acordo com os critérios técnicos operacionais para minigeração distribuída (ANEEL, 2012), considera-se que o ponto de conexão seja único para a central geradora e a unidade consumidora (cargas). Esse ponto de conexão deve estar situado na interseção das instalações de interesse restrito (propriedade do acessante) com o sistema de distribuição acessado (concessionária). Acrescentando, a esse critério operacional, a busca por resultados conservadores com isenção de fatores de atenuantes, desconsideram-se as impedâncias do cabeamento de baixa tensão e atribuem-se aos transformadores impedâncias com valores irrelevantes ao estudo de curto-circuito.

Como forma de balizar e referenciar as simulações, atribuem-se os seguintes itens para o caso base:

- $\quad$ Ângulo de incidência da falta de $0^{\circ}$;

- A aplicação da falta foi realizada a partir da estabilização do sistema e do índice de modulação, sendo: 0,2472 segundos para ângulo $0^{\circ}$ e 0,2514 segundos para ângulo $90^{\circ}$

- Tempo de eliminação da falta de dez ciclos;

- Potência ativa do gerador de $300 \mathrm{~kW}$ e reativa de $0 \mathrm{kVAr}$;

- Operação do gerador com fator de potência unitário.

Objetivando-se a situação mais severa para o gerador, consideram-se ocorrências de curtos-circuitos na saída do transformador de acoplamento, conforme localização do medidor apresentada na Figura 4.7. Entende-se que este local não apresenta impedâncias significativas que possam amortizar os valores de correntes fornecidos pelo gerador. Portanto, medições 
realizadas neste local, apresentam valores máximos de contribuições de correntes de curtoscircuitos que o gerador pode fornecer ao sistema.

\subsubsection{Análise Sobre a Influência do Ângulo de Aplicação de Falta}

Apresentam-se nesta seção os resultados dos testes sobre a influência do ângulo de incidência de falta na contribuição do gerador GD para a corrente de curto-circuito.

A Figura 4.8 apresenta os resultados obtidos do inversor submetido ao controle I.

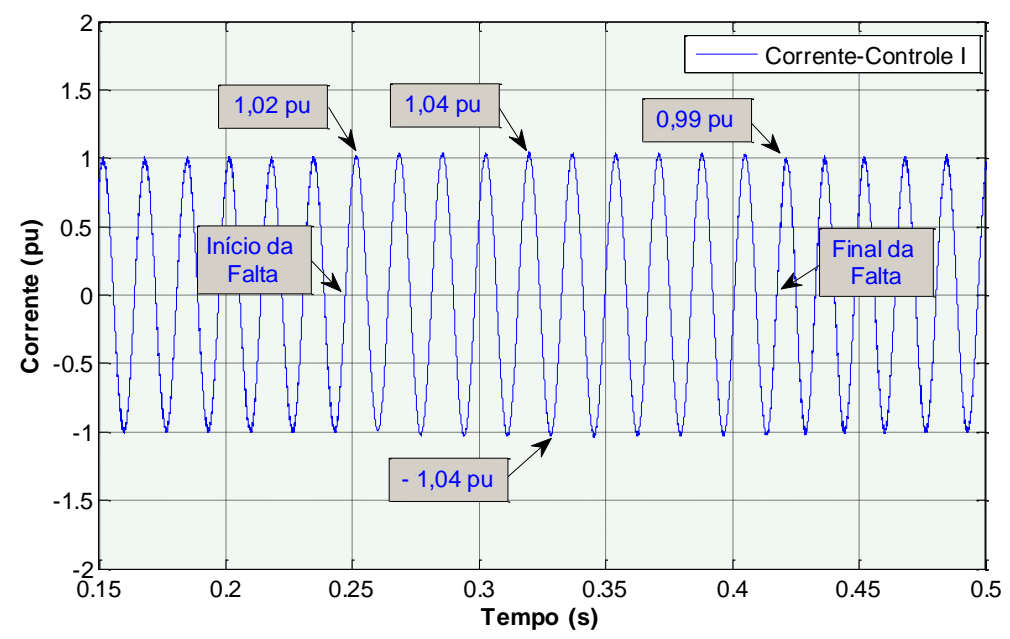

(a) Controle I - Curto-Circuito FP= 1 Ângulo 0 ${ }^{\circ}$.

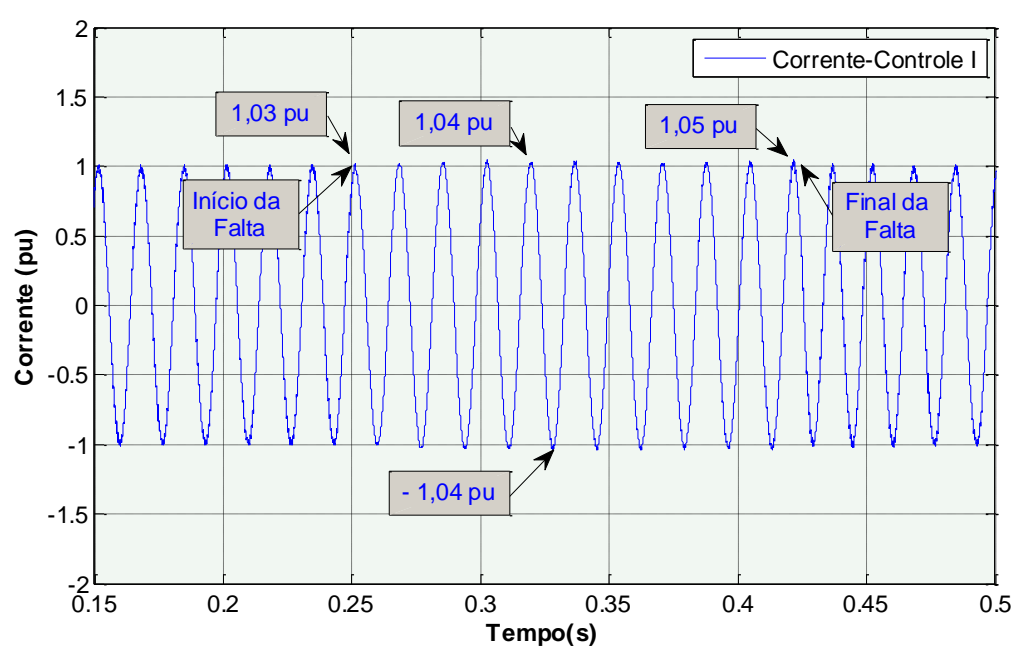

(b) Controle I - Curto-Circuito FP= 1 Ângulo $90^{\circ}$.

Figura 4.8 - Controle I - Influência do ângulo de incidência da falta na corrente de curto-circuito.

Através dos resultados obtidos nos testes sobre a influência do ângulo de aplicação da falta, verificam-se nas Figura 4.8 (a) e (b) que, para o Controle I, não se observa nenhuma influência significativa durante todo o período de aplicação da falta. Verifica-se também que essa modalidade de controle (I) é capaz de manter, mesmo com variação do ângulo de 
aplicação de falta, o valor da contribuição da corrente de falta do gerador em torno da sua corrente nominal, o que significa ser uma opção interessante, caso o objetivo seja limitar o valor da corrente de falta no sistema de distribuiçao de energia elétrica em que o gerador está inserido.

A Figura 4.9 apresenta os resultados obtidos do inversor com controle PQ.

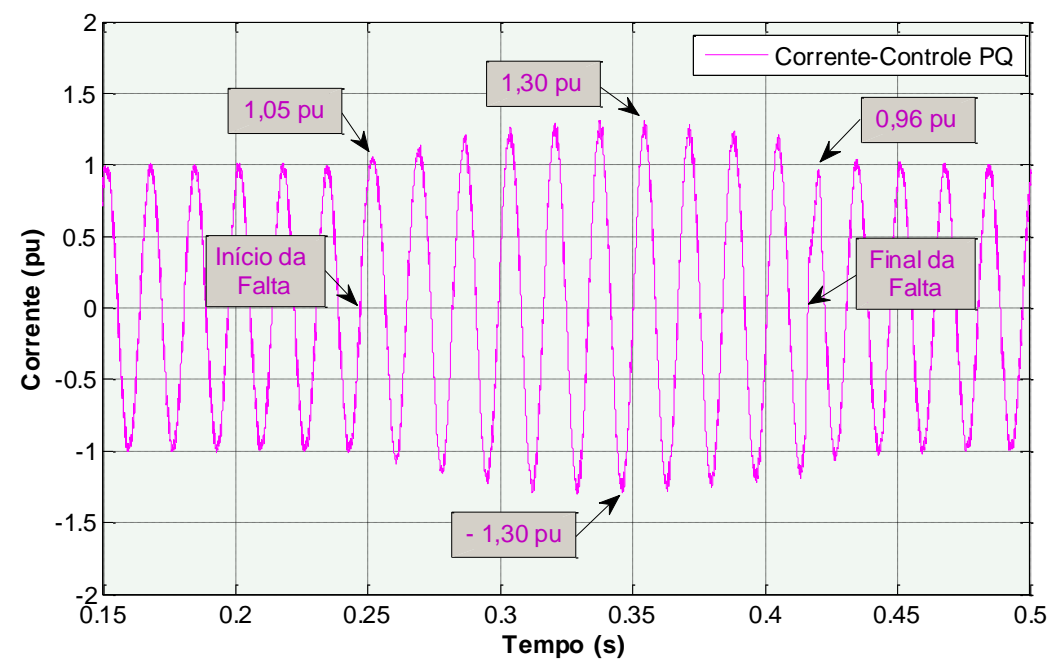

(a) Controle PQ - Curto-Circuito FP= 1 Ângulo $0^{\circ}$.

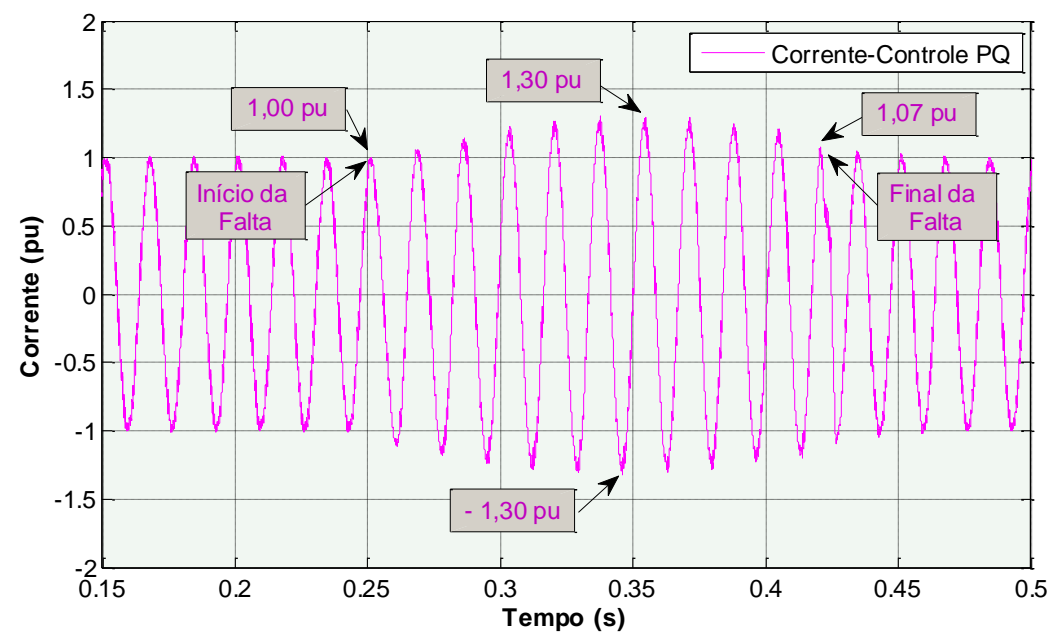

(b) Controle PQ - Curto-Circuito FP= 1 Ângulo 90 ${ }^{\circ}$.

Figura 4.9 - Controle PQ - Influência do ângulo de incidência da falta na corrente de curto-circuito.

Nas Figura 4.9 (a) e (b) verifica-se que, para o Controle PQ, também não houve influência significativa sobre a variação do ângulo de incidência da falta. Entretanto, diferentemente do Controle I, verifica-se que o valor de corrente de falta atingiu um valor $30 \%$ (1,3 pu) superior ao valor da corrente nominal do inversor, o que significa a necessidade de atenção para a questão de sua contribuição de corrente de falta no sistema de energia elétrica. 
A Figura 4.10 apresenta os resultados do inversor submetido ao controle PV.

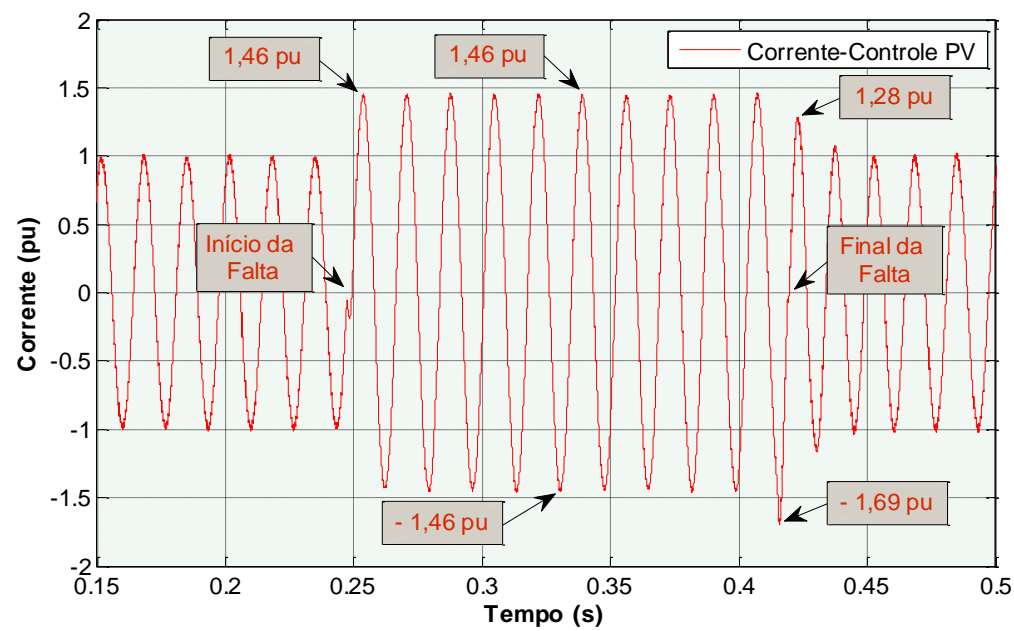

(a) Controle PV - Curto-Circuito $V=1 p u P=1,0$ pu Ângulo $0^{\circ}$.

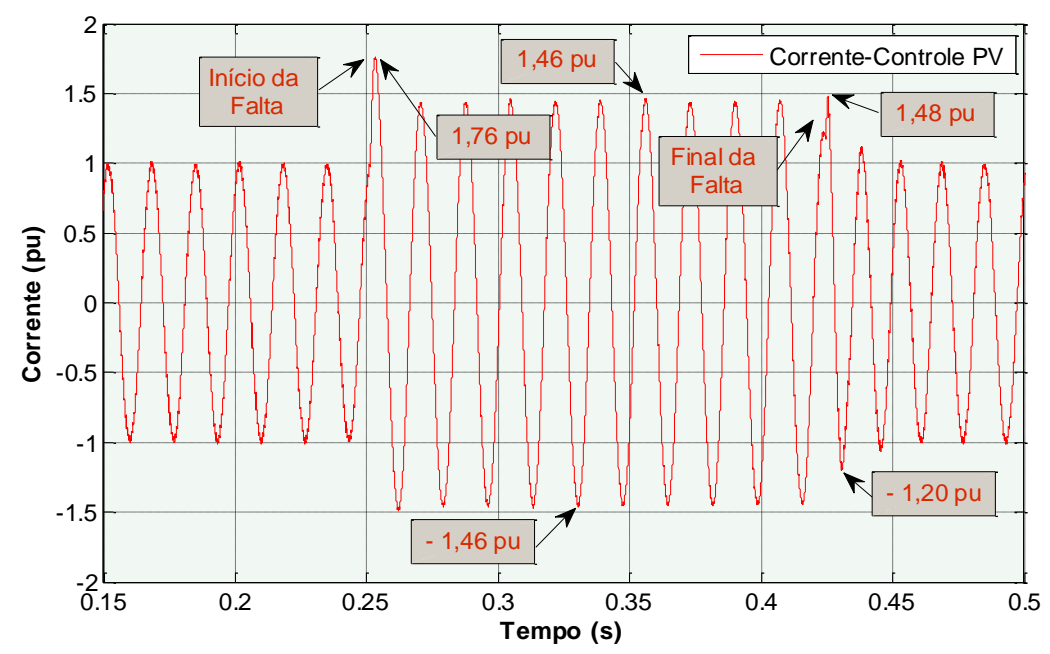

(b) Controle PV - Curto-Circuito $V=1 p u P=1,0$ pu Ângulo $90^{\circ}$.

Figura 4.10 - Controle PV - Influência do ângulo de incidência da falta na corrente de curto-circuito.

Para o caso do Controle PV, cujos resultados são apresentados nas Figura 4.10 (a) e (b), verifica-se uma influência mais expressiva do ângulo de incidência de falta, sendo que valor de corrente chegou a 1,76 pu durante o período transitório inicial da falta com ângulo de incidência $90^{\circ}$, o que significa um valor de aproximadamente $20 \%$ superior a corrente no mesmo instante da falta no caso com ângulo de incidência $0^{\circ}$, que foi de $1,46 \mathrm{pu}$. Apesar do expressivo valor inicial de corrente de falta, os valores de curto-circuito durante o período permanente da falta não superaram 1,5 pu em ambas as situações de ângulo de aplicação de falta. Assim como para o Controle PQ, a operação do inversor com o Controle PV merece atenção para a questão sobre sua contribuição de corrente de falta no caso de sua inserção no sistema de distribuição de energia elétrica. 


\subsubsection{Análise Sobre a Influência da Variação dos Parâmetros de Controle do Inversor}

Apresentam-se nesta seção os resultados dos testes sobre a influência dos parâmetros de operação do inversor na sua contribuição de corrente de falta. Os resultados mais expressivos são apresentados nas Figura 4.11 a 4.13, os demais são apresentados na Tabela 4.3.

Para o Controle I, efetuaram-se os testes para o gerador atuando como fornecedor das potências ativa e reativa, operando com fatores de potência de 0,92 (condição de fornecimento de potência total para a carga) e 0,50 , respectivamente.

A Figura 4.11 apresenta os resultados obtidos do inversor submetido ao Controle I.

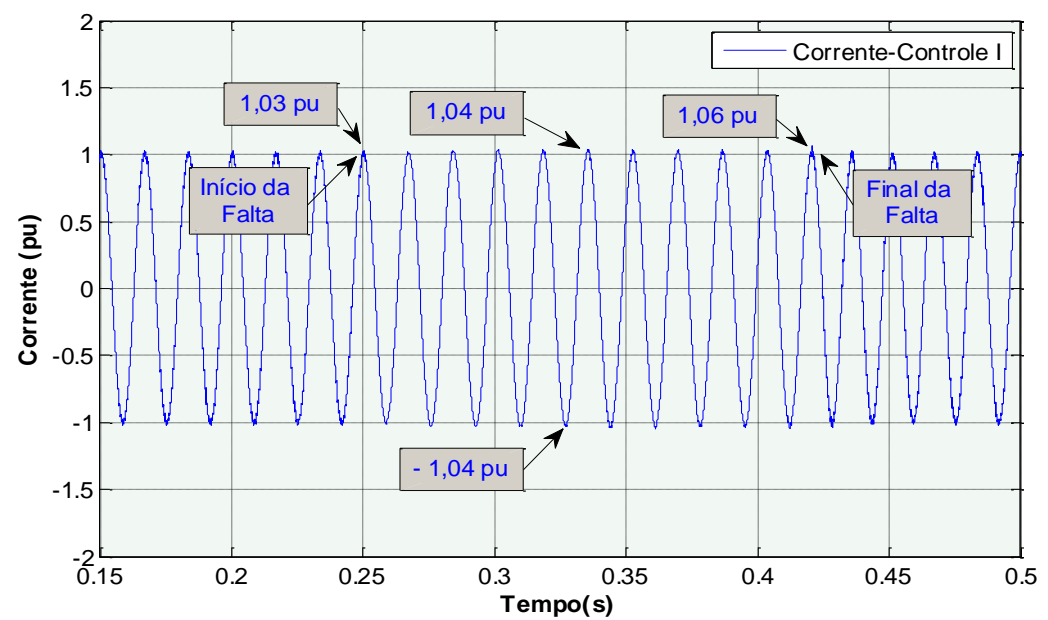

(a) Controle I - Curto-Circuito FP= 0,92 Ângulo 90.

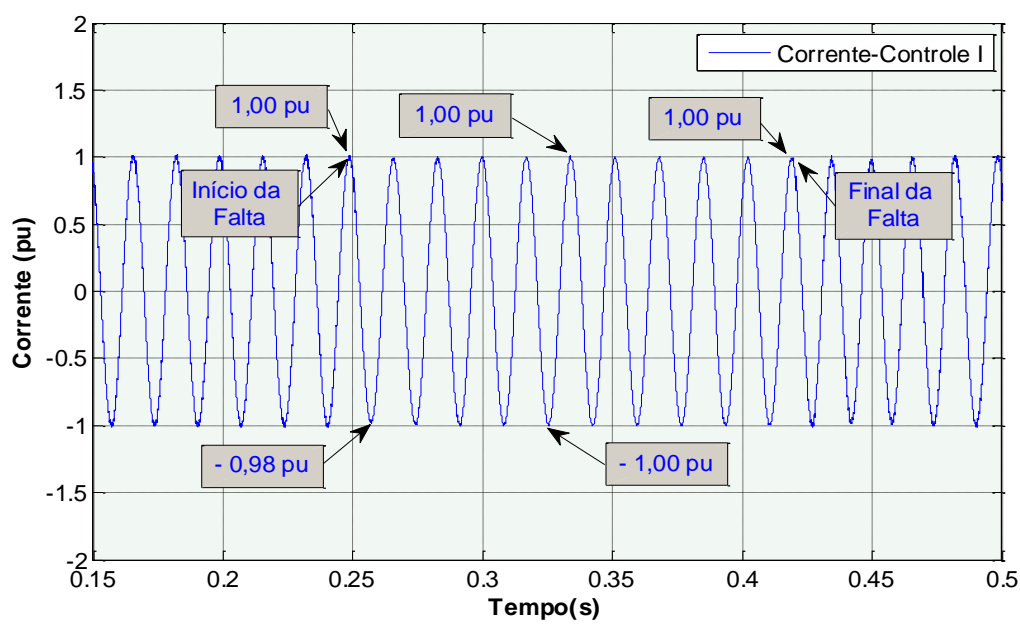

(b) Controle I - Curto-Circuito FP= 0,50 Ângulo $90^{\circ}$.

Figura 4.11 - Controle I - Influência da variação dos parâmetros de operação do inversor na corrente de curto-circuito. 
De acordo com os resultados obtidos nos testes sobre a influência da variação dos parâmetros de operação do inversor, verificam-se nas Figura 4.11 (a) e (b) que, para o Controle I, a variação no fator de potência não influencia na sua corrente de falta. Esse fato proporciona uma situação confortável para a utilização desse gerador também como fornecedor de potência reativa.

No Controle PQ, também foram efetuados testes com o gerador atuando como fornecedor de potências ativa e reativa, sendo os fatores de potência 0,92 e 0,50 , respectivamente. A Figura 4.12 apresenta os resultados obtidos do inversor com Controle PQ.

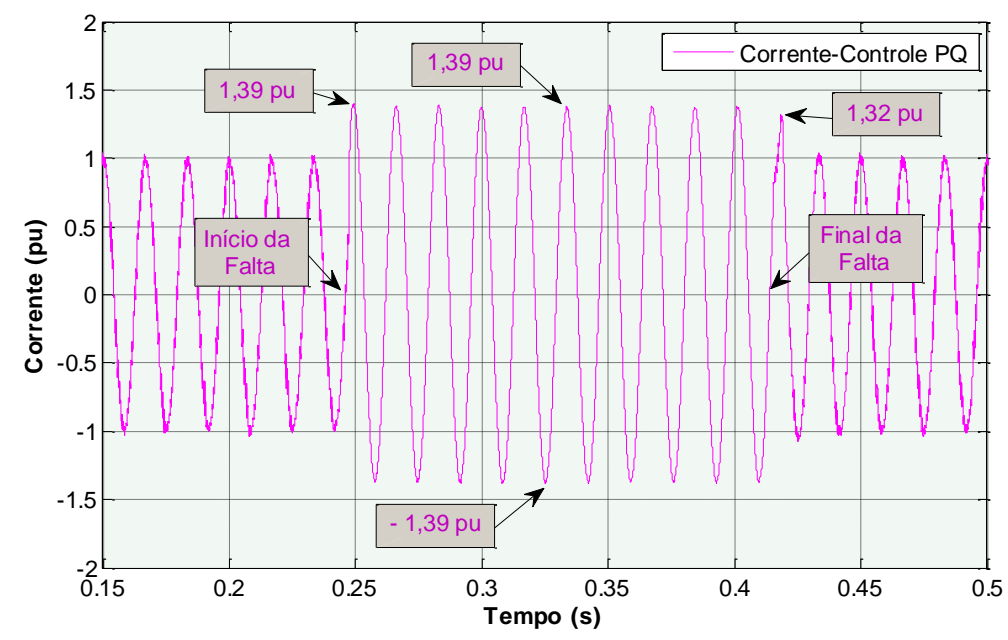

(a) Controle PQ - Curto-Circuito $\mathrm{FP}=0,92$ Ângulo $0^{\circ}$.

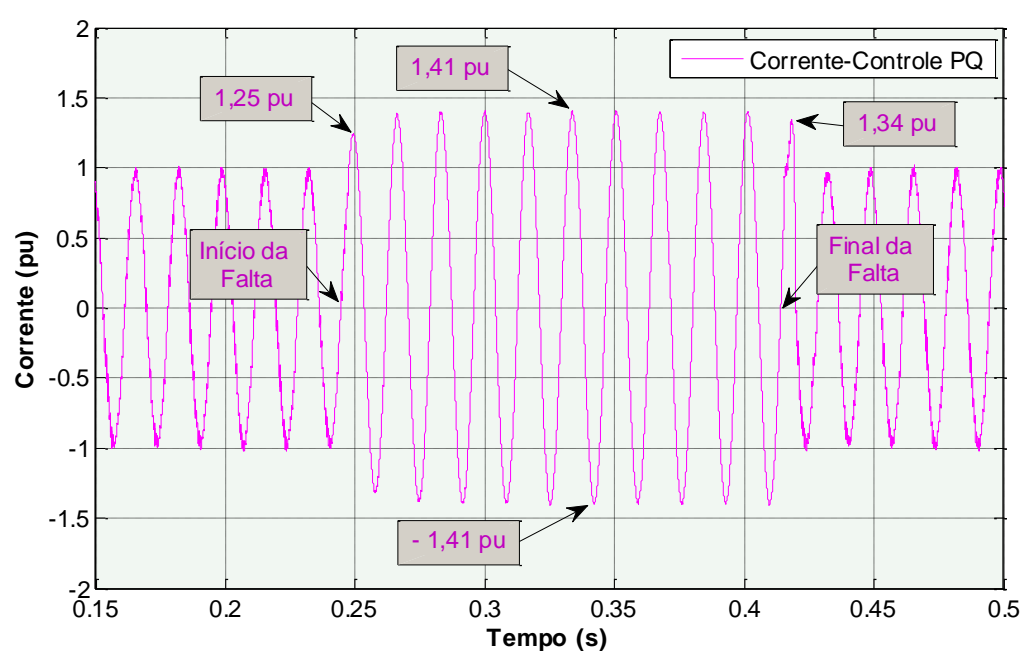

(b) Controle $P Q$ - Curto-Circuito $F P=0,50$ Ângulo 0 ${ }^{\circ}$.

Figura 4.12 - Controle PQ - Influência da variação dos parâmetros de operação do inversor na corrente de curto-circuito. 
Nas Figura 4.12 (a) e (b) verifica-se que, para o Controle PQ, a operação com fator de potência capacitivo provoca um aumento no valor de sua contribuição de corrente de falta. Neste caso, a operação com fator de potência 0,92 proporcionou, em relação ao caso base com fator de potência unitário, um aumento de, aproximadamente, $32 \%$ no valor da corrente de falta transitória inicial e 7\% no valor da corrente de falta permanente. Para operação com fator de potência 0,50 o aumento foi de $20 \%$ na corrente transitória inicial e $9 \%$ na falta permanente. $\mathrm{O}$ fato chama atenção quanto à inserção desse gerador no sistema de energia, caso o objetivo seja também o fornecimento de potência reativa.

Para o Controle PV, efetuam-se os testes com variação de 5\% no nível de tensão de saída do gerador, sendo 0,95 e 1,05 pu, respectivamente e também com a redução da potência do gerador para 0,5 pu. A Figura 4.13 apresenta os resultados obtidos do inversor com controle PV.

Para o caso do Controle PV, cujos resultados são apresentados nas Figura 4.13 (a), (b) e (c), verifica-se que a redução de 5\% no nível de tensão de fornecimento do gerador, proporcionou, em relação ao caso base com tensão de 1 pu, uma redução de aproximadamente $14 \%$ no valor da corrente de falta transitória inicial e praticamente manteve o valor de corrente de falta permanente. Para o caso da elevação de $5 \%$ no valor de tensão de fornecimento, ocorreu uma redução de $7 \%$ no valor de corrente de falta inicial e manteve no mesmo patamar o valor da corrente de falta permanente. Entende-se, portanto, que pequenas alterações no nível de tensão de fornecimento do gerador, submetido a esse tipo de controle, proporcionam efeitos significativos na sua contribuição de corrente de falta transitória inicial e efeitos pouco expressivos na corrente de falta permanente.

A redução do fornecimento de potência ativa para 0,5 pu proporcionou uma redução de aproximadamente $12 \%$ no valor da corrente de falta transitória inicial e a corrente de falta permanente se manteve no mesmo patamar do caso base. 


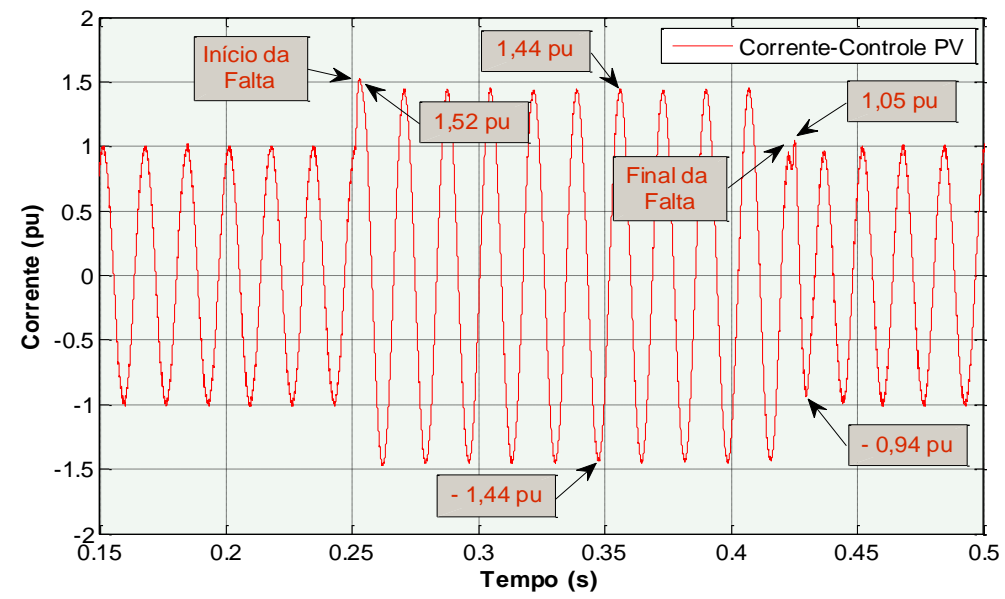

(a) Controle PV - Curto-Circuito $\mathrm{V}=\mathbf{0 , 9 5}$ pu $\mathrm{P}=1,0$ pu Ângulo $90^{\circ}$.

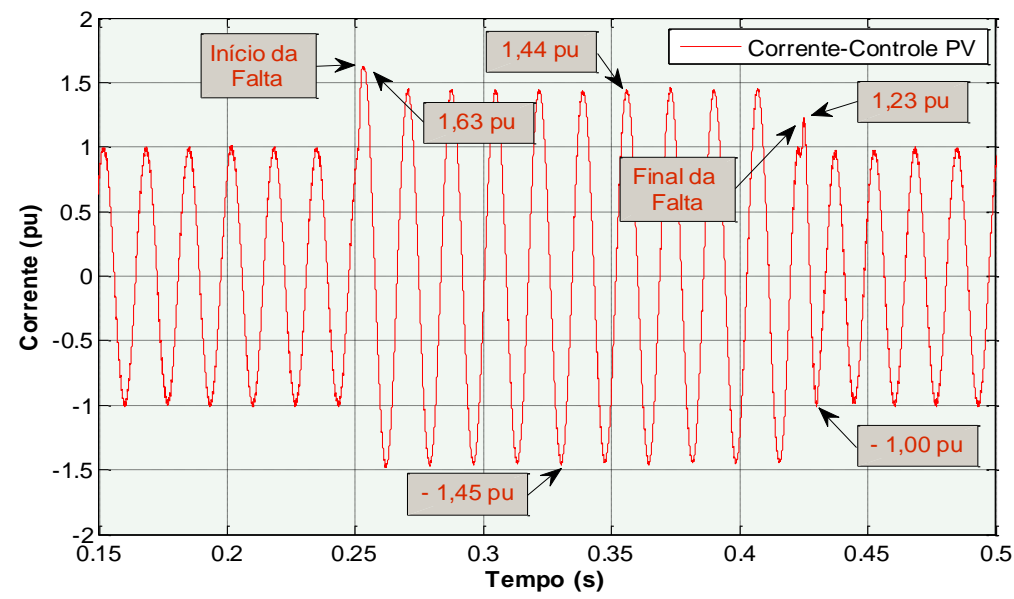

(b) Controle PV - Curto-Circuito $V=$ 1,05 pu $P=1,0$ pu Ângulo $90^{\circ}$.

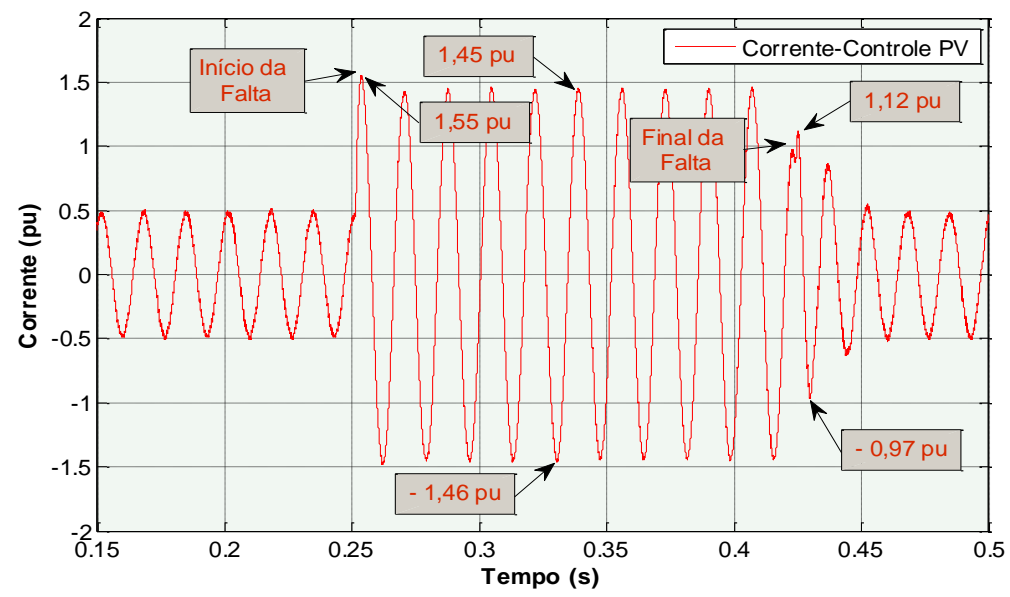

(c) Controle PV - Curto-Circuito $V=1,0$ pu $P=0,5$ pu Ângulo $90^{\circ}$.

Figura 4.13 - Controle PV - Influência da variação dos parâmetros de operação do inversor na corrente de curto-circuito. 


\subsubsection{Análise dos Resultados}

Neste tópico, apresenta-se a coletânea dos valores máximos de corrente de curto-circuito, em função das condições de ocorrência de falta e do tipo de controle. Nos casos em que o tipo de controle não possibilita a específica variação de parâmetro, atribui-se o termo de não se aplica (NA) na tabela. Os valores foram obtidos através dos resultados das simulações e resumidos na Tabela 4.3.

Tabela 4.3 - Valores máximos de corrente de curto-circuito em função do tipo de controle e condições de aplicação da falta trifásica.

\begin{tabular}{|c|c|c|c|}
\hline \multirow{2}{*}{$\begin{array}{c}\text { Condições de aplicação da falta } \\
\text { trifásica }\end{array}$} & \multicolumn{3}{|c|}{ Valor máximo de corrente (pu) } \\
\cline { 2 - 4 } & Controle (I) & Controle (PQ) & Controle (PV) \\
\hline Angulo $0^{\circ}$ & 1,04 & 1,30 & 1,69 \\
\hline Angulo $90^{\circ}$ & 1,05 & 1,30 & 1,76 \\
\hline $\mathrm{FP}=0,92$ e ângulo $0^{\circ}$ & 1,04 & 1,39 & NA \\
\hline $\mathrm{FP}=0,92$ e ângulo $90^{\circ}$ & 1,06 & 1,39 & NA \\
\hline $\mathrm{FP}=0,50$ e ângulo $0^{\circ}$ & 1,00 & 1,41 & NA \\
\hline $\mathrm{FP}=0,50$ e ângulo $90^{\circ}$ & 1,00 & 1,41 & NA \\
\hline $\mathrm{P}=1,0$ pu e $\mathrm{V}=0,95$ pu ângulo $0^{\circ}$ & NA & NA & 1,42 \\
\hline $\mathrm{P}=1,0$ pu e $\mathrm{V}=0,95$ pu ângulo $90^{\circ}$ & NA & NA & 1,52 \\
\hline $\mathrm{P}=1,0$ pu e $\mathrm{V}=1,05$ pu ângulo $0^{\circ}$ & NA & NA & 1,46 \\
\hline $\mathrm{P}=1,0$ pu e $\mathrm{V}=1,05$ pu ângulo $90^{\circ}$ & NA & NA & 1,63 \\
\hline $\mathrm{P}=0,5$ pu e $\mathrm{V}=1,00$ pu ângulo $0^{\circ}$ & NA & NA & 1,59 \\
\hline $\mathrm{P}=0,5$ pu e $\mathrm{V}=1,00$ pu ângulo $90^{\circ}$ & NA & NA & 1,55 \\
\hline
\end{tabular}

De acordo com os valores apresentados na Tabela 4.3, verifica-se que o maior valor de corrente de falta foi de $1,76 \mathrm{pu}$, sendo este, na condição de aplicação da falta com ângulo $90^{\circ}$ e controle PV. Deve-se ressaltar que, nesta tabela, são apresentados os valores máximos obtidos de um único ciclo.

Através dos resultados obtidos das figuras deste estudo, verificou-se que o maior valor de corrente com duração superior a três ciclos foi de 1,46 pu para o controle PV, considerando o gerador operando com potência e tensão iguais a 1 pu e ângulo de aplicação da falta de $90^{\circ}$.

Em uma análise mais abrangente desse estudo, percebe-se que o tema "contribuição de corrente de curto-circuito do gerador baseado em inversor" foi bastante explorado em diversas 
situações de ocorrência de falta e modalidades de controle. Entende-se, portanto, que os resultados apresentados na Tabela 4.3 e nas figuras desse estudo servem de subsídios e argumentos que sugerem a utilização conservadora do valor de $2 \mathrm{pu}$ como estimativa de contribuição máxima de corrente de curto-circuito desse tipo de gerador, em programas de cálculos de curto-circuito.

\subsection{Considerações Finais Sobre o Capítulo}

Os resultados dos estudos apresentados neste capítulo permitem apontar conclusões importantes que servirão de subsídios para outras análises.

Os resultados apresentados na seção 4.2 indicam a influência dos geradores e seus respectivos modos de controle na qualidade da energia elétrica em sistemas de distribuição de energia. Embora estudos relacionados à qualidade de energia elétrica não sejam o foco deste trabalho, é interessante demonstrar que a influência da geração distribuída deve ser estudada no sentido de estabelecer critérios de operação e de conexão para minimizar eventuais impactos negativos. Ainda na seção 4.2, verificou-se que os diferentes modos de controle dos geradores baseados em inversores de frequência causam impactos diferentes no sistema de distribuição sob diversos aspectos, tais como: correntes de curtos-circuitos, perfil de tensão, afundamento, variação e regulação de tensão e perdas elétricas;

Em relação ao estudo sobre correntes de curto-circuito apresentado na seção 4.3, foco desta pesquisa, verificou-se que o controle de corrente I apresentou melhor desempenho em relação à limitação e controle da corrente de falta. Nesta modalidade de controle, o gerador manteve o valor da sua contribuição de corrente de curto-circuito em torno do seu valor de corrente nominal em todos os testes realizados neste trabalho.

Quando submetido ao controle PQ, verificou-se que, no pior caso, o gerador atingiu o valor de corrente de falta $41 \%(1,41 \mathrm{pu})$ superior ao seu valor de corrente nominal. Este fato demanda atenção em relação aos cálculos de corrente de curto-circuito em sistema com esse tipo de gerador. Verificou-se também que os valores de contribuição de corrente de falta, para esse tipo de controle, se mostraram pouco sensíveis às variações do ângulo de incidência de falta, contudo, bastante sensíveis à variação do fator de potência.

Para o controle PV, o gerador atingiu, no pior caso dos testes, um valor de corrente de falta de 76\% (1,76 pu) superior ao valor de sua corrente nominal, o que representa a maior contribuição de corrente de falta dentre as três modalidades estudadas neste trabalho. Sendo 
assim, a inserção do gerador com esse tipo de controle no sistema de energia também requer atenção em relação aos cálculos de corrente de curto-circuito. Ainda no controle PV, verificou-se também que a contribuição de corrente de falta apresentou considerável sensibilidade à variação do ângulo de incidência de falta e às pequenas variações de tensão.

No geral, verificou-se no estudo da seção 4.3 que a contribuição de corrente de falta do gerador baseado em inversor de frequência não atingiu o valor de 2 pu em nenhuma condição de teste e controle, o que representa, no quesito limitação de corrente de falta, uma grande vantagem em relação aos geradores rotativos conectados diretamente no sistema.

Finalmente, os resultados apresentados nesses estudos contribuem para a avaliação e o estabelecimento de diretrizes operacionais para a inserção desse tipo de gerador nas redes de distribuição de energia e também para a realização de cálculos de correntes de curto-circuito. 

Contribuição para a Corrente de Curto-Circuito. 


\section{Capítulo 5}

\section{Metodologias para a Inserção dos Geradores Baseados em Inversores nos Cálculos de Curto-Circuito}

\subsection{Introdução}

As tradicionais metodologias de cálculo de corrente de curto-circuito são baseadas nos valores de tensão pré-falta e impedâncias do sistema de energia elétrica e de seus geradores. Atualmente, a maioria dos geradores conectados à rede de energia elétrica é do tipo síncrono, cujos valores de impedâncias são fornecidos pelos fabricantes.

Conforme relatado em capítulos anteriores, a crescente busca por fontes alternativas de energia fez aumentar a demanda e utilização de geradores baseados em inversores, que neste trabalho é chamado de GD. Os inversores são dotados, em sua composição física, de componentes semicondutores que proporcionam efeitos e respostas não lineares às variações de tensão e corrente. Este fato dificulta a obtenção precisa dos seus valores de impedâncias que, por consequência, dificulta sua inserção nas metodologias convencionais de cálculos de corrente de curto-circuito.

\subsection{Metodologias Propostas}

Este capítulo apresenta o desenvolvimento de duas metodologias para a inserção do gerador baseado em inversor de frequência (GD) nos cálculos de corrente de curto-circuito trifásico permanente em sistemas de distribuição de energia elétrica (SD). Como finalidade principal para o desenvolvimento das metodologias, buscou-se a simplicidade de suas aplicações, associação das mesmas com as teorias básicas de análise de circuitos elétricos e, 
por fim, independência de dados minuciosos e específicos dos fabricantes de inversores. As metodologias têm como base o padrão de contribuição de corrente de falta para os inversores que é aproximadamente duas vezes o valor da corrente nominal do inversor (Keller; Kroposki, 2010) e também nos valores encontrados e tabelados nos estudos apresentados no capítulo anterior, onde se comprova que a tendência do valor de corrente de curto-circuito trifásico desse tipo de gerador é não superar o dobro do valor de sua corrente nominal.

A validação das metodologias propostas neste trabalho é realizada através da apresentação das simulações, equacionamentos, cálculos e análise de resultados.

\subsubsection{Metodologia 1 para a Inserção do Gerador Baseado em Inversor GD nos Cálculos de Corrente de Curto-Circuito}

Essa metodologia propõe a inserção desses geradores de forma semelhante ao que se pratica convencionalmente para os geradores síncronos, que utiliza os seus valores de reatâncias nos cálculos de curtos-circuitos do sistema de distribuição. Enquanto para os geradores síncronos os valores de suas reatâncias são obtidos através dos ensaios específicos realizados por seus fabricantes, essa metodologia atribui um valor fixo, em pu, para a corrente de curto-circuito do GD e, através desse valor, encontra-se também um valor fixo, em pu, para sua reatância $\left(\mathrm{X}_{\mathrm{GD}}\right)$.

Essa metodologia, de forma conservadora, atribui a este gerador, de forma fixa, o valor de duas vezes a sua corrente nominal como valor de sua corrente de curto-circuito $\left(I_{C C G D}=2 I_{N}\right)$. Com essa atribuição e de posse da tensão equivalente pré-falta no ponto de conexão do gerador GD $\left(V_{e q}\right)$, calcula-se a reatância interna do gerador GD $\left(X_{G D}\right)$ através da equação (5.1).

$$
X_{G D}=\frac{V_{e q}}{I_{C C G D}}
$$

Considerando como valores de base os valores nominais de potência, tensão e corrente do gerador distribuído GD, atribui-se na equação (5.1) o valor de 1pu para tensão equivalente pré-falta do sistema de distribuição de energia $\left(V_{e q}\right)$ e o valor de 2 pu para corrente de curtocircuito do gerador distribuído GD $\left(I_{C C G D}\right)$, obtendo-se portanto, o valor fixo de reatância do gerador GD $\left(X_{G D}\right)$ de 0,5 pu, nas bases do gerador.

O fundamento dessa metodologia é a utilização desse valor de reatância para, juntamente com a aplicação do teorema de Thevènin, calcular, de forma simplificada, o valor da corrente de curto-circuito trifásico simétrico permanente do sistema de distribuição de energia elétrica 
com gerador baseado em inversor (GD). Destaca-se que, para a aplicação dessa metodologia, faz-se necessário a adequação dos valores de base em relação ao sistema em estudo.

Considerando os valores de base (tensão, corrente e potência) do gerador distribuído, segue o resumo da sequência de procedimentos para a aplicação da metodologia 1:

a) Atribui-se o valor de 2 pu para a contribuição de corrente de curto-circuito do GD $\left(I_{C C G D}=2 I_{N}\right)$

b) Atribui-se o valor de 1 pu para a tensão equivalente pré-falta no ponto de conexão do $\mathrm{GD}\left(V_{e q}=1 p u\right)$;

c) Por meio da equação (5.1), encontra-se o valor de 0,5 pu para a reatância interna do $\mathrm{GD}\left(X_{G D}=0,5 \mathrm{pu}\right)$

d) Faça a adequação do valor da reatância do GD $\left(X_{G D}\right)$ aos valores de base do sistema em estudo;

e) Considere o GD como a reatância cujo valor foi obtido do resultado da adequação das bases (etapa anterior) e utilize essa reatância para o emprego da metodologia convencional (que faz uso do Teorema de Thèvenin com geradores síncronos) de cálculo de curto-circuito trifásico simétrico.

Como forma de aprimorar o entendimento, apresenta-se na seção 5.3.3 a aplicação da metodologia 1.

\subsubsection{Metodologia 2 para Inserção do Gerador Baseado em Inversor nos Cálculos de Corrente de Curto-Circuito}

Nesta seção, apresenta-se a metodologia 2 para inserção dos geradores baseados em inversores (GD) nos cálculos de curto-circuito dos sistemas de distribuição de energia elétrica (SD).

O fundamento dessa metodologia é interpretar o gerador GD como uma fonte de corrente que, em situação de falta, fornece corrente com o dobro de seu valor nominal. Todavia, para a inserção dessa fonte de corrente nos cálculos de curto-circuito do sistema de distribuição é necessário transformá-la em fonte de tensão.

Considerando que os valores de base (potência, tensão e corrente) sejam os nominais do gerador GD, entende-se que, durante sua operação nominal, esse gerador forneça à sua carga o valor de tensão de 1 pu e corrente de 1 pu. Além disso, também como parte integrante dessa 
metodologia, considera-se que a impedância interna do gerador GD seja uma reatância com o valor de 1 pu, conforme ilustra a Figura 5.3.

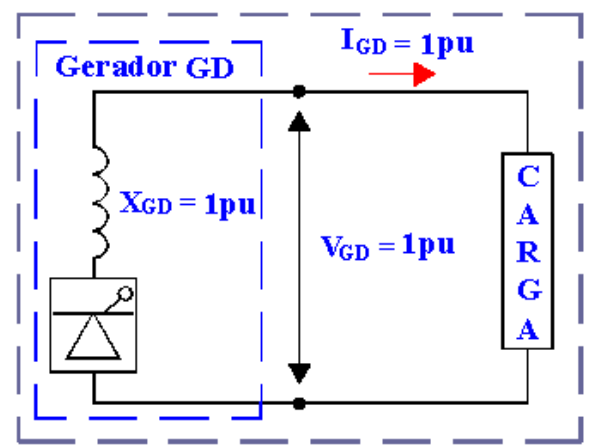

Figura 5.1 - Gerador GD como fonte de tensão operando em condições nominais de fornecimento de energia para carga.

A transformação da fonte de corrente em fonte de tensão é realizada através da equação (5.2), que segue a prática convencional de equivalência entre fontes de tensão e corrente, considerando que essas fontes possuam o mesmo valor de impedância interna e forneçam a mesma corrente ou mesma tensão de saída para a carga. Na equação (5.2), $V_{F G D}$ é o valor da tensão do gerador GD representado como fonte de tensão, $X_{G D}$ é a reatância interna do gerador (fonte de tensão ou corrente) e $I_{F G D}$ é o valor de corrente do gerador GD representado como fonte de corrente.

$$
V_{F G D}=X_{G D} \times I_{F G D}
$$

Fazendo-se as substituições de $I_{F G D}$ pelo valor de corrente de curto-circuito do gerador GD $\left(I_{C C G D}\right)$, que é considerado igual a 2 pu e $X_{G D}$ como 1 pu (consideração dessa metodologia), obtém-se o valor de $V_{F G D}$ de $2 \mathrm{pu}$, que é a tensão equivalente pré-falta do gerador GD $\left(V_{G D}\right)$ representado como fonte de tensão.

A Figura 5.2 ilustra a transformação da fonte de corrente em fonte de tensão.

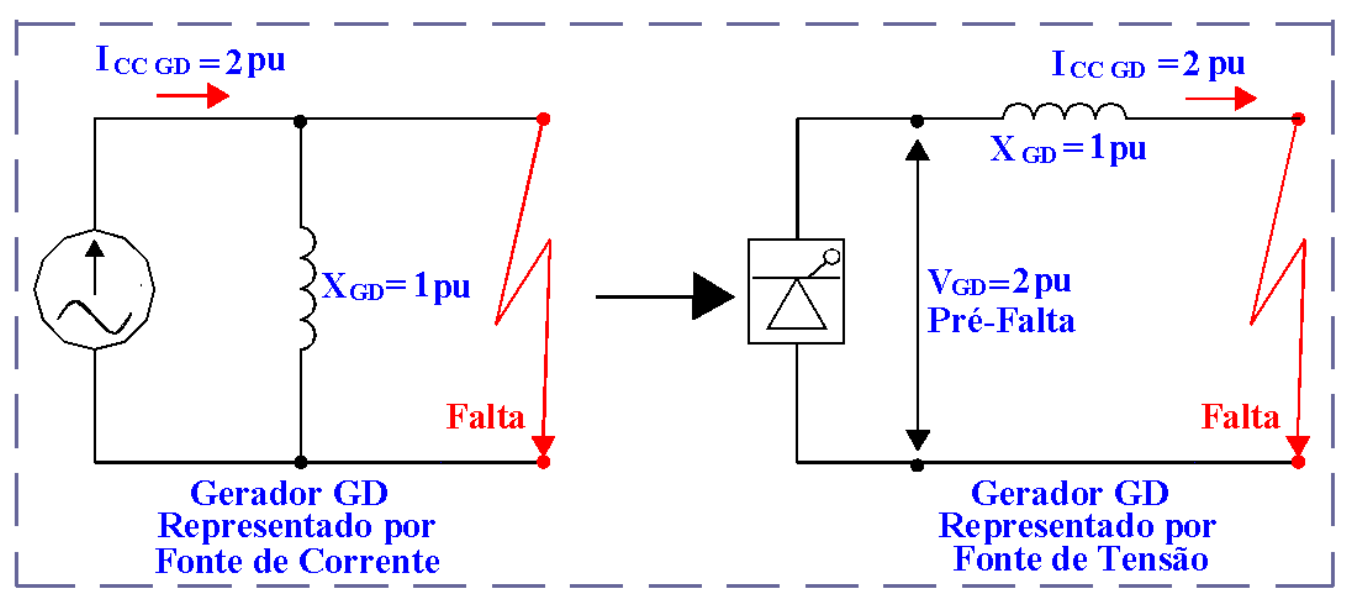

Figura 5.2 - Transformação da fonte de corrente sob condição de falta em fonte de tensão, considerando os valores de base do Gerador GD. 
Na Figura 5.2 observa-se a fonte de corrente que representa o gerador GD com valor de corrente de falta $\left(I_{C C G D}\right)$ de 2 pu e reatância interna $\left(X_{G D}\right)$ de 1 pu. Verifica-se também o resultado da transformação dessa fonte de corrente em fonte de tensão com valor de tensão equivalente de saída $\left(V_{G D}\right)$ de 2 pu e reatância interna de 1 pu. Essa metodologia propõe utilizar essa configuração da fonte de tensão para representar e inserir o gerador GD nos cálculos de corrente de curto-circuito dos sistemas de distribuição. Assim como na metodologia anterior, faz-se necessária a adequação dos valores de base em relação ao sistema em estudo.

Considerando os valores de base (tensão, corrente e potência) do gerador distribuído, segue o resumo da sequência de procedimentos da metodologia 2 :

a) Sob condição de falta, considera-se o GD como uma fonte de corrente que injeta no sistema o valor de 2 pu como sua contribuição de corrente de curto-circuito $\left(I_{F G D}=2 I_{N}\right)$;

b) Atribui-se o valor de 1 pu para a reatância interna do $\operatorname{GD}\left(X_{G D}=1 \mathrm{pu}\right)$;

c) Efetuam-se as adequações dos valores de base, respectivamente, da reatância $\left(X_{G D}\right)$ e a corrente $\left(I_{F G D}\right)$ aos valores de base do sistema em estudo;

d) Por meio da equação (5.2), efetua-se a conversão do GD, considerado como fonte de corrente $\left(I_{F G D}\right)$, para fonte de tensão $\left(V_{F G D}\right)$. Nessa etapa, o resultado de $V_{F G D}$ deverá ser de 2 pu;

e) De posse da fonte de tensão, que representa o GD, cujo valor de $V_{F G D}$ e é de 2 pu e reatância interna $X_{G D}$ com o valor já adequado às bases do sistema em estudo (item (c)), faça a introdução dessa fonte no circuito do sistema em estudo e calcule a corrente total de curto-circuito através do Teorema da Superposição.

Para facilitar o entendimento, apresenta-se na seção 5.3.4 a aplicação da metodologia 2. 


\subsection{Aplicações e Análises das Metodologias de Cálculos de Curto-Circuito}

Nesta seção, são realizadas as aplicações e análises das metodologias de cálculos de curtocircuito propostas neste trabalho. O sistema de distribuição de energia elétrica (SD) utilizado para simulações, aplicações e validação das metodologias de cálculos de curto-circuito é apresentado na Figura 5.3. Os valores naturais dos parâmetros dos componentes estão dispostos nas tabelas A.11 a A.14 do apêndice A e os valores em pu e de base estão dispostos na Figura 5.3.

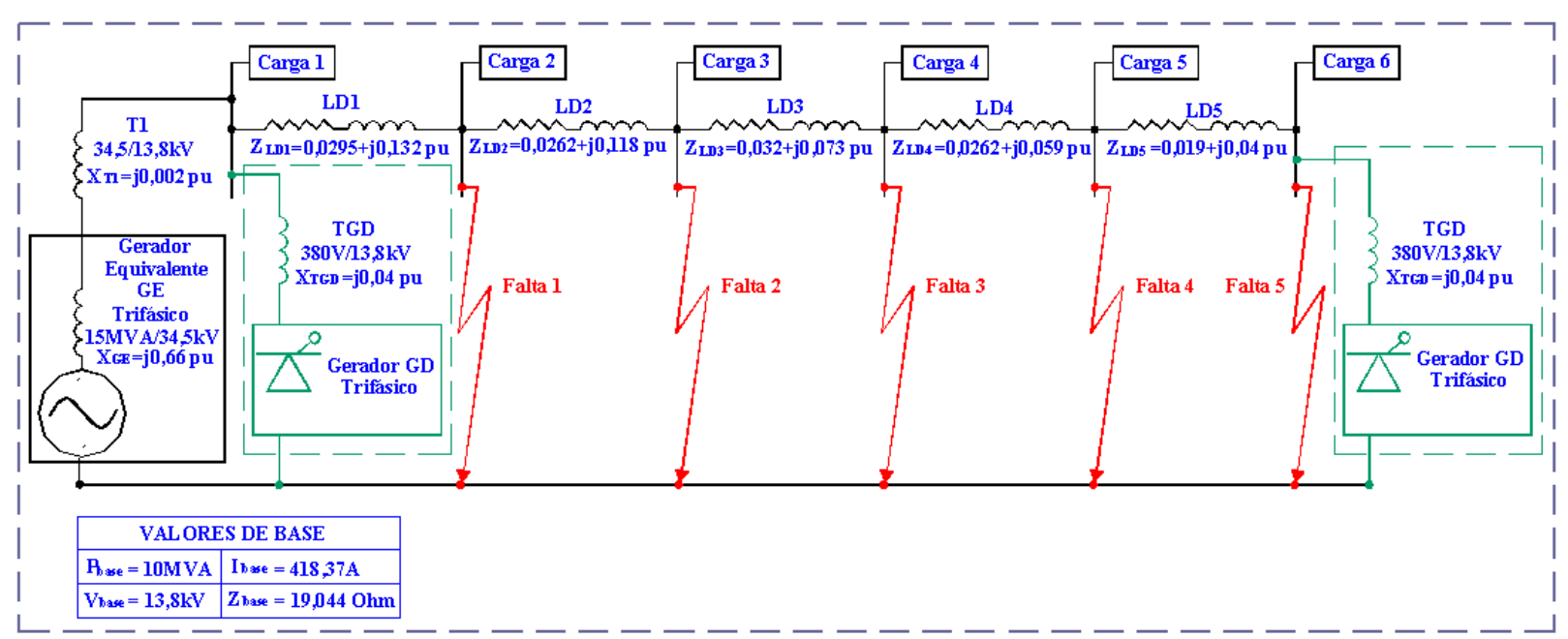

Figura 5.3 - Sistema de distribuição de energia elétrica em estudo.

No sistema de distribuição da Figura 5.3, a potência de curto-circuito do gerador equivalente da concessionária (GE) é de 15 MVA em 34,5 kV e o gerador distribuído baseado em inversor (GD) é composto por um grupo uniforme de dez geradores em paralelo de 300 kVA em 380V. Sendo assim, a capacidade total do grupo GD é de 3 MVA, o que equivale a $20 \%$ da capacidade do gerador GE e a uma porcentagem ainda maior do que $20 \%$ da potência de curto-circuito da linha ao longo de sua extensão. Essa porcentagem, que representa o nível de penetração da geração distribuída no sistema de energia em estudo, denota um sistema com significativa dependência do gerador distribuído. Dessa forma, os valores de correntes fornecidos pelo GD e obtidos nos cálculos e simulações são significativos perante os valores totais envolvidos no estudo, ou seja, os resultados se apresentam de forma mais contundente e contribuem para diagnósticos e avaliações mais precisas sobre as metodologias propostas.

Para a realização das simulações e cálculos, considerou-se, de forma alternada e não concomitante, quatro configurações diferentes para o sistema em estudo, sendo:

1) Sistema sem o GD;

2) Grupo do GD de 3 MVA instalado no início das linhas junto com o gerador GE; 
3) Grupo do GD de 3 MVA instalado no final das linhas do sistema de distribuição;

4) Um grupo de gerador GD de 1,5 MVA no início das linhas junto com o gerador GE e outro grupo GD de 1,5 MVA no final das linhas do sistema de distribuição.

Vale destacar que na segunda configuração as correntes fornecidas por ambos geradores (GE e GD) compartilham as impedâncias dos condutores por toda extensão da rede de distribuição, desde a geração até o local de aplicação da falta. Na terceira, a disposição do gerador GD não proporciona o compartilhamento de condutores pelas correntes fornecidas por ambos geradores (GE e GD).

As faltas trifásicas foram aplicadas, de forma sequencial e não concomitante, em cinco diferentes pontos ao longo da linha de distribuição de energia elétrica (LD). Os locais das aplicações das faltas são apresentados e identificados na Figura 5.3, respectivamente por Falta 1, Falta 2 e assim, sucessivamente até a Falta 5.

As aplicações das metodologias de cálculos, juntamente com suas respectivas figuras, estão relacionadas com a Figura 5.3. Sendo assim, por ser bastante explorada ao longo do desenvolvimento deste capítulo e facilitar o entendimento, além de constar na lista de símbolos e siglas, toda a nomenclatura utilizada especificamente nas figuras das aplicações das metodologias de cálculos está disposta de maneira concentrada na Tabela 5.1. 
Tabela 5.1 - Nomenclatura utilizada nas aplicações numéricas das metodologias propostas neste capítulo.

\begin{tabular}{|l|}
\hline \multicolumn{1}{|c|}{ Nomenclatura } \\
\hline GE - Gerador Equivalente da Concessionária \\
\hline $\mathbf{X}_{\mathbf{G E}}$ - Impedância interna do gerador GE \\
\hline $\mathbf{X}_{\mathbf{G E T}}$ - Impedância total do ramo do gerador GE \\
\hline $\mathbf{T 1}$ - Transformador da saída do gerador GE \\
\hline $\mathbf{X}_{\mathbf{T 1}}$ - Impedância do transformador T1 \\
\hline $\mathbf{L D}$ - Linha de Distribuição de Energia Elétrica \\
\hline $\mathbf{Z}_{\mathbf{L D}}$ - Impedância da linha LD \\
\hline $\mathbf{Z}_{\mathbf{L D e q} 1}$ - Impedância equivalente da linha LD desde o GE até a falta \\
\hline $\mathbf{Z}_{\mathbf{L D e q} 2}$ - Impedância equivalente da linha LD desde o final das linhas até a falta \\
\hline $\mathbf{Z}_{\mathbf{e q}}$ - Impedância equivalente total do circuito \\
\hline $\mathbf{V}_{\mathbf{e q}}$ - Tensão equivalente no local identificado \\
\hline $\mathbf{G D}$ - Gerador Baseado em Inversor de Frequência 3MVA \\
\hline $\mathbf{X}_{\mathbf{G D}}$ - Impedância interna do gerador GD \\
\hline $\mathbf{X}_{\mathbf{G D T}}$ - Impedância total do ramo do gerador GD \\
\hline TGD - Transformador saída do gerador GD \\
\hline $\mathbf{X}_{\mathbf{T G D}}$ - Impedância do transformador TGD \\
\hline
\end{tabular}

Na próxima seção, apresentam-se as considerações e resultados obtidos das simulações.

\subsubsection{Simulações}

As simulações do sistema de distribuição de energia elétrica apresentado na Figura 5.3 foram realizadas através da ferramenta computacional SimPowerSystems. Os resultados dessas simulações são comparados com os resultados obtidos das aplicações das metodologias de cálculos de curto-circuito.

Em função de ter proporcionado aos inversores os maiores valores de corrente de curtocircuito nas simulações realizadas no estudo do capítulo anterior, utiliza-se o controle de potência ativa e tensão (PV) em todas as simulações deste capítulo.

Os resultados das simulações são apresentados nas figuras seguintes e estão dispostos conforme sequência dos cinco pontos de aplicação de falta apresentada na Figura 5.3. Para cada local de aplicação $\left(1^{\circ}\right.$ ao $\left.5^{\circ}\right)$ do curto-circuito, apresentam-se, de forma sequencial, os resultados das quatro diferentes configurações de operação do sistema de distribuição de 
energia (Sem GD, GD no início das linhas, GD no final das linhas e 2 GDs), citadas anteriormente.

Como forma de facilitar a compreensão, seguem, após a sequência de resultados das simulações, o resumo apresentado na Tabela 5.2 dos valores de corrente total de falta em regime permanente e a análise de resultados. A Figura 5.4 apresenta os resultados da Falta 1.

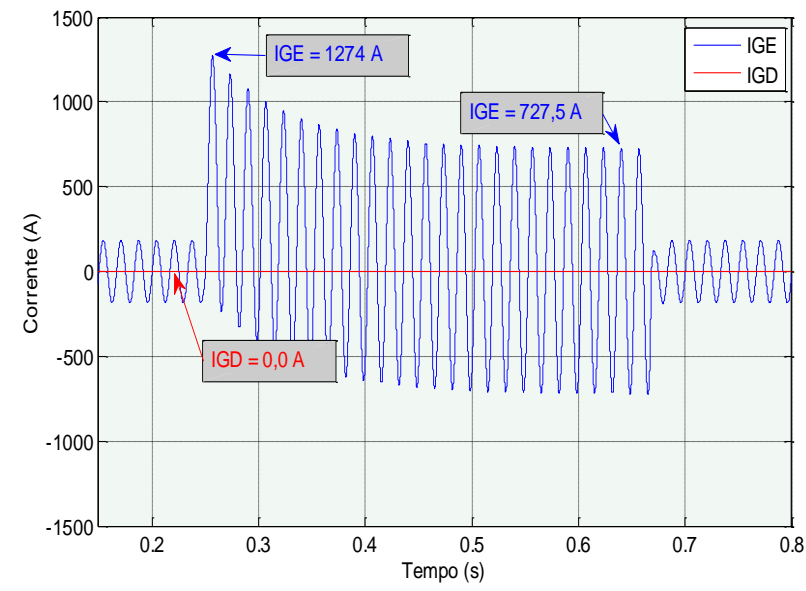

(a) Sem Gerador GD

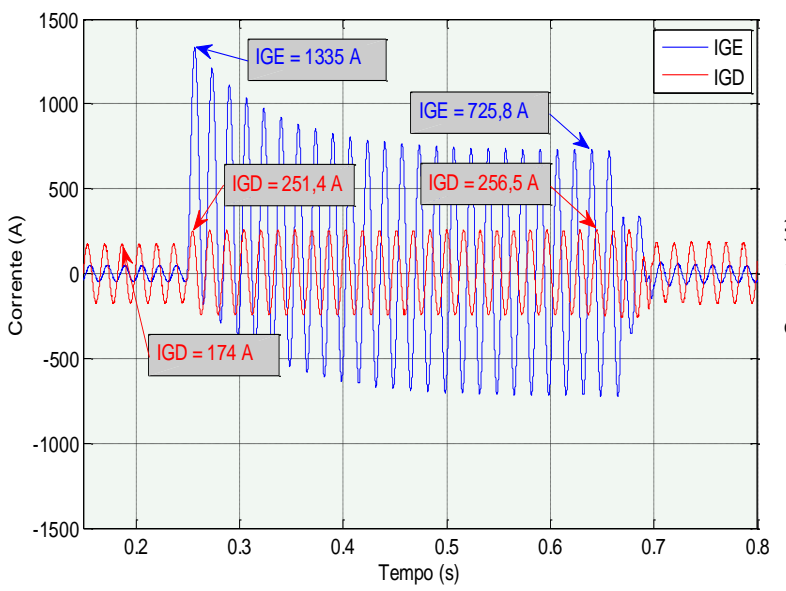

(c) Gerador GD de 3MVA no final da linha

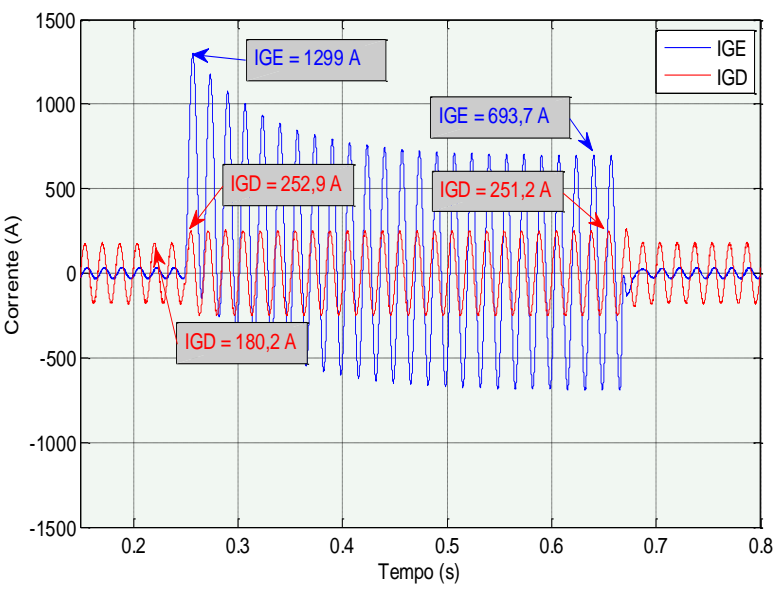

(b) Gerador GD de 3MVA no início da linha

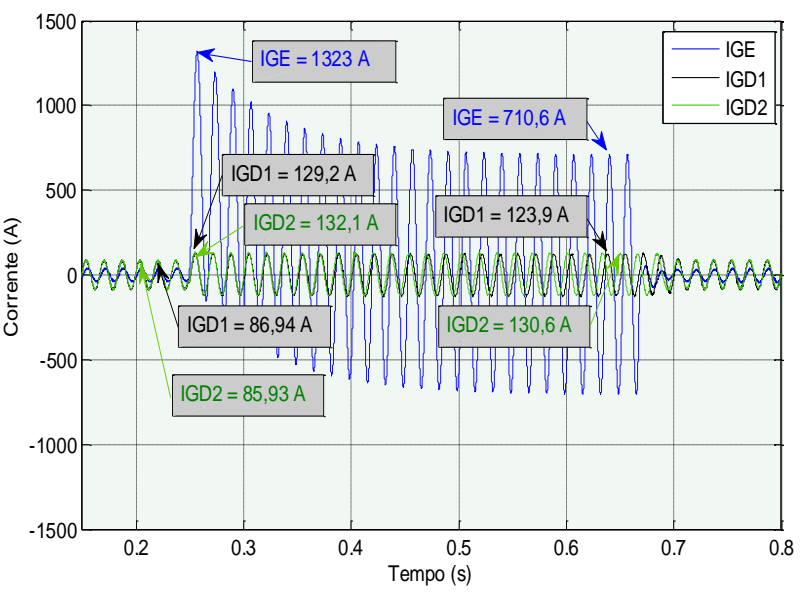

(d) 2 GDs de 1,5MVA - GD1 no início da linha e GD2 no final da linha

Figura 5.4 - Resultados das simulações com aplicação da Falta 1. 
A Figura 5.5 apresenta os resultados das simulações com aplicação da Falta 2.

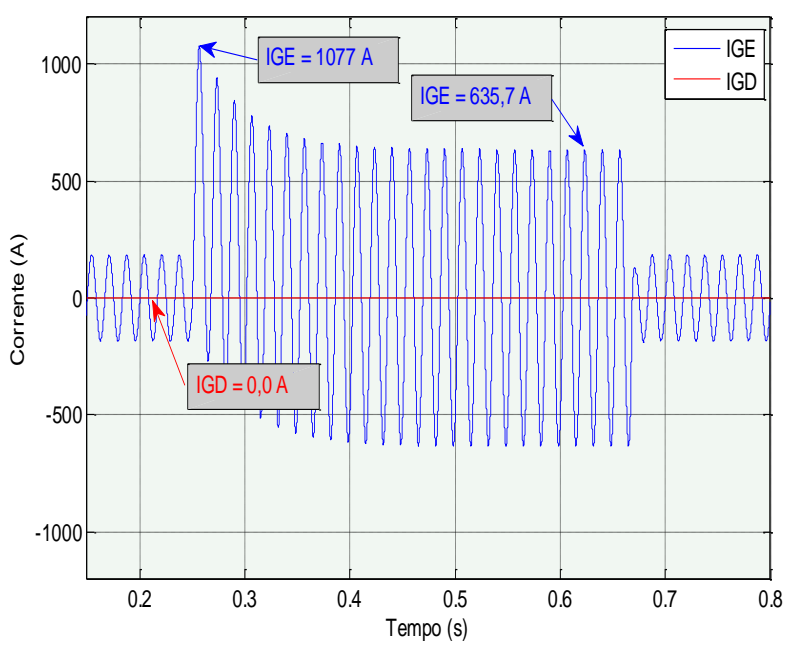

(a) Sem Gerador GD

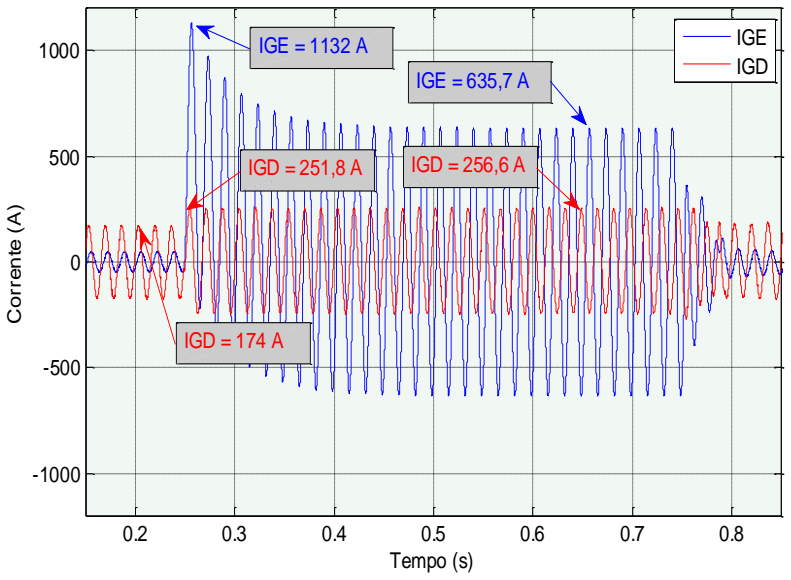

(c) Gerador GD de 3MVA no final da linha

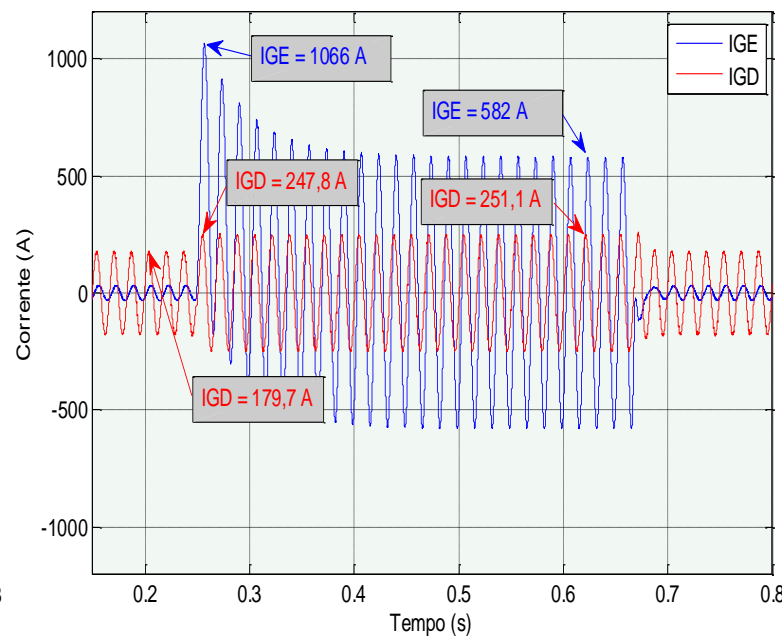

(b) Gerador GD de 3MVA no início da linha

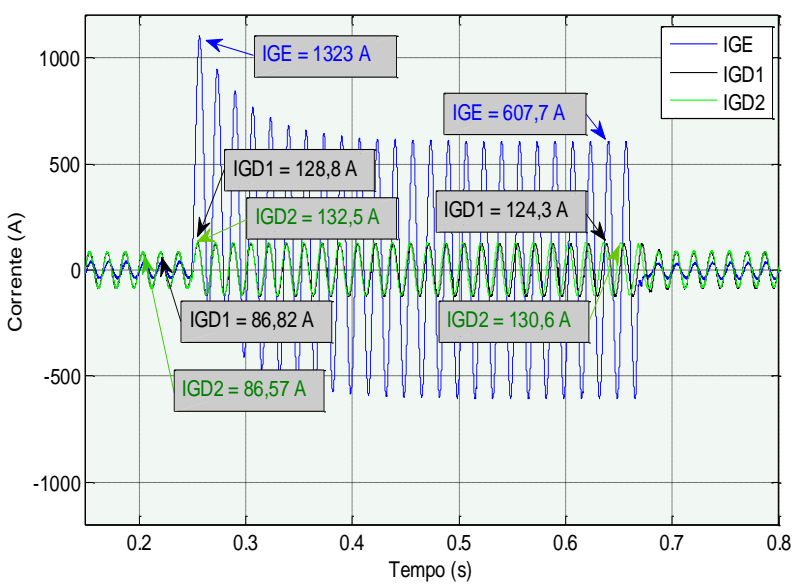

(d) 2 GDs de 1,5MVA - GD1 no início da linha e GD2 no final da linha

Figura 5.5 - Resultados das simulações com aplicação da Falta 2. 
A Figura 5.6 apresenta os resultados das simulações com aplicação da Falta 3.

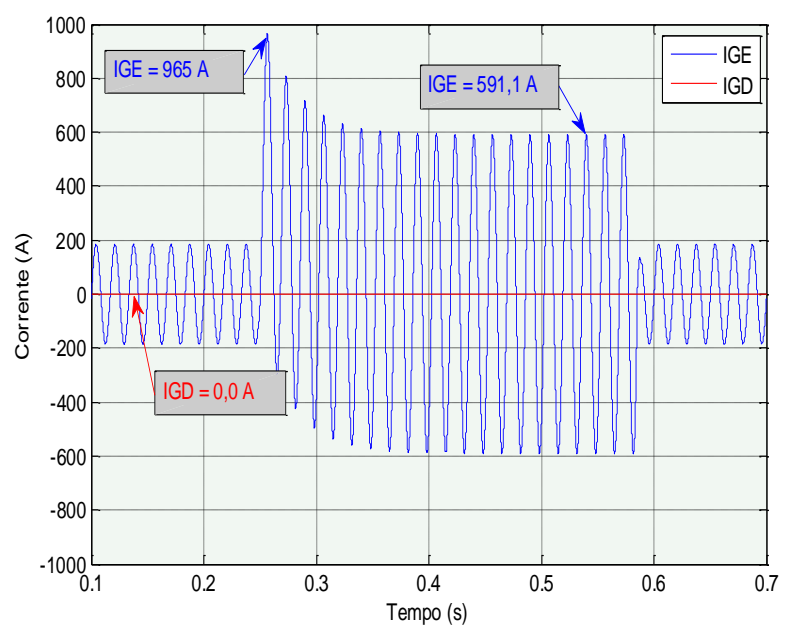

(a) Sem Gerador GD

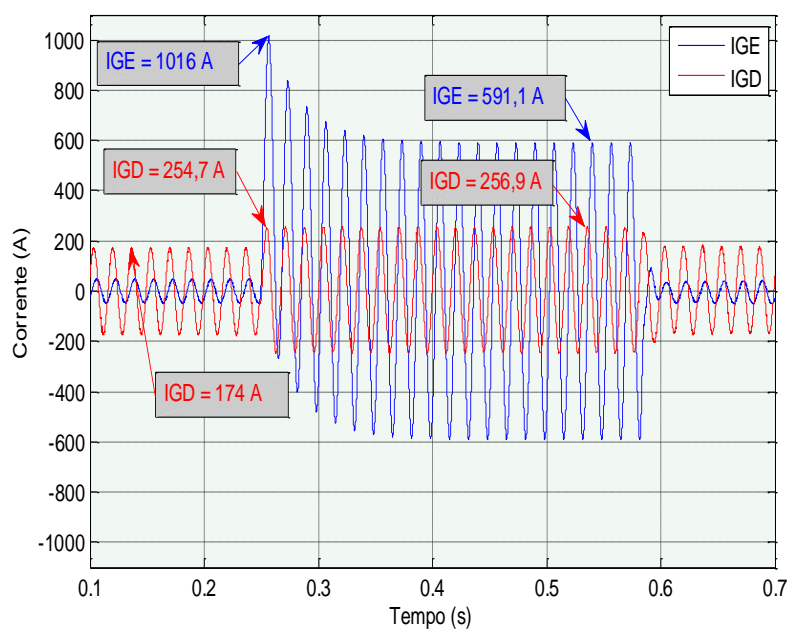

(c) Gerador GD de 3MVA no final da linha

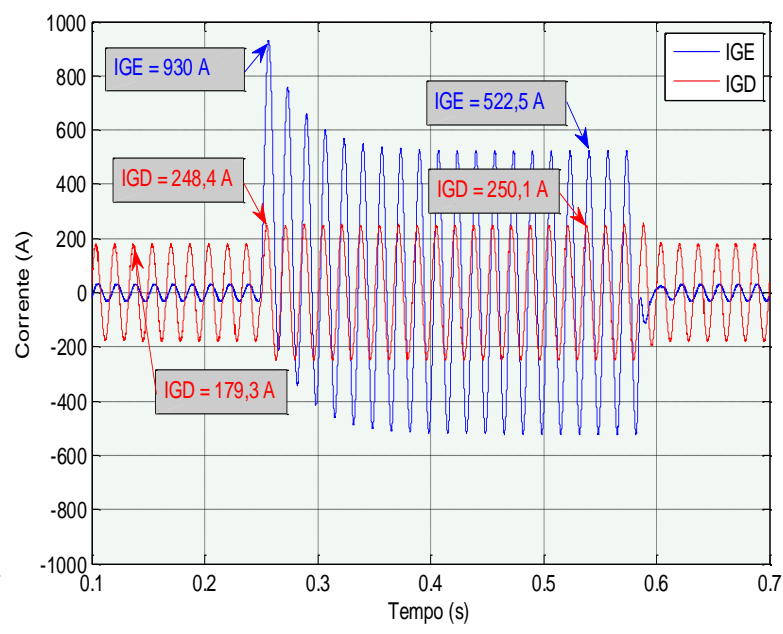

(b) Gerador GD de 3MVA no início da linha

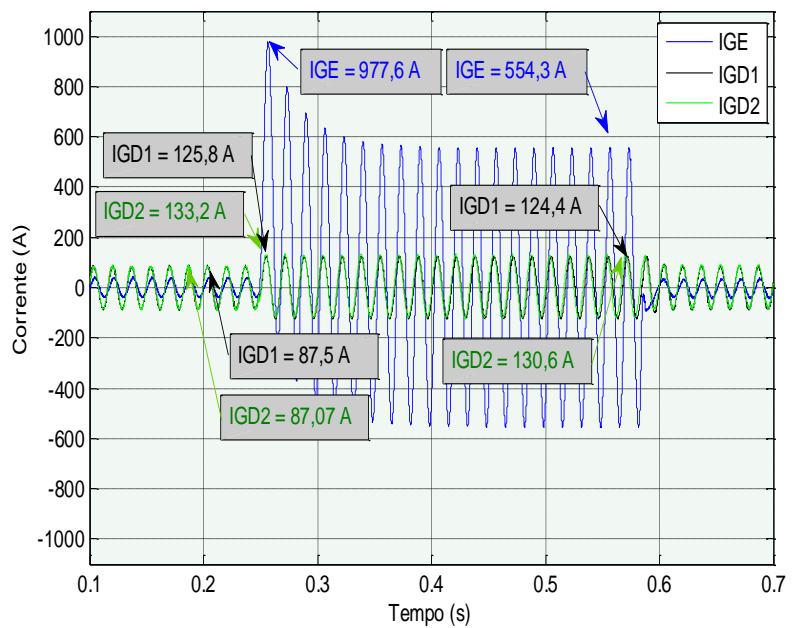

(d) 2 GDs de 1,5MVA - GD1 no início da linha e GD2 no final da linha

Figura 5.6- Resultados das simulações com aplicação da Falta 3. 
A Figura 5.7 apresenta os resultados das simulações com aplicação da Falta 4.

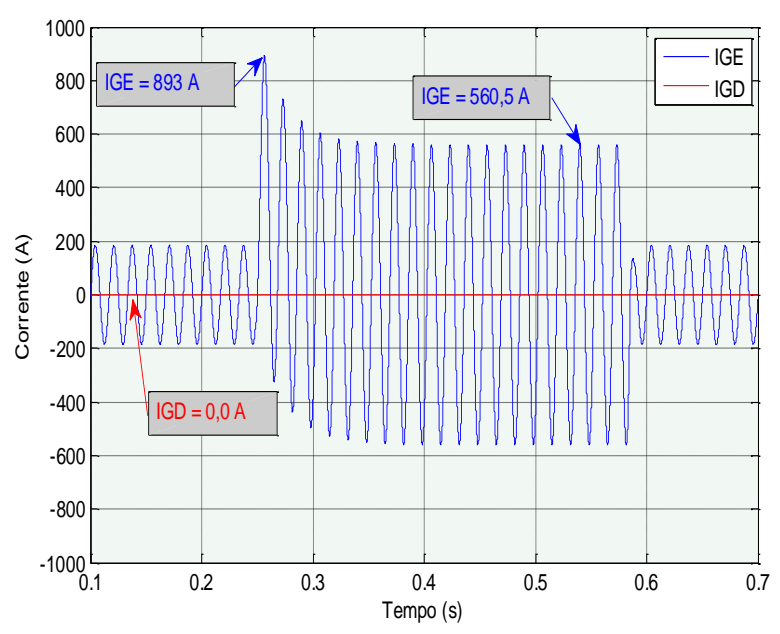

(a) Sem Gerador GD

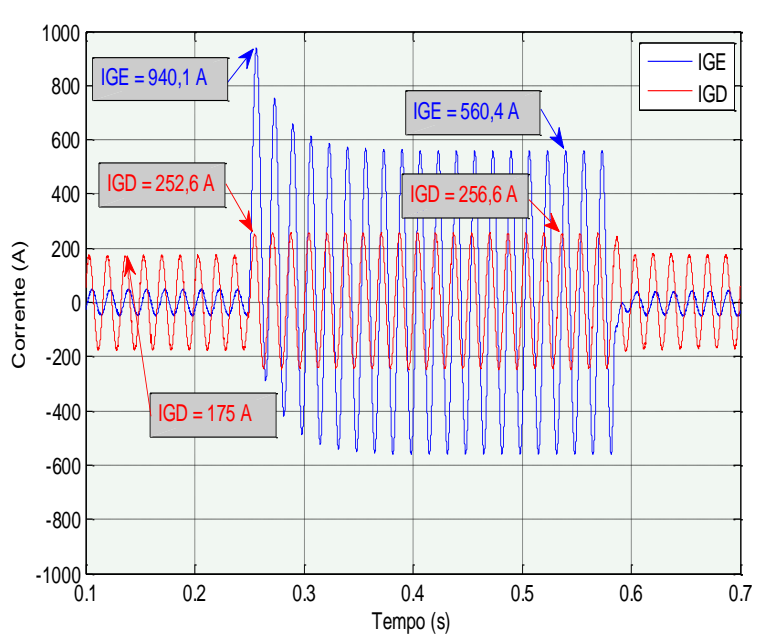

(c) Gerador GD de 3MVA no final da linha

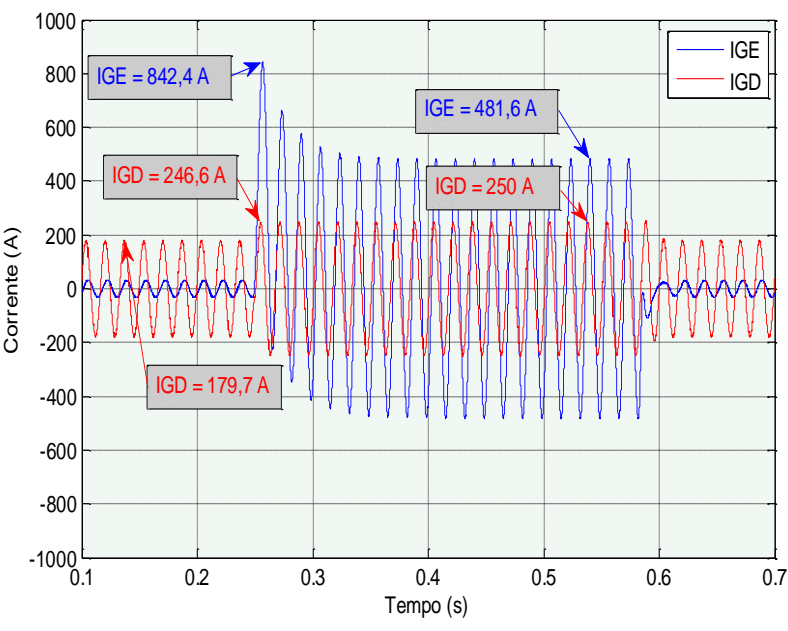

(b) Gerador GD de 3MVA no início da linha

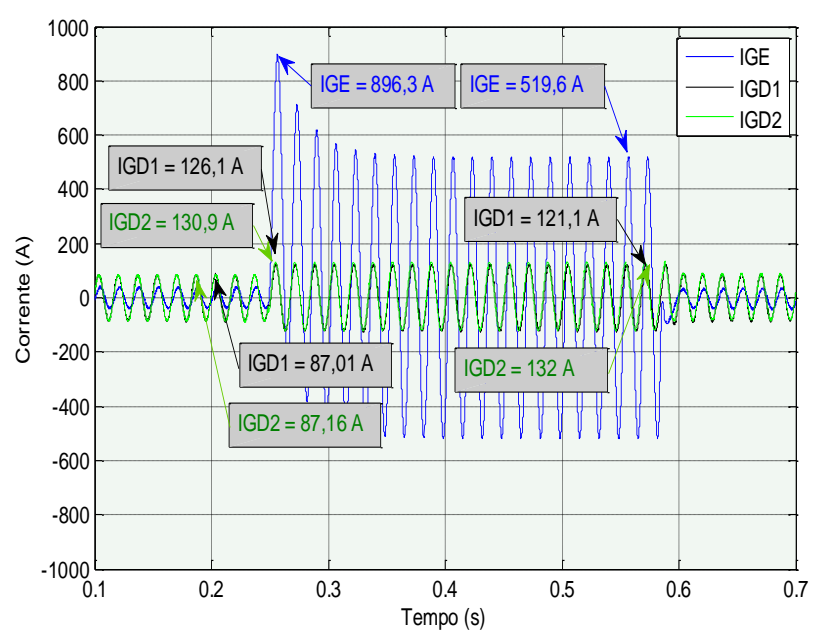

(d) 2 GDs de 1,5MVA - GD1 no início da linha e GD2 no final da linha

Figura 5.7 - Resultados das simulações com aplicação da Falta 4. 
A Figura 5.8 apresenta os resultados das simulações com aplicação da Falta 5.

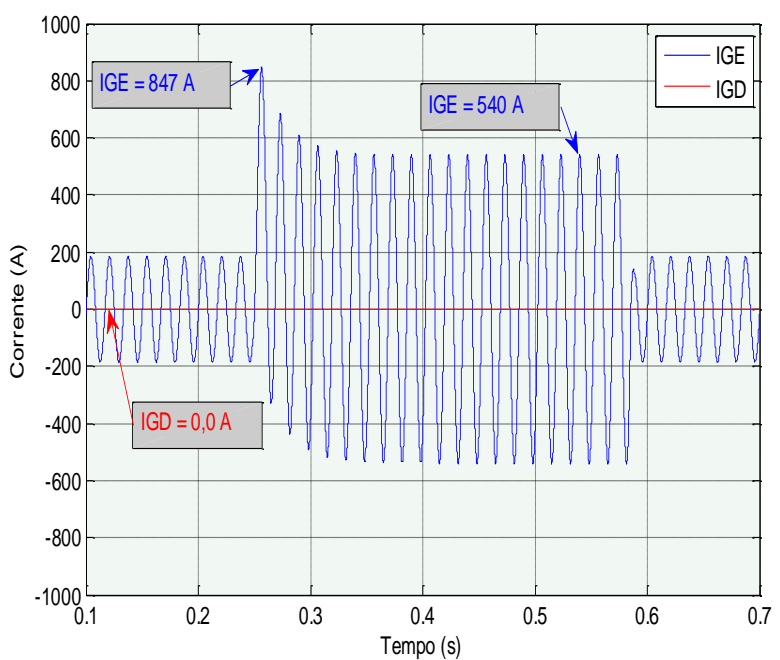

(a) Sem Gerador GD

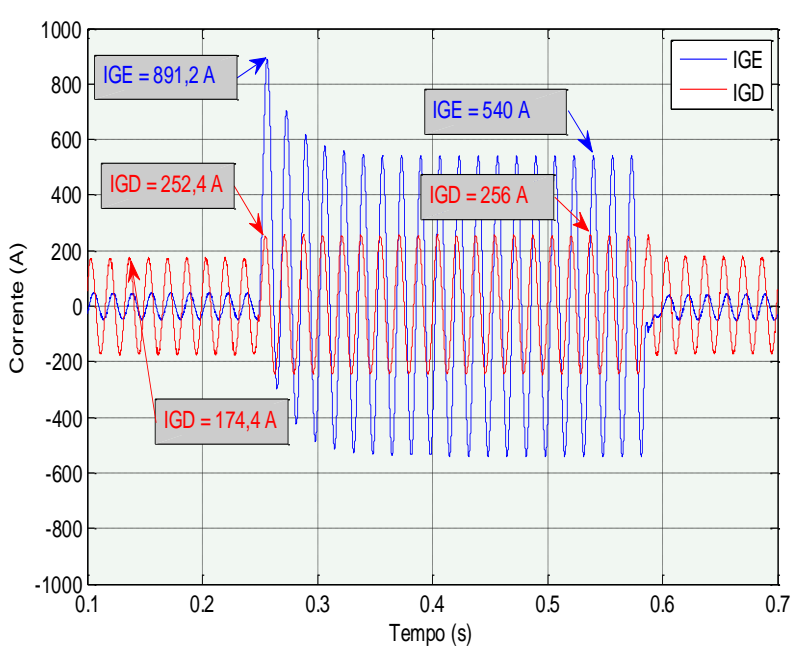

(c) Gerador GD de 3MVA no final da linha

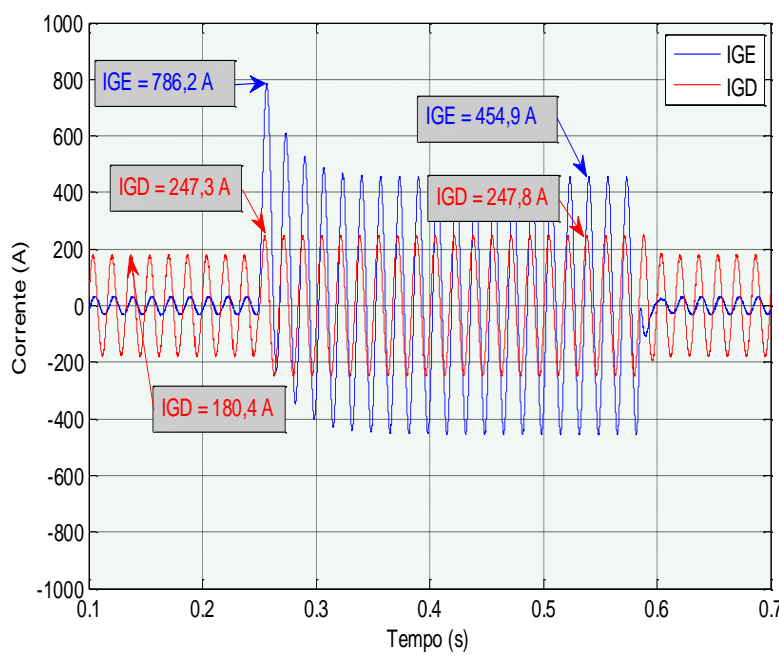

(b) Gerador GD de 3MVA no início da linha

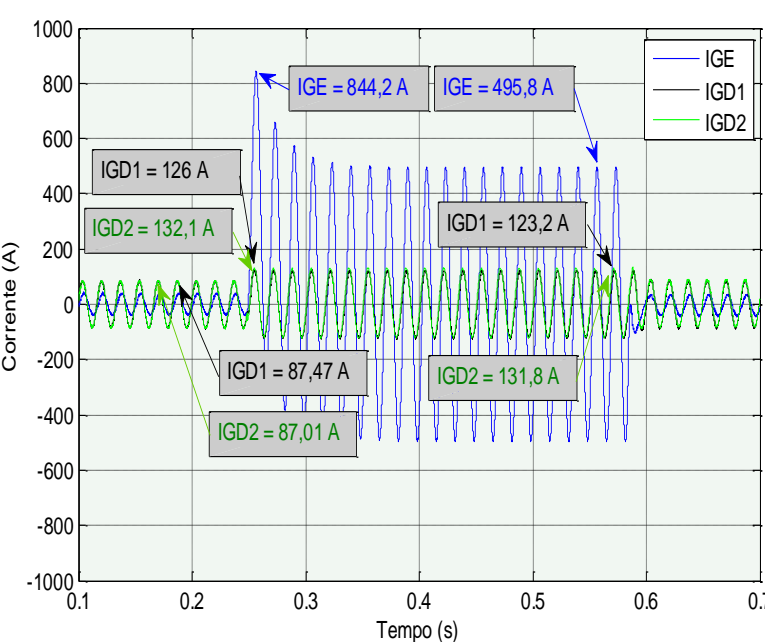

(d) 2 GDs de 1,5MVA - GD1 no início da linha e GD2 no final da linha

Figura 5.8 - Resultados das simulações com aplicação da Falta 5.

Como forma de manter o conservadorismo, considera-se, como valor total simulado da corrente instantânea de curto-circuito, a soma do valor de pico da corrente de falta fornecida pelo gerador equivalente da concessionária GE (IGE) mais o valor de pico da corrente de falta do gerador distribuído GD (IGD).

Os valores obtidos das simulações estão dispostos na Tabela 5.2, considerando a máxima corrente de falta e a corrente de curto-circuito permanente. 

nos Cálculos de Curto-Circuito.

Tabela 5.2 - Resultados dos valores das correntes de curto-circuito obtidos das simulações.

\begin{tabular}{|c|c|c|c|c|}
\hline \multirow{2}{*}{$\begin{array}{c}\text { Local de } \\
\text { aplicação da } \\
\text { Falta }\end{array}$} & \multicolumn{4}{|c|}{ Valores de Pico da Corrente Total de Falta - Soma IGE + IGDs } \\
\cline { 2 - 5 } & Sem GD & $\begin{array}{c}\text { GD de 3 MVA no } \\
\text { início da linha }\end{array}$ & $\begin{array}{c}\text { GD de 3 MVA } \\
\text { no final da linha }\end{array}$ & $\begin{array}{c}\text { GD1 de 1,5 MVA no } \\
\text { início e GD2 de 1,5 MVA } \\
\text { no final da linha }\end{array}$ \\
\hline Falta 1 & $727,50 \mathrm{~A}$ & $944,90 \mathrm{~A}$ & $982,30 \mathrm{~A}$ & $965,10 \mathrm{~A}$ \\
\hline Falta 2 & $635,70 \mathrm{~A}$ & $833,10 \mathrm{~A}$ & $892,30 \mathrm{~A}$ & $862,60 \mathrm{~A}$ \\
\hline Falta 3 & $591,10 \mathrm{~A}$ & $772,60 \mathrm{~A}$ & $848,00 \mathrm{~A}$ & $809,30 \mathrm{~A}$ \\
\hline Falta 4 & $560,50 \mathrm{~A}$ & $731,60 \mathrm{~A}$ & $817,00 \mathrm{~A}$ & $772,70 \mathrm{~A}$ \\
\hline Falta 5 & $540,00 \mathrm{~A}$ & $702,70 \mathrm{~A}$ & $796,00 \mathrm{~A}$ & $750,80 \mathrm{~A}$ \\
\hline
\end{tabular}

Conforme se observa nos valores apresentados na Tabela 5.2, o local de instalação do gerador distribuído interfere nos valores simulados de corrente de curto-circuito total.

Em relação ao gerador GE, observa-se nos valores apresentados na Figura 5.4 à Figura 5.8, que na situação em que o GD é instalado no início das linhas, a parcela de contribuição de corrente de falta do gerador GE (IGE), para cada ponto de falta, fica sensivelmente reduzida em relação à situação do sistema de energia sem o gerador GD. Por outro lado, na situação em que o GD é instalado no final das linhas, nota-se que a parcela de contribuição de corrente de curto-circuito do gerador GE permanece com valor semelhante ao praticado na situação em que o sistema de distribuição não possui geração distribuída (sem gerador GD).

Em relação ao gerador GD, para cada ponto de falta, observa-se que, na situação em que este é instalado no início das linhas, os valores de corrente de curto-circuito (IGD) são levemente menores, quando comparados aos valores da situação em que o gerador GD está instalado no final das linhas.

Mantendo-se o mesmo nível de penetração da geração distribuída (GD com 20\% do total da capacidade do GE), a divisão do grupo gerador de 3 MVA em dois grupos de 1,5 MVA, sendo cada um instalado em cada extremo da linha (um no início e outro no final), proporcionou aos geradores GE e GD efeitos semelhantes aos relatados nos dois últimos parágrafos, entretanto, com intensidades menores. Nessa situação, também os resultados de corrente de falta total se apresentam com valores intermediários entre os que foram obtidos nas situações com GD de 3 MVA no início da linhas e GD de 3 MVA no final das linhas. 
Os valores das correntes de curtos-circuitos obtidos das simulações e resumidos na Tabela 5.2 serão confrontados com os valores obtidos dos cálculos que fazem uso das metodologias propostas neste trabalho.

Para efeito de comparação entre resultados, os cálculos de correntes de curtos-circuitos seguem a mesma ordem dos locais de aplicação de falta $\left(1^{\circ}\right.$ ao $\left.5^{\circ}\right)$ e configurações do sistema de distribuição desenvolvidas nas simulações, sendo: sistema sem o gerador GD, sistema com o gerador GD de 3 MVA instalado no início das linhas, gerador GD de 3 MVA instalado no final das linhas e, por fim, dois grupos geradores GDs de 1,5 MVA cada, sendo GD1 instalado no início das linhas e GD2 no final das linhas do sistema de distribuição de energia.

Em função da localização intermediária entre os extremos (início e final) das linhas do sistema de distribuição (SD) em estudo, apresenta-se, neste capítulo, somente aplicações das metodologias de cálculos de curto-circuito para ocorrência da Falta 3.

Ao final dos cálculos, apresenta-se a tabela resumo dos valores obtidos dos cálculos e simulações dos cinco pontos de aplicação de falta e a análise de desempenho da metodologia utilizada.

\subsubsection{Cálculo da Corrente de Curto-Circuito do Sistema de Distribuição de Energia Sem a Inclusão do Gerador Distribuído GD}

Para efeitos de referência, comparação e balizamento das aplicações das estratégias de cálculos de curto-circuito que incluem o GD, inicialmente, efetuam-se os cálculos de corrente de curto-circuito sem a inclusão desse gerador. Os cálculos são realizados através da metodologia convencional de cálculo de falta simétrica com aplicação do Teorema de Thevènin abordada em Almeida e Freitas (1995). O sistema de distribuição de energia elétrica (SD) utilizado nos cálculos é o da Figura 5.3.

Como início do desenvolvimento dos cálculos, a Figura 5.9 apresenta o circuito resultante da Falta 3. Neste circuito, em função de não exercer influência significativa na corrente de curto-circuito, negligenciam-se as cargas e as linhas 4 e 5. 

nos Cálculos de Curto-Circuito.

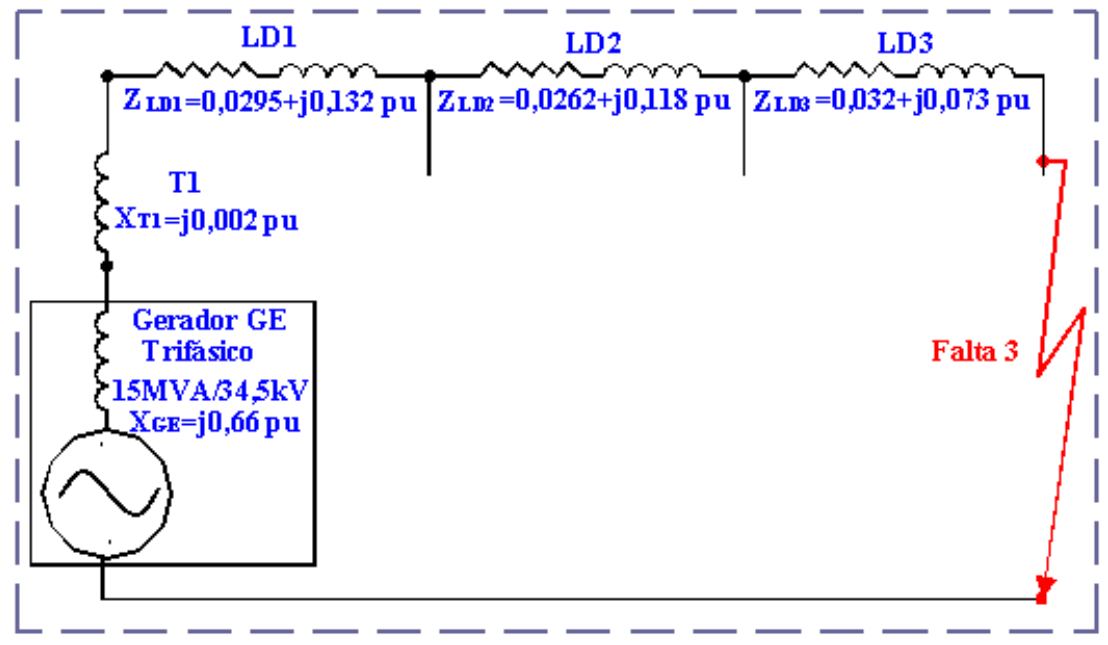

Figura 5.9 - Metodologia Convencional - Circuito resultante para Falta 3 sem gerador GD.

Na sequência, a Figura 5.10 apresenta a simplificação do circuito de impedâncias, onde $\mathrm{Z}_{\text {LDeq1 }}$ equivale à soma das impedâncias da linha de distribuição desde o gerador GE até a falta e $\mathrm{X}_{\mathrm{GET}}$ representa a soma das reatâncias do gerador equivalente da concessionária $\mathrm{X}_{\mathrm{GE}}$ mais a do transformador $\mathrm{X}_{\mathrm{T} 1}$.

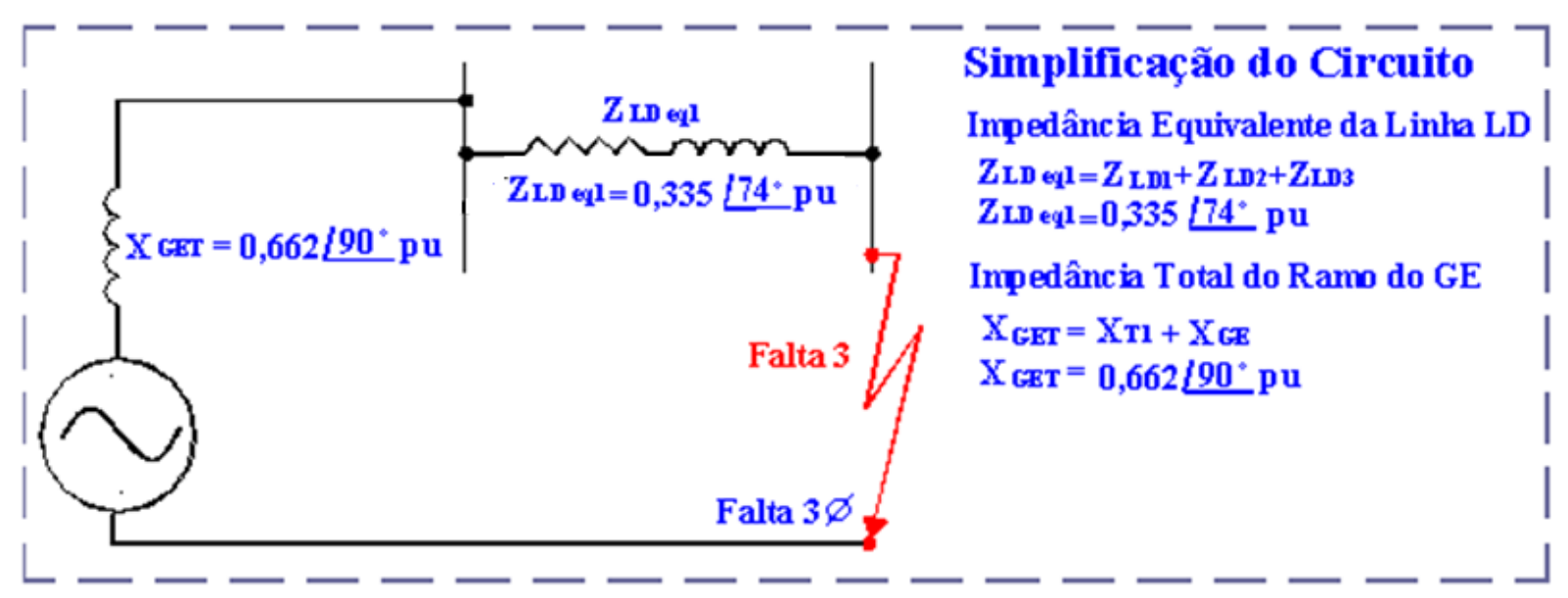

Figura 5.10 - Metodologia Convencional - Simplificação do circuito de impedâncias para Falta 3

Sistema de distribuição de energia sem Gerador GD.

Como etapa final, a Figura 5.11 apresenta o circuito com a impedância equivalente total do circuito $\mathrm{Z}_{\mathrm{eq}}$ e a tensão equivalente pré-falta do circuito $\mathrm{V}_{\mathrm{eq}}$, considerada igual a 1pu. Ainda nesta mesma figura, apresenta-se o desenvolvimento do cálculo da impedância equivalente total e a corrente de curto-circuito da Falta $3\left(\mathrm{I}_{\mathrm{F} 3}\right)$. 


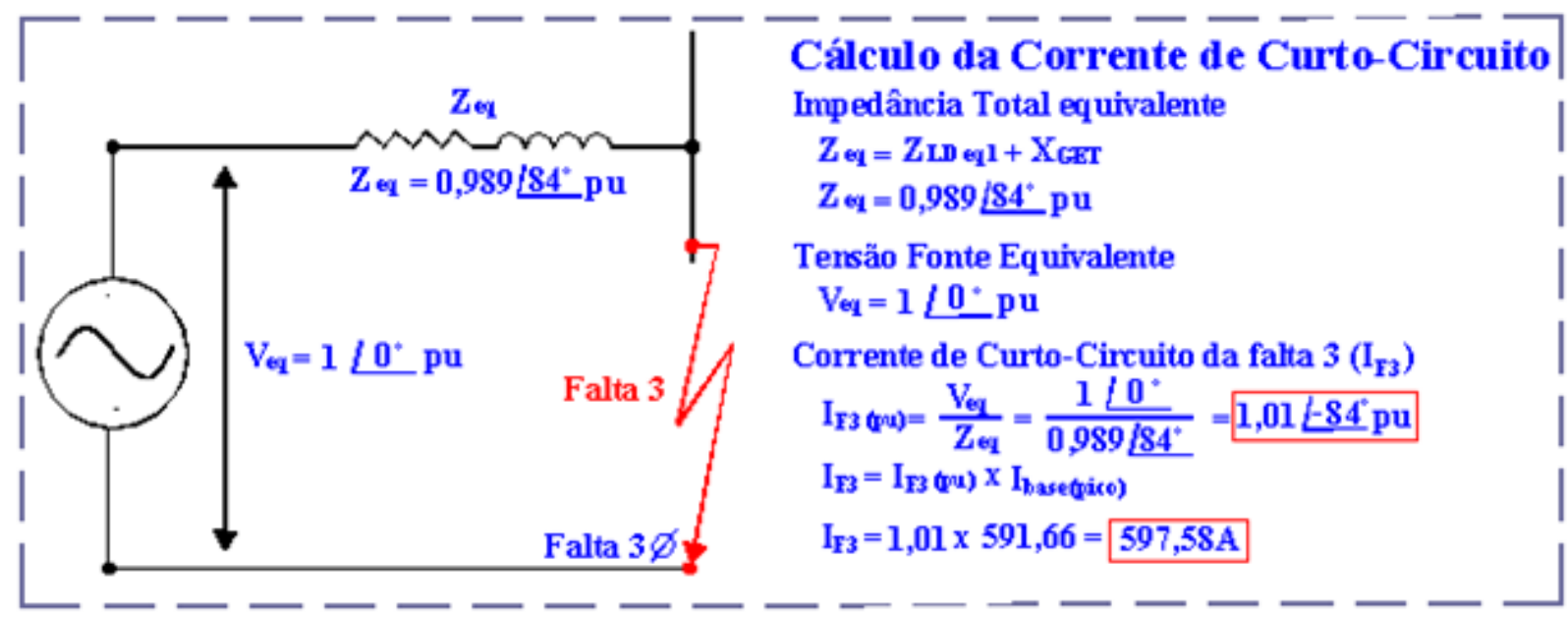

Figura 5.11 - Metodologia Convencional - Circuito resultante total e cálculo de corrente de curto-circuito para Falta 3 - Sistema de distribuição de energia sem Gerador GD.

Os cálculos dos curtos-circuitos dos demais pontos de aplicação de falta $\left(1^{\circ}\right.$ ao $\left.5^{\circ}\right)$ ilustrados na Figura 5.3 seguem a mesma sequência de procedimentos.

A Tabela 5.3 apresenta os valores obtidos dos cálculos das correntes de curto-circuito permanente, os valores de correntes de curto-circuito permanente simulados e os erros praticados nos cálculos em relação aos valores simulados (referência).

Tabela 5.3 - Valores das correntes de curto-circuito obtidos dos cálculos e simulações realizadas no Sistema de Distribuição de Energia sem o Gerador GD.

\begin{tabular}{|c|c|c|c|c|}
\hline $\begin{array}{c}\text { Local de aplicação } \\
\text { da falta }\end{array}$ & $\begin{array}{c}\text { Valor Calculado } \\
\text { (pu) }\end{array}$ & $\begin{array}{c}\text { Valor de pico } \\
\text { Calculado } \\
\text { (A) }\end{array}$ & $\begin{array}{c}\text { Valor de pico } \\
\text { Simulado } \\
\text { (A) }\end{array}$ & $\begin{array}{c}\text { Erro } \\
(\%)\end{array}$ \\
\hline Falta 1 & 1,26 & 745,49 & 727,50 & 2,47 \\
\hline Falta 2 & 1,09 & 644,91 & 635,70 & 1,45 \\
\hline Falta 3 & 1,01 & 597,58 & 591,10 & 1,10 \\
\hline Falta 4 & 0,95 & 562,08 & 560,50 & 0,28 \\
\hline Falta 5 & 0,92 & 544,33 & 540,00 & 0,80 \\
\hline
\end{tabular}

De acordo com os resultados apresentados na Tabela 5.3, os erros percentuais obtidos dos valores calculados em relação aos simulados são baixos. Em função da utilização da metodologia convencional de cálculo de corrente de curto-circuito e também por se tratar de um sistema de distribuição de energia composto por equipamentos convencionais e sem geradores baseados em inversores, esses baixos valores percentuais dos erros já eram esperados.

Conforme relatado anteriormente, os resultados obtidos dos cálculos e simulações de curtos-circuitos do sistema de distribuição SD sem o gerador distribuído GD servem de base comparativa e balizamento para as estratégias de inserção do gerador GD nos cálculos de curto-circuito desse mesmo sistema. 
As próximas seções apresentam as aplicações das duas metodologias para a inserção do gerador baseado em inversor de frequência GD nos cálculos de curto-circuito desse sistema de distribuição de energia em estudo.

\subsubsection{Aplicação da Metodologia 1 para a Inserção do Gerador Baseado em Inversor GD nos Cálculos de Corrente de Curto-Circuito}

Nesta seção, faz-se a aplicação da metodologia 1 para inserção dos geradores baseados em inversores nos cálculos de curto-circuito dos sistemas de distribuição de energia elétrica (SD).

Conforme relatado na subseção 5.2.1, o valor de reatância $\left(X_{G D}\right)$ encontrado através da equação (5.1) é referente aos valores de base do gerador GD, que são diferentes dos valores de base considerados neste estudo e relatados na Figura 5.3. De acordo com Almeida e Freitas, (1995), utiliza-se a equação (5.3) para a adequação dos valores de base das reatâncias.

$$
X_{b 2}=X_{b 1} x \frac{S_{b 2}}{S_{b 1}} x\left(\frac{V_{b 1}}{V_{b 2}}\right)^{2}
$$

Sendo:

$X_{b 1} \rightarrow$ Reatância na base anterior;

$X_{b 2} \rightarrow$ Reatância na base nova;

$S_{b 1} \rightarrow$ Potência na base anterior;

$S_{b 2} \rightarrow$ Potência na base nova;

$V_{b 1} \rightarrow$ Tensão na base anterior;

$V_{b 2} \rightarrow$ Tensão na base nova.

Seguem, portanto, as mudanças de base dos valores das reatâncias $X_{G D}$ considerando os valores de base adotados neste estudo:

Considerando a instalação do grupo gerador GD de 3 MVA.

- Estimativa para a estratégia de cálculo $\rightarrow X_{G D(1 \text { unidade })}=0,5 p u$ (na base do GD)

- Mudança para base considerada no estudo:

$X_{G D(p u)}=0,5 \times \frac{10 \times 10^{6}}{300 \times 10^{3}} \times\left(\frac{380}{380}\right)^{2} \rightarrow X_{G D}=16,67 p u$

- Considerando o grupo gerador com 10 unidades em paralelo $\rightarrow \boldsymbol{X}_{G D}=\mathbf{1}, 667 \boldsymbol{p u}$

Considerando a instalação dos grupos de geradores GD de 1,5 MVA. 
- Estimativa para a estratégia de cálculo $\rightarrow X_{G D(1 \text { unidade })}=0,5 p u$ (na base do GD)

- Mudança para base considerada no estudo:

$$
X_{G D(p u)}=0,5 \times \frac{10 \times 10^{6}}{150 \times 10^{3}} \times\left(\frac{380}{380}\right)^{2} \rightarrow X_{G D}=33,34 p u
$$

- Considerando o grupo gerador com 10 unidades em paralelo $\rightarrow \boldsymbol{X}_{\boldsymbol{G D}}=\mathbf{3}, \mathbf{3 3 4} \boldsymbol{p u}$

Os valores de $X_{G D}$ acima obtidos pelas mudanças de base são utilizados nas aplicações da metodologia 1.

\subsubsection{Aplicação da Metodologia 1 - Cálculo da Corrente de Curto-Circuito com Gerador GD no Início da Linha do Sistema de Distribuição}

Como primeira etapa, a Figura 5.12 apresenta o circuito resultante da Falta 3. Neste circuito, faz-se a inserção do GD de 3 MVA no início da linha de distribuição e negligenciamse as cargas e as linhas 4 e 5 .

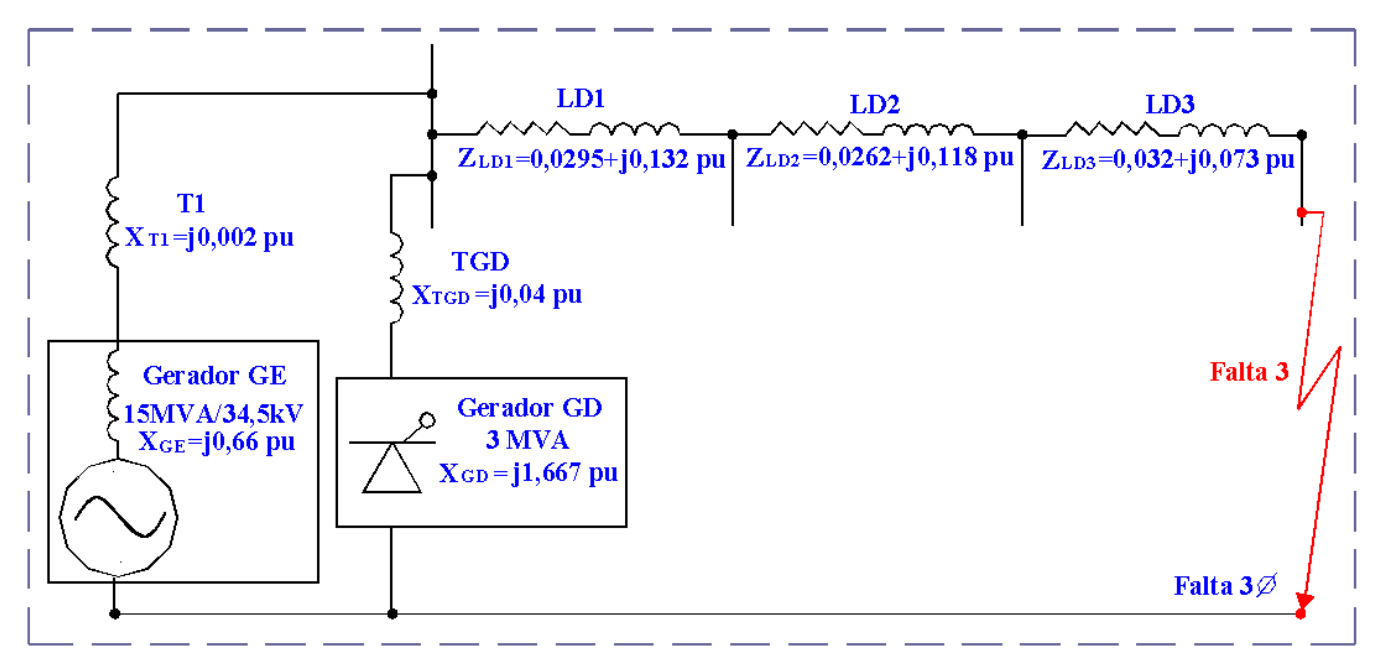

Figura 5.12 - Metodologia 1 - Circuito resultante para Falta 3 com a inserção do GD no início das linhas.

$\mathrm{Na}$ sequência, a Figura 5.13 ilustra o curto-circuito das fontes geradoras GE e GD, restando somente, as impedâncias do circuito para Falta 3. 


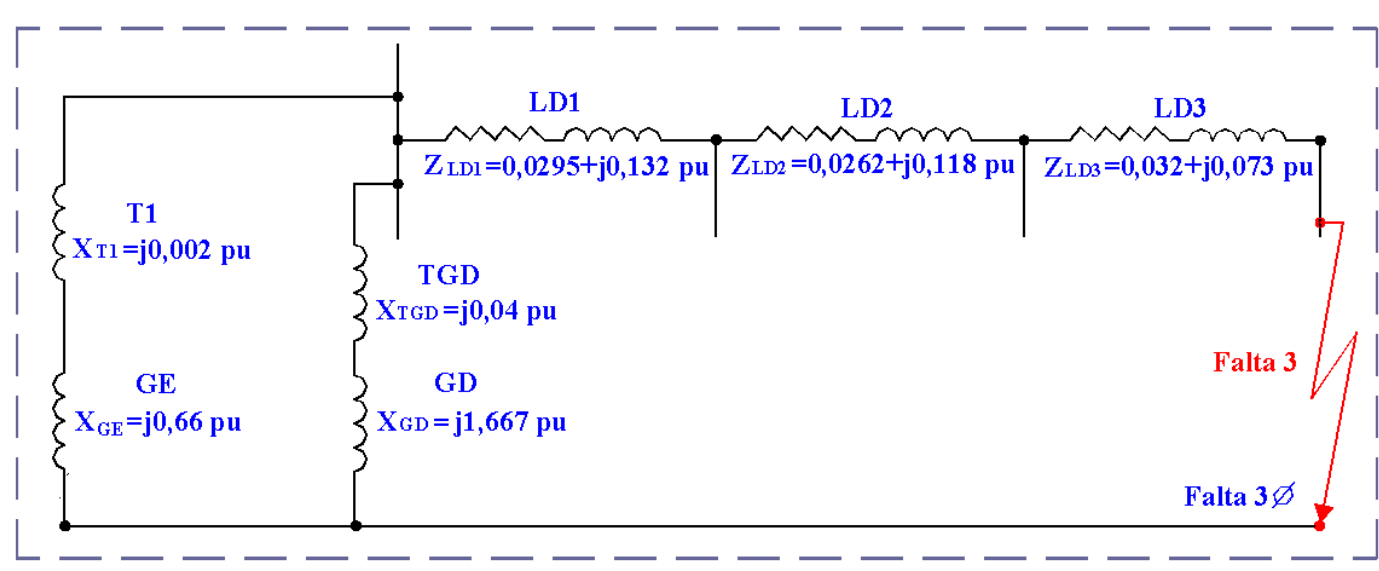

Figura 5.13 - Metodologia 1 - Diagrama de impedâncias para a Falta 3 e GD no início das linhas.

Na Figura 5.14, apresenta-se a simplificação do diagrama de impedâncias, onde $\mathrm{X}_{\mathrm{GET}}$ representa a soma das reatâncias do gerador equivalente da concessionária $X_{\mathrm{GE}} \mathrm{e}$ a do transformador $\mathrm{X}_{\mathrm{T} 1}$.

A reatância resultante da soma que foi atribuída ao gerador distribuído $\mathrm{X}_{\mathrm{GD}}$ (fundamento dessa estratégia) mais a reatância do transformador de saída do grupo gerador $\mathrm{X}_{\mathrm{TGD}}$ é chamada de $\mathrm{X}_{\mathrm{GDT}}$ e a resultante da soma das impedâncias das linhas de distribuição é chamada de $\mathrm{Z}_{\mathrm{LDeq} 1}$.

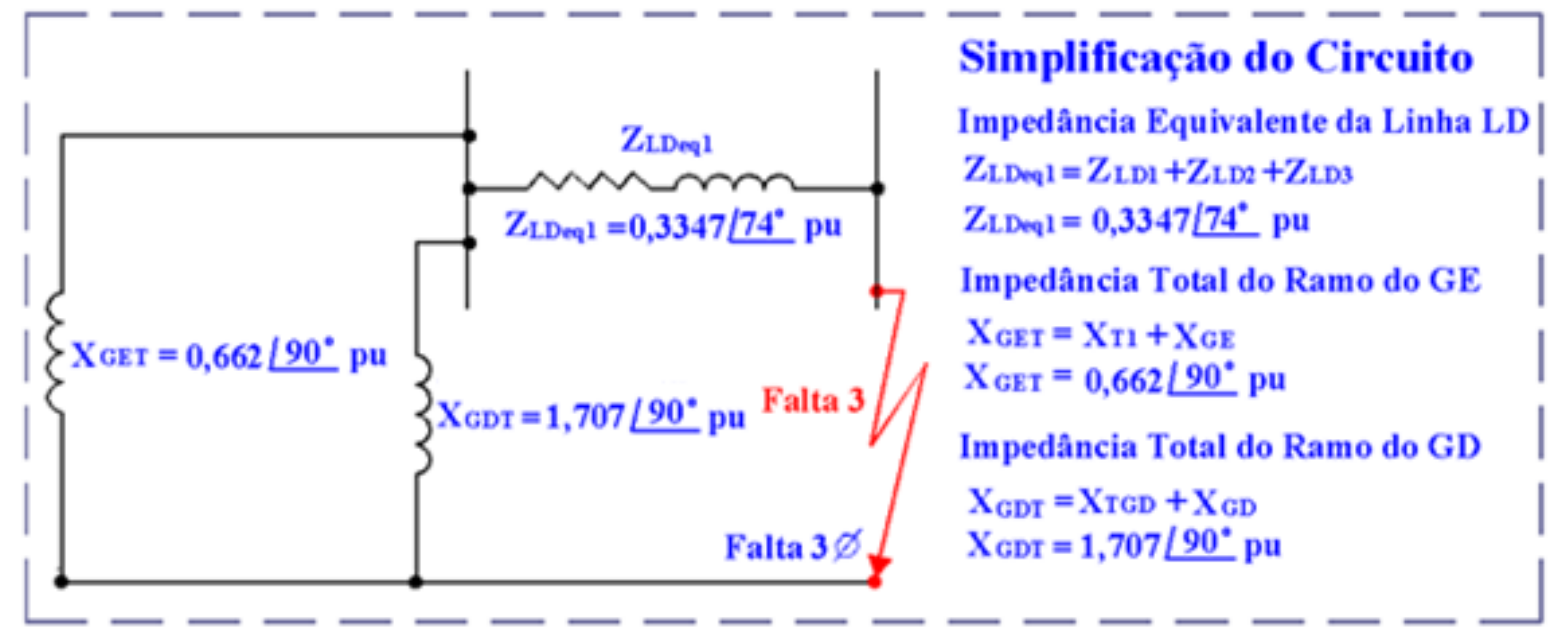

Figura 5.14 - Metodologia 1- Simplificação do diagrama de impedâncias para a Falta 3 e GD no início das linhas.

Como etapa final, a Figura 5.15 apresenta o circuito com a impedância equivalente total do circuito $\mathrm{Z}_{\text {eq }}$ e a tensão equivalente do circuito $\mathrm{V}_{\text {eq }}$, considerada igual a $1 \mathrm{pu}$. Ainda nesta mesma figura, apresentam-se os cálculos da impedância equivalente total e a corrente de curto-circuito total para a Falta $3\left(\mathrm{I}_{\mathrm{F} 3}\right)$. 


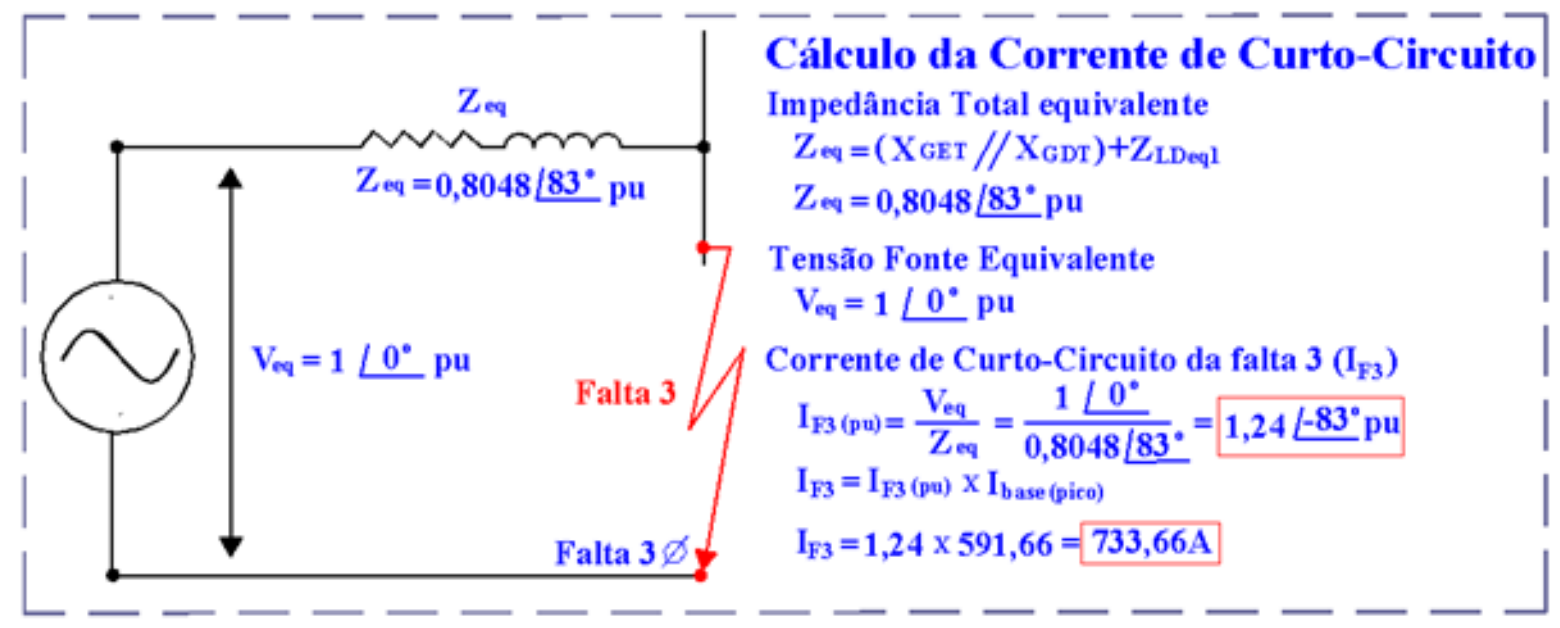

Figura 5.15 - Metodologia 1- Circuito resultante total e cálculo de corrente de curto-circuito para Falta 3 com GD no início das linhas.

\subsubsection{Aplicação da Metodologia 1 - Cálculo da Corrente de Curto-Circuito com Gerador GD no Final da Linha do Sistema de Distribuição}

Apresenta-se nesta seção, a aplicação da metodologia 1 com a inserção do grupo GD de 3 MVA no final das linhas do sistema de distribuição.

Seguindo as mesmas etapas e procedimentos apresentados no item anterior, a Figura 5.16 apresenta o circuito resultante para a Falta 3.

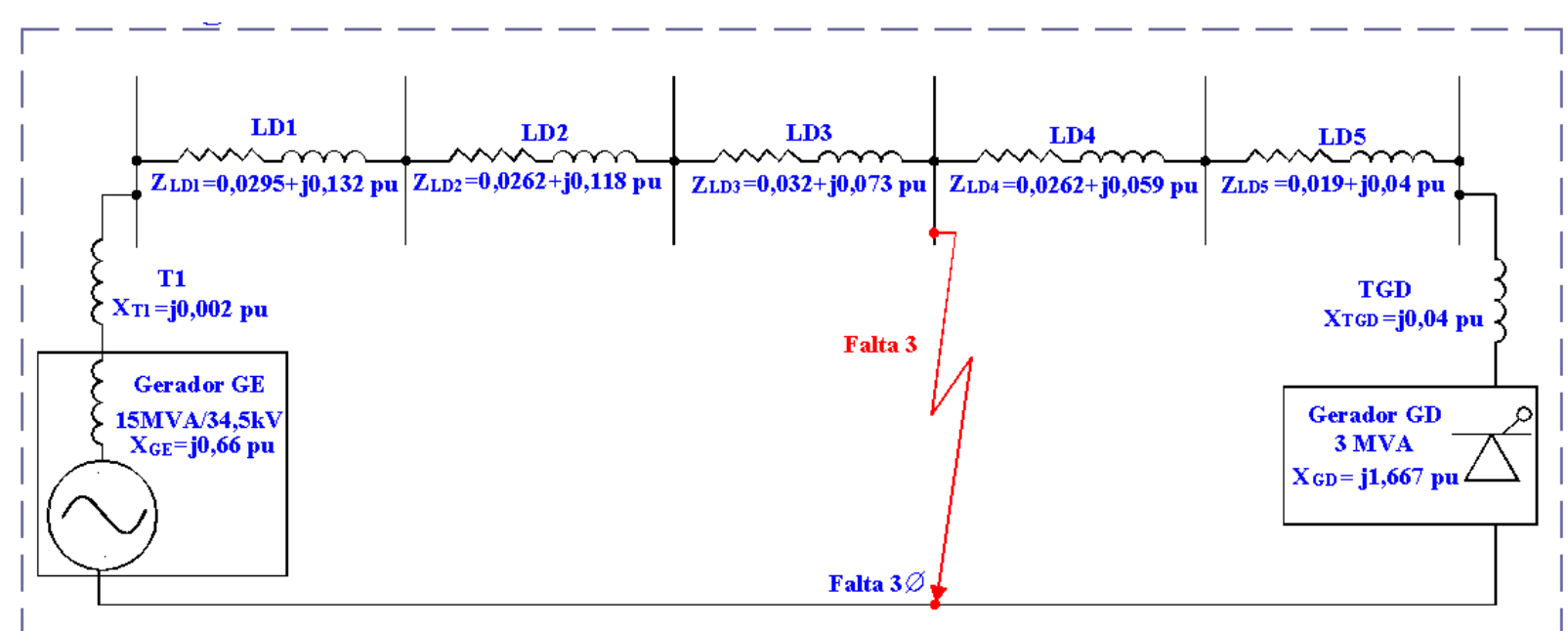

Figura 5.16 - Metodologia 1 - Circuito resultante para Falta $3 \mathrm{com}$ a inserção do GD no final das linhas.

A Figura 5.17 ilustra o diagrama de impedâncias para a Falta 3 com GD de 3MVA no final das linhas. 


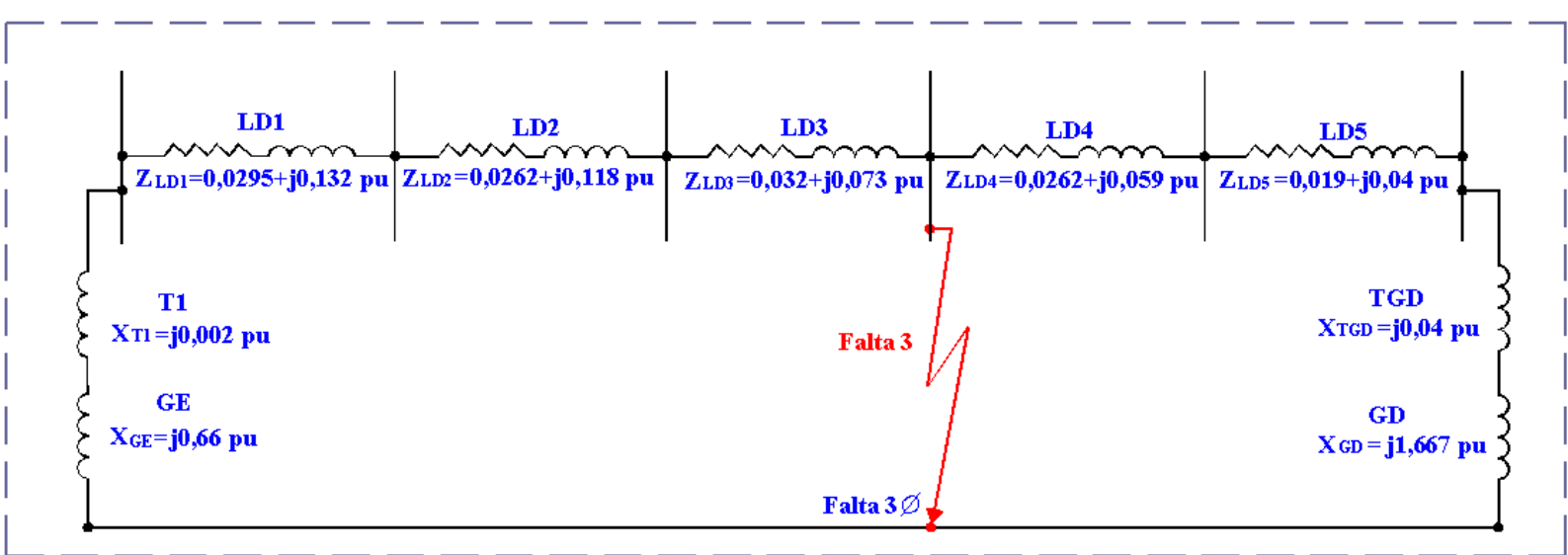

Figura 5.17 - Diagrama de impedâncias para a Falta 3 e GD no final das linhas.

Na sequência, a Figura 5.18 ilustra a simplificação do circuito de impedâncias com a apresentação dos cálculos de $\mathrm{X}_{\mathrm{GET}}, \mathrm{X}_{\mathrm{GDT}}, \mathrm{X}_{\mathrm{TGD}}, \mathrm{Z}_{\mathrm{LDeq} 1}$ e $\mathrm{Z}_{\mathrm{LDeq} 2}$.

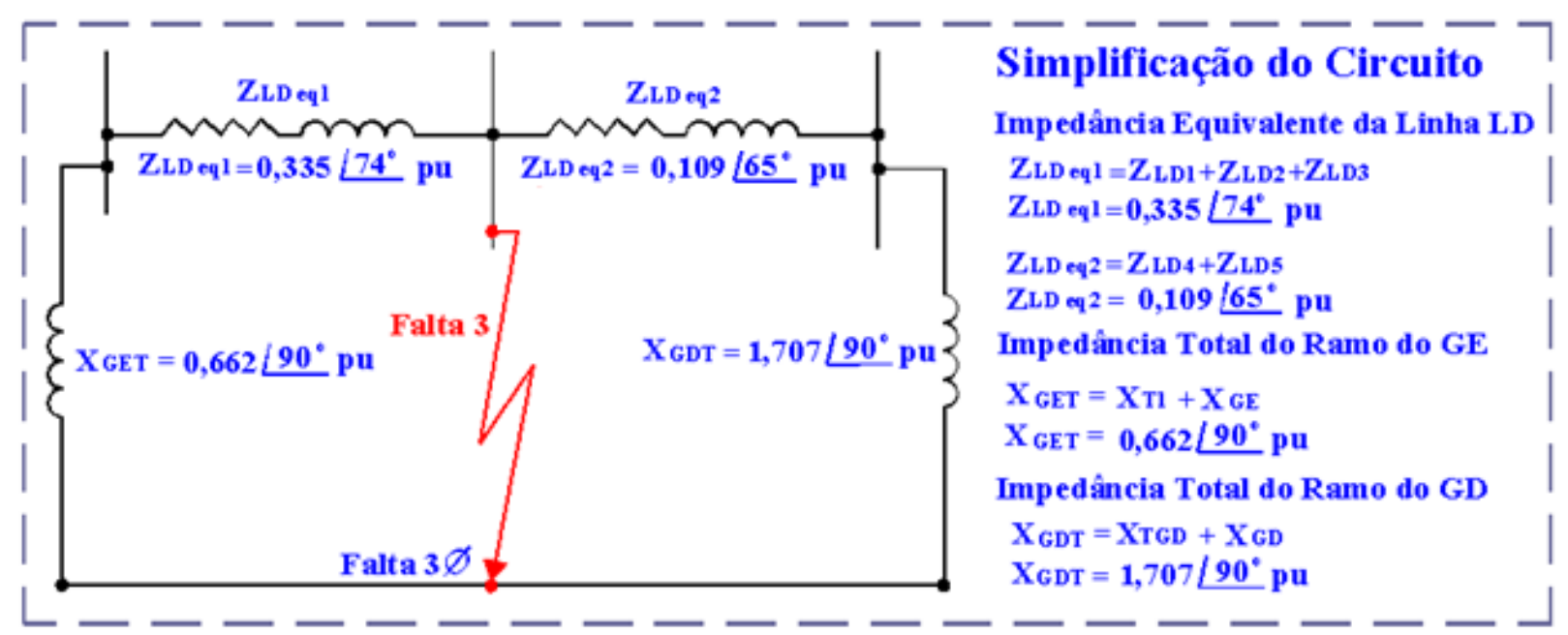

Figura 5.18 - Simplificação do diagrama de impedâncias para Falta 3 e GD no final das linhas.

Por fim, a Figura 5.19 ilustra o circuito e os cálculos da impedância equivalente total e corrente de curto-circuito da Falta 3 ( $\mathrm{I}_{\mathrm{F} 3}$ ) com GD de 3MVA no final das linhas de distribuição. 


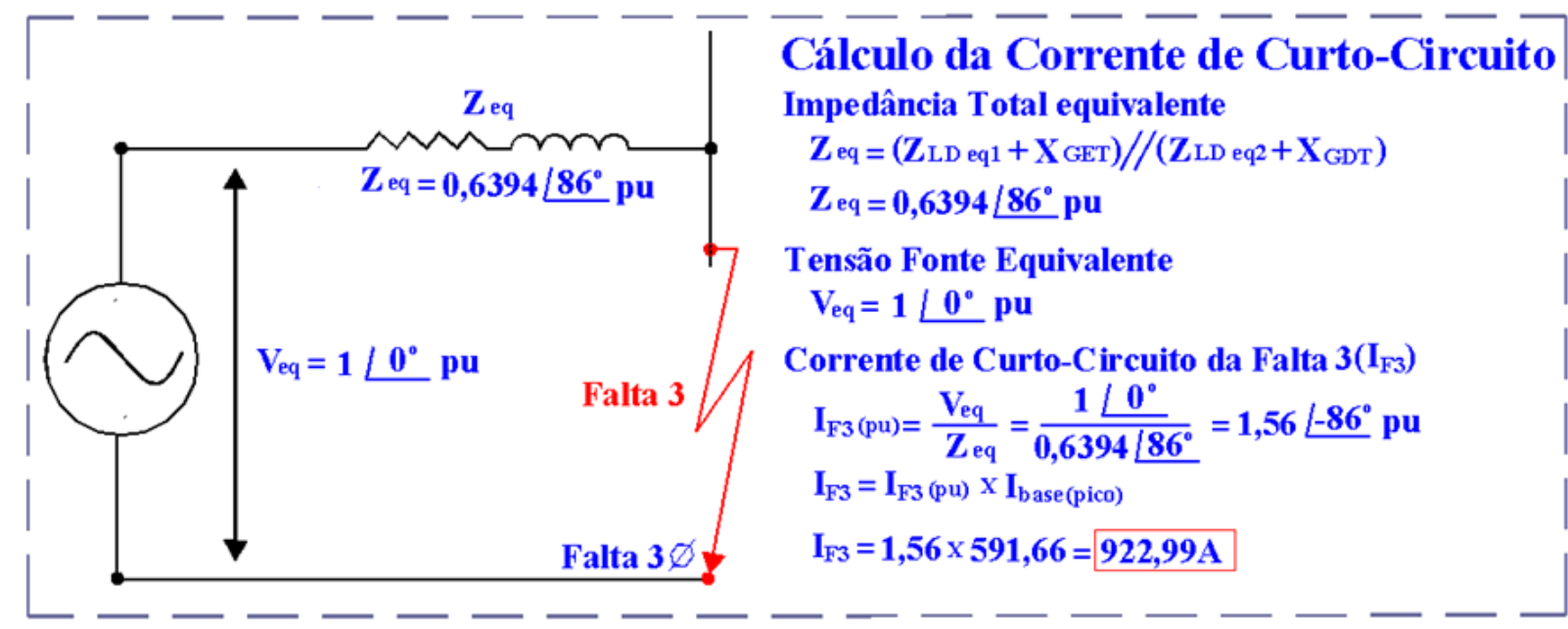

Figura 5.19 - Metodologia 1 - Circuito resultante total e cálculo de corrente de curto-circuito para Falta 3 com GD no final das linhas.

\subsubsection{Aplicação da Metodologia 1 - Cálculo da Corrente de Curto-Circuito Com Dois Geradores Distribuídos}

Apresenta-se nesta seção, a aplicação da metodologia 1 com a inserção de dois grupos GDs de 1,5 MVA cada, sendo GD1 no início da linha e GD2 no final da linha do sistema de distribuição.

A Figura 5.20 apresenta o sistema resultante para a Falta 3 e dois geradores de 1,5 MVA instalados.

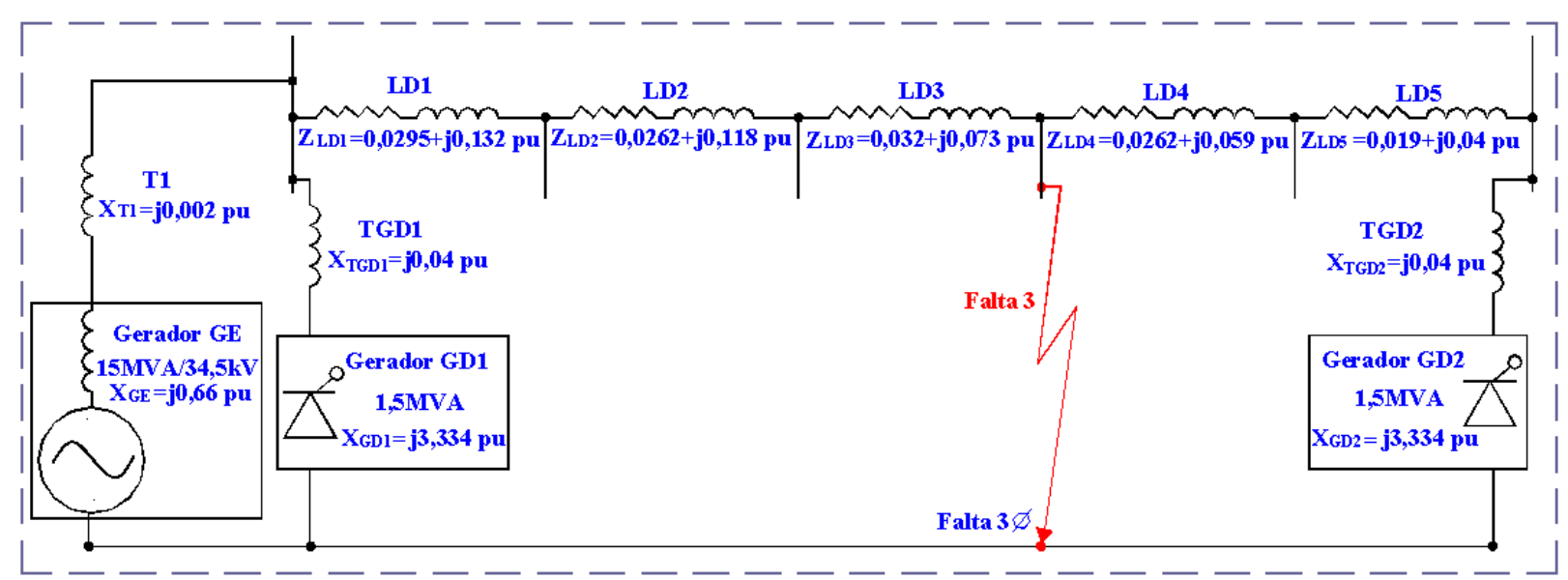

Figura 5.20 - Metodologia 1 - Circuito de resultante para a Falta 3 e dois GDs instalados.

A Figura 5.21 ilustra o diagrama de impedâncias para a Falta 3, sendo $\mathrm{X}_{\mathrm{TGD} 1}$ a reatância do transformador do gerador GD1, $\mathrm{X}_{\mathrm{GD} 1}$ a reatância interna do gerador GD1, $\mathrm{X}_{\mathrm{TGD} 2}$ a reatância do transformador do gerador GD2 e $\mathrm{X}_{\mathrm{GD} 2}$ a reatância interna do gerador GD2. 


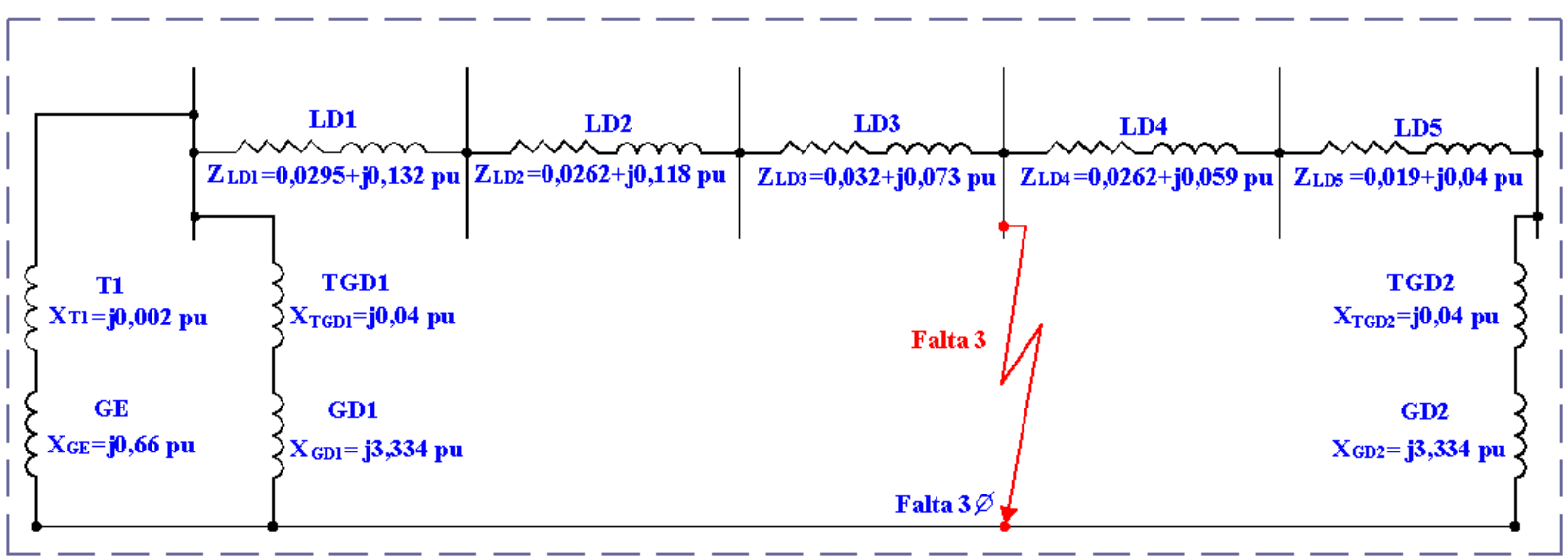

Figura 5.21 - Metodologia 1 - Diagrama de impedâncias para a Falta 3 e dois GDs instalados.

Na sequência, a Figura 5.22 ilustra a simplificação do diagrama de impedâncias e os cálculos de $\mathrm{X}_{\mathrm{GD} 1 \mathrm{~T}}$, que representa a reatância total do ramo do gerador GD1, $\mathrm{X}_{\mathrm{GD} 2 \mathrm{~T}}$ a reatância total do ramo do gerador GD2 e os cálculos dos valores das reatâncias e impedâncias, anteriormente definidas, $\mathrm{X}_{\mathrm{GET}}, \mathrm{X}_{\mathrm{TGD}}, \mathrm{Z}_{\mathrm{LDeq} 1} \mathrm{e} \mathrm{Z}_{\mathrm{LDeq} 2}$.

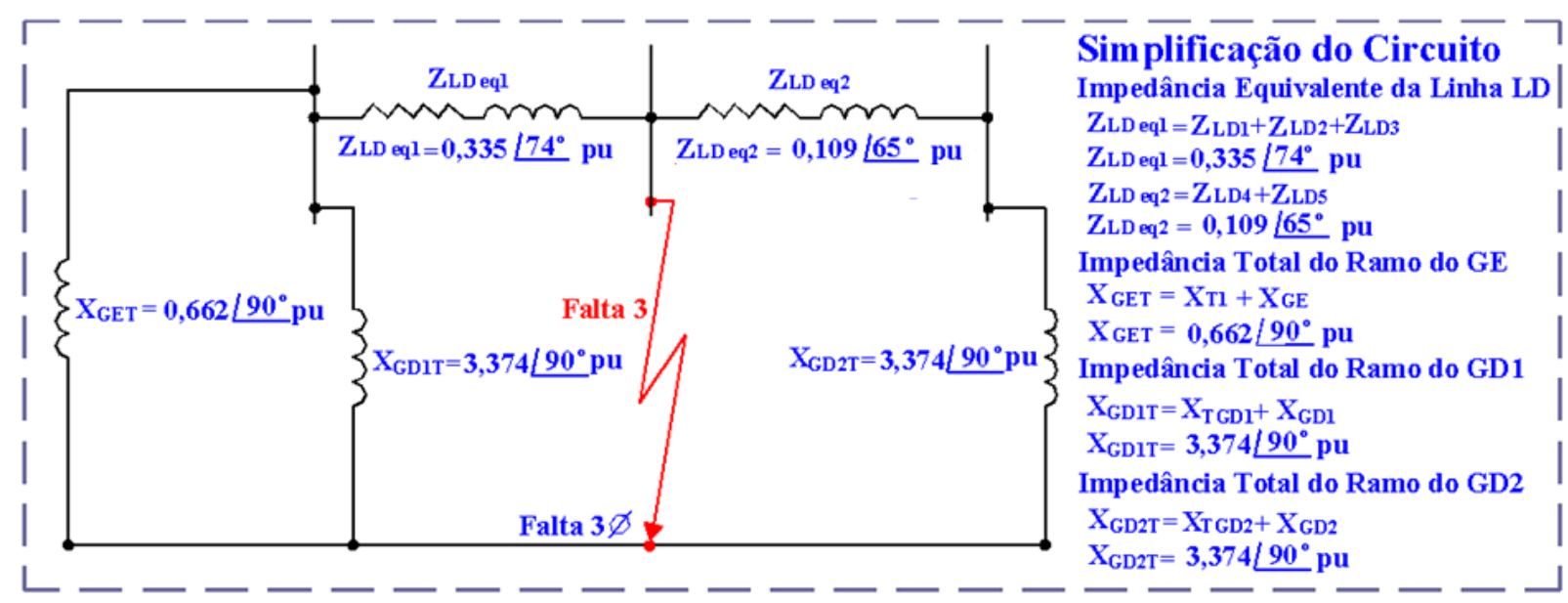

Figura 5.22 - Metodologia 1 - Simplificação do diagrama de impedâncias para Falta 3 com dois GDs instalados.

Por fim, a Figura 5.23 ilustra o diagrama e os cálculos da impedância equivalente total $\left(\mathrm{Z}_{\mathrm{eq}}\right)$ e corrente de curto-circuito da Falta $3\left(\mathrm{I}_{\mathrm{F} 3}\right)$. 


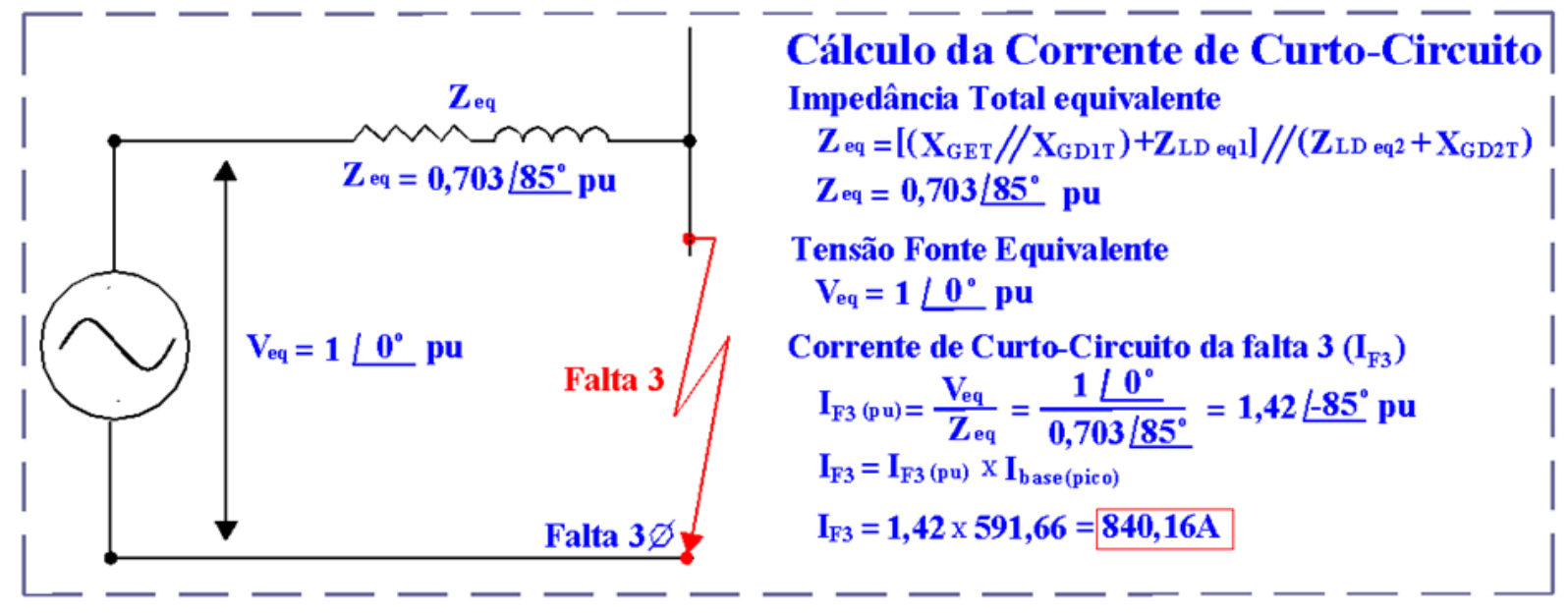

Figura 5.23 - Metodologia 1 - Circuito resultante total e cálculo de corrente de curto-circuito para Falta 3 com dois GDs instalados.

Os demais pontos de aplicação de falta seguem a mesma sequência de procedimentos adotados pela metodologia 1 e estão dispostos na Tabela 5.4 à 5.6.

\subsubsection{Análise dos Resultados da Metodologia 1 para Inserção dos Geradores Baseados em Inversores nos Cálculos de Curto-Circuito}

Após a inserção do gerador distribuído GD no sistema de distribuição de energia elétrica ilustrado na Figura 5.3, apresenta-se a seguir, em forma de tabelas, a síntese dos resultados obtidos dos cálculos, das simulações e os erros praticados nos cálculos em relação aos valores simulados (referência). Considerando-se que a norma IEC 60909, de forma conservadora, admite a tensão pré-falta de 1,1 pu (10\% superior ao nominal), este trabalho também admite o erro percentual de $10 \%$ na aplicação da metodologia proposta como aceitável no contexto da engenharia. Além disso, atribui-se o sinal negativo para os erros praticados em situações cujos valores calculados são inferiores aos simulados.

A Tabela 5.4 apresenta os resultados que consideram o grupo gerador GD de 3 MVA instalado no início das linhas do sistema de distribuição de energia. A coluna "Valor de pico calculado" apresenta os valores calculados segundo a metodologia 1, ao passo que a coluna "Valor de pico simulado" refere-se aos valores das correntes de falta simulados. Ressalta-se neste ponto que as comparações foram realizadas em relação aos valores das correntes de curto-circuito em regime, pois na metodologia proposta o curto-circuito não foi calculado considerando as reatâncias de regime subtransitório e transitório do gerador equivalente da concessionária. No entanto isso não invalida a metodologia proposta, pois para considerar os efeitos subtransitório e transitório da corrente de falta, basta utilizar os respectivos valores dessas reatâncias para os outros geradores, deixando o GD com a reatância calculada 
conforme proposto na metodologia 1. Esta consideração vale para todas as análises apresentadas neste capítulo, deste ponto em diante.

Tabela 5.4 - Valores das correntes de curtos-circuitos obtidos das simulações e cálculos realizados através da aplicação da metodologia 1 com a inserção do gerador GD no início das linhas.

\begin{tabular}{|c|c|c|c|c|}
\hline $\begin{array}{c}\text { Local de aplicação } \\
\text { da falta }\end{array}$ & $\begin{array}{c}\text { Valor calculado } \\
\text { (pu) }\end{array}$ & $\begin{array}{c}\text { Valor de pico } \\
\text { calculado } \\
\text { (A) }\end{array}$ & $\begin{array}{c}\text { Valor de pico } \\
\text { simulado } \\
\text { (A) }\end{array}$ & $\begin{array}{c}\text { Erro } \\
\text { (\%) }\end{array}$ \\
\hline Falta 1 & 1,64 & 970,32 & 944,90 & 2,69 \\
\hline Falta 2 & 1,37 & 810,57 & 833,10 & $-2,70$ \\
\hline Falta 3 & 1,24 & 733,66 & 772,60 & $-5,04$ \\
\hline Falta 4 & 1,15 & 680,41 & 731,60 & $-7,00$ \\
\hline Falta 5 & 1,10 & 650,83 & 702,70 & $-7,38$ \\
\hline
\end{tabular}

Verifica-se na Tabela 5.4 que a instalação do gerador distribuído no início das linhas de distribuição de energia proporciona erros menores que 10\%, entretanto, observa-se que a partir da Falta 2 os valores calculados são inferiores aos valores simulados. Este fato pode comprometer a segurança da aplicação dessa estratégia em projetos que envolvam dimensionamentos de equipamentos elétricos e proteção.

Como forma viabilizar sua utilização, efetua-se, assim como normalmente se faz em projetos e nos dimensionamentos em geral, a multiplicação por um fator de segurança $\left(\mathrm{F}_{\mathrm{S}}\right)$ dos cálculos de curtos-circuitos que envolvam a metodologia 1, nas condições em que ocorra o compartilhamento de condutores pelas correntes de falta do GE e GD. No caso específico desse estudo com alto nível de penetração do gerador GD (20\% do GE), sugere-se FS com valor de 1,1 , ou seja, valor de curto-circuito calculado mais $10 \%$.

A Tabela 5.5 apresenta os resultados que consideram o grupo gerador GD de 3 MVA instalado no final das linhas do sistema de distribuição de energia.

Tabela 5.5 - Valores das correntes de curtos-circuitos obtidos das simulações e cálculos realizados através da aplicação da metodologia 1 com a inserção do gerador GD no final das linhas.

\begin{tabular}{|c|c|c|c|c|}
\hline $\begin{array}{c}\text { Local de aplicação } \\
\text { da falta }\end{array}$ & $\begin{array}{c}\text { Valor calculado } \\
\text { (pu) }\end{array}$ & $\begin{array}{c}\text { Valor de pico } \\
\text { calculado } \\
\text { (A) }\end{array}$ & $\begin{array}{c}\text { Valor de pico } \\
\text { simulado } \\
\text { (A) }\end{array}$ & $\begin{array}{c}\text { Erro } \\
\text { (\%) }\end{array}$ \\
\hline Falta 1 & 1,76 & 1041,32 & 982,30 & 6,00 \\
\hline Falta 2 & 1,63 & 964,41 & 892,30 & 8,08 \\
\hline Falta 3 & 1,56 & 922,99 & 848,00 & 8,84 \\
\hline Falta 4 & 1,52 & 899,32 & 817,00 & 10,08 \\
\hline Falta 5 & 1,50 & 887,49 & 796,00 & 11,49 \\
\hline
\end{tabular}

De acordo com os resultados apresentados na Tabela 5.5, verifica-se que os erros praticados pelos cálculos também são pequenos. Além disso, observa-se que todos os valores 
de corrente de falta calculados superam os valores obtidos das simulações. Este fato exclui a necessidade de aplicação de fator de segurança (Fs) e viabiliza a utilização da metodologia 1 em projetos e dimensionamentos que envolvam o cálculo de corrente de curto-circuito nas condições em que não ocorra o compartilhamento de condutores pelas correntes de falta oriundas do GE e GD.

A Tabela 5.6 apresenta os resultados que consideram dois grupos geradores GDs de 1,5 MVA cada, sendo GD 1 instalado no início das linhas e GD 2 instalado no final das linhas do sistema de distribuição de energia.

Tabela 5.6 - Valores das correntes de curtos-circuitos obtidos dos cálculos e simulações realizadas no Sistema de Distribuição de Energia com aplicação da metodologia 1 para inserção de dois grupos geradores de 1,5 MVA.

\begin{tabular}{|c|c|c|c|c|}
\hline $\begin{array}{c}\text { Local de aplicação } \\
\text { da falta }\end{array}$ & $\begin{array}{c}\text { Valor calculado } \\
(\mathbf{p u})\end{array}$ & $\begin{array}{c}\text { Valor de pico } \\
\text { calculado } \\
\text { (A) }\end{array}$ & $\begin{array}{c}\text { Valor de pico } \\
\text { simulado } \\
(\mathbf{A})\end{array}$ & $\begin{array}{c}\text { Erro } \\
(\mathbf{\%})\end{array}$ \\
\hline Falta 1 & 1,73 & 1023,57 & 965,10 & 6,06 \\
\hline Falta 2 & 1,52 & 899,32 & 862,60 & 4,26 \\
\hline Falta 3 & 1,42 & 840,16 & 809,30 & 3,81 \\
\hline Falta 4 & 1,35 & 798,74 & 772,70 & 3,37 \\
\hline Falta 5 & 1,31 & 775,07 & 750,80 & 3,23 \\
\hline
\end{tabular}

Verifica-se na Tabela 5.6 que os erros praticados pelos cálculos de curtos-circuitos em relação aos valores simulados são pequenos. Além disso, observa-se que os valores calculados superaram os simulados.

Em síntese geral, a metodologia 1 se apresenta com facilidade de entendimento e aplicação. Considerando o alto nível de penetração do GD (20\% da capacidade do GE) no sistema de distribuição de energia em estudo, entende-se que os erros percentuais praticados pela aplicação dessa metodologia de inserção do GD nos cálculos de corrente de curtocircuito são muito baixos.

O melhor desempenho de aplicação dessa metodologia está nos cálculos de curtos-circuitos em que o gerador GD não está na barra da subestação. Em outra situação, a aplicação de fator de segurança nos cálculos viabiliza a utilização da metodologia 1. 


\subsubsection{Aplicação da Metodologia 2 para Inserção do Gerador Baseado em Inversor nos Cálculos de Corrente de Curto-Circuito}

Nesta seção, faz-se a aplicação da metodologia 2 para inserção dos geradores baseados em inversores nos cálculos de curto-circuito dos sistemas de distribuição de energia elétrica (SD).

Conforme relatado na subseção 5.2.2, os valores de reatância $\left(X_{G D}\right)$, corrente de curtocircuito $\left(I_{C C G D}\right)$ e tensão equivalente pré-falta de saída do gerador $\left(V_{G D}\right)$ devem ser adaptados e referenciados aos valores de base desse estudo. Utiliza-se a equação (5.3) para a mudança de base das impedâncias e a equação (5.4) para a mudança de base da corrente (Almeida; Freitas, 1995).

$$
I_{b 2}=I_{b 1} x \frac{V_{b 2}}{V_{b 1}} x \frac{S_{b 1}}{S_{b 2}}
$$

Sendo:

$I_{b 1} \rightarrow$ Corrente na base anterior;

$I_{b 2} \rightarrow$ Corrente na base nova;

$S_{b 1} \rightarrow$ Potência na base anterior;

$S_{b 2} \rightarrow$ Potência na base nova;

$V_{b 1} \rightarrow$ Tensão na base anterior;

$V_{b 2} \rightarrow$ Tensão na base nova.

Seguem, portanto, as mudanças dos valores de reatância e corrente de acordo com os valores de base adotados nesse estudo:

Considerando a instalação do grupo gerador GD de 3 MVA.

- Reatância interna do gerador GD $\left(X_{G D}\right)$

Estimativa para a estratégia de cálculo $\rightarrow X_{G D(1 \text { unidade })}=1 p u$ (na base do GD).

Mudando para base considerada no estudo:

$X_{G D(p u)}=1 \times \frac{10 \times 10^{6}}{300 \times 10^{3}} \times\left(\frac{380}{380}\right)^{2} \rightarrow X_{G D}=33,34 p u$

Considerando 10 unidades em paralelo $\rightarrow \boldsymbol{X}_{G D}=\mathbf{3 , 3 3 4} \boldsymbol{p u}$

- Corrente de falta do gerador GD (ICCGD)

Estimativa para a estratégia de cálculo $\rightarrow I_{C C G D}=2 p u$ (na base do GD). 
Mudando para base considerada no estudo:

$$
I_{C C G D(p u)}=2 x \frac{380}{380} \times \frac{300 \times 10^{3}}{10 \times 10^{6}} \rightarrow I_{C C G D(p u)}=\mathbf{0 , 0 6} \mathbf{p u}
$$

Considerando 10 unidades em paralelo $\rightarrow \boldsymbol{I}_{\boldsymbol{C C G D}}=\mathbf{0 , 6} \mathbf{p u}$

Considerando os valores do GD referenciados às novas bases, sendo $X_{G D}=3,334 p u$ e $I_{C C G D}=0,6 \mathbf{p u}$, obtém-se, na transformação de fonte de corrente em fonte de tensão, também o valor de tensão pré-falta $\boldsymbol{V}_{\boldsymbol{G} D}=\mathbf{2} \boldsymbol{p} \boldsymbol{u}$, conforme Figura 5.24.

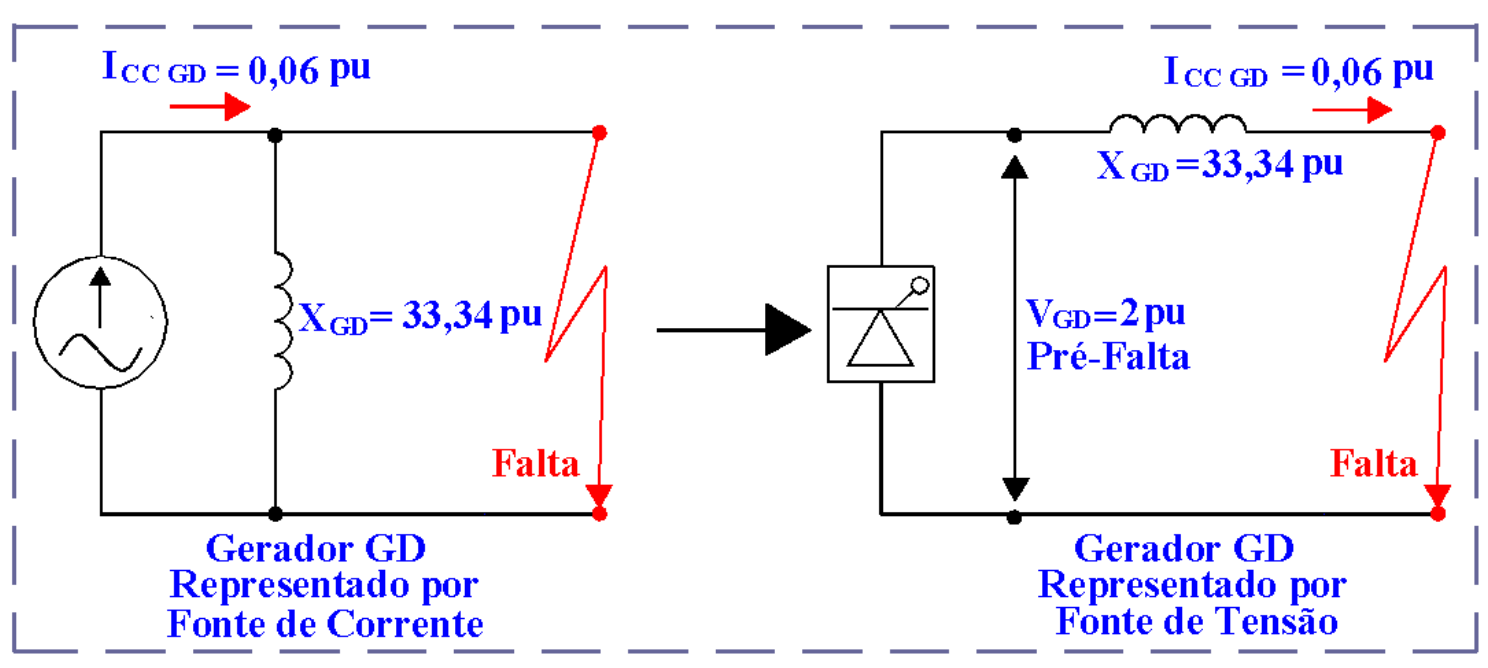

Figura 5.24 - Transformação da fonte de corrente em fonte de tensão sob condição de falta, conforme valores das bases consideradas no estudo - Unidade do GD de 0,3 MVA.

Considerando a instalação dos grupos de geradores GD de 1,5 MVA.

\section{- Reatância interna do gerador GD $\left(X_{G D}\right)$}

Estimativa para a estratégia de cálculo $\rightarrow X_{G D(1 \text { unidade })}=1 p u$ (na base do GD).

Mudando para base considerada no estudo:

$X_{G D(p u)}=1 \times \frac{10 \times 10^{6}}{150 \times 10^{3}} x\left(\frac{380}{380}\right)^{2} \rightarrow X_{G D}=66,67 p u$

Considerando 10 unidades em paralelo $\rightarrow \boldsymbol{X}_{G D}=\mathbf{6 , 6 6 7} \boldsymbol{p u}$

\section{- Corrente de falta do gerador GD ( $\left.I_{C C G D}\right)$}

Estimativa para a estratégia de cálculo $\rightarrow I_{C C G D}=2 p u$ (na base do GD).

Mudando para base considerada no estudo:

$I_{C C G D(p u)}=2 x \frac{380}{380} \times \frac{150 \times 10^{3}}{10 \times 10^{6}} \rightarrow I_{C C G D(p u)}=\mathbf{0 , 0 3} \boldsymbol{p u}$

Considerando 10 unidades em paralelo $\rightarrow \boldsymbol{I}_{\boldsymbol{C C G D}}=\mathbf{0 , 3} \mathbf{p u}$ 
Considerando os valores do GD referenciados às novas bases, sendo $\boldsymbol{X}_{G D}=\mathbf{6 , 6 6 7} \mathbf{p u} \mathrm{e}$ $I_{C C G D}=0,3 \mathbf{p u}$, obtém-se, na transformação de fonte de corrente em fonte de tensão, também o valor de tensão pré-falta $\boldsymbol{V}_{\boldsymbol{G} D}=\mathbf{2} \boldsymbol{p u}$, conforme Figura 5.25.

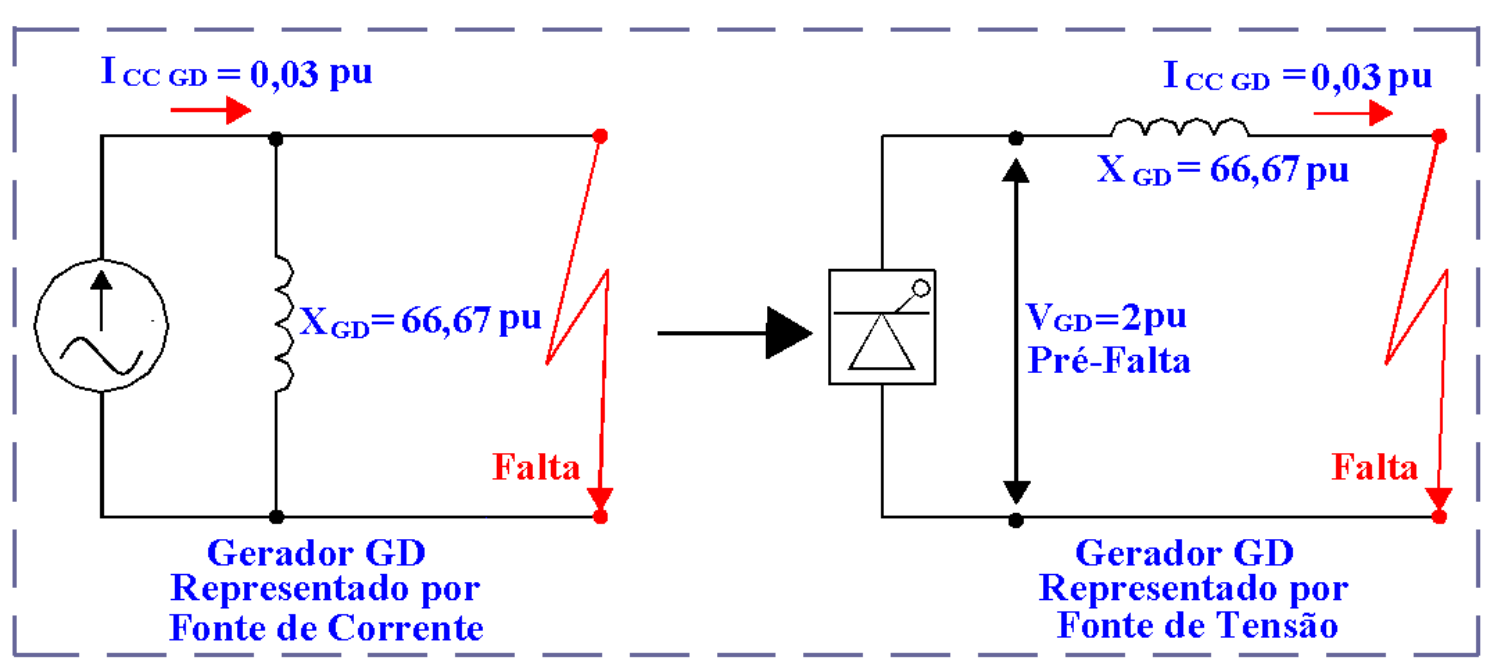

Figura 5.25 - Transformação da fonte de corrente em fonte de tensão sob condição de falta, conforme valores das bases consideradas no estudo - Unidade do GD de 0,15 MVA.

\subsubsection{Aplicação da Metodologia 2 - Cálculo da Corrente de Curto-Circuito com Gerador GD no Início da Linha do Sistema de Distribuição}

Apresenta-se nesta seção a aplicação da metodologia 2 com a inserção do gerador GD no início das linhas do sistema de distribuição de energia elétrica ilustrado na Figura 5.3. Assim como nas aplicações da metodologia anterior, apresenta-se a seguir os cálculos para a aplicação da Falta 3.

Na Figura 5.26 apresenta-se o circuito resultante para ocorrência da Falta 3. Neste circuito, faz-se a inserção do gerador GD com o valor da reatância estabelecido pela proposta dessa estratégia e adaptado aos valores de base desse estudo. 


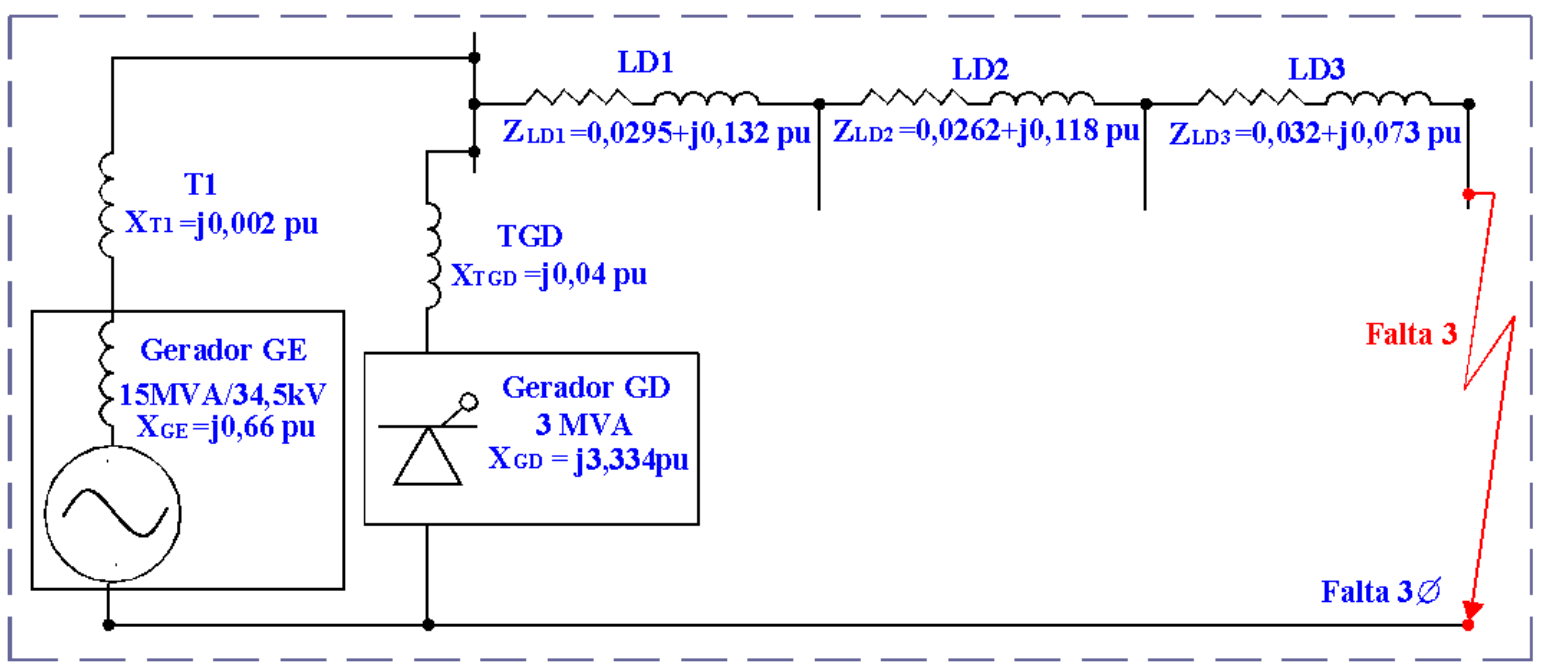

Figura 5.26 - Metodologia 2 GD no início das linhas - Circuito resultante para Falta 3.

Aplicando-se o Teorema da Superposição, a Figura 5.27 ilustra a simplificação do circuito que considera exclusivamente a contribuição do gerador equivalente da concessionária (GE) e os cálculos das impedâncias equivalentes totais dos ramos da linha de distribuição $\left(Z_{\mathrm{LDeq1}}\right)$, do gerador equivalente da concessionária (X $\left.\mathrm{X}_{\mathrm{GET}}\right)$ e do gerador distribuído GD (X $\mathrm{XDT}$ ).

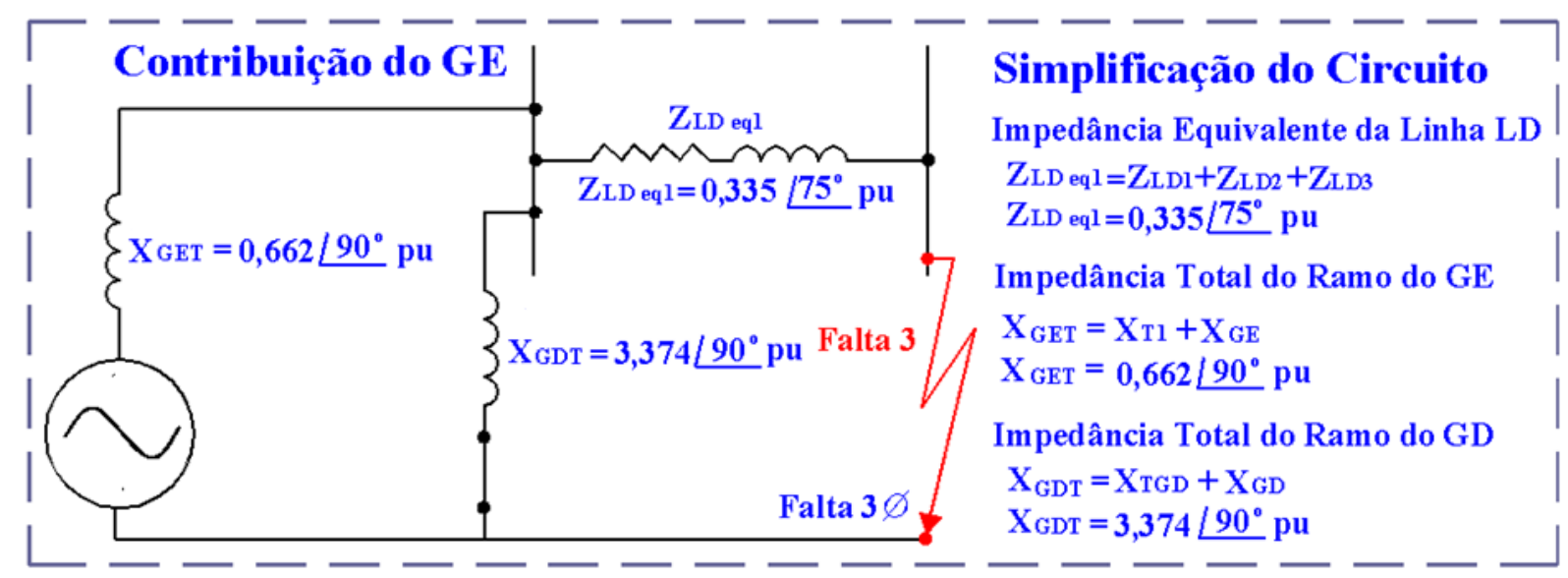

Figura 5.27 - Metodologia 2 GD no início das linhas - Simplificação do circuito considerando a contribuição do gerador GE.

Na sequência de desenvolvimento do circuito, a Figura 5.28 apresenta o circuito resultante total que considera a operação exclusiva do GE e os cálculos da impedância total equivalente $\left(\mathrm{Z}_{\mathrm{eq}}\right)$, corrente total fornecida pelo $\mathrm{GE}\left(\mathrm{I}_{\mathrm{TGE}}\right)$ e a parcela de contribuição de corrente do GE para a Falta 3 (I $\mathrm{I}_{\mathrm{F} 3 \mathrm{GE}}$ ). 


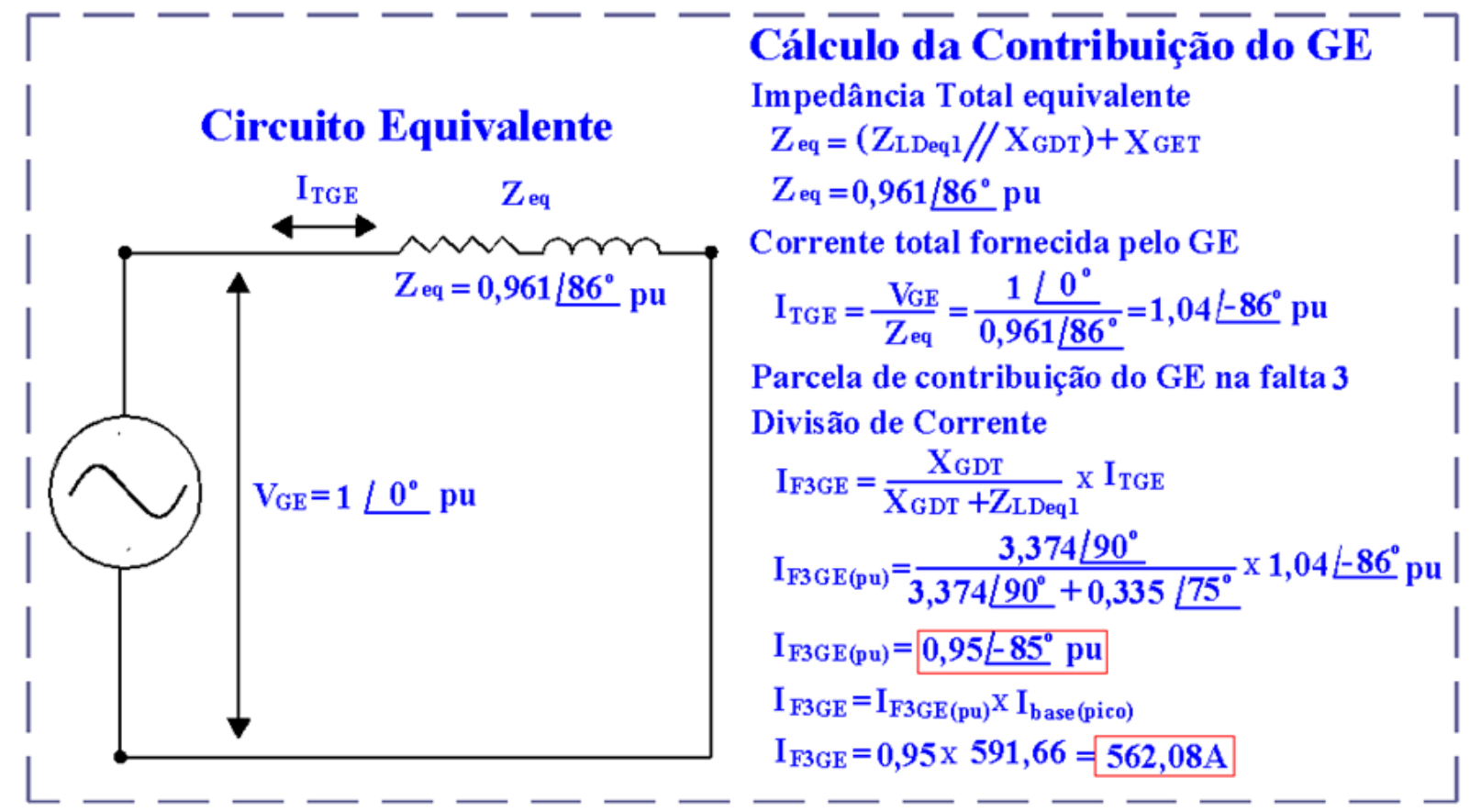

Figura 5.28 - Metodologia 2 GD no início das linhas - Circuito equivalente total e cálculo da contribuição do gerador GE para a corrente de Falta 3.

Considerando somente a contribuição do gerador distribuído, a Figura 5.29 apresenta a simplificação do circuito e os cálculos das impedâncias totais resultantes em cada ramo.

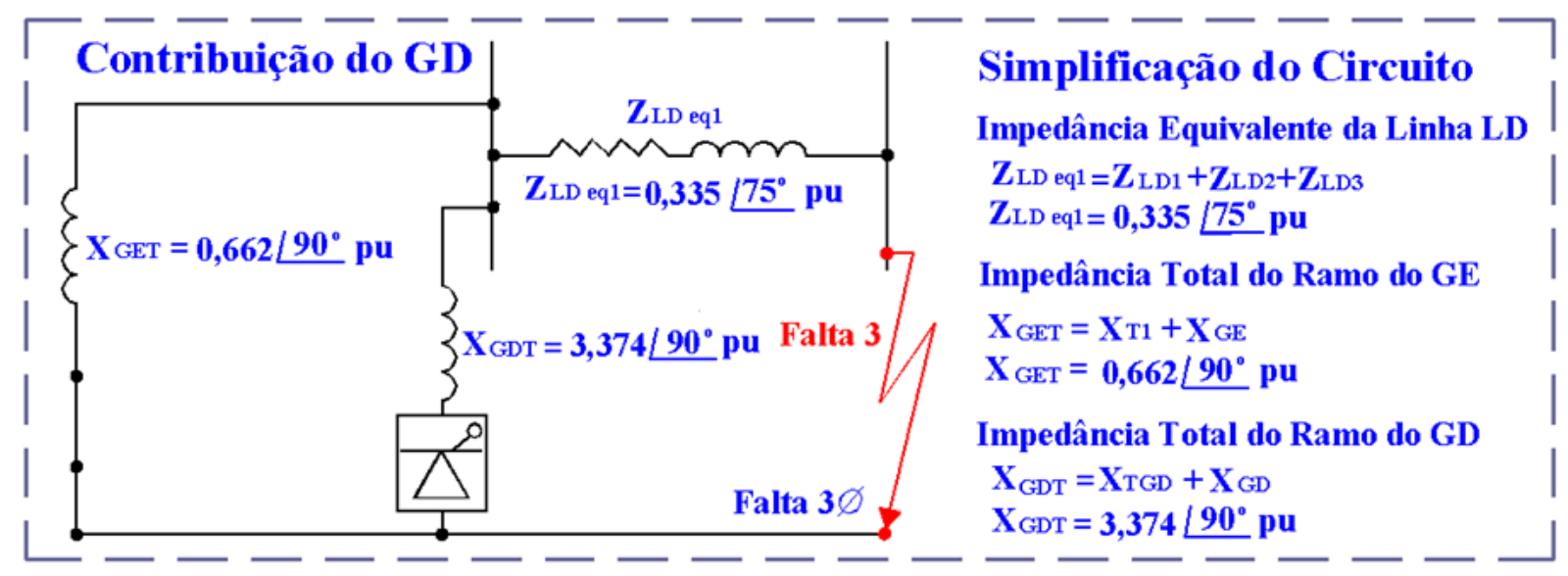

Figura 5.29 - Metodologia 2 GD no início das linhas - Simplificação do circuito considerando a contribuição do gerador GD.

No desenvolvimento do circuito, a Figura 5.30 apresenta o circuito resultante total que considera a operação exclusiva do GD e os cálculos da impedância total equivalente $\left(Z_{\mathrm{eq}}\right)$, corrente total fornecida pelo GD (ITGD) e a parcela de contribuição de corrente do gerador GD para a Falta $3\left(\mathrm{I}_{\mathrm{F} 3 \mathrm{GD}}\right)$. 


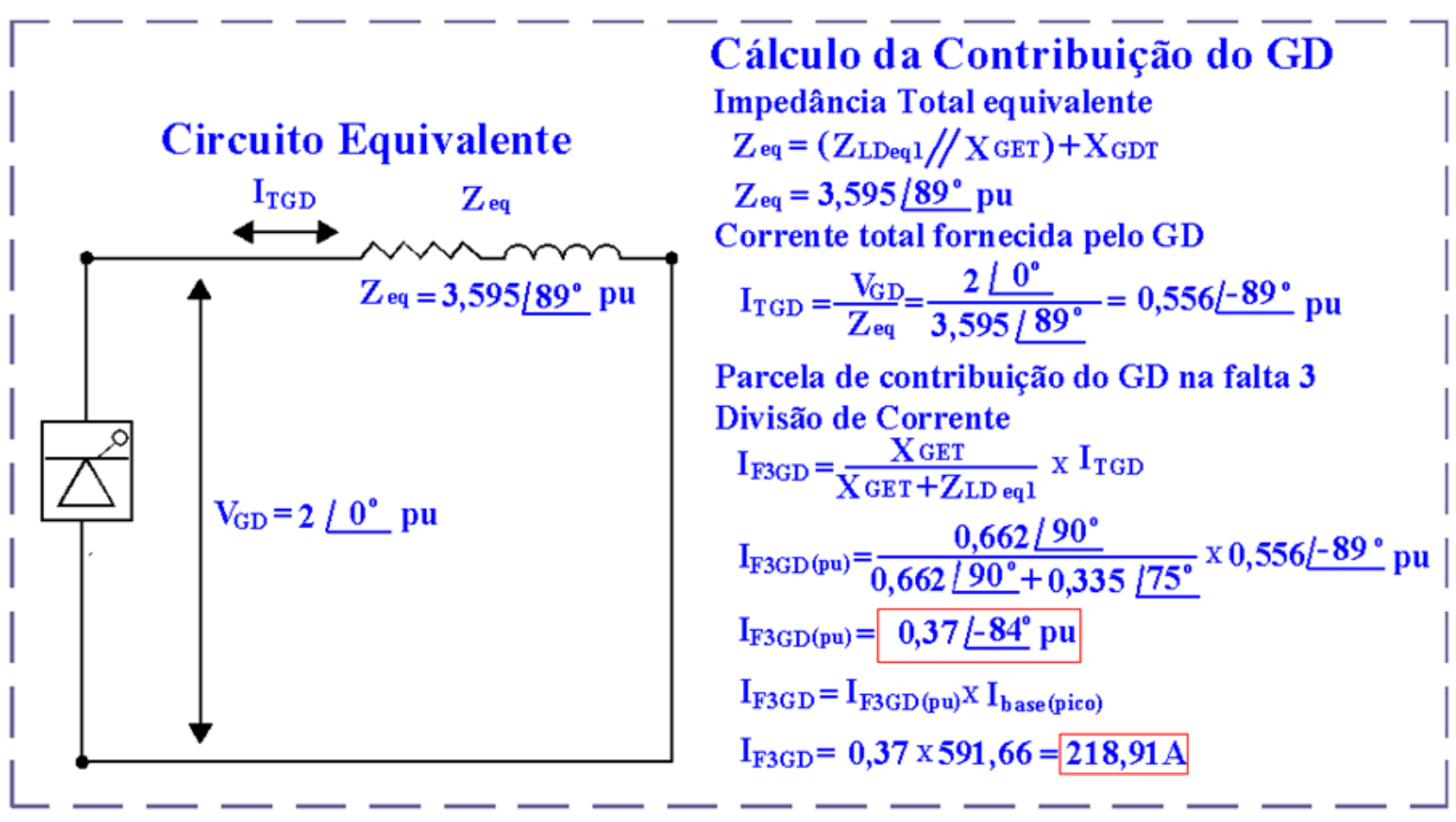

Figura 5.30 - Metodologia 2 GD no início das linhas - Circuito equivalente total e cálculo da contribuição do gerador GD para a corrente de Falta 3.

Concluindo a aplicação da metodologia 2 com GD instalado no início das linhas de distribuição, a Figura 5.31 apresenta os cálculos finais que, seguindo o Teorema da Superposição, efetua a soma das contribuições de corrente de falta do GE ( $\mathrm{I}_{\mathrm{F3GE}}$ ) mais a do GD ( $\mathrm{I}_{\mathrm{F} 3 \mathrm{GD}}$ ). O resultado dessa soma representa o valor total calculado para a corrente da Falta $3\left(\mathrm{I}_{\mathrm{F} 3}\right)$.

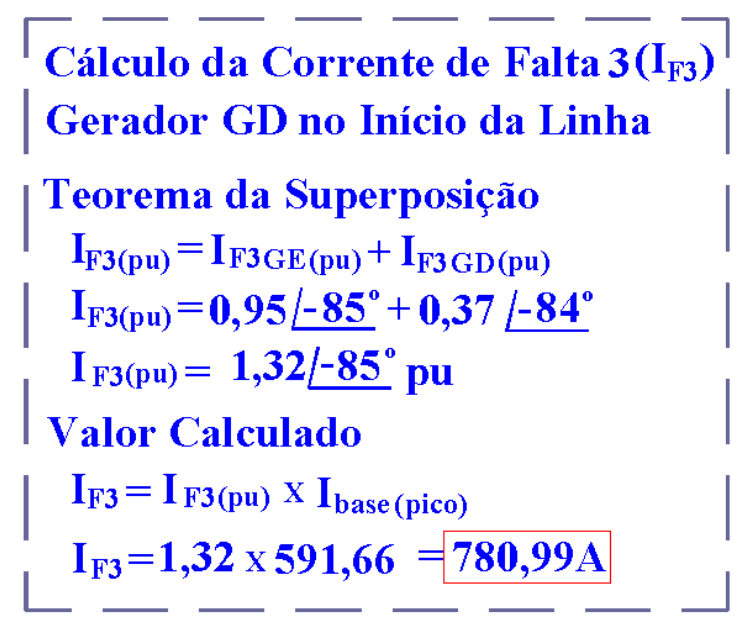

Figura 5.31 - Metodologia 2 GD no início das linhas - Cálculo do valor total da corrente da Falta 3 (IF3). 


\subsubsection{Aplicação da Metodologia 2 - Cálculo da Corrente de Curto-Circuito com Gerador GD no Final da Linha do Sistema de Distribuição}

Nesta seção, apresenta-se a aplicação da metodologia 2 com a inserção do gerador GD no final das linhas do sistema de distribuição de energia elétrica. A seguir, apresenta-se a sequência do desenvolvimento dos cálculos.

Na Figura 5.32, apresenta-se o circuito resultante com a inserção do gerador GD no final das linhas de distribuição de energia e aplicação da Falta 3.

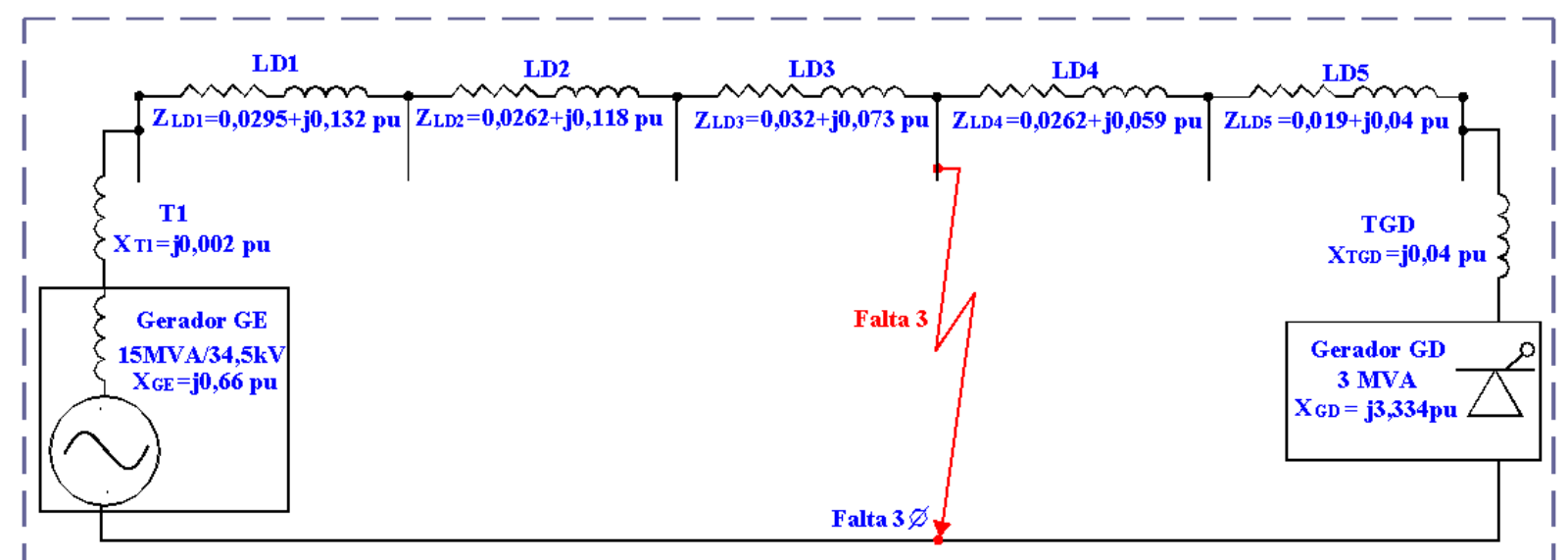

Figura 5.32 - Metodologia 2 GD no final das linhas - circuito resultante para Falta 3.

A Figura 5.33 ilustra a simplificação do circuito que considera exclusivamente a contribuição do gerador equivalente da concessionária (GE) e os cálculos das impedâncias equivalentes totais dos ramos da linha de distribuição $\left(Z_{L D e q 1}\right)$ e do gerador equivalente da concessionária $\left(\mathrm{X}_{\mathrm{GET}}\right)$.

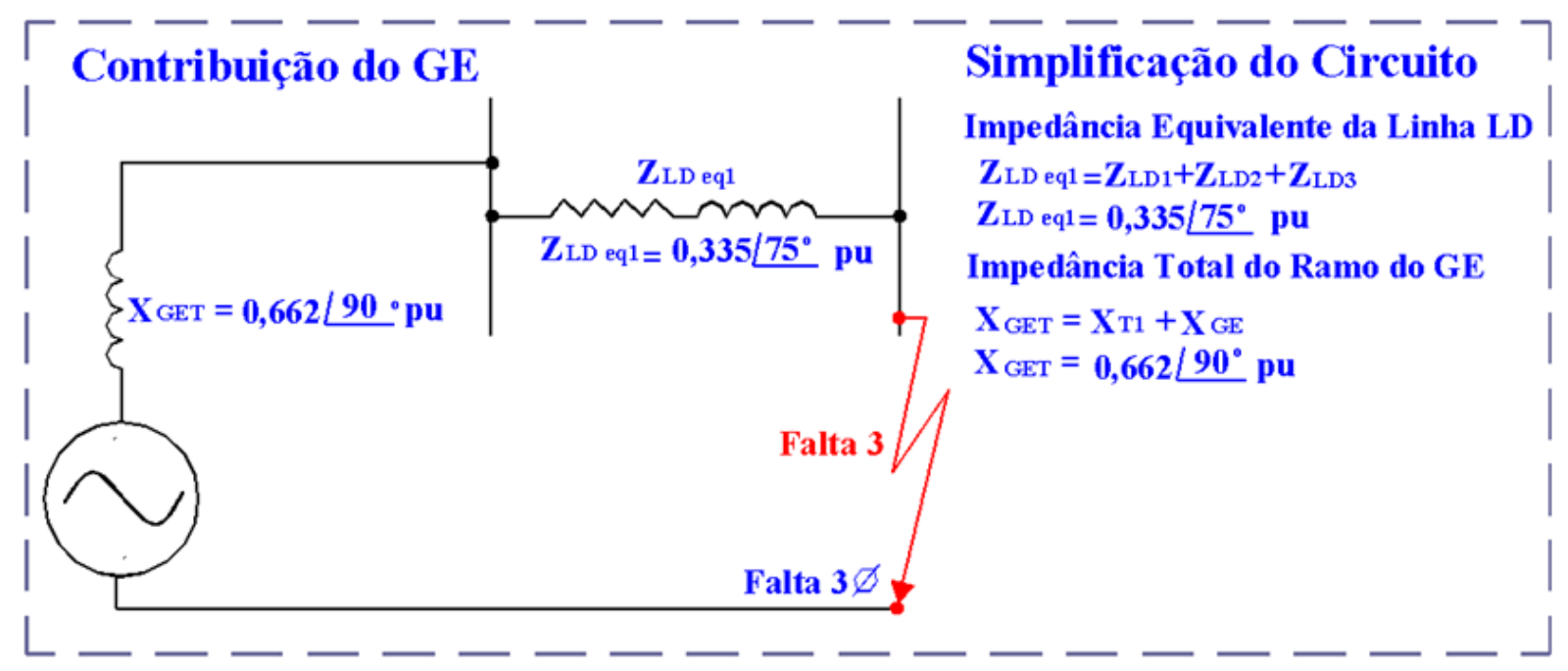

Figura 5.33 - Metodologia 2 - Simplificação do circuito considerando a contribuição do gerador GE.

Seguindo a sequência de desenvolvimento do circuito, a Figura 5.34 apresenta o circuito resultante total que considera a operação exclusiva do gerador GE e os cálculos da 
impedância total equivalente $\left(\mathrm{Z}_{\mathrm{eq}}\right)$, corrente total fornecida pelo gerador GE (ITGE) e a parcela de contribuição de corrente do gerador GE para a Falta 3 (I $\left.\mathrm{I}_{\mathrm{F} 3 \mathrm{GE}}\right)$.

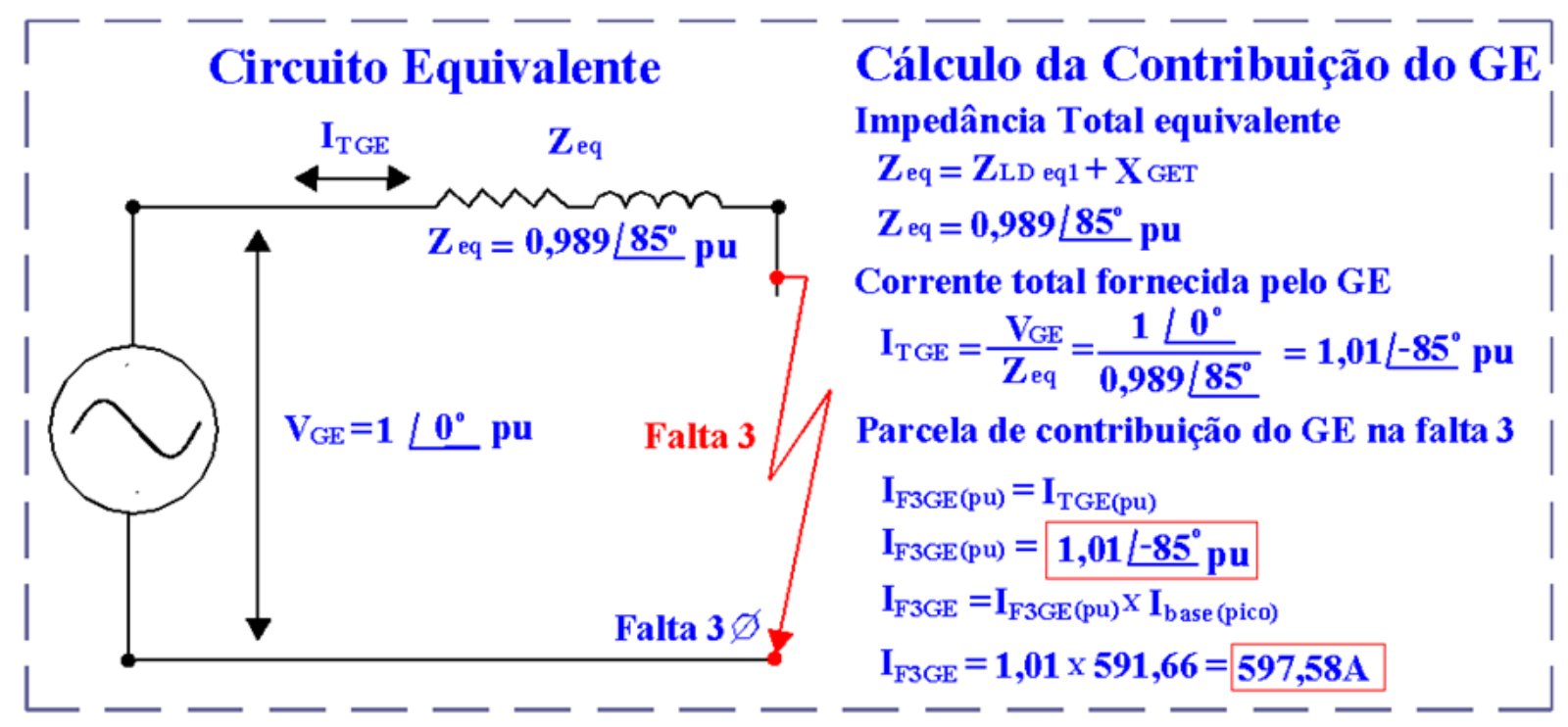

Figura 5.34 - Metodologia 2 GD no final das linhas - Circuito equivalente total e cálculo da contribuição do gerador GE para a corrente de Falta 3.

Considerando somente a contribuição do gerador distribuído, a Figura 5.35 apresenta a simplificação do circuito e os cálculos das impedâncias resultantes em cada ramo.

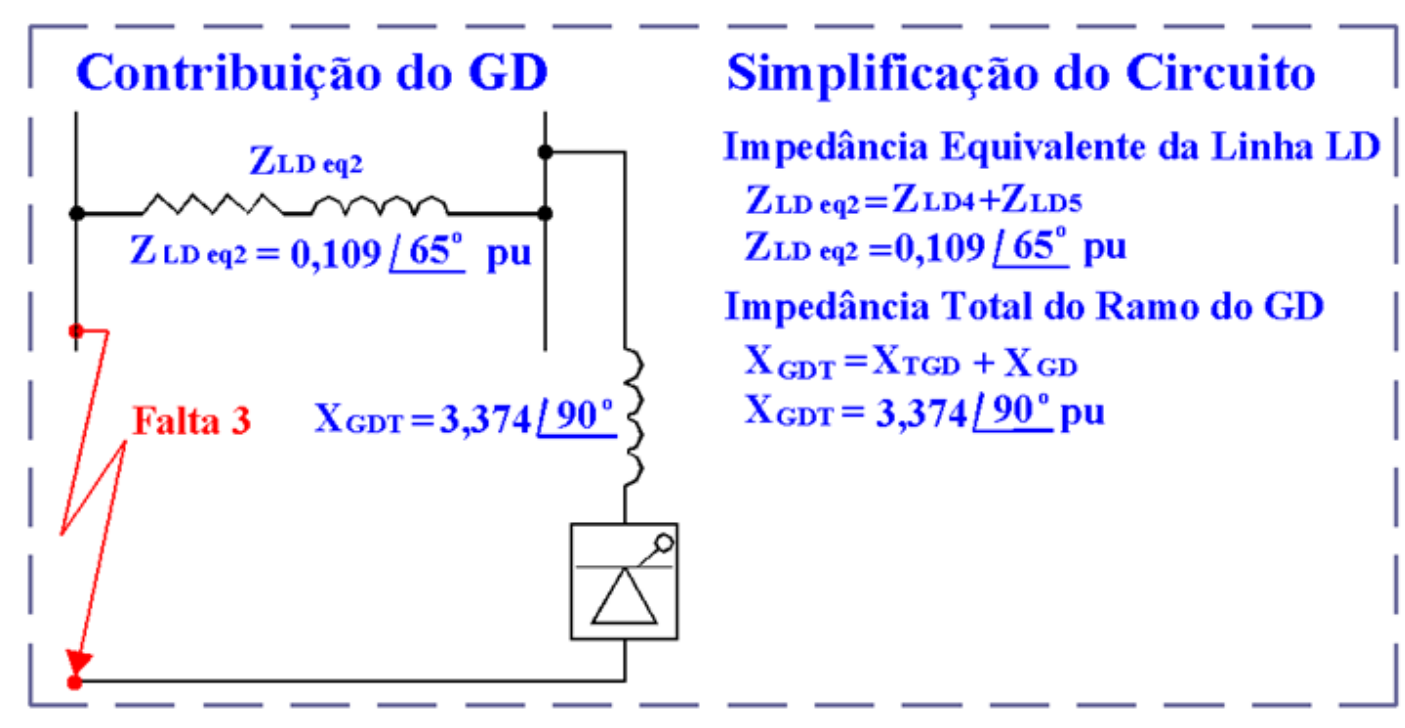

Figura 5.35 - Metodologia 2 GD no final das linhas - Simplificação do circuito considerando a contribuição do gerador GD.

Na sequência, a Figura 5.36 apresenta o circuito resultante total que considera a operação exclusiva do GD e os cálculos da impedância total equivalente $\left(Z_{\mathrm{eq}}\right)$, corrente total fornecida pelo gerador GD (ITGD) e a parcela de contribuição de corrente do gerador GD para a Falta 3 (IF3GD). 


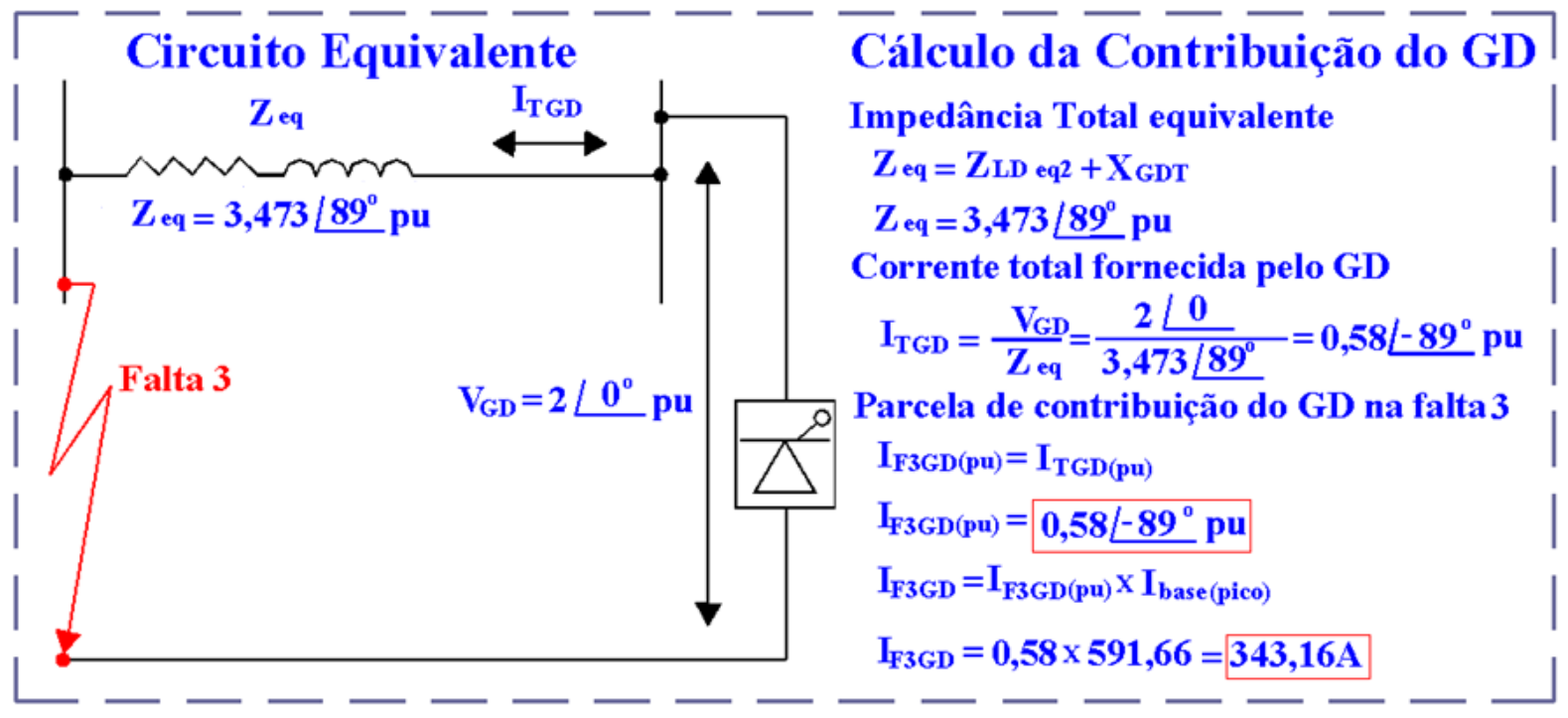

Figura 5.36 - Metodologia 2 GD no final das linhas - Circuito equivalente total e cálculo da contribuição do gerador GD para a corrente de Falta 3.

Para finalizar a aplicação da metodologia 2 com GD instalado no final das linhas de distribuição, a Figura 5.37 apresenta os cálculos finais com a soma da contribuição de corrente de falta do gerador GE ( $\mathrm{I}_{\mathrm{F} 3 \mathrm{GE}}$ ) mais a contribuição da corrente de falta do gerador GD ( $\left.\mathrm{I}_{\mathrm{F} 3 \mathrm{GD}}\right)$. O resultado dessa soma representa o valor total calculado para a corrente da Falta 3 $\left(\mathrm{I}_{\mathrm{F} 3}\right)$.

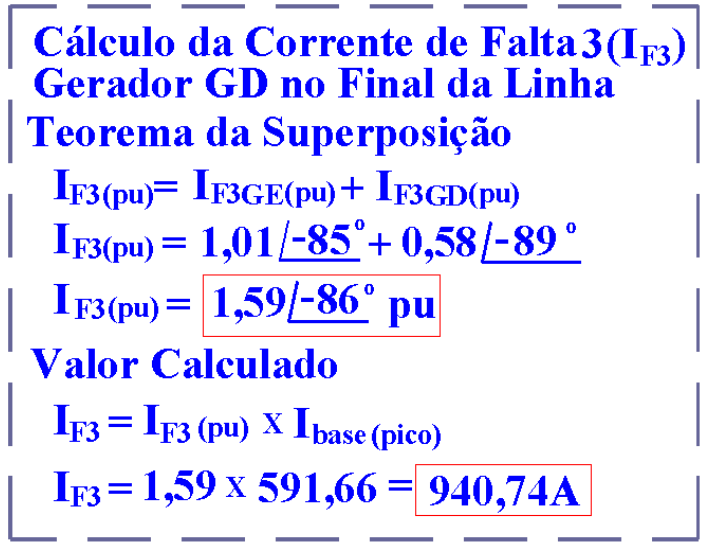

Figura 5.37 - Metodologia 2 GD no final das linhas - Cálculo do valor total da corrente da Falta 3 (IF3). 


\subsubsection{Aplicação da Metodologia 2 - Cálculo da Corrente de Curto-Circuito com Dois Geradores Distribuídos}

Nesta seção, apresenta-se a aplicação da metodologia 2 com a inserção de dois grupos GDs de 1,5 MVA cada, sendo GD1 no início da linha e GD2 no final da linha do sistema de distribuição.

A Figura 5.38 apresenta o sistema resultante para Falta 3 com dois geradores GDs de 1,5 MVA instalados.

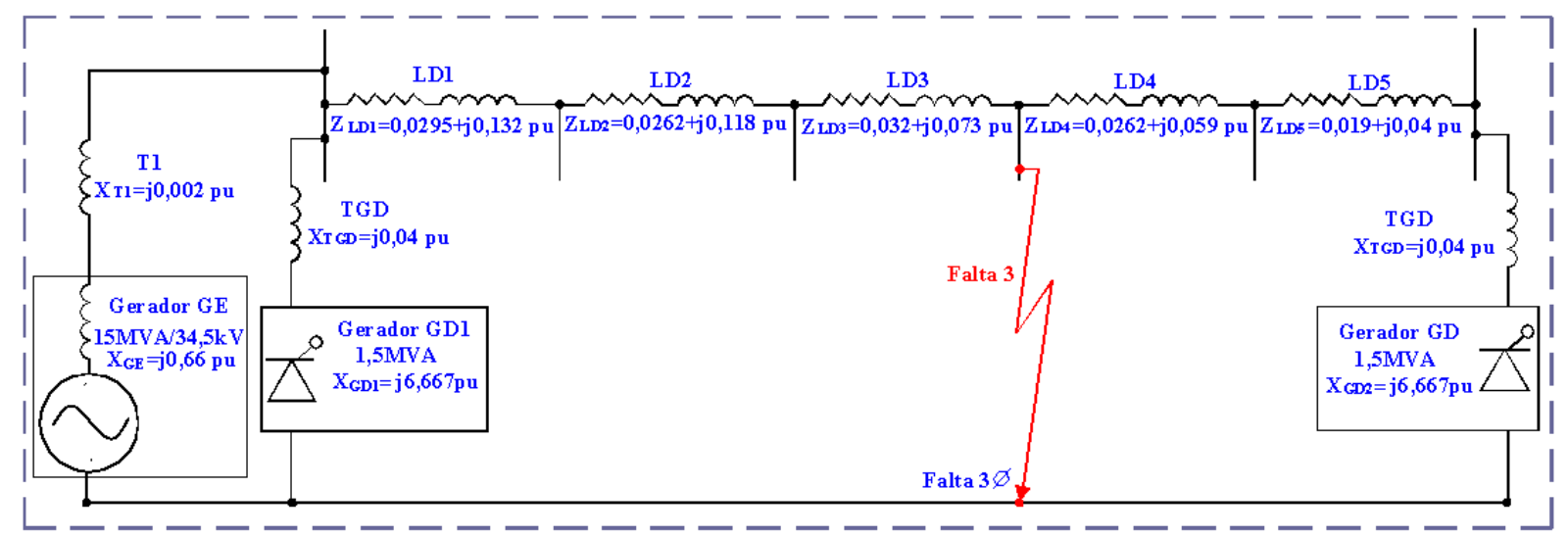

Figura 5.38 - Metodologia 2 com dois GDs instalados - Circuito de resultante para a Falta 3.

A Figura 5.39 ilustra a simplificação do circuito que considera exclusivamente a contribuição do gerador equivalente da concessionária (GE) e os cálculos das impedâncias equivalentes totais dos ramos da linha de distribuição $\left(Z_{L D e q 1}\right)$ e do gerador equivalente da concessionária $\left(\mathrm{X}_{\mathrm{GET}}\right)$.

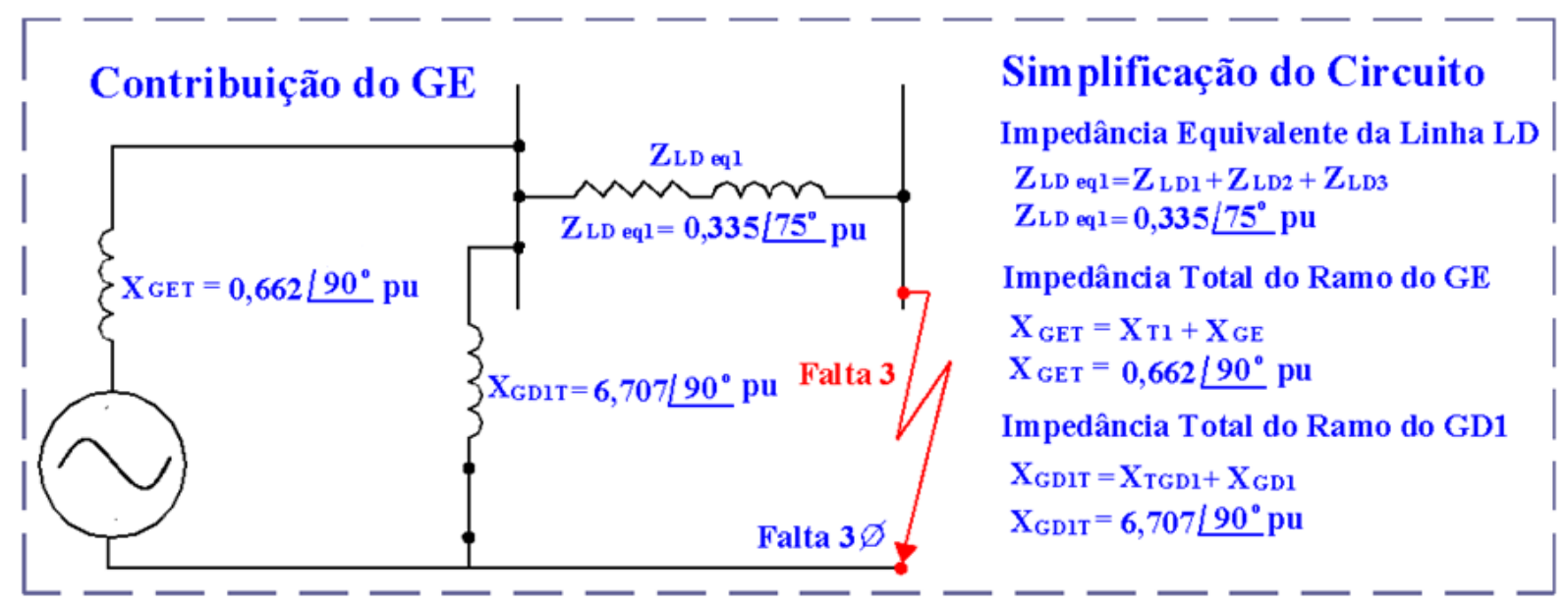

Figura 5.39 - Metodologia 2 com dois GDs instalados - Simplificação do circuito considerando a contribuição do gerador GE.

Seguindo a sequência de desenvolvimento do circuito, a Figura 5.40 apresenta o circuito resultante total que considera a operação exclusiva do gerador GE e os cálculos da 
impedância total equivalente $\left(\mathrm{Z}_{\mathrm{eq}}\right)$, corrente total fornecida pelo gerador GE (ITGE) e a parcela de contribuição de corrente do gerador GE para a Falta 3 (I $\left.\mathrm{I}_{\mathrm{F} 3 \mathrm{GE}}\right)$.

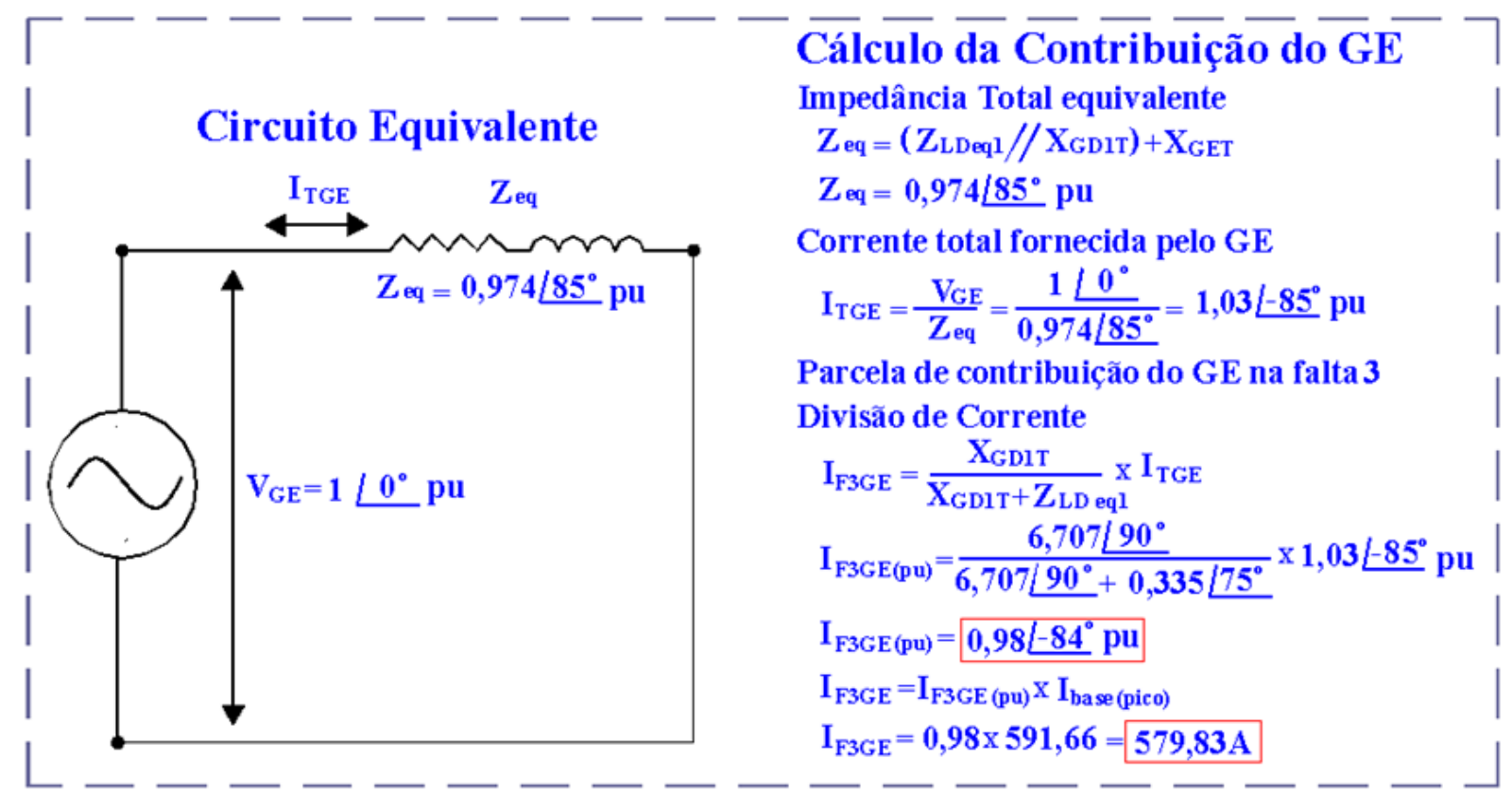

Figura 5.40 - Metodologia 2 com dois GDs instalados - Circuito equivalente total e cálculo da contribuição do gerador GE para a corrente de Falta 3.

Considerando somente a contribuição do gerador distribuído 1 (GD1), a Figura 5.41 apresenta a simplificação do circuito e os cálculos das impedâncias equivalentes totais de cada ramo, inclusive a do ramo do gerador GD1 ( $\mathrm{X}_{\mathrm{GD} 1 \mathrm{~T}}$ ) que é a soma da impedância do transformador $\left(\mathrm{X}_{\mathrm{TGD} 1}\right)$ mais a impedância interna do gerador $\left(\mathrm{X}_{\mathrm{GD} 1}\right)$.

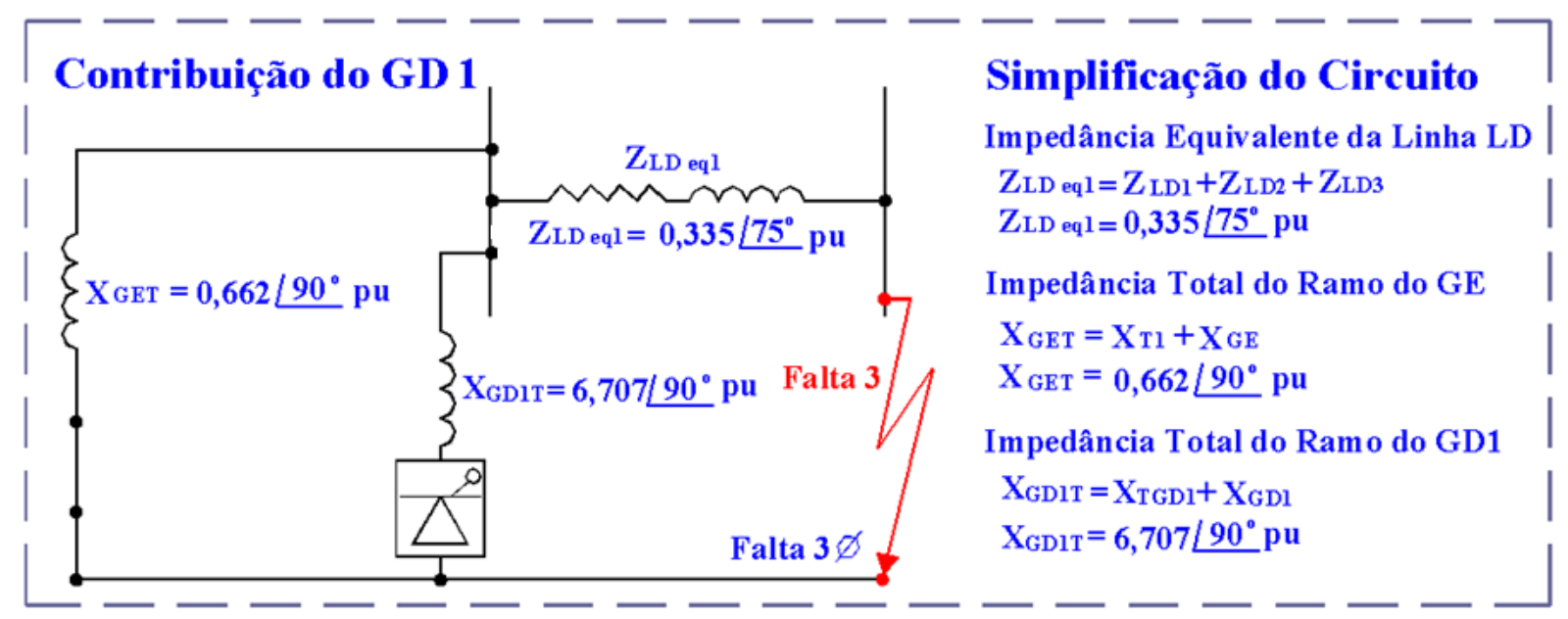

Figura 5.41 - Metodologia 2 com dois GDs instalados - Simplificação do circuito considerando a contribuição do gerador GD1.

Na sequência, a Figura 5.42 apresenta o circuito resultante total que considera a operação exclusiva do gerador GD1 e os cálculos da impedância total equivalente $\left(\mathrm{Z}_{\mathrm{eq}}\right)$, corrente total fornecida pelo gerador GD1 (ITGD1) e a parcela de contribuição de corrente do gerador GD1 para a Falta $3\left(\mathrm{I}_{\mathrm{F} 3 \mathrm{GD} 1}\right)$. 


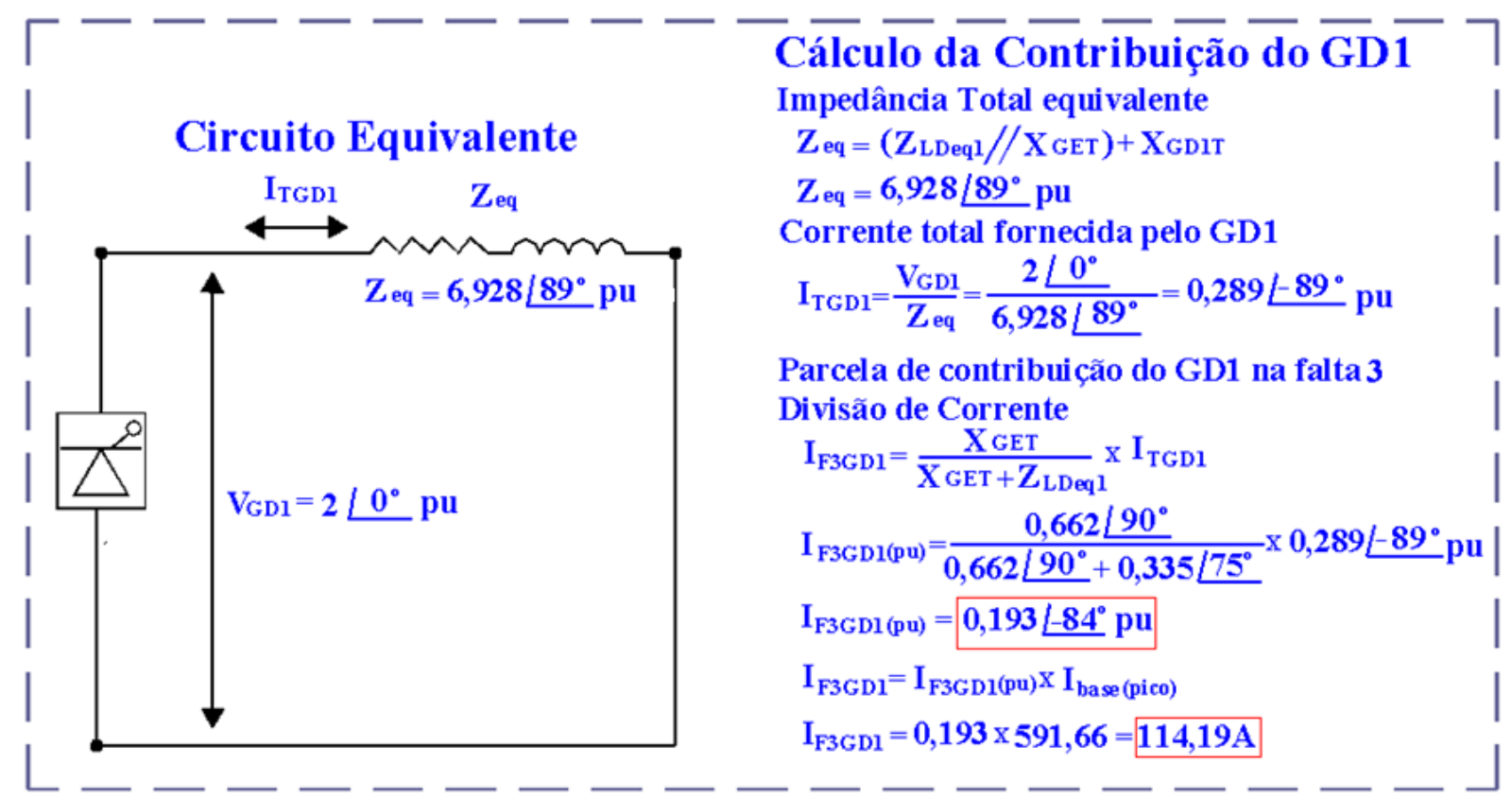

Figura 5.42 - Metodologia 2 com dois GDs instalados - Circuito equivalente total e cálculo da contribuição de corrente do gerador GD1 para a Falta 3.

Considerando agora a contribuição do gerador distribuído 2 (GD2), a Figura 5.43 apresenta a simplificação do circuito e impedâncias totais de cada ramo.

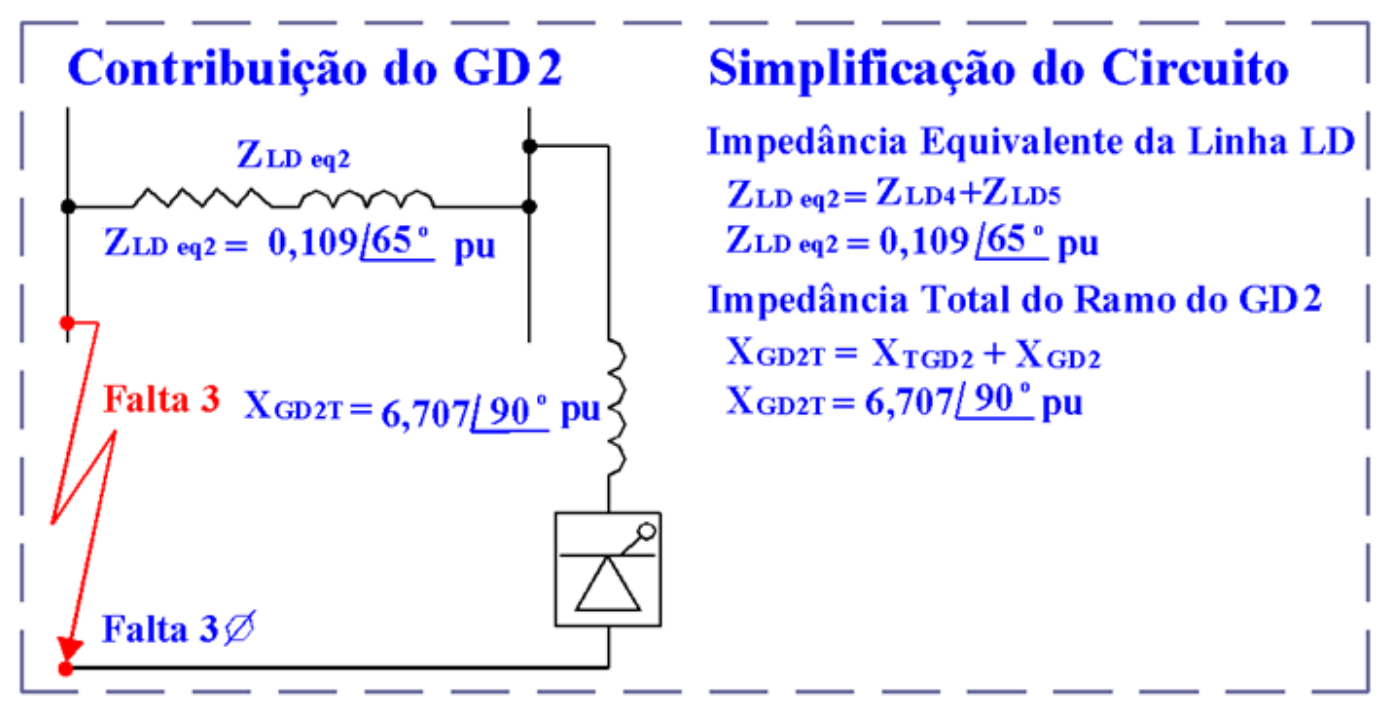

Figura 5.43 - Metodologia 2 com dois GDs instalados - Simplificação do circuito considerando a contribuição do gerador GD2.

A Figura 5.44 apresenta o circuito resultante total que considera a operação exclusiva do gerador GD2 e os cálculos da impedância total equivalente $\left(Z_{\mathrm{eq}}\right)$, corrente total fornecida pelo gerador GD2 (I $\left.\mathrm{I}_{\mathrm{TGD} 2}\right)$ e a parcela de contribuição de corrente do GD2 para a Falta 3 (I $\left.\mathrm{I}_{\mathrm{F} 3 \mathrm{GD} 2}\right)$. 


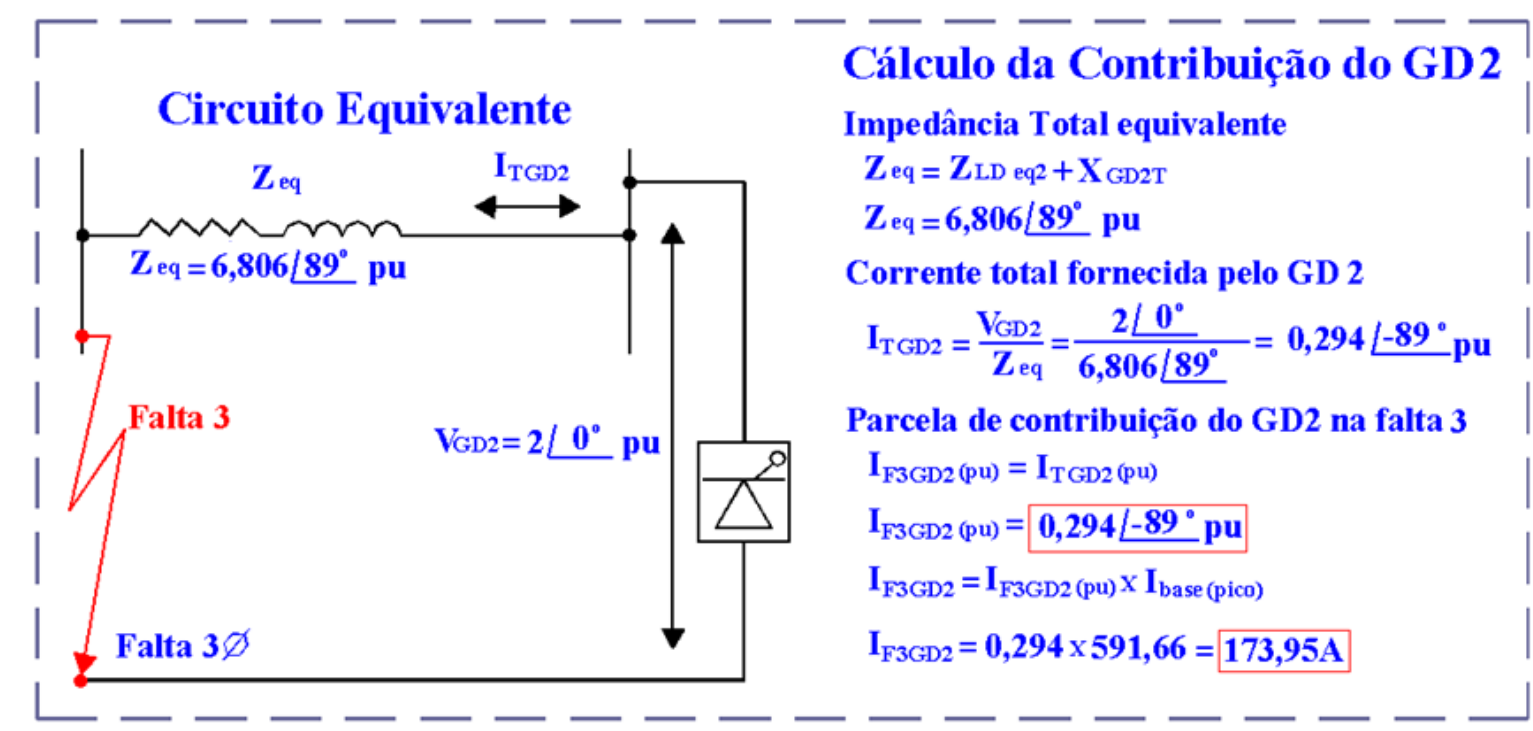

Figura 5.44 - Metodologia 2 com dois GDs instalados - Circuito equivalente total e cálculo da contribuição de corrente do gerador GD2 para a Falta 3.

Para concluir a aplicação da metodologia 2 com dois geradores GDs de 1,5 MVA instalados no sistema de distribuição, a Figura 5.45 apresenta os cálculos finais com a soma da contribuição de corrente de falta do GE ( $\left.\mathrm{I}_{\mathrm{F} 3 \mathrm{GE}}\right)$ mais a contribuição da corrente de falta do gerador GD1 ( $\left.\mathrm{I}_{\mathrm{F} 3 \mathrm{GD} 1}\right)$ e a contribuição da corrente de falta do GD2 ( $\left.\mathrm{I}_{\mathrm{F} 3 \mathrm{GD}}\right)$. O resultado dessa soma representa o valor total calculado para a corrente da Falta $3\left(\mathrm{I}_{\mathrm{F} 3}\right)$.

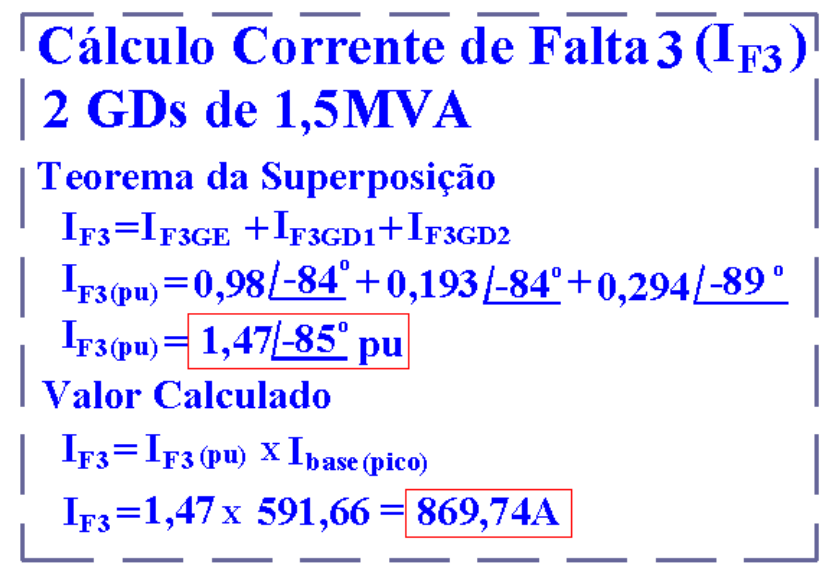

Figura 5.45 - Metodologia 2 com dois GDs instalados - Cálculo do valor total da corrente da Falta 3 (IF3).

Os cálculos para os demais pontos de aplicação de falta seguem a mesma sequência de procedimentos e os valores estão dispostos nas Tabela 5.7 à 5.9 . 


\subsubsection{Análise dos Resultados da Metodologia 2 para Inserção dos Geradores Baseados em Inversores de Frequência nos Cálculos de Curto-Circuito}

Apresenta-se a seguir, a síntese dos resultados obtidos das simulações e dos cálculos que fazem uso da metodologia 2 para inserção de geradores baseados em inversores de frequência nos cálculos de curto-circuito do sistema de distribuição de energia elétrica.

A Tabela 5.7 apresenta os resultados que consideram o grupo gerador GD de 3 MVA instalado no início das linhas do sistema de distribuição de energia.

Tabela 5.7 - Valores das correntes de curtos-circuitos obtidos das simulações e cálculos realizados através da aplicação da metodologia 2 com a inserção do gerador GD no início das linhas.

\begin{tabular}{|c|c|c|c|c|}
\hline $\begin{array}{c}\text { Local de aplicação } \\
\text { da falta }\end{array}$ & $\begin{array}{c}\text { Valor calculado } \\
\text { (pu) }\end{array}$ & $\begin{array}{c}\text { Valor de pico } \\
\text { Calculado } \\
\text { (A) }\end{array}$ & $\begin{array}{c}\text { Valor de pico } \\
\text { Simulado } \\
\text { (A) }\end{array}$ & $\begin{array}{c}\text { Erro } \\
\text { (\%) }\end{array}$ \\
\hline Falta 1 & 1,70 & 1005,82 & 944,90 & 6,45 \\
\hline Falta 2 & 1,44 & 851,99 & 833,10 & 2,27 \\
\hline Falta 3 & 1,32 & 780,99 & 772,60 & 1,09 \\
\hline Falta 4 & 1,24 & 733,66 & 731,60 & 0,28 \\
\hline Falta 5 & 1,17 & 704,08 & 702,70 & 0,20 \\
\hline
\end{tabular}

De acordo com os resultados apresentados na Tabela 5.7, verifica-se que a instalação do gerador distribuído no início das linhas de distribuição de energia proporcionou erros bem menores do que 10\%. Além disso, todos os valores calculados superam os simulados, fornecendo assim, maior segurança para a aplicação dessa metodologia em projetos e dimensionamentos em geral.

Em relação à instalação do grupo gerador GD de 3 MVA no final das linhas do sistema de distribuição de energia, a Tabela 5.8 apresenta os resultados obtidos dos cálculos e simulações.

Tabela 5.8 - Valores das correntes de curtos-circuitos obtidos das simulações e cálculos realizados através da aplicação da metodologia 2 com a inserção do gerador GD no final das linhas

\begin{tabular}{|c|c|c|c|c|}
\hline $\begin{array}{c}\text { Local de aplicação } \\
\text { da falta }\end{array}$ & $\begin{array}{c}\text { Valor calculado } \\
\text { (pu) }\end{array}$ & $\begin{array}{c}\text { Valor de pico } \\
\text { Calculado } \\
\text { (A) }\end{array}$ & $\begin{array}{c}\text { Valor de pico } \\
\text { Simulado } \\
(\mathbf{A})\end{array}$ & $\begin{array}{c}\text { Erro } \\
(\boldsymbol{\%})\end{array}$ \\
\hline Falta 1 & 1,81 & 1070,90 & 982,30 & 9,02 \\
\hline Falta 2 & 1,65 & 976,24 & 892,30 & 9,41 \\
\hline Falta 3 & 1,59 & 940,74 & 848,00 & 10,94 \\
\hline Falta 4 & 1,54 & 911,16 & 817,00 & 11,53 \\
\hline Falta 5 & 1,51 & 893,41 & 796,00 & 12,24 \\
\hline
\end{tabular}

Os resultados apresentados na Tabela 5.8 demonstram boa eficiência na aplicação dessa metodologia para o cálculo de curto-circuito com o gerador distribuído instalado no final das 
linhas. Os valores calculados superam os simulados e os erros praticados se mantiveram estáveis e com valores aceitáveis no contexto da engenharia.

A Tabela 5.9 apresenta os resultados que consideram dois grupos geradores GDs de 1,5 MVA cada, sendo GD1 instalado no início das linhas e GD 2 instalado no final das linhas do sistema de distribuição de energia.

Tabela 5.9 - Valores das correntes de curtos-circuitos obtidos dos cálculos e simulações realizadas no Sistema de Distribuição de Energia (SD) com aplicação da metodologia 2 para inserção de dois grupos geradores de 1,5 MVA.

\begin{tabular}{|c|c|c|c|c|}
\hline $\begin{array}{c}\text { Local de aplicação } \\
\text { da falta }\end{array}$ & $\begin{array}{c}\text { Valor calculado } \\
(\mathbf{p u})\end{array}$ & $\begin{array}{c}\text { Valor de pico } \\
\text { Calculado } \\
(\mathbf{A})\end{array}$ & $\begin{array}{c}\text { Valor de pico } \\
\text { Simulado } \\
(\mathbf{A})\end{array}$ & $\begin{array}{c}\text { Erro } \\
(\mathbf{\%})\end{array}$ \\
\hline Falta 1 & 1,77 & 1047,24 & 965,10 & 8,51 \\
\hline Falta 2 & 1,57 & 928,91 & 862,60 & 7,69 \\
\hline Falta 3 & 1,47 & 869,74 & 809,30 & 7,47 \\
\hline Falta 4 & 1,40 & 828,32 & 772,70 & 7,20 \\
\hline Falta 5 & 1,35 & 798,74 & 750,80 & 6,39 \\
\hline
\end{tabular}

$\mathrm{Na}$ situação em que foram instalados dois grupos de geradores GDs, sendo um em cada extremo das linhas de distribuição, os resultados da aplicação dessa estratégia se mostraram satisfatórios. Os valores calculados superam os simulados e os percentuais de erros são baixos.

Em síntese geral, a metodologia 2 apresenta facilidade de entendimento e aplicação, não depende de dados minuciosos e específicos dos inversores, proporciona resultados que não necessitam do emprego de fatores de segurança para uso em projetos e dimensionamentos e os erros percentuais praticados são perfeitamente aceitáveis no contexto da engenharia. 


\subsection{Considerações Finais Sobre o Capítulo}

Este capítulo apresentou duas metodologias para a inserção do gerador baseado em inversor nos cálculos de corrente de curto-circuito trifásico em sistemas de distribuição de energia elétrica.

A Tabela 5.10 apresenta o resumo geral com os valores das correntes de curto-circuito medidos na simulação, os valores calculados através das metodologias 1 e 2 e os erros percentuais dos cálculos de cada metodologia em relação aos valores simulados.

Tabela 5.10 - Valores de correntes de curtos-circuitos obtidos através das simulações e metodologias 1 e 2.

\begin{tabular}{|c|c|c|c|c|c|c|}
\hline \multirow{2}{*}{$\begin{array}{l}\text { Configuração do } \\
\text { Sistema de } \\
\text { distribuição }\end{array}$} & \multirow{2}{*}{$\begin{array}{c}\text { Local } \\
\text { da } \\
\text { Falta }\end{array}$} & \multirow{2}{*}{$\begin{array}{c}\text { Simulação } \\
\text { Valor } \\
\text { Medido (A) }\end{array}$} & \multicolumn{2}{|c|}{ Metodologia 1} & \multicolumn{2}{|c|}{ Metodologia 2} \\
\hline & & & $\begin{array}{c}\text { Valor } \\
\text { Calculado (A) }\end{array}$ & $\begin{array}{l}\text { Erro } \\
(\%)\end{array}$ & $\begin{array}{c}\text { Valor } \\
\text { Calculado (A) }\end{array}$ & $\begin{array}{l}\text { Erro } \\
(\%)\end{array}$ \\
\hline \multirow{5}{*}{$\begin{array}{l}\text { GD 3MVA no } \\
\text { início da linha }\end{array}$} & 1 & 944,90 & 970,32 & 2,69 & 1005,82 & 6,45 \\
\hline & 2 & 833,10 & 810,57 & $-2,70$ & 851,99 & 2,27 \\
\hline & 3 & 772,60 & 733,66 & $-5,04$ & 780,99 & 1,09 \\
\hline & 4 & 731,60 & 680,41 & $-7,00$ & 733,66 & 0,28 \\
\hline & 5 & 702,70 & 650,83 & $-7,38$ & 704,08 & 0,20 \\
\hline \multirow{5}{*}{$\begin{array}{l}\text { GD 3MVA no } \\
\text { final da linha }\end{array}$} & $\mathbf{1}$ & 982,30 & 1041,32 & 6,00 & 1070,90 & 9,02 \\
\hline & 2 & 892,30 & 964,41 & 8,08 & 976,24 & 9,41 \\
\hline & 3 & 848,00 & 922,99 & 8,84 & 940,74 & 10,94 \\
\hline & 4 & 817,00 & 899,32 & 10,08 & 911,16 & 11,53 \\
\hline & 5 & 796,00 & 887,49 & 11,49 & 893,41 & 12,24 \\
\hline \multirow{5}{*}{$\begin{array}{c}\text { GD1 de 1,5 MVA } \\
\text { no início e GD2 } \\
\text { de 1,5 MVA no } \\
\text { final da linha }\end{array}$} & 1 & 965,10 & 1023,57 & 6,06 & 1047,24 & 8,51 \\
\hline & 2 & 862,60 & 899,32 & 4,26 & 928,91 & 7,69 \\
\hline & 3 & 809,30 & 840,16 & 3,81 & 869,74 & 7,47 \\
\hline & 4 & 772,70 & 798,74 & 3,37 & 828,32 & 7,20 \\
\hline & 5 & 750,80 & 775,07 & 3,23 & 798,74 & 6,39 \\
\hline
\end{tabular}

Através dos valores apresentados na Tabela 5.10, verifica-se que os erros percentuais praticados pelos cálculos da primeira metodologia são baixos, no entanto, na situação em que o GD está na subestação, essa metodologia pode apresentar valores calculados inferiores aos medidos. Sendo assim, necessita de um fator de segurança (Fs) para sua utilização em projetos que envolvam dimensionamentos de equipamentos e proteção. Por outro lado, na 
situação em que não ocorre o compartilhamento, os valores calculados superam os medidos e os erros praticados pelos cálculos também são baixos.

$\mathrm{Na}$ segunda metodologia, observa-se também que os erros de cálculos em relação aos valores simulados são baixos. Além disso, em todas as situações e configurações do sistema, os valores calculados superaram os simulados.

No contexto geral, ambas as metodologias fazem uso dos conceitos básicos de circuitos elétricos, são válidas, não dependem de dados minuciosos e específicos dos inversores, apresentaram erros baixos e são de fácil entendimento e aplicabilidade. No entanto, a primeira se destaca pelos menores erros percentuais e a segunda se destaca por não necessitar de fator de segurança em sua aplicação. 


\section{Capítulo 6}

\section{Conclusões}

Neste trabalho, foi realizada uma abordagem bibliográfica sobre as contribuições das correntes de curto-circuito dos principais tipos de geradores, na qual, estão presentes os geradores baseados em inversores, síncronos e assíncronos. Em relação aos geradores rotativos, as publicações apontam diferenças entre o comportamento das correntes de curtoscircuitos dos geradores síncronos e assíncronos e entre os diversos tipos de assíncronos, no entanto, nota-se que, tanto os síncronos quanto os assíncronos, podem proporcionar elevados valores iniciais de corrente de curto-circuito.

No caso de geradores baseados em inversores, as publicações, de uma maneira geral, apresentam resultados conservadores quanto à contribuição desses tipos de geradores nas correntes de curto-circuito. Os valores encontrados estão entre uma a cinco vezes maior que o valor da corrente nominal do gerador e podem variar de acordo com a tecnologia de controle empregada. Além disso, a quantidade de trabalhos que investiga o impacto desses geradores nos níveis de curto-circuito é muito inferior em relação aos de máquinas rotativas.

Outro assunto destacado pela literatura e chamado de "Fault Ride Through" aborda estudos sobre a capacidade dos geradores distribuídos permanecerem conectados e atuantes durante e após a eliminação da falta no sistema elétrico. Verifica-se que sistemas mais fracos que fazem uso de geradores distribuídos tornam-se muito ou totalmente dependentes da continuidade de funcionamento desses geradores para que não entrem em colapso de tensão e frequência. Em função da importância do assunto, pesquisadores e demais envolvidos no setor elétrico de diversos países estudam e estabelecem diretrizes para o comportamento e permanência do funcionamento dos geradores distribuídos frente à ocorrência de curtoscircuitos e de afundamentos de tensão. Sendo assim, entende-se que esse assunto reforça a 
necessidade de estudos que abordem a contribuição de corrente de curto-circuito por parte dos geradores baseados em inversores.

Considerando que o foco principal deste trabalho está no estudo relacionado ao gerador baseado em inversores, realizou-se a modelagem e a implementação computacional de dois sistemas de distribuição de energia elétrica contendo esses tipos de geradores, sendo estes, com três diferentes modalidades de controle: I, PQ e PV. A partir de então, realizaram-se as simulações necessárias aos estudos desenvolvidos neste trabalho.

Como primeira etapa das simulações, foram realizados os estudos sobre o comportamento do sistema de distribuição de energia com a instalação de gerador distribuído baseado em inversor e os impactos relacionados ao curto-circuito, sobretudo, aos aspectos da qualidade de energia, sendo: perfil de tensão nos barramentos, afundamento de tensão, variação de tensão devido à saída repentina do grupo gerador, regulação de tensão e perdas técnicas de potência ativa nas linhas.

Em relação ao perfil de tensão, verificou-se que tanto na situação em que o inversor foi submetido ao controle I quanto ao controle PQ, houve riscos de violação no perfil de tensão da rede estudada. $\mathrm{O}$ controle $\mathrm{PV}$ se mostrou mais adequado para manter o perfil de tensão nos barramentos estudados.

Para o estudo de afundamento de tensão, observou-se que o destaque na tentativa de amenizar o afundamento de tensão ficou para o controle PV.

Em relação à variação de tensão devido à saída repentina do grupo gerador, o estudo mostra que quanto maior o carregamento do sistema, maior a parcela de contribuição e dependência do grupo gerador, portanto, quanto mais carregado o sistema, maior será o impacto na tensão diante da saída repentina do grupo gerador.

No estudo de regulação de tensão, o controle PV se mostra mais adequado, pois, dentre as três modalidades de controle estudadas, foi a que apresentou os menores índices e, portanto, a melhor condição em relação à regulação de tensão. Esse fato pode ser atribuído à capacidade dessa estratégia de controle em fazer o grupo gerador injetar ou absorver potência reativa no sistema.

Em relação às perdas técnicas de potência ativa nas linhas, observa-se que o nível de perdas elétricas pode diminuir ou aumentar, dependendo da localização do gerador, da quantidade de potência gerada e da topologia do sistema analisado. 
Em outra etapa das simulações, também foi realizado um estudo para verificar a parcela de contribuição de corrente de curto-circuito do gerador baseado em inversor de frequência.

Verificou-se que o controle I apresentou melhor desempenho em relação à limitação e controle da corrente de falta. Nesta modalidade de controle, o gerador manteve o valor da sua contribuição de corrente de curto-circuito em torno do seu valor de corrente nominal em todos os testes realizados neste trabalho.

Para o controle PQ, verificou-se que o maior valor de corrente de curto-circuito foi de 1,41 pu. Este fato demanda atenção em relação aos cálculos de corrente de curto-circuito em sistema com esse tipo de gerador. Verificou-se também que os valores de contribuição de corrente de falta, para esse tipo de controle, se mostraram pouco sensíveis às variações do ângulo de incidência de falta, entretanto, bastante sensíveis à variação do fator de potência.

Para o controle PV, o gerador atingiu, no pior caso dos testes, o valor de corrente de falta de até $1,76 \mathrm{pu}$, o que representa a maior contribuição de corrente de falta dentre as três modalidades estudadas neste trabalho. Sendo assim, a inserção do gerador com esse tipo de controle no sistema de energia também requer atenção em relação aos cálculos de corrente de curto-circuito. Ainda no controle PV, verificou-se também que a contribuição de corrente de falta apresentou considerável sensibilidade à variação do ângulo de incidência de falta e às pequenas variações de tensão.

No geral, verificou-se que a contribuição de corrente de falta desses geradores não atingiu o valor de 2 pu em nenhuma condição de teste e controle, o que representa, no quesito limitação de corrente de falta, uma grande vantagem em relação aos geradores rotativos conectados diretamente no sistema.

Dentre todas as realizações contidas neste trabalho, a maior contribuição está na apresentação de duas metodologias para a inclusão dos geradores baseados em inversores de frequência nos cálculos de curto-circuito. As metodologias têm como base o padrão de contribuição de corrente de falta para os inversores que é aproximadamente duas vezes o valor da corrente nominal do inversor (Keller; Kroposki, 2010) e também nos valores encontrados e tabelados nos estudos apresentados no quarto capítulo, onde se comprova que a tendência do valor de corrente de curto-circuito trifásico desse tipo de gerador é não superar o dobro do valor de sua corrente nominal. Sendo assim, ambas as estratégias consideram que o maior valor de corrente de curto-circuito desse tipo de gerador é de 2 pu. 
Na primeira estratégia, verifica-se que os erros percentuais praticados pelos cálculos são baixos. No entanto, há situações em que os valores calculados apresentam valores inferiores aos medidos. Sendo assim, apesar da eficiência dos resultados, essa estratégia requer a aplicação de fator de segurança (Fs) para sua utilização em projetos que envolvam dimensionamentos de equipamentos e proteção.

Na segunda estratégia, verifica-se que os erros percentuais praticados também são baixos. Em todas as situações, os valores calculados superaram os simulados. Sendo assim, essa estratégia apresenta a vantagem de não necessitar da aplicação de fator de segurança nos cálculos.

Em relação às duas estratégias para inserção do gerador baseado em inversor nos cálculos de curto-circuito, ambas fazem uso dos conceitos básicos de circuitos elétricos, são de fácil entendimento e de fácil aplicação, apresentam pequena margem de erro nos resultados e não dependem de dados minuciosos e específicos dos inversores.

Para trabalhos futuros relacionados a esta tese, seguem as seguintes sugestões:

- Estabelecer diretrizes para calcular o fator de segurança a ser aplicado em condições específicas da primeira estratégia de inserção do GD nos cálculos de curto-circuito;

- Avaliar a aplicação das estratégias considerando que o nível de penetração de geradores baseados em inversores seja $100 \%$ da carga do sistema elétrico.

- Desenvolver metodologias para tornar possível a aplicação das estratégias em cálculos de curto-circuito monofásico e bifásico. 


\section{Referências Bibliográficas}

Agência Nacional de Energia Elétrica (ANEEL). Acesso ao Sistema de Distribuição. Procedimentos de Distribuição de Energia Elétrica no Sistema Elétrico Nacional - PRODIST. Módulo 3. Brasília, 2012. Disponível em: 〈http://www.aneel.gov.br > Acesso em fevereiro 2013.

Agência Nacional de Energia Elétrica (ANEEL). Micro e Minigeração Distribuída. Caderno Temático. Brasília, 2014. Disponível em: 〈http://www.aneel.gov.br $>$ Acesso em janeiro 2014.

Agência Nacional de Energia Elétrica (ANEEL). Revista_PD. Arquivos. Brasília, 2010. Disponível em: <http://www.aneel.gov.br> Acesso em maio 2010.

Almeida, W.; Freitas, F. D. Circuitos Polifásicos. 1 ed. Brasília: Editora Finatec, 1995.

Baran, M. E.; El-Markaby, I. "Fault Analysis on Distribution Feeders with Distributed Generators," IEEE Trans. Power System, vol. 20, n. 4, pp. 1757-1764, 2005.

Barker, P.; DeMello, R. W. "Determining the impact of DG on power systems, radial distribution," in Proc. IEEE Power Eng. Soc. Summer meeting, pp. 1645-1656, 2000.

Boljevic, S.; Conlon, M. F. "The Contribution to Distribution Network Short-Circuit Current Level from the Connection of Distributed Generation", IEEE Universities Power Engineering Conference (UPEC), 2008.

Borbely, A. M.; Kreider, J. F. Distributed Generation - The Power Paradigm for the New Millennium, Boca Raton: CRC Press, 2001.

Borghetti, A; Caldon, R.; Guerrieri, S.; Rosseto, F. "Dispersed Generators Interfaced with Distribution Systems: Dynamic Response to Faults and Perturbations", in 2003 IEEE Bologna PowerTech Conference, Bologna, 2003.

Buso, S.; Mattavelli, P. "Digital Control in Power Electronics", Morgan \& Claypool Publishers, 2006.

CIRED Working Group 4, “Dispersed Generation”, CIRED, Technical Report, 1999. 
Companhia Paulista de Força e Luz (CPFL). Conexão de Micro e Minigeração Distribuída sob Sistema de Compensação de Energia Elétrica. Normas Técnicas GED - 15303. São Paulo, 2012. Disponível em: 〈http://www.cpfl.com.br> Acesso em fevereiro 2013.

Darwish, A.; Abdel-Khalik, A. S.; Elserougi, A.; Ahmed, S.; Massoud, A. "Fault current contribution scenarios for grid-connected voltage source inverter-based distributed generation with an LCL filter” Elsevier, Electric Power Systems Research 104, pp. 93-103, Jul. 2013.

Elgerd, O. I. Electric Energy Systems Theory: An Introduction, New York: McGraw-Hill, 1971.

Fitzgerald, A. E.; Kingsley Jr, C.; Umans, S. D. Electric Machinery, New York: McGrawHill, 1992.

Freitas, W.; Vieira, J. C. M.; Morelato, A.; Silva, L. C. P.; Costa, V. F.; Lemos, F. A. B. “ Comparative Analysis Between Synchronous and Induction Machines for Distributed Generation", IEEE Trans. on Power Systems, vol. 21, no. 1, Feb., 2006.

Freitas, W.; Vieira, J. C. M.; Silva, L. C. P.; Morelato, A.; Matos, C. A.; Azevedo, V. L. "Impacto de geração distribuída no afundamento de tensão em redes de distribuição de energia elétrica devido a faltas desbalanceadas," in: VI Seminário Brasileiro sobre Qualidade da Energia Elétrica (SBQEE), Belém, 2005a.

Freitas, W.; Vieira, J. C. M.; Morelato, A.; Xu, W. "Influences of Excitation System Control Modes on the Allowable Penetration Level of Distributed Synchronous Generators", IEEE Trans. Energy Conversion, vol. 20, no. 2, pp. 474-480, 2005 b.

Gomez, J. C.; Nesci, S. M.; Barbero, F. A. "Short-Circuit Currents Supplied for Induction Generators", in: CIRED, $20^{\text {th }}$ Int. Conf. on Eletr. Distribution, Prague, Jun. 2010.

IEEE Application Guide for IEEE Std 1547. IEEE Standard for Interconnecting Distributed Resources with Electric Power Systems. IEEE Std 1547.2-2008, p.1-207, April, 2009.

Iov, F.; Hansen, A. D.; Sorensen, P.; Cutululis, N.A. "Mapping of Grid Faults and Grid Codes", Aalborg University, Institute of Energy Technology Ris, National Laboratory of Denmark, Wind Energy Department, Technical Report, Roskilde, Jul., 2007.

Jenkins, N.; Allan, R.; Crossley, P.; Kischen, D.; Strbac, G. Embedded Generation, London: The Institute of Electrical Engineers, 2000.

Jiang, Z.; Yu, X. "Active power-voltage control scheme for islanding operation of inverterinterfaced microgrids", in Proc. IEEE PES General Meeting., p. 7, 2009.

Katiraei, F.; Aguero, J. R. "Solar PV Integration Challenges", IEEE Power \& Energy Magazine, Jun., 2011. 
Kaura, V.; Blasco, V. "Operation of a Phase Locked Loop System Under Distorted Utility Conditions", IEEE Trans. on Industry Application, vol. 33, no. 1, Jan., 1997.

Keller, J.; Kroposki, B. "Understanding Fault Characteristics of Inverter-Based Distributed Energy Resources”, Technical Report NREL/TP-550-46698, Jan. 2010.

Kindermann, G. Curto-Circuito. 2 ed. Porto Alegre: Editora Luzzato, 1997.

Kroposki, B.; Pink, C.; DeBlasio, R.; Thomas, H.; Simoes, M.; Sen, P. K.; "Benefits of Power Electronic Interfaces for Distributed Energy Systems", in 2006 IEEE Power Engineering Society General Meeting, Montreal, 2006.

Kundur, P. Power System Stability and Control, $1^{\text {a. }}$ ed., New York: McGraw-Hill Inc, 1994.

Leite, H.; Barros, J.; Miranda, V. "Evolutionary Algorithm EPSO Helping Doubly-Fed Induction Generators in Ride-Through-Fault", IEEE Bucharest Power Tech Conference, Romania, Jul., 2009.

Lora, E. E. S.; Haddad, J. Geração distribuída: aspecto tecnológicos, ambientais e institucionais. Rio de Janeiro: Interciência, 2006.

Massoud, A. M.; Ahmed, S.; Finney, S. J.; Williams, B. W. "Inverter-Based Versus Synchronous-Based Distributed Generation: Fault Current Limitation and Protection Issues", IEEE Energy Conversion Congress and Exposition (ECCE), pp.58-63, 2010.

Matsumoto, E. Y. Guia Prático Simulink 7.2. 1 ed. São Paulo: Editora Érica Ltda, 2008.

Medeiros, D. M. "Estudo de Geradores de Indução na Geração de Energia Elétrica em Microcentrais Hidrelétricas”, Rev. Ciências Exatas, Taubaté, vol. 11, no. 2, pp 9-14, 2005.

Monticelli, A.; Garcia, A. Introdução a sistemas de energia elétrica. 1 ed. Campinas: Editora da Unicamp, 2003.

Morcos, M.; Gomez, J. C. "Distributed Generation: Short-Circuit Current Supplied for Induction Generators", IEEE Transmission and Distribution Conference and Exposition: Latin America, 2008.

Nimpitiwan, N.; Heydt, G. T.; Ayyanar, R.; Suryanarayanan, S. "Fault Current Contribution from Synchronous Machine and Inverter-based Distributed Generators", IEEE Trans. Power Delivery, vol. 22, no. 1, pp. 634-641, 2007.

Pizzali, L. F. O. “ Desempenho de Redes de Distribuição com Geradores Distribuídos”, Tese de Doutorado, Universidade Estadual Paulista, Ilha Solteira - SP, 2006. 
Probert, S.; Nutt, S. "Generator Fault-Ride Through (FRT) Investigation”, Technical Report Transpower Newzealand, 2009.

Rafal, M. B.; Rafal, K.; Jasinski, M.; Kazmierkowski, M. P. "Grid Synchronization and Symmetrical Components Extraction with PLL Algorithm for Grid Connected Power Electronic Converters - a Review', Institute of Control and Industrial Electronics, Warsaw University of Technology, Bulletin of the Polish Academy of Sciences, vol. 59, n4, Poland, 2011.

Salman, S. K. "The Impact of Embedded Generation on Voltage Regulation and Losses of Distribution Networks", IEEE Embedded Generation on Distribution Conference, London. Oct., 1996.

Severino, M. M; Camargo, I. M. T; Oliveira, M. A. G. "Geração Distribuída: Discussão Conceitual e Nova Definição”, Revista Brasileira de Energia, vol. 14, n 1, $1^{\circ}$ Sem. pp 47-69, 2008 .

Silva, R. S.; Trindade, F. C. L.; Freitas, W. "Impactos da Suportabilidade de Geradores Síncronos Distribuídos a Afundamentos de Tensão na Proteção de Sobrecorrente e Antiilhamento", SBSE, Anais n 96282, 2012.

Stevenson Jr, W.D. Elementos de Análise de Sistemas de Potência. 2 ed. São Paulo: Editora McGraw-Hill do Brasil Ltda, 1986.

Timbus, A. V.; Teodorescu, R.; Blaabjerg, F.; Liserre, M.; Rodriguez, P. “ PLL Algorithm for Power Generation Systems Robust to Grid Voltage Faults", IEEE Power Electronics Specialists Conference, Jeju. Jun., 2006.

TransÉnergie Technologies Inc, SimPowerSystems User's Guide, 2010. Disponível em: $<$ http://www.mathworks.com>.

Tu, D. V.; Chaitusaney, S. "Impacts of Inverter-based Distributed Generation Control Modes on Short-circuit Currents in Distribution Systems" IEEE Industrial Electronics and Applications Conference, Singapore, July 18-20. 2012.

Turcotte, D.; Katiraei, F. "Fault Contribution of Grid-Connected Inverters", IEEE Electrical Power Conference, Canada. Oct., 2010.

Wang, X. "Investigation of Positive Feedback Anti-Islanding Scheme for Inverter-Based Distributed Generation.", Thesis (PhD). University of Alberta, Edmonton, 2008.

Zanetta, L. C. Fundamentos de Sistemas Elétricos de Potência. ed. 1. São Paulo: Editora Livraria da Física, 2006.

Zeineldin, H. H.; El-Saadany, E. F.; Salama, M. M. A. "Impact of DG Interface Control on Islanding Detection and Nondetection Zone," IEEE Trans. Power Delivery, vol. 21, no. 3, pp. 1515-1523, Jul. 2006. 


\section{Apêndice A}

\section{Parâmetros dos Sistemas Analisados}

Seguem abaixo os dados e parâmetros dos sistemas utilizados nas simulações dos estudos realizados na seção 4.2 .

Os dados e parâmetros do sistema ilustrado na Figura 4.1 estão dispostos na Tabela A.1 a Tabela A.4.

A Tabela A.1 apresenta os dados da subestação principal e do transformador do sistema elétrico ilustrado na Figura 4.1.

Tabela A.1 - Dados da subestação principal e transformador do sistema representado na Figura 4.1.

\begin{tabular}{|c|c|}
\hline Parâmetros & Valores \\
\hline Potência Nominal (MVA) & 150 \\
\hline Tensão Primária (kV) & 132 \\
\hline Tensão Secundária (kV) & 13,8 \\
\hline Impedância do Transformador (\%) & 10 \\
\hline Impedância de Magnetização (\%) & Desconsiderada \\
\hline Conexão do Enrolamento Primário & $\Delta$ (Delta) \\
\hline Conexão do Enrolamento Secundário & Y (Estrela aterrado) \\
\hline
\end{tabular}

A Tabela A.2 apresenta os dados dos trechos de linhas existentes no sistema da Figura 4.1. 
Tabela A.2 - Dados das linhas do sistema representado na Figura 4.1.

\begin{tabular}{|l|l|l|}
\hline Linha & $\begin{array}{c}\text { Resistência } \\
(\mathbf{\Omega})\end{array}$ & $\begin{array}{c}\text { Reatância } \\
(\mathbf{\Omega})\end{array}$ \\
\hline Linha 1 & 0,5624 & 2,5318 \\
\hline Linha 2 & 0,5000 & 2,2505 \\
\hline Linha 3 & 0,6248 & 1,4066 \\
\hline Linha 4 & 0,5000 & 1,1252 \\
\hline Linha 5 & 0,3750 & 0,8439 \\
\hline
\end{tabular}

A Tabela A.3 apresenta os dados e parâmetros de uma unidade de gerador distribuído do sistema da Figura 4.1.

Tabela A.3 - Dados e parâmetros de uma unidade dos inversores do sistema representado na Figura 4.1.

\begin{tabular}{|c|c|c|c|}
\hline Parâmetros & $\begin{array}{c}\text { Controle de } \\
\text { Corrente (I) }\end{array}$ & $\begin{array}{c}\text { Controle de } \\
\text { Potência Ativa e } \\
\text { Tensão (PV) }\end{array}$ & $\begin{array}{c}\text { Controle de } \\
\text { Potência Ativa e } \\
\text { Reativa (PQ) }\end{array}$ \\
\hline $\mathrm{V}_{\mathrm{CC}}(\mathrm{V})$ & 2000 & 2000 & 2000 \\
\hline $\begin{array}{c}\text { PWM } \\
\text { Frequência da } \\
\text { Portadora (Hz) }\end{array}$ & 8000 & 8000 & 8000 \\
\hline$k_{i i}$ & 500 & 100 & 500 \\
\hline$k_{p i}$ & 0,5 & 0,5 & 0,5 \\
\hline$k_{i p}$ & ---- & 500 & 100 \\
\hline$k_{p p}$ & ---- & 0,5 & 0,5 \\
\hline$k_{p v}$ & ---- & 0,5 & ---- \\
\hline$k_{i v}$ & ---- & 500 & ---- \\
\hline$d r o o p$ & ---- & 0,05 & ---- \\
\hline $\mathrm{L}_{\mathrm{F}}(\mathrm{mH})$ & 2 & 2 & 500 \\
\hline $\mathrm{C}_{\mathrm{F}}(\mu \mathrm{F})$ & 35,18 & 12,60 & 2 \\
\hline$k_{p P L L}$ & 50 & 50 & 500 \\
\hline$k_{i P L L}$ & 500 & 500 & \\
\hline & & & 500 \\
\hline
\end{tabular}

A Tabela A.4 apresenta os dados do transformador elevador localizado na saída do grupo de geradores e utilizado para a interligação deste grupo ao sistema de distribuição. 
Tabela A.4 - Dados do transformador elevador (saída do gerador GD) do sistema da Figura 4.1.

\begin{tabular}{|c|c|}
\hline Parâmetros & Valor \\
\hline Potência Nomimal (MVA) & 1 \\
\hline Tensão Primária (kV) & 13,8 \\
\hline Tensão Secundária (kV) & 0,38 \\
\hline Impedância do transformador (\%) & 2 \\
\hline Impedância de Magnetização (\%) & Desconsiderada \\
\hline Conexão do Enrolamento Primário & $\Delta$ (Delta) \\
\hline Conexão do Enrolamento Secundário) & Y (Estrela não Aterrado) \\
\hline
\end{tabular}

Os dados e parâmetros do sistema ilustrado na Figura 4.7 estão dispostos na Tabela A.5 a Tabela A.10.

Tabela A.5 - Dados da subestação principal do sistema de energia apresentado na Figura 4.7.

\begin{tabular}{|c|c|}
\hline Parâmetros & Valores \\
\hline Potência de Curto-Circuito $(\mathrm{MVA})$ & 150 \\
\hline Tensão Primária $(\mathrm{kV})$ & 134 \\
\hline Tensão Secundária $(\mathrm{kV})$ & 34,5 \\
\hline Resistência $(\Omega)$ & 0 \\
\hline Indutância $(\mathrm{H})$ & 0,308 \\
\hline
\end{tabular}

Tabela A.6 - Dados da linha de distribuição do sistema de energia apresentado na Figura 4.7.

\begin{tabular}{|c|c|}
\hline Parâmetros & Valores \\
\hline Resistência $(\Omega)$ & 0,1875 \\
\hline Indutância $(\mathrm{H})$ & 0,8439 \\
\hline
\end{tabular}

Tabela A.7 - Dados do transformador T1 do sistema de energia apresentado na Figura 4.7.

\begin{tabular}{|c|c|}
\hline Parâmetros & Valores \\
\hline Potência Nomimal (MVA) & 100 \\
\hline Tensão Primária (kV) & 132 \\
\hline Tensão Secundária (kV) & 34,5 \\
\hline Impedância do transformador (\%) & 5 \\
\hline Impedância de Magnetização (\%) & Desconsiderada \\
\hline Conexão do Enrolamento Primário & $\Delta$ (Delta) \\
\hline Conexão do Enrolamento Secundário) & Y (Estrela Aterrado) \\
\hline
\end{tabular}


Tabela A.8 - Dados do transformador T2 do sistema de energia apresentado na Figura 4.7.

\begin{tabular}{|c|c|}
\hline Parâmetros & Valores \\
\hline Potência Nomimal (MVA) & 1 \\
\hline Tensão Primária (kV) & 34,5 \\
\hline Tensão Secundária (V) & 380 \\
\hline Impedância do transformador (\%) & 2 \\
\hline Impedância de Magnetização (\%) & Desconsiderada \\
\hline Conexão do Enrolamento Primário & $\Delta$ (Delta) \\
\hline Conexão do Enrolamento Secundário) & Y (Estrela Aterrado) \\
\hline
\end{tabular}

Tabela A.9 - Dados do transformador T3 do sistema de energia apresentado na Figura 4.7.

\begin{tabular}{|c|c|}
\hline Parâmetros & Valores \\
\hline Potência Nomimal (MVA) & 1 \\
\hline Tensão Primária (V) & 380 \\
\hline Tensão Secundária (V) & 2 \\
\hline Impedância do transformador (\%) & Desconsiderada \\
\hline Impedância de Magnetização (\%) & Y (Estrela Aterrado) \\
\hline Conexão do Enrolamento Primário & $\Delta$ (Delta) \\
\hline Conexão do Enrolamento Secundário) & \\
\hline
\end{tabular}

Tabela A.10 - Dados do gerador distribuído do sistema de energia apresentado na Figura 4.7.

\begin{tabular}{|c|c|c|c|}
\hline \multirow{2}{*}{ Parâmetros } & \multicolumn{3}{|c|}{ Parâmetros do Gerador Distribuído e Controle } \\
\cline { 2 - 4 } & Controle I & Controle PQ & Controle PV \\
\hline $\mathrm{V}_{\mathrm{DC}}(\mathrm{V})$ & 900 & 900 & 900 \\
\hline PWM Frequência De Chav. $(\mathrm{Hz})$ & 8000 & 8000 & 8000 \\
\hline $\mathrm{K}_{\mathrm{pi}}$ & 5 & 5 & 1 \\
\hline $\mathrm{K}_{\mathrm{ii}}$ & 500 & 500 & 1000 \\
\hline $\mathrm{K}_{\mathrm{pp}}$ & --- & 2.5 & 0.2 \\
\hline $\mathrm{K}_{\mathrm{ip}}$ & --- & 250 & 500 \\
\hline $\mathrm{K}_{\mathrm{pv}}$ & --- & --- & 0.5 \\
\hline $\mathrm{k}_{\mathrm{iv}}$ & --- & --- & 500 \\
\hline $\mathrm{kp}_{\mathrm{PLL}}$ & 50 & 50 & 50 \\
\hline $\mathrm{ki}_{\mathrm{PLL}}$ & 500 & 500 & 500 \\
\hline $\mathrm{droop}_{\mathrm{L}}(\mathrm{mH})$ & --- & --- & -0.05 \\
\hline $\mathrm{C}_{\mathrm{F}}(\mu \mathrm{F})$ & 0.5 & 0.5 & 0.5 \\
\hline
\end{tabular}

Os dados e parâmetros do sistema ilustrado na Figura 5.3 estão dispostos na Tabela A.11 a Tabela A.14. 
A Tabela A.11 apresenta os dados da subestação principal e do transformador do sistema elétrico da Figura 5.3.

Tabela A.11 - Dados da subestação principal e transformador do sistema representado na Figura 5.3.

\begin{tabular}{|c|c|}
\hline Parâmetros & Valores \\
\hline Potência Nominal (MVA) & 15 \\
\hline Tensão Primária (kV) & 34,5 \\
\hline Tensão Secundária (kV) & 13,8 \\
\hline Impedância do Transformador (\%) & 10 \\
\hline Impedância de Magnetização (\%) & Desconsiderada \\
\hline Conexão do Enrolamento Primário & $\Delta$ (Delta) \\
\hline Conexão do Enrolamento Secundário & Y (Estrela aterrado) \\
\hline
\end{tabular}

A Tabela A.12 apresenta os dados dos trechos de linhas existentes no sistema da Figura 5.3 .

Tabela A.12 - Dados das linhas do sistema representado na Figura 5.3.

\begin{tabular}{|l|c|c|}
\hline Linha & $\begin{array}{c}\text { Resistência } \\
(\mathbf{\Omega})\end{array}$ & $\begin{array}{c}\text { Reatância } \\
(\mathbf{\Omega})\end{array}$ \\
\hline Linha 1 & 0,5624 & 2,5318 \\
\hline Linha 2 & 0,5000 & 2,2505 \\
\hline Linha 3 & 0,6248 & 1,4066 \\
\hline Linha 4 & 0,5000 & 1,1252 \\
\hline Linha 5 & 0,3750 & 0,8439 \\
\hline
\end{tabular}

A Tabela A.13 apresenta os dados e parâmetros de uma unidade de gerador distribuído do sistema da Figura 5.3. 
Tabela A.13 - Dados e parâmetros de uma unidade dos inversores do sistema representado na Figura 5.3.

\begin{tabular}{|c|c|c|c|}
\hline Parâmetros & $\begin{array}{c}\text { Controle de } \\
\text { Corrente (I) }\end{array}$ & $\begin{array}{c}\text { Controle de } \\
\text { Potência Ativa e } \\
\text { Tensão (PV) }\end{array}$ & $\begin{array}{c}\text { Controle de } \\
\text { Potência Ativa e } \\
\text { Reativa (PQ) }\end{array}$ \\
\hline V $_{\mathrm{CC}}(\mathrm{V})$ & 2000 & 2000 & 2000 \\
\hline PWM \\
Portadôncia da $(\mathrm{Hz})$
\end{tabular}

A Tabela A.14 apresenta os dados do transformador elevador localizado na saída do grupo de geradores e utilizado para a interligação deste grupo ao sistema de distribuição representado na Figura 5.3.

Tabela A.14 - Dados do transformador elevador (saída do gerador GD) do sistema representado na Figura 5.3.

\begin{tabular}{|c|c|}
\hline Parâmetros & Valor \\
\hline Potência Nomimal (MVA) & 1 \\
\hline Tensão Primária (kV) & 13,8 \\
\hline Tensão Secundária (kV) & 0,38 \\
\hline Impedância do transformador (\%) & 2 \\
\hline Impedância de Magnetização (\%) & Desconsiderada \\
\hline Conexão do Enrolamento Primário & $\Delta$ (Delta) \\
\hline Conexão do Enrolamento Secundário) & Y (Estrela não Aterrado) \\
\hline
\end{tabular}




\section{Apêndice B}

\section{Divulgação do Trabalho em Eventos Científicos}

Apresentam-se nesta seção as referências dos trabalhos divulgados em eventos científicos.

\section{B.1 Publicação em Eventos Científicos}

PETEAN, D.; VIEIRA, J. C. M.; MACHADO, R. Q. “Influence of Inverter-based Distributed Generator Interface Control on the Performance of Power Distribution Systems". In: Bulk Power System Dynamics and Control (IREP) - VIII (IREP), 2010 IREP Symposium. Buzios, Brazil, p. 1-8, 2010.

PETEAN, D.; VIEIRA, J. C. M. "Avaliação das Correntes de Curto-Circuito dos Geradores Distribuídos Baseados em Inversores de Frequência". In: International Conference on Industry Applications (INDUSCON) - XI (INDUSCON). Juiz de Fora, Brazil, Dec. 7-10. 2014 